\author{
Universidade de São Paulo \\ Instituto de Química de São Carlos
}

\title{
LIGNOSULFONATO DE SÓDIO COMO AGENTE DE MODIFICAÇÃO DA SUPERFÍCIE DE FIBRAS LIGNOCELULÓSICAS E DA FORMULAÇÃO DE TERMORRÍGIDO FENÓLICO
}

Fernando de Oliveira

\begin{abstract}
Dissertação apresentada ao Instituto de Química de São Carlos, como parte dos requisitos para obtenção do título de Mestre em Ciências (Físico-Química).
\end{abstract}

Orientadora: Profa. Dra. Elisabete Frollini 
Este exemplar foi revisado e alterado em relação à versão original, sob a exclusiva responsabilidade do autor.

São Carlos, 14 de Junho de 2010

Fernando de Oliveira 
Dedico este trabalho a todas as pessoas que amo, sobretudo aos meus pais: Márío e Genecí 


\section{AGRADECIMENTOS}

À Deus, por seu amor eterno e incondicional, que me amparou para que eu chegasse até aqui.

À minha orientadora, Prof ${ }^{a}$ Dr $^{a}$ Elisabete Frollini, pela compreensão, orientação, disposição e dedicação prestada.

Aos meus pais, Mário e Geneci, meus irmãos Vagner, Rodrigo (e respectivas cunhadas Manuela e Juliana), minha irmã Fernanda e minha sobrinha Lorena. A estes, minha profunda gratidão pelos gestos de amor, apoio e coragem.

À Daniele, Cristina e Elaine, companheiras de linha de pesquisa, pelos laços de amizade, pelo incentivo, pela paciência e por toda ajuda que me ofereceram neste aprendizado contínuo da "ciência dos compósitos".

Aos amigos atuais e aos que já fizeram parte do Grupo de Físico-Química Orgânica: Talita, Jorge, Bianca, Érika, Bruno, Daiane, Daniella, Maurício, Franciéli, Marcinha.

Aos amigos-irmãos da República Light Show, pela acolhida, convivência, alegria e partilhas que tornaram memorável minha vivência na cidade de São Carlos: Lucas Sobral, Carlão, Alessandro, Renato, Mário, Júlio, Alex, Leandro, Eduardo (Rondônia), Eduardo (Maringá) e Helton Alves.

Aos queridos amigos da época de graduação em Maringá, que vivem no meu coração e que sempre torcem e rezam por mim, mesmo eu estando longe: Dra. Renate e Wellington, Sabrina e Luisinho, Luaninha e Paula Montanher.

À família "Ministério Universidades Renovadas" de São Carlos - SP, que abrange todos integrantes dos Grupos de Oração Universitários Sal \& Luz e Resgate (USP) e Jesus Vive (UFSCar), por cada momento de unidade, oração, partilha e confraternização. Agradecimento especial à Evelise, Lucas Torres, Marcos Vinícius e Ritinha. 
À família "Ministério Universidades Renovadas" de Maringá - PR e todos os amigos da "Cidade Canção" pelas amizades, crescimento espiritual, e incentivo desde o início da minha graduação.

Aos técnicos do grupo, Márcia e Luiz, pela amizade e realização de análises de SEC e análises térmicas; e ao Luisão pelo auxílio na extração das fibras de sisal.

Aos funcionários do Instituto de Química de São Carlos, presentes na Central de Análises Química, Biblioteca Prof. Johannes Rüdiger Lechat, Serviço de Pós-graduação, Setor Financeiro e Oficinas Mecânica e Eletrônica, pelos diversos serviços prestados.

Ao Prof. Dr. Elias Hage Júnior (DEMa - UFSCar) por permitir a realização dos ensaios de impacto e flexão; e ao Henrique pela grande generosidade na realização dos ensaios de flexão propriamente ditos.

Ao Instituto de Química de São Carlos (Universidade de São Paulo), pelo apoio institucional e de infraestrutura;

A Ligno Tech Brasil (Borregaard), pelo gentil fornecimento do lignosulfonato de sódio.

Ao CNPq, pela bolsa concedida; e à CAPES e FAPESP, pelo suporte financeiro.

Agradeço à todos aqueles que de alguma forma agregaram em meu enriquecimento intelectual e pessoal. 


\section{RESUMO}

Considerando o grande interesse atual em biocompósitos, seja pela utilização de fibras lignocelulósicas como reforço em compósitos poliméricos ou pela produção de matrizes oriundas de fontes renováveis, buscou-se neste estudo a melhora de propriedades do termorrígido fenólico com a inserção de fibras de sisal tratadas com lignosulfonato de sódio. As fibras de sisal, largamente produzidas no Brasil, são provenientes de fontes renováveis, possuem baixa densidade e apresentam boas propriedades mecânicas. Lignosulfonatos são obtidos através do processo de polpação sulfito da madeira, sendo considerado material renovável. As fibras de sisal foram modificadas via adsorção de lignosulfonato via aquecimento a $70{ }^{\circ} \mathrm{C} / 1 \mathrm{~h}$ e por meio de irradiação com ultra-som em diferentes tempos (1h e $2 \mathrm{~h}$ ) e por $14 \mathrm{~h}$ de imersão na solução aquosa de lignosulfonato seguindo de $1 \mathrm{~h}$ de irradiação com ultra-som. 0 lignosulfonato também foi utilizado como substituinte do fenol no preparo de resinas fenol-formaldeído, o que é possível devido à presença de anéis fenólicos em sua estrutura. As fibras de sisal, antes e após os tratamentos, foram caracterizadas segundo teor de componentes majoritários, análise elementar, microscopia eletrônica de varredura (MEV), espectroscopia na região do infravermelho (IV), ensaio de tração, análise térmica (TG e DSC) e difração de raios X. Estes resultados revelaram o efeito do ultra-som sobre a superfície da fibra, a presença de lignosulfonato na superfície das fibras e aumento relativo da resistência à tração após as modificações. Os pré-polímeros fenólico e lignosulfonato-formaldeído foram caracterizados por cromatografia de exclusão de tamanho, IV, TG e DSC. Os compósitos preparados em todo trabalho foram caracterizados por ensaio de resistência ao impacto Izod sem entalhe, ensaio de resistência à flexão, análise térmica dinâmico-mecânica, TG, DSC, ensaio de absorção de água e condutividade térmica. O ensaio de resistência ao impacto para os compósitos fenólicos indicaram uma melhora nesta propriedade quando fibras modificadas (à 70 ${ }^{\circ} \mathrm{C} / 1 \mathrm{~h}$ e ultra-som/1 h) foram utilizadas para preparar estes materiais. 0 ensaio de flexão também indicou melhora de propriedade quando as fibras modificadas por irradiação com ultra-som (1 e 2 h) foram utilizadas em compósitos fenólicos. Os resultados obtidos mostraram que os tratamentos com lignosulfonato de sódio associados a irradiação ultra-som é um tratamento promissor, pois modifica a morfologia da superfície das fibras sem levar à degradação química, sendo que a separação dos feixes de fibra que ocorre permite melhor interação fibra/matriz na interface. 0 ensaio de 
absorção de água, mostrou que os tratamentos aplicados à superfícies influenciam pouco na absorção de água dos compósitos fenólicos. Todos os compósitos preparados com matriz lignosulfonato-formaldeído obtiveram valores resistência ao impacto superiores que os compósitos fenólicos, sendo que o compósito preparado com fibra não-modificada alcançou $1000 \mathrm{~J} \cdot \mathrm{m}^{-1}$. As modificações nas fibras de sisal, para estes compósitos, não provocaram os efeitos esperados nas propriedades mecânicas destes materiais, embora se tenha observado uma boa adesão na interface fibra/matriz pelas imagens de MEV, resultado da semelhança químico-estrutural entre a matriz e a fibra de sisal. Uma melhora nas propriedades mecânicas dos materiais aqui investigados faz com que estes se tornem atraentes para aplicações nas indústrias automobilística e aeronáutica, visto que na sua produção são utilizados materiais oriundos de fontes renováveis, como as fibras lignocelulósicas e o lignosulfonato, e tratamentos físicos, como o aquecimento e a irradiação de ultra-som, estando de acordo com políticas de sustentabilidade e preservação do meio-ambiente. 


\begin{abstract}
Due to the great current interest in biocomposites because of both the use of lignocellulosic fibers as reinforcers of polymer matrices and the production of matrices prepared from renewable raw material, this study has sought to improve the properties of phenolic thermosets using sodium lignosulphonate as a macromonomer, and the insertion of sisal fibers, either treated or not with sodium lignosulphonate, as a reinforcer. Sisal fibers, which are widely produced in Brazil, are renewable, have low density, and present good mechanical properties. Lignosulphonates are obtained by a wood sulphite pulping process, thus using materials from a renewable source. The sisal fibers were modified by lignosulphonate adsorption by heating at $70{ }^{\circ} \mathrm{C}$ for $1 \mathrm{~h}$, followed by sonication for different time periods ( $1 \mathrm{~h}$ and $2 \mathrm{~h}$ ) or by immersion for $14 \mathrm{~h}$ in aqueous lignosulphonate solution, followed by sonication for $1 \mathrm{~h}$. Fiber surface treatment by adsorption of a compatibilizing agent rather than by chemical reaction was chosen with the intent of minimizing the reduction of the fiber mechanical properties. The major sisal fiber components were characterized before and after treatment by elemental analysis, scanning electron microscopy, infrared spectroscopy (IR), tensile strength, thermogravimetry (TG) and differential scanning calorimentry (DSC), and X-ray diffraction. The treatments resulted in a significant increase in fiber tensile strength. The phenolic pre-polymers and lignosulphonate-formaldehyde were characterized by size exclusion chromatography, IR, TG, and DSC. The composites were characterized as to Izod impact strength, flexural strength, dynamic mechanic thermal analysis, TG and DSC, water absorption, and thermal conductivity. The phenolic composites reinforced with modified fibers $\left(70^{\circ} \mathrm{C} / 1 \mathrm{~h}\right.$ and sonication/1 h) presented improved impact strength. The flexural strength of phenolic composites reinforced with sonication modified fibers ( 1 and $2 \mathrm{~h}$ ) improved. The results obtained demonstrate that fiber treatment with sodium lignosulphonate associated with sonication is a promising method, as it modifies the surface morphology of the fibers without drastically changing their properties. The resulting fiber bundle separation allows for a better fiber/matrix interaction. The water absorption assay demonstrated that the fiber surface treatment had little influence on the water absorption of phenolic composites reinforced with these fibers. All the composites prepared with the lignosulphonate-formaldehyde matrix had higher impact strength than phenolic composites; the composite prepared with non-modified fiber reached $1000 \mathrm{~J}^{\mathrm{m}} \mathrm{m}^{-1}$. The modification of sisal fibers in these composites did not induce
\end{abstract}


effects on the material mechanical properties. However, good adhesion was observed at the fiber/matrix interface, as shown by the SEM images, due to the chemical-structural similarity of the matrix and treated sisal fiber. In this case, the modification of the matrix formulations was the factor that most influenced the material properties. Both the thermosets and the composites had similar thermal conductivity, that is, the presence of untretated or treated sisal fibers did not alter the thermal conductivity of the material. The materials properties that were investigated here show that they may have potential application in the car and aircraft industries (non-structural applications) with the advantage that their production uses renewable resource materials, such as lignocellulosic fibers and lignosulphonate, and physical treatments, such as heating and sonication, meeting the current sustainability and environment preservation policies. 


\section{LISTA DE FIGURAS}

Figura 1. Esquema de vários tipos de compósitos. 21

Figura 2. (a) Planta de sisal e (b) Processamento das fibras de sisal .............................. 24

Figura 3. Estrutura da celobiose (unidade repetitiva da celulose) .................................. 25

Figura 4. Estruturas de unidades de monossacarídeos presentes na hemicelulose

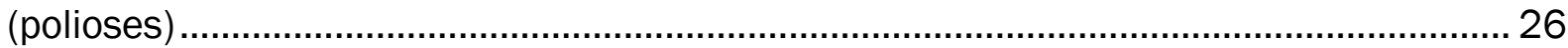

Figura 5. Unidades presentes na lignina ................................................................ 27

Figura 6. Estrutura de lignina de coníferas propostas por Adler (1977).......................... 28

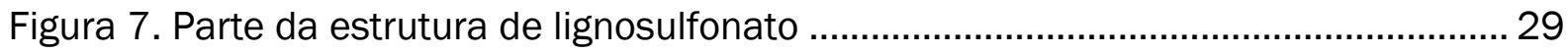

Figura 8. Reação entre ânion fenolato e formaldeído ...................................................... 30

Figura 9. Reação de auto-condensação de hidroximetilfenóis ............................................ 31

Figura 10. Reação de entrecruzamento da resina fenólica .............................................. 32

Figura 11. Três diferentes condições de molhabilidade: (a) molhabilidade completa, (b) molhabilidade parcial (c) condição que não molha ..........................................................34

Figura 12. Interfaces entre o reforço e a matriz. (a) Interface ideal: planar; (b) Interface

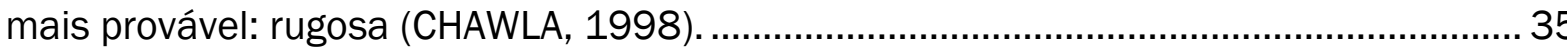

Figura 13. Mecanismos de interação interfacial; (a) adesão mecânica, (b) interação eletrostática e (c) ligação química

Figura 14. Semelhança química-estrutural entre polímero fenólico, lignosulfonato de sódio e fibra lignocelulósica. (a) termorrígido fenólico, (b) parte da estrutura do lignosulfonato de sódio, (c) celobiose: principal unidade da celulose e (d) unidades presentes na lignina.

Figura 15. Demonstração da formação e colapso de bolha de cavitação.

Figura 16. Combinação de elementos para concepção de biocompósitos de elevado desempenho

Figura 17. Sistema utilizado para misturar fibras na matriz.

Figura 18. Representação do processo de obtenção dos compósitos de matriz fenólica e fibras de sisal

Figura 19. Esquema representativo do ensaio de flexão em três pontos.

Figura 20. Espectros na região do infravermelho: (a) fibras de sisal não-modificadas (FSNM) e modificadas (FSM1, FSM2, FSM3 e FSM4); (b) lignosulfonato de sódio; (c) região ampliada (1800 a $1600 \mathrm{~cm}^{-1}$ ) do espectro das fibras de sisal não-modificadas e modificadas e (d) região ampliada (800 a $\left.400 \mathrm{~cm}^{-1}\right)$ do espectro das fibras de sisal nãomodificadas e modificadas.

Figura 21. Difratogramas de raios $X$ das fibras de sisal submetidas à modificações (FSM1, FSM2, FSM3 e FSM4) e sem modificação (FSNM).

Figura 22. Índice de cristalinidade das fibras de sisal não-modifcadas e modificadas com lignosulfonato de sódio. FSNM - Fibra de sisal não-modificada; FSM1 - Fibra de sisal (70 
${ }^{\circ} \mathrm{C} / 1 \mathrm{~h}$ ); FSM2 - Fibra de sisal (Ultra-som/1 h); FSM3 - Fibra de sisal (Ultra-som /2 h); FSM4 - Fibra de sisal (14 h imersão/1 h Ultra-som) .....

Figura 23. Imagens de MEV da superfície da fibra de sisal não-modificada (FSNM)...... 75

Figura 24. Imagens de MEV da superfície das fibras de sisal modificadas. (a) e (b) FSM1: fibra de sisal modificação $1\left(70^{\circ} \mathrm{C} / 1 \mathrm{~h}\right) ;(\mathrm{c})$, (d), (e) e (f) FSM2: fibra de sisal modificação 2 (Ultra-som/1 h) ....

Figura 25. Imagens de MEV da superfície das fibra de sisal modificadas. (a) e (b) FSM3: fibra de sisal modificação 3 (Ultra-som/2 h); (c) e (d) FSM4: fibra de sisal modificação 4 (14 $\mathrm{h}$ imersão/ $1 \mathrm{~h}$ Ultra-som)....

Figura 26. Curvas (a) TG, (b) dTG e (c) DSC das fibras de sisal nao modificada e modificadas com lignosulfonato de sódio (FSM1, FSM2, FSM3 e FSM4), atmosfera de $\mathrm{N}_{2}$, fluxo de $20 \mathrm{~mL} \cdot \mathrm{min}^{-1}$ e razao de aquecimento de $10^{\circ} \mathrm{C} \cdot \mathrm{min}^{-1}$.....

Figura 27. Espectros na região do infravermelho para o termorrígido e pré-polímero fenólico.

Figura 28. Espectros na região do infravermelho para o termorrígido e pré-polímero lignosulfonato-formaldeído.

Figura 29. Cromatogramas de distribuição de massa molar: (a) pré-polímero fenólico, (b) lignosulfonato e (c) pré-polímero lignosulfonato-formaldeído.....

Figura 30. Curvas TG/dTG e DSC para o lignosulfonato de sódio, atmosfera de $\mathrm{N}_{2}$, fluxo de $20 \mathrm{~mL}$. $\mathrm{min}^{-1}$ e razão de aquecimento de $10^{\circ} \mathrm{C} \cdot \mathrm{min}^{-1}$.

Figura 31. Curvas (a) dTG e (b) DSC para o pré-polímero e termorrígido fenólico, atmosfera de $\mathrm{N}_{2}$, fluxo de $20 \mathrm{~mL} \cdot \mathrm{min}^{-1}$ e razão de aquecimento de $10^{\circ} \mathrm{C}$. $\mathrm{min}^{-1}$.

Figura 32. Curvas (a) dTG e (b) DSC para o pré-polímero e termorrígido lignosfulfonatoformaldeído; atmosfera de $\mathrm{N}_{2}$, fluxo de $20 \mathrm{~mL} \cdot \mathrm{min}^{-1}$ e razão de aquecimento de $10^{\circ} \mathrm{C} \cdot \mathrm{min}^{-1}$.

Figura 33. Resistência ao Impacto Izod (corpos de prova não entalhados) de termorrígido fenólico (TF) e compósitos de matriz fenólica (CF) reforçados com fibras de sisal nãomodificadas (FSNM) e fibras modificadas (FSM1, FSM2, FSM3 e FSM4), 30\% em massa e com $3 \mathrm{~cm}$ de comprimento (distribuição aleatória).

Figura 34. Corpos-de-prova de compósitos fenólicos reforçados com fibras de sisal. (a) fenômeno "fiber bridging" observado nos compósitos CF-FSM1, CF-FSM2, CF-FSM4 (b) ruptura completa observada no compósito CF-FSM3.

Figura 35. Representação esquemática das forças que agem num ensaio de flexão ..... 90

Figura 36. Resistência à flexão de termorrígido fenólico (TF) e compósitos de matriz fenólica (CF) reforçados com fibras de sisal não-modificada (FSNM) e modificadas (FSM1, FSM2, FSM3 e FSM4), 30\% em massa e $3 \mathrm{~cm}$ de comprimento (distribuição aleatória).91

Figura 37. Módulo de flexão (ou elasticidade) de termorrígido fenólico (TF) e compósitos de matriz fenólica (CF) reforçados com fibras de sisal não-modificada (FSNM) e modificadas (FSM1, FSM2, FSM3), 30\% em massa e $3 \mathrm{~cm}$ de comprimento (distribuição aleatória).

Figura 38. Imagens de MEV da superfície de fratura do termorrígido fenólico com ampliação de (a) 100, (b) 500 e (c) 3000 vezes. 
Figura 39. Imagens de MEV da superfície de fratura de compósitos fenólicos reforçados com fibras de sisal não-modificada.

Figura 40. Imagens de MEV da superfície de fratura de compósitos fenólicos reforçados com fibras de sisal modificadas por aquecimento à $70^{\circ} \mathrm{C} / 1 \mathrm{~h}$ (CF-FSM1). 95

Figura 41. Imagens de MEV da superfície de fratura de compósitos fenólicos reforçados com fibras de sisal modificadas em ultra-som/1 h (CF-FSM2). 95

Figura 42. Imagens de MEV da superfície de fratura de compósitos fenólicos reforçados com fibras de sisal modificadas em ultra-som/2 h (CF-FSM3).....

Figura 43. Imagens de MEV da superfície de fratura de compósitos fenólicos reforçados com fibras de sisal modificadas em $14 \mathrm{~h}$ imersão em lignosulfonato(aq) $/ 2 \mathrm{~h}$ ultra-som (CF-FSM4).

Figura 44. Curvas (a) TG, (b) dTG e (c) DSC para o termorrígido fenólico (TF) e compósitos fenólicos preparados com fibras de sisal não-modificadas (CF-FSNM) e modificadas (CF-FSM1, CF-FSM2, CF-FSM3 e CF-FSM4), atmosfera de $\mathrm{N}_{2}$, fluxo de 20 $\mathrm{mL} \cdot \mathrm{min}^{-1} \mathrm{e}$ razão de aquecimento de $10^{\circ} \mathrm{C} \cdot \mathrm{min}^{-1}$.

Figura 45. (a) Módulo de armazenamento (E') em função da temperatura, (b) Módulo de perda (E") em função da temperatura e (c) Tan $\delta$ em função da temperatura para o termorrígido fenólico (TF) e compósitos fenólicos reforçados com fibras sisal nãomodificadas (CF-FSNM) e modificadas (CF-FSM1, CF-FSM2, CF-FSM3, CF-FSM4).

Figura 46. Resultados de absorção de água para o termorrígido fenólico (TF) e compósitos fenólicos (CF) reforçados com fibras de sisal não-modificadas (FSNM) e modificadas (FSM1, FSM2, FSM3 e FSM4).

Figura 47. Coeficiente de difusão (D) para o termorrígido fenólico (TF) e compósitos fenólicos (CF) reforçados com fibras de sisal não-modificadas (FSNM) e modificadas (FSM1, FSM2, FSM3 e FSM4)

Figura 48. Fotografia de placa de termorrígido lignosulfonato-formaldeído sem fibras (a) e compósito de matriz lignosulfonato-formaldeído reforçado com fibra de sisal. 104

Figura 49. Fotografia de compósitos de matriz lignosulfonato-formaldeído reforçados com fibras de sisal. (a) sem excesso de resina e (b) com excesso de resina. 105

Figura 50. Resistência ao Impacto Izod de compósitos de matriz lignosulfonatoformaldeído reforçados com fibras de sisal não-modificada (CL-FSNM) e modificadas (CLFSM1 e CL-FSM2).

Figura 51. Fotografia de corpos de prova de compósitos de matriz lignosulfonatoformaldeído reforçados com fibras de sisal não-modificadas e modificadas (CL-FSNM, CFFSM1 e CF-FSM2).

Figura 52. Resistência à flexão de compósitos de matriz lignosulfonato-formaldeído reforçado com fibras de sisal não-modificadas (CL-FSNM) e modificadas (CL-FSM1 e CLFSM2)

Figura 53. Módulo de flexão de compósitos de matriz lignosulfonato-formaldeído (CL) reforçados com fibras de sisal não-modificada (FSNM) e modificadas (FSM1 e FSM2).

Figura 54. Imagens de MEV da superfície fraturada em $\mathrm{N}_{2}(\mathrm{I})$ do termorrígido lignosulfonato-formaldeído. (a) aumento de 500 vezes e (b) aumento de 3000 vezes. 112 
Figura 55. Imagens de MEV da superfície de fratura de compósitos de matriz lignosulfonato-formaldeído preparados sem excesso de resina. (a) e (b) CL-FSNM: compósito com fibras de sisal não-modificadas; (c) e (d) CL-FSM1: compósito com fibras de sisal modificadas a $70^{\circ} \mathrm{C} / 1 \mathrm{~h}$; (e) e (f) CL-FSM2: compósito com fibras de sisal modificadas em ultra-som/ $1 \mathrm{~h}$....

Figura 56. Imagens de MEV da superfície de fratura de compósitos de matriz lignosulfonato-formaldeído preparados com excesso de resina. (a) CL-FSNM: compósito com fibras de sisal não-modificadas - com 25\% de excesso; (b) CL-FSM1: compósito com fibras de sisal modificadas em $70{ }^{\circ} \mathrm{C} / 1 \mathrm{~h}$ - com 40\% de excesso; (c) CL-FSM2: compósito com fibras de sisal modificadas em ultra-som/1 h - com 40\% de excesso e (d) CL-FSM2: compósito com fibras de sisal modificadas em ultra-som/1h - com $6 \%$ de excesso. ...114

Figura 57. Curvas (a) TG, (b) dTG e (c) DSC para o termorrígido lignosulfonatoformaldeído (TL) e compósitos de matriz lignosulfonato-formaldeído reforçados com fibras de sisal não-modificadas (CL-FSNM) e modificadas (CL-FSM1 e CL-FSM2).

Figura 58. (a) Módulo de armazenamento (E') em função da temperatura, (b) Módulo de perda (E") em função da temperatura e (c) Tan $\delta$ em função da temperatura para os compósitos de matriz lignosulfonato-formaldeído reforçados com fibras sisal modificadas e não-modificadas.

Figura 59. Curvas de absorção de água para compósitos de matriz lignosulfonatoformaldeído reforçado com fibras de sisal não-modificadas (CL-FSNM) e modificadas (CLFSM1 e CL-FSM2), e preparados com diferentes proporções de resina. 119

Figura 60. Coeficiente de difusão (D) para compósitos de matriz lignosulfonatoformaldeído reforçados com fibras não-modificadas (CL-FSNM) e fibras modificadas (CLFSM1 e CL-FSM2), em diferentes proporções de resina. 


\section{LISTA DE TABELAS}

Tabela 1. Resumo das modificações realizadas nas fibras de sisal, com solução aquosa de lignosulfonato de sódio ( $5 \%$ em massa).

Tabela 2. Análise química das fibras de sisal não-modificadas e modificadas com lignosulfonato de sódio.

Tabela 3. Análise elementar de S das fibras não-modificada e modificadas e do lignosulfonato de sódio.

Tabela 4. Principais absorções observadas no espectro na região do infravermelho da fibra de sisal e seus respectivos modos vibracionais.

Tabela 5. Principais absorções observadas em espectro de infravermelho de lignosulfonatos.

Tabela 6. Resistência à tração e alongamento das fibras de sisal não-modificadas e modificadas com lignosulfonato de sódio.

Tabela 7. Principais absorções observadas no espectro de infravermelho da resina fenólica, resina lignosulfonato-formaldeído e seus respectivos termorrígidos

Tabela 8. Massa molar ponderal média $\left(M_{w}\right)$, massa molar numérica média $\left(M_{n}\right)$ e polidspersividade $\left(M_{w} / M_{n}\right)$ da resina fenólica.

Tabela 9. Massa molar ponderal média $\left(M_{w}\right)$, massa molar numérica média $\left(M_{n}\right)$ e polidspersividade $\left(\mathrm{M}_{\mathrm{w}} / \mathrm{M}_{\mathrm{n}}\right)$ do lignosulfonato e da resina lignosulfonato-formaldeído.

Tabela 10. Porcentagem de fibras nos compósitos de matriz lignosulfonato-formaldeído conforme quantidade de resina utilizada no processamento.

Tabela 11. Difusividade térmica, capacidade térmica, densidade e condutividade térmica para termorrígido fenólico (TL), compósitos fenólicos reforçados com fibras de sisal não modificada (CF-FSNM) e modificada (CF-FSM2), termorrígido lignosulfonato-formaldeído (TL) e compósito de matriz lignosulfonato-formaldeído reforçado com fibras de sisal nãomodificadas (CL-FSNM). 


\title{
LISTA DE ABREVIATURAS, SIGLAS E SÍMBOLOS
}

\author{
CF Compósito de matriz fenólica \\ CL Compósito de matriz lignosulfonato-formaldeído \\ $\mathrm{C}_{\mathrm{p}} \quad$ Calor específico à pressão constante \\ D Coeficiente de difusão \\ DSC Calorimetria exploratório diferencial (Differential Scanning Calorimetry) \\ dTG Derivada primeira da curva TG \\ E' Módulo de armazenamento \\ E" Módulo de perda \\ $\mathrm{E}_{\mathrm{f}} \quad$ Módulo de flexão (ou módulo de elasticidade) \\ FSM1 Fibras de sisal submetidas à Modificação 1 \\ FSM2 Fibras de sisal submetidas à Modificação 2 \\ FSM3 Fibras de sisal submetidas à Modificação 3 \\ FSM4 Fibras de sisal submetidas à Modificação 4 \\ FSNM Fibras de sisal não-modificadas \\ Ic Índice de cristalinidade \\ IV Espectroscopia na região do infravermelho \\ k Constante da lei de difusão de Fick \\ M1 Modificação 1 (lignosulfonato $/ 70^{\circ} \mathrm{C} / 1 \mathrm{~h}$ ) \\ M2 Modificação 2 (lignosulfonato/ultra-som / 1h) \\ M3 Modificação 3 (lignosulfonato/ultra-som / 2h) \\ M4 Modificação 4 (14 h imersão em lignosulfonato / $1 \mathrm{~h}$ Ultra-som) \\ MEV Microscopia eletrônica de varredura \\ $\mathrm{Mn}_{\mathrm{n}} \quad$ Massa molar numérica média \\ $\mathrm{M}_{\mathrm{w}} \quad$ Massa molar ponderal média \\ SEC Cromatografia de exclusão por tamanho (Size Exclusion Chromatography) \\ TF Termorrígido fenólico \\ TG Termogravimetria \\ TL Termorrígido lignosulfonato-formaldeído \\ $\alpha \quad$ Difusividade térmica \\ $\lambda \quad$ Condutividade térmica \\ $\rho \quad$ Densidade \\ $\sigma_{\mathrm{f}} \quad$ Resistência à flexão
}




\section{SUMÁRIO}

\section{LISTA DE FIGURAS \\ LISTA DE TABELAS \\ LISTA DE ABREVIATURAS, SIGLAS E SÍMBOLOS}

1. INTRODUÇÃO

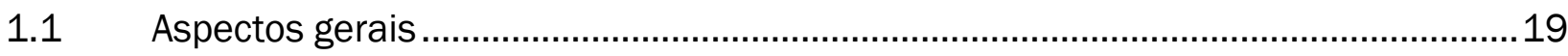

1.2 Compósitos de matriz polimérica ……………......................................................20

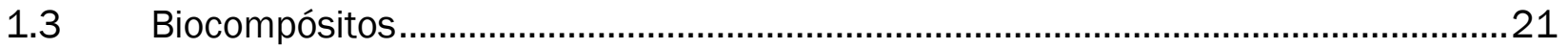

1.4 Fibras naturais como agentes de reforço em compósitos de matriz polimérica ......23

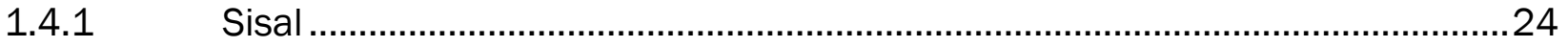

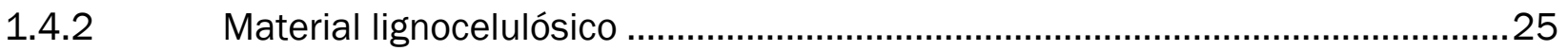

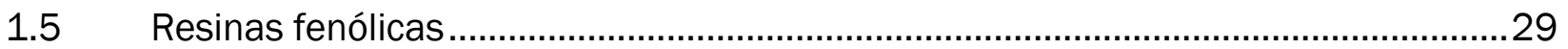

1.6 Ligninas em resinas fenólicas............................................................................

$1.7 \quad$ Interface fibra-matriz ...................................................................................

$1.8 \quad$ Tratamentos em fibras lignocelulósicas.................................................................

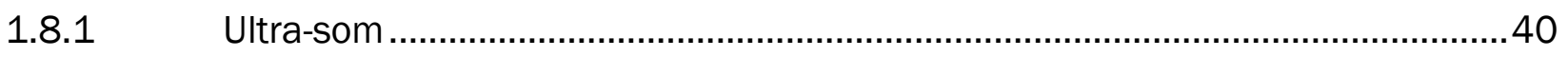

1.9 Projetando compósitos....................................................................................

1.10 Caracterização de compósitos reforçados com fibras naturais .................................42

1.10.1 Propriedades mecânicas...............................................................................42

1.10.2 Condutividade térmica e Difusividade térmica..................................................43

1.10.3 Absorção de água .......................................................................................... 44

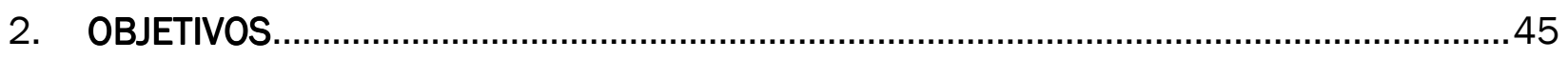

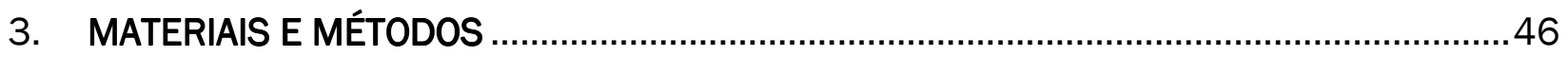

$3.1 \quad$ Origem dos materiais .......................................................................................

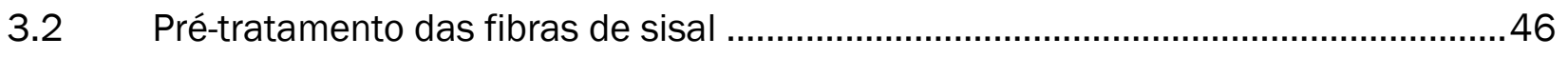

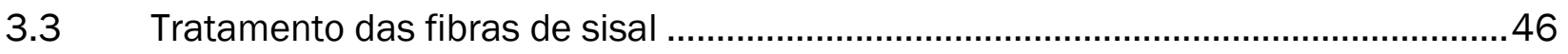

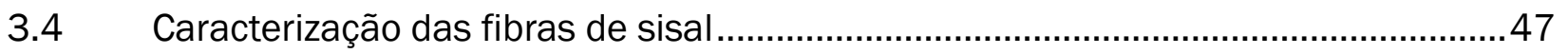

3.4.1 Determinação do teor de umidade ………………………........................... 48

3.4.2 Determinação do teor de cinzas....................................................................48

3.4.3 Determinação do teor de holocelulose ........................................................... 49

3.4.4 Determinação de $\alpha$-celulose ..........................................................................4

3.4.5 Determinação do teor de lignina ………........................................................... 


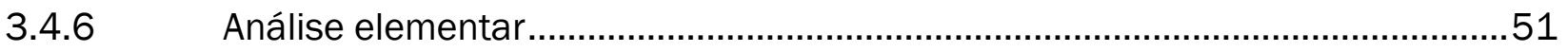

3.4.7 Microscopia Eletrônica de Varredura (MEV) ...................................................51

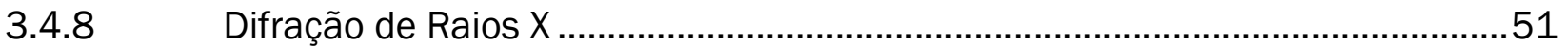

3.4.9 Resistência à tração das fibras de sisal ..........................................................52

3.4.10 Espectroscopia na região do Infravermelho …...............................................52

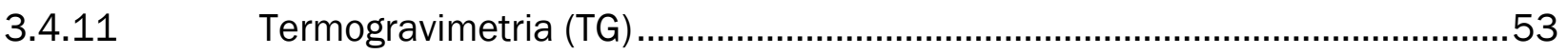

3.4.12 Calorimetria exploratório diferencial (DSC) .................................................53

3.5 Síntese do pré-polímero fenólico .............................................................................53

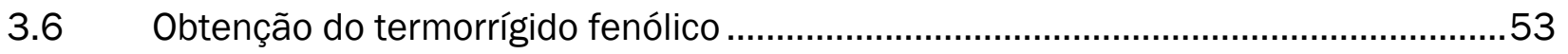

3.7 Obtenção dos compósitos de matriz fenólica reforçados com fibras de sisal

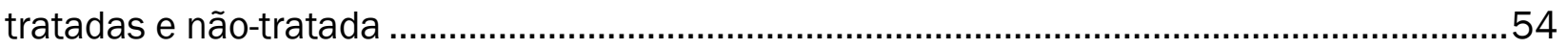

3.8 Síntese do pré-polímero lignosulfonato-formaldeído .................................................56

3.9 Obtenção do termorrígido lignosulfonato-formaldeído ..............................................56

3.10 Obtenção dos compósitos de matriz lignosulfonato-formaldeído ...............................57

3.11 Caracterização do lignosulfonato e dos pré-polímeros ................................................58

3.11.1 Cromatografia de exclusão por tamanho (SEC) .............................................58

3.11.2 Espectroscopia na região do infravermelho .................................................59

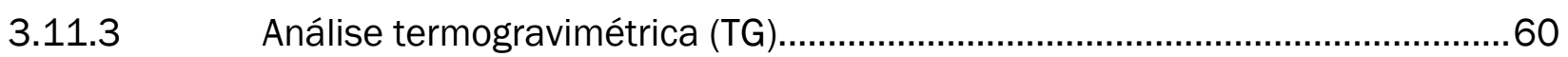

3.11.4 Calorimetria Exploratório Diferencial (DSC) ...............................................60

3.12 Caracterização dos termorrígidos e compósitos .......................................................60

3.12.1 Espectropia na região do infravermelho .........................................................60

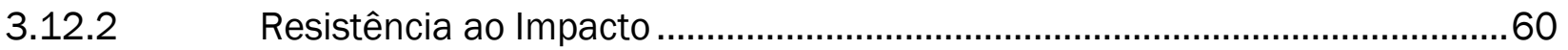

3.12.3 Resistência à flexão..................................................................................... 61

3.12.4 Microscopia eletrônica de varredura (MEV) ...............................................63

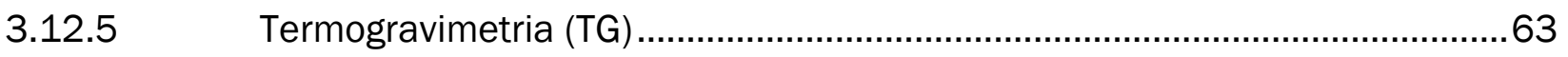

3.12.6 Calorimetria Exploratória Diferencial (DSC) .................................................63

3.12.7 Análise térmica dinâmico-mecânica (DMTA) .................................................63

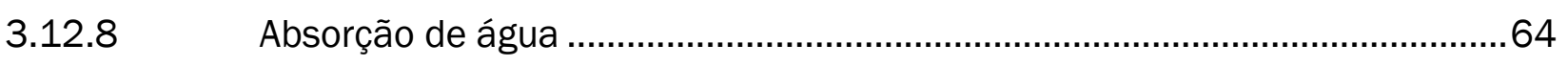

3.12.9 Condutividade térmica e difusividade térmica ...............................................66

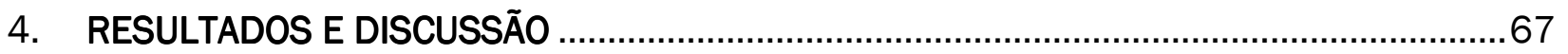

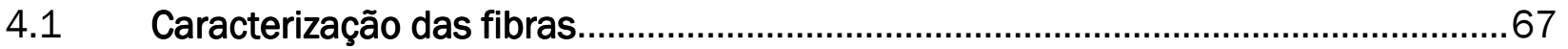

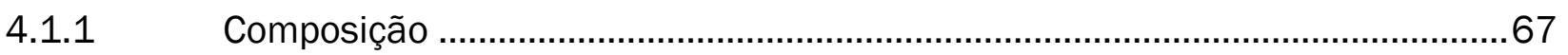

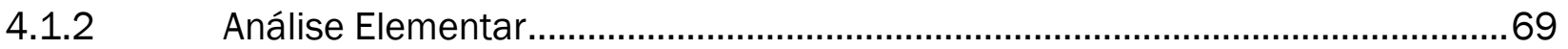

4.1.3 Espectroscopia na região do Infravermelho .................................................. 70 


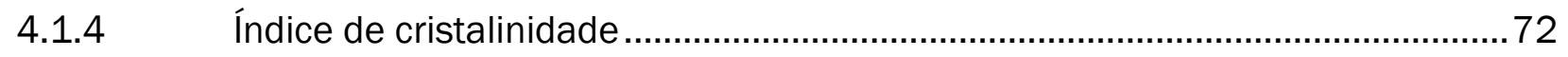

4.1.5 Resistência à tração das fibras ..................................................................... 74

4.1.6 Microscopia eletrônica de varredura (MEV) ....................................................75

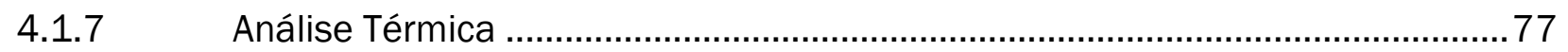

4.2 Caracterização do lignosulfonato, dos pré-polímeros e termorrígidos fenólico e

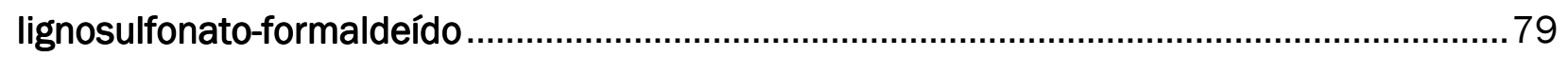

4.2.1 Espectroscopia na região do infravermelho ....................................................79

4.2.2 Cromatografia de exclusão por tamanho (SEC) …...........................................81

4.2.3 Análise Térmica ........................................................................................ 84

4.3 Caracterização dos compósitos de matriz fenólica...................................................87

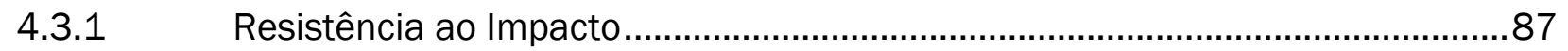

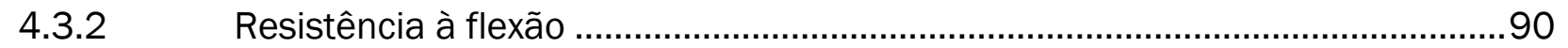

4.3.3 Microscopia Eletrônica de Varredura (MEV) ........................................................93

4.3.4 Análise Térmica ................................................................................................. 97

4.3.5 Análise Térmica Dinâmico-Mecânica ..............................................................99

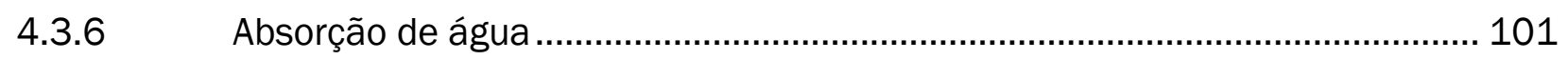

4.4 Caracterização dos compósitos de matriz lignosulfonato-formaldeído.................. 104

4.4.1 Resistência ao Impacto............................................................................ 106

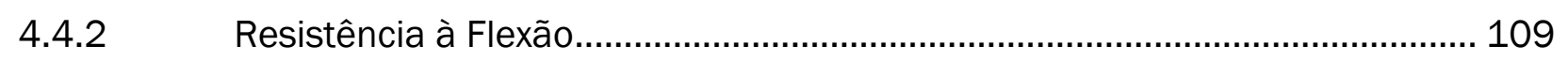

4.4.3 Microscopia eletrônica de varredura (MEV) ................................................ 111

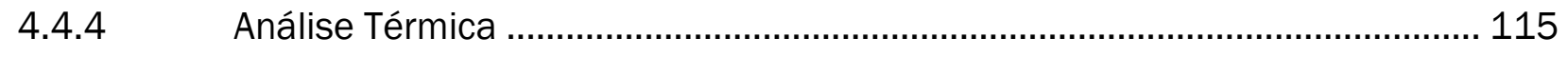

4.4.5 Análise térmica dinâmico-mecânica .................................................................... 116

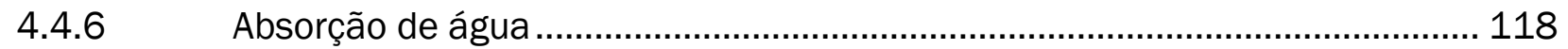

4.5 Condutividade térmica e difusividade térmica de termorrígidos e compósitos..... 121

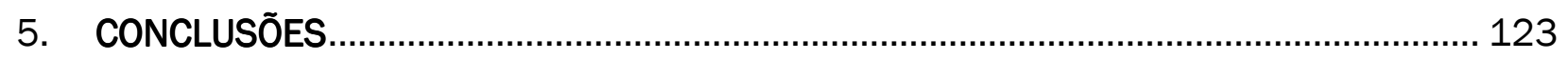

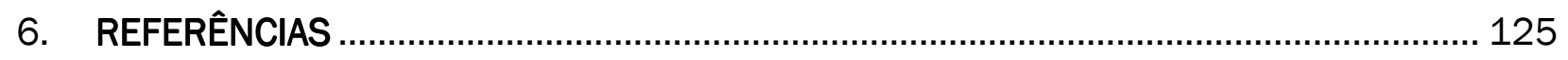

ANEXO 


\section{INTRODUÇÃO}

\subsection{Aspectos gerais}

As preocupações com o meio-ambiente e a possibilidade de escassez de recursos fósseis estão impulsionando o desenvolvimento de uma ampla variedade de novos produtos, baseados em fontes renováveis (ALEMDAR; SAIN, 2008). A utilização de biomassa para produção de energia, produtos químicos e materiais que vem ao encontro com os anseios atuais é, sem dúvida, um dos principais temas que deve ser considerado atualmente, tanto no que diz respeito à pesquisa básica como aplicada.

A produção de substâncias químicas e novos materiais a partir de fontes renováveis não é uma idéia nova. Muitos produtos eram obtidos de fontes renováveis até parte do início do século passado. No entanto, o sucesso do crescimento da indústria petroquímica no século XX desacelerou o desenvolvimento de produtos fabricados a partir de matéria-prima renovável. 0 aumento no rigor de regulamentações ambientais e as crescentes preocupações da sociedade por um desenvolvimento sustentável, aliado a redução de fontes de petróleo, têm desencadeado a busca por novos materiais, produtos e processos que são compatíveis com o meio ambiente (MOHANTY et al., 2005).

Considerando a área disponível para cultivo no país e a relevância do desenvolvimento de pesquisas relacionadas à utilização de biomassa, assim como a importância da formação de recursos humanos na área, é imperativo que esforços sejam concentrados no sentido de valorizar a matéria-prima proveniente da agricultura, com destaque para fibras naturais lignocelulósicas.

As fibras naturais, especialmente as fibras lignocelulósicas extraídas de plantas, estão ganhando atenção como reforços de compósitos de matriz polimérica devido suas vantagens comparativas em relação às fibras sintéticas. No século passado, a prioridade foi dada as fibras sintéticas, que eram fabricadas usando processos envolvendo alto consumo energético. Nos últimos tempos, acredita-se que a maioria das fontes comuns de energia como o petróleo, carvão e gás natural são responsáveis pelas preocupantes mudanças climáticas (MOHANTY et al., 2005).

A possibilidade de substituir materiais tradicionais, em cujos processamentos alto custo energético está envolvido, pelos materiais naturais desperta atenção nos últimos tempos. De fato, os materiais naturais, como as fibras lignocelulósicas, têm importância não só pela possibilidade de economia de energia no processamento, mas também por serem oriundos de fontes renováveis e por normalmente serem biodegradáveis, o que os 
tornam neutros em relação às emissões de $\mathrm{CO}_{2}$, que por sua vez tem impacto no efeito estufa atmosférico e, portanto, no aquecimento global (MONTEIRO et al., 2009).

Assim, a utilização em larga escala de compósitos reforçados com fibras lignocelulósicas pode contribuir para com o desenvolvimento sustentável, tanto no que se refere a aspectos econômicos, reduzindo os custos com relação a compósitos reforçados com fibras sintéticas (FROLLINI et al., 2004), assim como a aspectos ambientais, já que material proveniente de fonte renovável substitui outro não oriundo de fontes deste tipo.

No presente estudo, compósitos de matriz polimérica termorrígida, reforçados com fibras lignocelulósicas, foram considerados.

\subsection{Compósitos de matriz polimérica}

De forma simplificada, um compósito pode ser definido como um material que apresenta duas ou mais fases distintas sendo, portanto, um material heterogêneo (HERAKOVICH, 1998). As duas fases quimicamente distintas presentes nos compósitos são: matriz, que é contínua e circunda a outra fase, e reforço, que é o constituinte disperso. As propriedades de compósitos são funções das propriedades das fases constituintes, das suas quantidades relativas e da geometria da fase dispersa (CALLISTER, 2007).

Compósitos são encontrados na natureza, como a madeira, que é composta de fibras de celulose em uma matriz de lignina (MAZUMDAR, 2002).

Existem diversos tipos de materiais que podem ser empregados como matriz. Estes materiais podem ser cerâmicos, poliméricos ou metálicos (MATTHEWS, 1999). As matrizes poliméricas podem ser divididas em termorrígidas ou termoplásticas. Compósitos confeccionados com matriz polimérica têm se tornado mais comum e são largamente utilizados em diversas indústrias.

Os compósitos podem ser classificados em três principais divisões: reforçados por partícula, reforçados por fibras e estruturais; e ainda existem no mínimo duas subdivisões para cada divisão (Figura 1) (CALLISTER, 2007). 


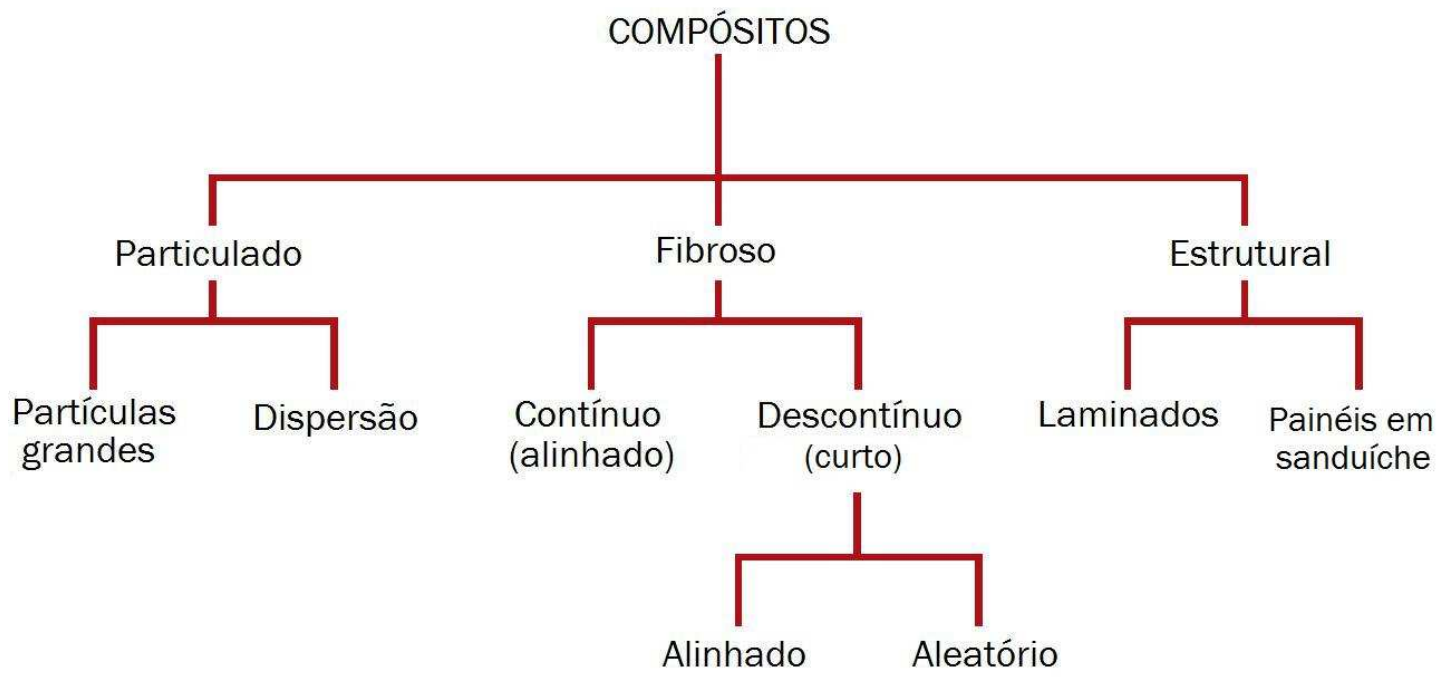

Figura 1. Esquema de vários tipos de compósitos (CALLISTER, 2007).

Entre as funções das fibras em um compósito, pode-se citar a transferência de carga; fornecimento de rigidez, força, estabilidade térmica e estrutural; condutividade elétrica ou isolamento, dependendo do tipo de fibra utilizada. As funções importantes de uma matriz incluem a transferência de carga às fibras. A matriz isola as fibras de modo que possam agir separadamente, o que interrompe ou retarda a propagação de uma rachadura. Ainda, a matriz protege as fibras de danos ambientais, decorrentes, por exemplo, de altas temperaturas e umidade (MAZUMDAR, 2002).

Os reforços, tais como as fibras, são adicionados a polímeros (matriz) para melhorar as propriedades, o que pode ainda estar aliado à busca pela redução de custos. O grande desafio consiste em combinar fibras e matriz de tal forma que um material mais eficiente para determinada aplicação seja produzido (BERLIN et al., 1986; HERAKOVICH, 1998).

\subsection{Biocompósitos}

Plásticos reforçados com fibras começaram a ser preparados em 1908, com fibras de celulose em compostos fenólicos (JOHN; THOMAS, 2008), mais tarde estendendo à uréia e melamina, atingindo o status de "commodity" (mercadorias) com plásticos reforçados com fibra de vidro. A variedade de aplicações dos compósitos é muito grande: construção civil, eletrônicos, indústria automobilística e aeroespacial, artigos esportivos, embalagens e aplicações mecânicas em geral (GAY; HOA; TSAI, 2002; 
MOHANTY et al., 2005). A fibra de vidro é usada em 95\% dos compósitos termoplásticos e termorrígidos reforçados (MOHANTY et al., 2005; JOHN; THOMAS, 2008).

Atualmente, é considerado como de extrema importância a necessidade de desenvolver e comercializar materiais baseados em constituintes de origem natural (biobased composites, biocompósitos), o que terá impacto do ponto de vista da redução da dependência de materiais provenientes de combustíveis fósseis, e também do ponto vista ambiental e econômico (JOSHI et al., 2004; MOHANTY et al., 2004), conforme já mencionado.

Destaca-se que o termo biocompósito pode ser aplicado a materiais em que uma ou mais fases têm origem biológica (FOWLER; HUGHES; ELIAS, 2006). A partir dessa definição, biocompósitos podem ser aqueles preparados com fibras naturais, em matrizes poliméricas oriundas de fontes renováveis ou não. Quando a fibra e a matriz têm origem biológica (matriz baseada em biopolímeros), os biocompósitos são geralmente chamados de "green composites" (compósitos verdes) (MOHANTY et al., 2005).

A emissão de $\mathrm{CO}_{2}$ devido a atividades do homem (chamado de efeito antropogênico) atingiu níveis que fizeram com que o interesse por fibras naturais, considerável nas primeiras décadas do século XX, ressurgisse novamente (WAMBUA; IVENS; VERPOEST, 2003; PERVAIZ; SAIN, 2003; KEENER; STUART; BROWN, 2004; MAFFEZOLI et al., 2004; THIELEMANS; WOOL, 2004). Como resultado, plásticos reforçados com fibras naturais são de interesse como alternativas viáveis a plásticos reforçados com fibras sintéticas, em um número cada vez maior de setores industriais, incluindo a indústria automotiva, de embalagens, mobiliária e de construção civil (ALEMDAR; SAIN, 2008; HABIBI et al., 2008).

Muitos estudos têm sido realizados para investigar a possibilidade de empregar fibras lignocelulósicas (sisal, rami, linho, juta, bagaço de cana) como componentes de reforço em matrizes poliméricas oriundas de fontes renováveis ou não (RAY et al., 2007; BRODOS et al., 2007; JOHN; SAIN, 2008). Com a inserção de fibras, geralmente as propriedades mecânicas da matriz polimérica são melhoradas (BRODOS; REIHMANE; GASSAN, 2007).

$\mathrm{Na}$ área de compósitos reforçados com fibras de origem natural, do tipo lignocelulósicas ou celulósicas, pode-se considerar que a maior parte dos trabalhos aborda a preparação e a caracterização de compósitos de matriz termoplástica. Comparativamente, poucos trabalhos têm sido desenvolvidos considerando matrizes 
termorrígidas (apesar da extensa aplicação das mesmas) e, dentre estes, um número menor se refere à matriz termorrígida fenólica, que é a considerada no presente trabalho, assim como em outros já desenvolvidos nesta área (MEGIATTO et al., 2007a; HOAREAU et al., 2006; PAIVA; FROLLINI, 2006; TRINDADE et al., 2005; TRINDADE et al., 2004; RAZERA; FROLLINI, 2004; RAMIRES, 2010).

\subsection{Fibras naturais como agentes de reforço em compósitos de matriz polimérica}

Fibras sintéticas (aramidas, vidro, carbono), são amplamente usadas como reforços em plásticos. Entretanto, devido às recentes restrições ambientais, esforços vêm sendo feitos para disponibilizar para a indústria de polímeros novos materiais que causem menor impacto ambiental. As fibras lignocelulósicas extraídas de plantas cultivadas como sisal, curauá, juta, cânhamo, coco, linho, madeira, abacaxi, banana e buriti são exemplos típicos de materiais naturais (MONTEIRO et al., 2009).

0 interesse crescente no uso de fibras lignocelulósicas decorre também de sua produção, que exige poucos equipamentos, e a sua baixa densidade, quando comparadas às de vidro. Fibras naturais têm impacto ambiental positivo, pois são recursos renováveis e sua produção consome pouca energia. Além disso, apresentam grande disponibilidade mundial e condições de trabalho no geral mais seguras quando comparadas aos materiais convencionalmente utilizados, como as fibras de vidro (JOHN; SAIN, 2008; HABIBI et al., 2008).

Ao contrário de fibras como as de vidro e carbono, que são extensivamente produzidos em países altamente industrializados, as lignocelulósicas são cultivadas principalmente nas regiões tropicais de países em desenvolvimento. Isto é relevante do ponto de vista social, pois representa uma importante fonte de renda para sustentar a economia de populações locais, como na África, América Latina, e norte e sul da Ásia (MONTEIRO et al., 2009).

Há quem preveja a gradual substituição de aditivos tradicionais (particularmente fibras de vidro) por fibras vegetais, o que sem dúvida representa uma excelente abertura de mercado para países com vocação agrícola. Depois de substituir praticamente a totalidade das fibras naturais usadas na produção automobilística até 1960 por fibras sintéticas, ao longo das décadas de 1970 e 1980, as montadoras voltaram na última década a considerar o emprego de materiais originados de fontes renováveis (POU et al., 2001; JOHN; SAIN, 2008). 
As fibras lignocelulósicas que serão utilizadas no presente trabalho correspondem às fibras de sisal.

\subsubsection{Sisal}

O sisal, Agave sisalana (Figura 2a), é um planta originária da América Central, mais especificamente do México, e cresce em países tropicais como a Tanzânia e o Brasil, sendo estes atualmente os dois maiores produtores mundiais (GUTIÉRREZ; RODRIGUEZ; DEL RIO, 2008). Aproximadamente 4,5 milhões de toneladas de fibras de sisal são produzidas anualmente em todo mundo (BISMARCK; MISHRA; LAMPKE, 2005). No Brasil, a produção de fibras de sisal em 2008 foi de 215.760 t 1 .
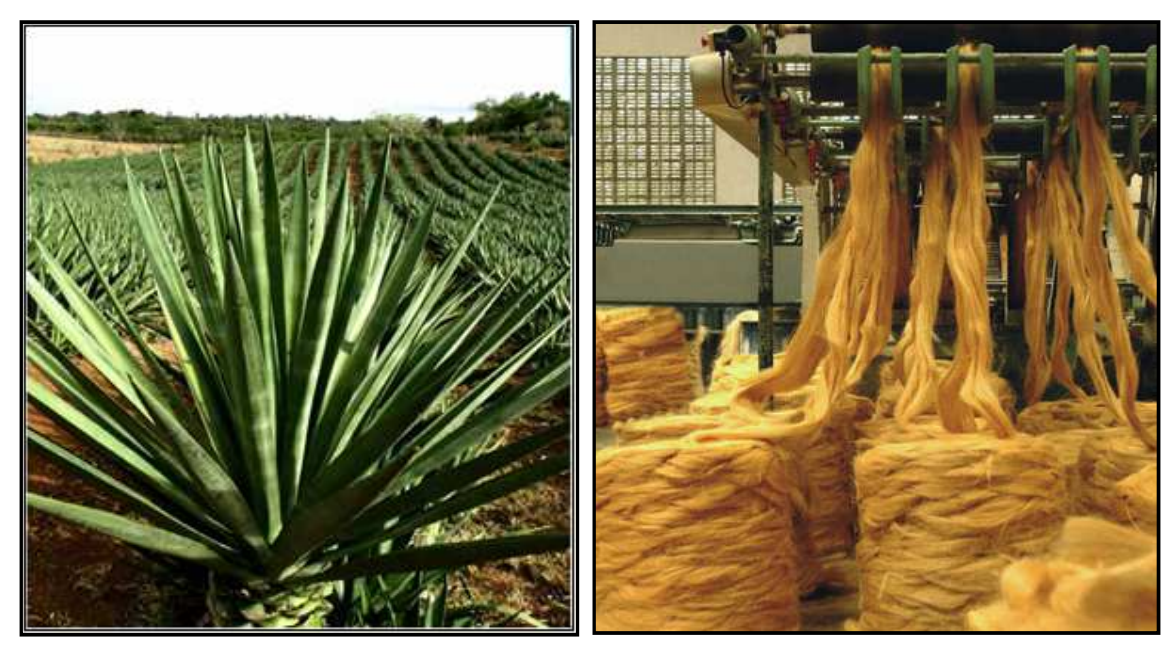

Figura 2. (a) Planta de sisal e (b) Processamento das fibras de sisal 2

A fibra de sisal (Figura 2b) é uma das fibras naturais mais amplamente utilizadas, e a razão para isso é à facilidade de cultivo e seu curto tempo de renovação (MISHRA, 2004), visto que as fibras são colhidas geralmente a cada nove meses ${ }^{3}$. São constituídas principalmente por celulose, hemicelulose, lignina, além de pectina, ceras e substâncias solúveis em água. A celulose, hemicelulose e lignina são os principais componentes responsáveis pelas propriedades físicas das fibras (GEORGOPOULOS et al., 2005).

As fibras de sisal, que são obtidas a partir das folhas da planta, têm diversas aplicações. Elas são rotineiramente utilizadas na fabricação de cordas, tapetes, redes de pesca e artesanatos em geral. Devido às excelentes propriedades mecânicas, podem ser

\footnotetext{
${ }^{1}$ Fonte: IBGE - Produção Agrícola Municipal e Levantamento Sistemático da Produção Agrícola (Janeiro/09).

2 http://www.braziliansisal.com/Livro.asp acessado em 11/09/2008 às 17h43min

${ }^{3}$ http://www.seagri.ba.gov.br/Sisal.htm\#Plantio acessado em 10/02/2010 às 00h37min
} 
consideradas como bons reforços para matrizes poliméricas. (MEGIATTO et al., 2007b). Como todas as fibras lignocelulósicas, podem ser consideradas como compósitos que ocorrem naturalmente consistindo principalmente de fibrilas de celulose unidas por uma matriz amorfa de lignina (JOHN; SAIN, 2008; ACHA; MARCOVICH; REBOREDO, 2009).

\subsubsection{Material lignocelulósico}

O material lignocelulósico é constituído basicamente por celulose, hemicelulose e lignina. A proporção de cada um depende da fonte a partir da qual o material foi extraído, além de poder sofrer influências de condições climáticas e do tipo de solo onde a planta foi cultivada. Pequenas proporções de proteínas, lipídeos (gorduras, ceras, óleos) e cinzas (material inorgânico) geralmente também estão presentes.

A celulose é o principal constituinte dos tecidos vegetais. Trata-se de um polissacarídeo que consiste de unidades de D-anidroglicose $\left(\mathrm{C}_{6} \mathrm{H}_{10} \mathrm{O}_{5}\right)_{n}$, conectadas por ligações 1,4- $\beta$-D-glicosídicas no C1 e C4 (Figura 3). A estrutura de celulose presente nos tecidos das plantas é a mesma, com longas cadeias poliméricas contendo unidades de glicose. As diferenças nas propriedades de celulose são devidas, principalmente, aos diferentes graus de polimerização e de cristalinidade. Na Figura 3 está mostrada a unidade repetitiva da celulose, a celobiose. A presença de grupos hidroxilas e suas habilidades para ligações hidrogênio definem a cristalinidade, e também governam as propriedades físicas da celulose (JOHN; SAIN, 2008).

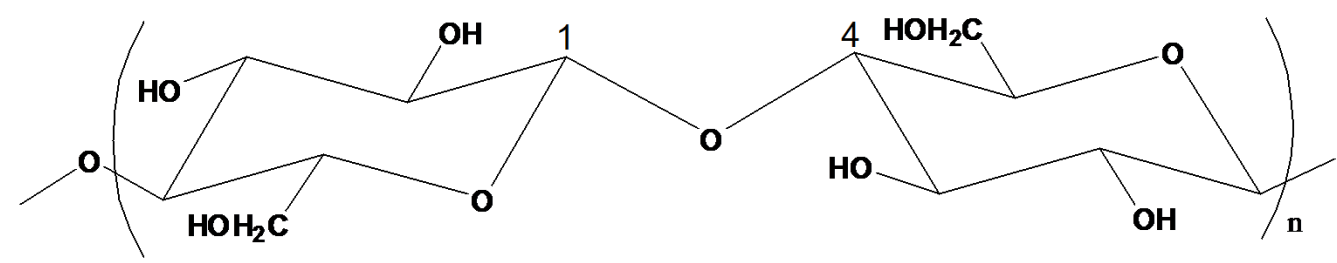

Figura 3. Estrutura da celobiose (unidade repetitiva da celulose) (FENGEL; WENEGER, 1989).

As hemiceluloses, também chamadas de polioses (Figura 4), correspondem a polissacarídeos com grau de polimerização menor (aproximadamente de 10 a 100 vezes menor) comparativamente ao da celulose (FENGEL; WENEGER, 1989). Ela difere da celulose por conter diferentes unidades de açúcares, enquanto a celulose possui apenas a D-anidroglicose. Holocelulose é o termo utilizado para indicar a fração total de 
carboidratos da planta (hemicelulose e celulose), a qual permanece após a remoção da lignina (PATURAU, 1989). A hemicelulose pode ser considerada como um compatibilizador entre celulose e lignina na fibra lignocelulósica (ACHA; MARCOVICH; REBOREDO, 2009).

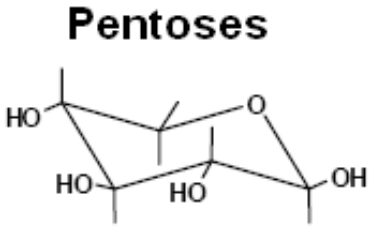

$\beta$-D-xilanopiranose

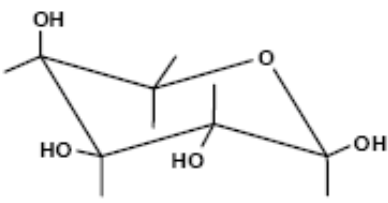

$\alpha$-L-arabinopiranose

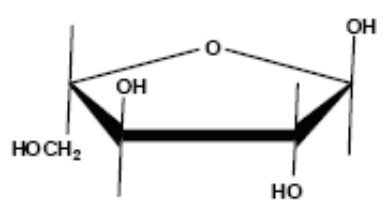

$\alpha$-L-arabinofuranose

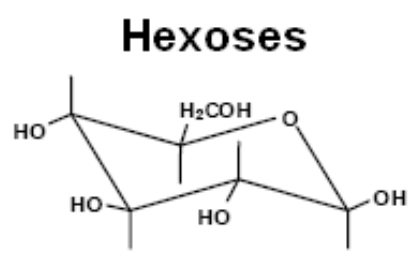

$\beta$-D-glicopiranose

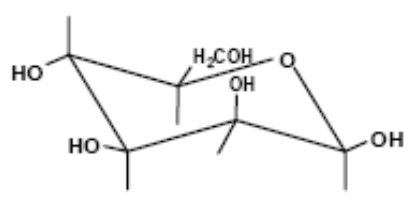

$\beta$-D-manopiranose

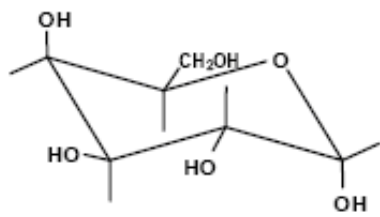

$\alpha$-D-galactopiranose

\section{Ácidos hexourônicos}

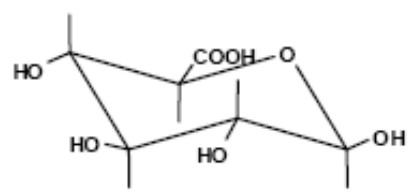

Acido $\beta$-D-glicurônico

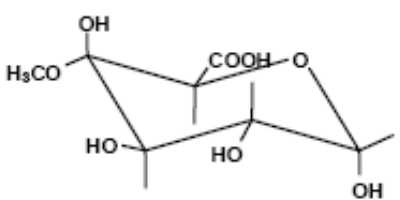

Acido $\alpha$-D-4-O-metil-glicurônico

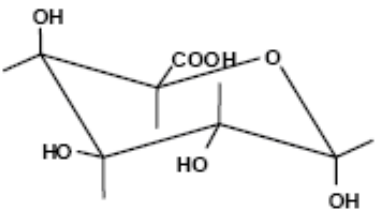

Acido $\alpha$-D-galacturônico

Figura 4. Estruturas de unidades de monossacarídeos presentes na hemicelulose (polioses) (FENGEL; WENEGER, 1989).

A lignina corresponde a uma macromolécula com estrutura complexa, de natureza aromática, com anéis do tipo fenólico presentes em sua estrutura. No que diz respeito ao reino vegetal, é o segundo composto mais abundante, depois da celulose. A lignina pode ser dividida em duas classes: guaiacila e guaiacila-siringila. Nas guaiacilas, existem principalmente unidades guaiacila e nas guaiacila-siringila existem unidades guaiacila e siringila em proporções aproximadamente iguais, sendo que ambas as classes possuem proporções menores de unidades para-hidroxifenila (Figura 5) (FENGEL; WENEGER, 1989). 
<smiles>Cc1ccc(O)cc1</smiles>

p-hidroxifenila<smiles>COc1cc(C)ccc1O</smiles>

guaiacila<smiles>COc1cc(C)cc(OC)c1O</smiles>

siringila

Figura 5. Unidades presentes na lignina (FENGEL; WENEGER, 1989).

Megiatto et al. (2007b) isolaram e caracterizaram a hemicelulose e a lignina presentes na fibra de sisal. A xilose foi o açúcar livre encontrado em maior proporção, sugerindo a presença de alto teor de xilana na estrutura da hemicelulose. Ainda, uma quantidade apreciável de galactose foi detectada e quantidades pequenas de arabinose, glicose e manose foram identificadas na fração de hemicelulose. As caracterizações da lignina demonstraram que a lignina da fibra de sisal é do tipo guaiacila-siringila, com quantidades de unidades de siringila consideravelmente maior que de guaiacila.

Como um componente estrutural das plantas, a lignina é um dos produtos renováveis mais abundantes na natureza. Em relação à sua estrutura e composição química, é uma macromolécula natural complexa. Geralmente, é considerada uma macromolécula amorfa tridimensional, disposta aleatoriamente, composta de unidades de fenilpropano. Na Figura 6 é possível observar a estrutura da lignina de coníferas proposta por Adler (1977). É importante ressaltar que a estrutura da lignina é dependente da espécie de planta da qual foi extraída e das condições de processamento. Um problema relacionado ao estudo de lignina vem da impossibilidade prática, até o momento, de extraí-la sem alterar sua estrutura, sendo que mesmo usando o mesmo procedimento é difícil isolar amostras idênticas (RODRÍGUEZ, 2005). 


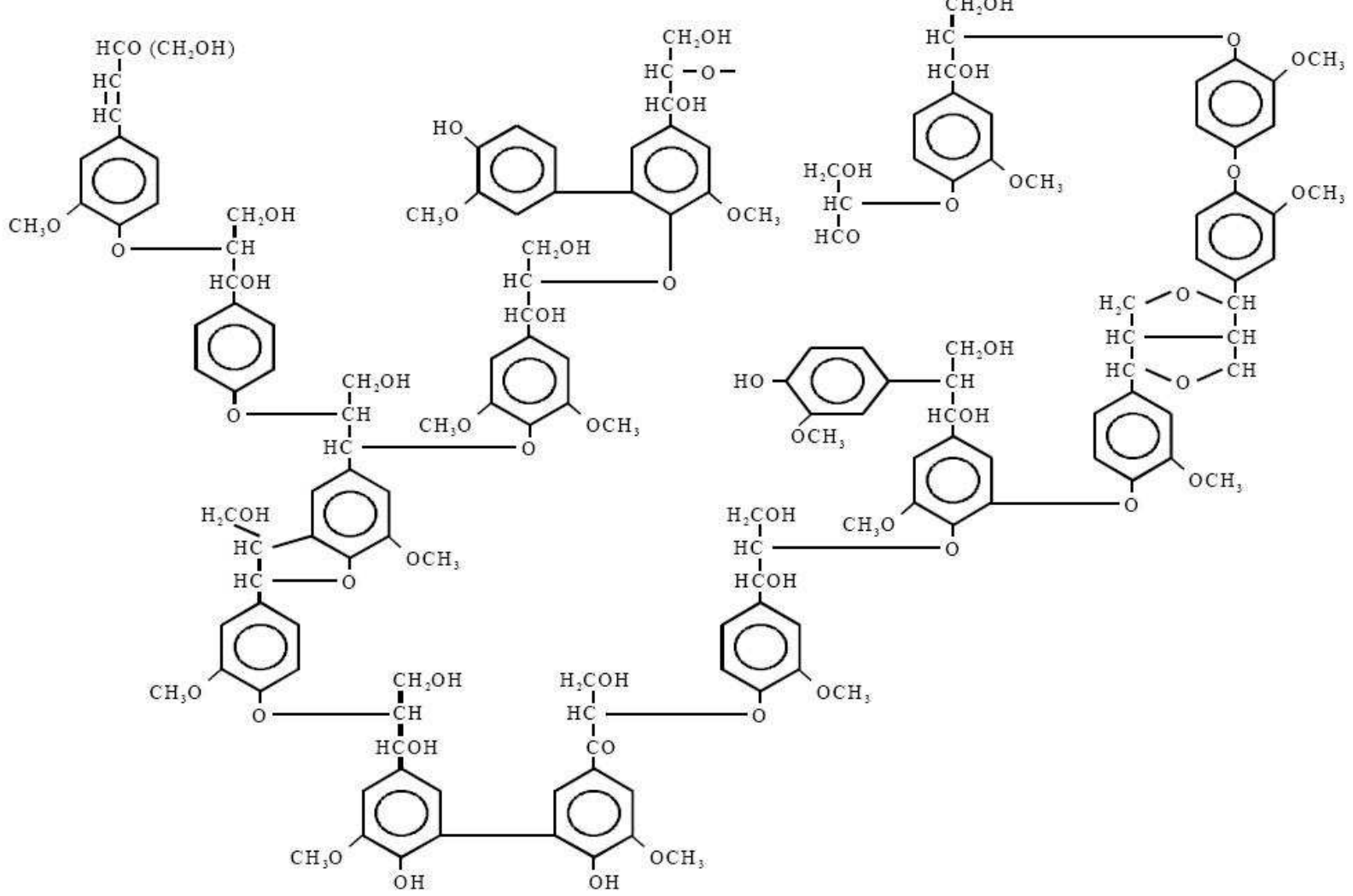

Figura 6. Estrutura de lignina de coníferas propostas por Adler (1977).

Ligninas são geralmente encontradas como subprodutos da indústria de papel e celulose, e são frequentemente utilizadas como combustível para o balanço energético do processo de polpação, sendo relativamente de baixo custo. A lignina é utilizada comercialmente como um estabilizante (antioxidante) para plásticos e borracha bem como na formulação de dispersantes, adesivos e surfactantes (DE PAOLI; FURLAN, 1985; ACHA; MARCOVICH; REBOREDO, 2009).

Os lignosulfonatos, também chamados de ligninas sulfonadas, são obtidos como um subproduto do processo de polpação sulfito da madeira, para obtenção da celulose. Podem ser obtidos também pela sulfonação de ligninas obtidas por processos Kraft. Dependendo do tipo de processo de polpação, lignosulfonatos diversificados podem ser obtidos, como os de cálcio, sódio, magnésio e amônio (RODRíGUEZ, 2005). Ao contrário da lignina, os lignosulfonatos são solúveis em água, devido à introdução de grupos sulfonatos (Figura 7), sendo considerados por alguns como polieletrólitos ramificados (FREDEHEIM; BRAATEN; CHRISTENSEN, 2002; FREDEHEIM; BRAATEN; CHRISTENSEN, 2003; MYRVOLD, 2008). 


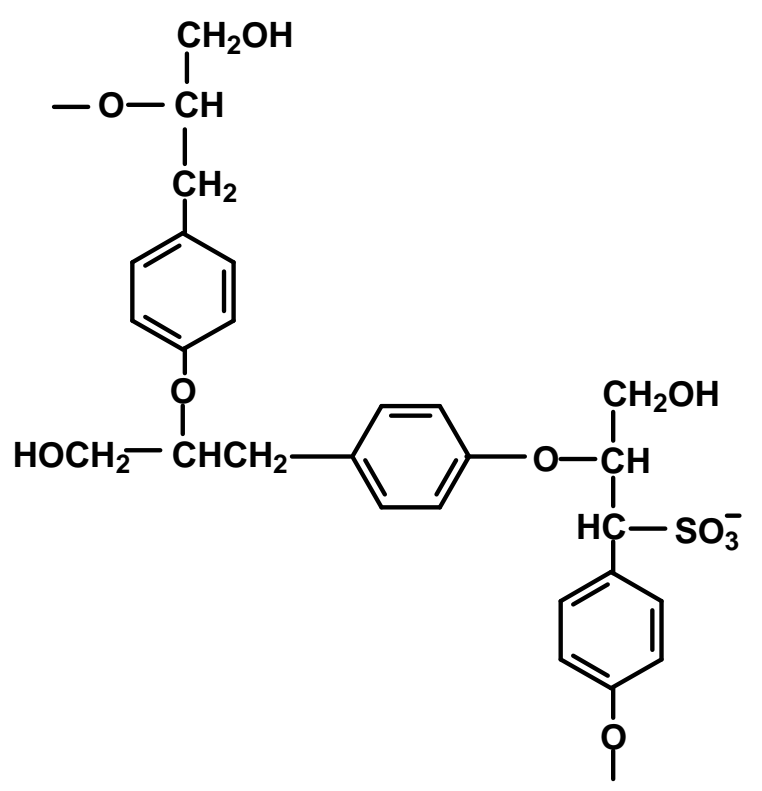

Figura 7. Parte da estrutura de lignosulfonato proposta por Fredheim (2003).

Tradicionalmente, os lignosulfonatos têm sido o único derivado de lignina largamente utilizada na indústria. O caráter macromolecular e o elevado teor de grupos sulfônicos, quando na forma de ácidos, conferem aos lignosulfonatos importantes propriedades, as quais têm sido utilizadas em diversas aplicações, tais como dispersantes, aglutinantes, emulsificantes e resinas de troca iônica (TEJADO et al., 2007). Em termos de quantidade, o lignosulfonato é mais utilizado na indústria de construção civil, pois atua como plastificante, o que melhora a fluidez e a atuação dos concretos (PLANCK, 2004).

\subsection{Resinas fenólicas}

As resinas fenólicas correspondem a materiais sintéticos que estão entre as resinas termorrígidas mais utilizadas pela indústria, numa ampla variabilidade de aplicações. Apresentam alta resistência ao desgaste, mesmo em altas temperaturas (SINGHA; THAKUR, 2008; ZÁRATE; ARANGUREN; REBOREDO, 2008), além de possuir propriedades adesivas, alta rigidez, estabilidade dimensional e resistência à chama, devido a uma estrutura aromática altamente reticulada (JOSEPH et al., 2002; MU; WEl; FENG, 2009). Dentre as aplicações, pode-se destacar o uso em adesivos e termorrígidos para aeronaves.

As resinas fenólicas são preparadas pela reação de fenol, ou de fenóis substituídos, com aldeídos, principalmente o formaldeído, na presença de catalisador 
ácido ou básico. Estas resinas são produtos de reação de polimerização do tipo policondensação (KNOP; PILATO, 1985). Dependendo do meio onde ocorre a reação, as resinas fenólicas são classificadas como resol e novolacas. Os resóis são obtidos sob catálise básica, sendo utilizada a reação entre fenol e excesso de formaldeído. Já as novolacas são obtidas sob catálise ácida, e a reação é feita com formaldeído e excesso de fenol (FINK, 2005).

Devem ser consideradas três seqüências de reação na obtenção de resinas fenólicas: adição do formaldeído ao fenol, crescimento da cadeia ou formação do prépolímero e, finalmente, o entrecruzamento ou reação de cura (KNOP; PILATO, 1985).

No presente trabalho, a resina fenólica utilizada como matriz correspondeu a um resol, ou seja, foi sintetizada a partir da reação entre o fenol e um excesso de formaldeído, sob catalise básica (KOH).

As resinas fenólicas do tipo resol são produzidas utilizando-se razão molar de formaldeído e fenol de 1,2:1 a 3,0:1 e catalisadores alcalinos como NaOH e KOH (KNOP; PILATO, 1985). Os resóis podem ser sólidos ou líquidos, solúveis ou insolúveis em água, de cura lenta ou rápida.

$\mathrm{Na}$ etapa inicial forma-se o ânion fenolato $\left(\mathrm{C}_{6} \mathrm{H}_{5} \mathrm{O}^{-}\right)$, que reage, por exemplo, com formaldeído (o qual reage na forma de metileno glicol $\left(\mathrm{HO}-\mathrm{CH}_{2}-\mathrm{OH}\right)$, já que uma solução aquosa do aldeído é usada), ocorrendo a introdução de grupos o-hidroximetila e phidroximetila $\left(-\mathrm{CH}_{2} \mathrm{OH}\right)$, ou seja, entrada dos grupos nas posições ativadas para o ataque eletrofílico devido à "deslocalização" de elétrons (Figura 8).

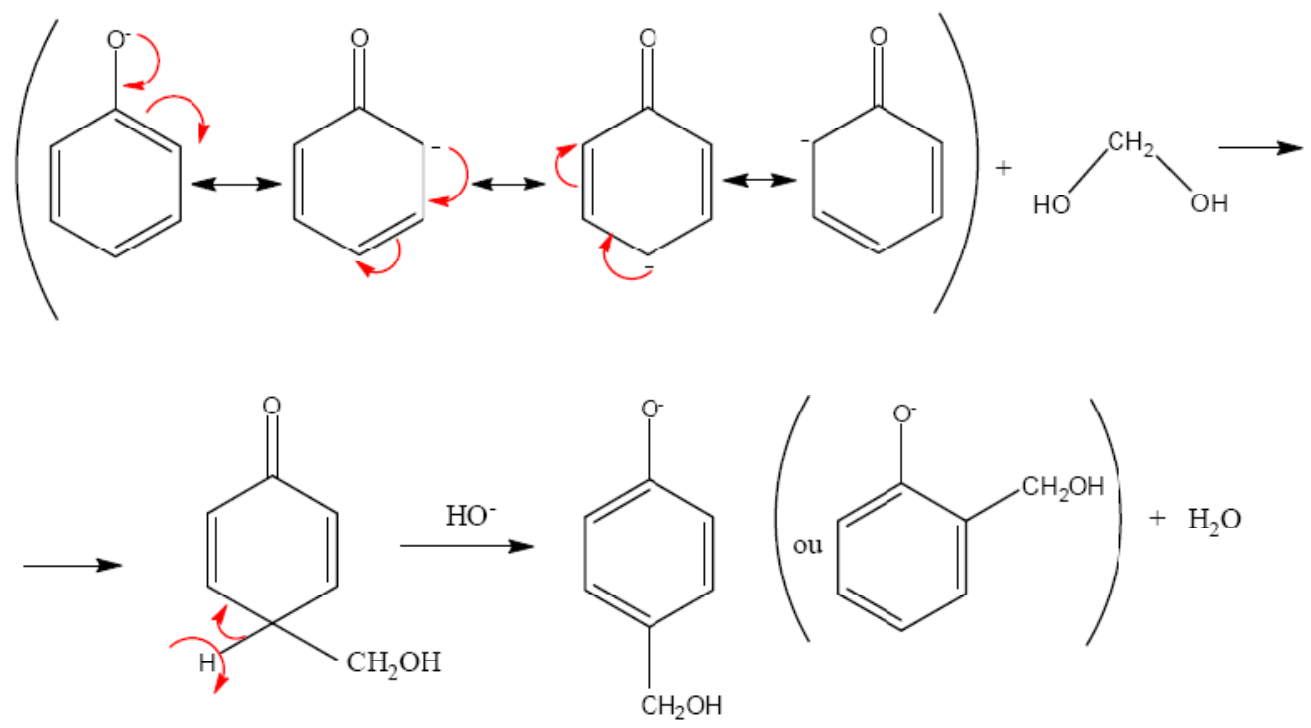

Figura 8. Reação entre ânion fenolato e formaldeído 
Os hidroximetilfenóis ou "metilóis" resultantes são mais reativos frente ao formaldeído que o fenol original, devido à ativação do anel para o ataque eletrofílico, em decorrência do efeito eletrônico doador de elétrons do grupo hidroximetila para o anel aromático (- $\mathrm{CH}_{2}$ - ligado ao anel doa elétrons por efeito indutivo e por hiperconjugação). Assim, rapidamente ocorre outra reação de substituição com a formação de derivados dimetilol e trimetilol (SAUNDERS, 1988).

Os hidroximetilfenóis assim obtidos são relativamente estáveis na presença de álcali, mas pode ocorrer autocondensação, com liberação de água ou de formaldeído, formando fenóis dinucleares e polinucleares, nos quais os núcleos fenólicos estão geralmente ligados através de grupos metilênicos (Figura 9).

A)
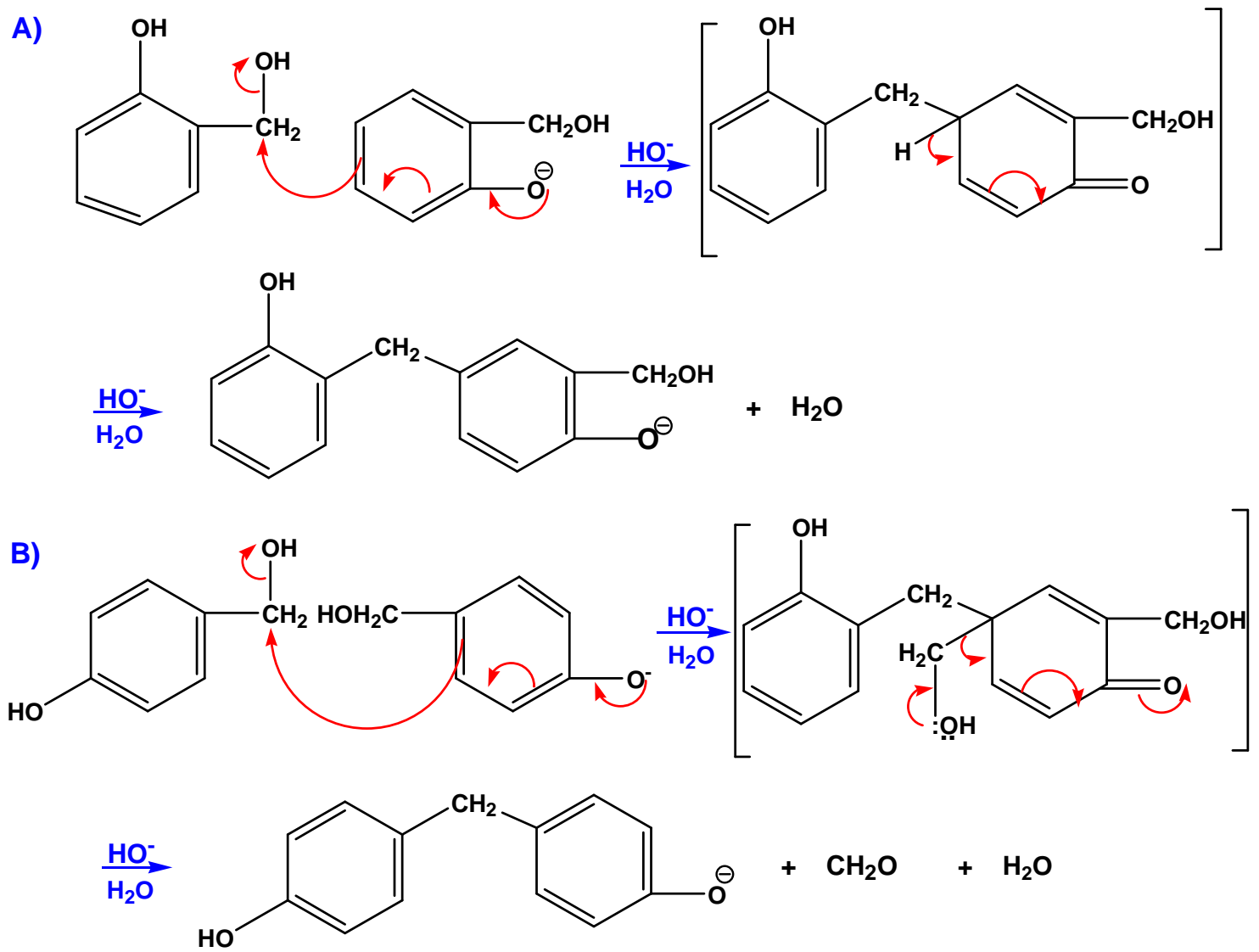

Figura 9. Reação de auto-condensação de hidroximetilfenóis (SAUNDERS, 1998).

A reação de formação de fenóis dinucleares pode ser repetida, formando fenóis trinucleares e assim por diante. Assim, o produto obtido pela reação de fenol e formaldeído, sob condições alcalinas, chamado de pré-polímero fenólico, é uma mistura complexa de fenóis mono e polinucleares, na qual os núcleos fenólicos estão principalmente ligados por grupos metilênicos. 
O processo de cura (entrecruzamento) é complexo, podendo envolver vários tipos de reações. Resumidamente, pode-se propor que na cura térmica, como a que será considerada no presente trabalho, o carbono eletrofílico dos grupos hidroximetila livres, reagem com o anel aromático de uma cadeia vizinha, provocando o entrecruzamento, através de uma reação do tipo substituição eletrofílica em anel aromático, conforme mostrado na Figura 10.<smiles>CCc1cccc(Cc2cc(Cc3cc(Cc4ccc(COCc5cccc(C)c5O)c(O)c4CC)cc(Cc4cc(CO)cc(C)c4O)c3O)ccc2O)c1O</smiles>

Figura 10. Reação de entrecruzamento da resina fenólica

Como após o entrecruzamento o produto obtido é insolúvel, torna-se mais difícil a investigação a respeito de todos os tipos de reações que realmente ocorrem.

\subsection{Ligninas em resinas fenólicas}

O processo de produção de resinas fenólicas não sofreu alterações significativas ao longo do século passado. No entanto, neste século têm sido feito esforços a fim de reduzir a dependência da indústria do fenol, cujo preço está sujeito a flutuações típicas dos produtos derivados de petróleo (ALONSO et al., 2000).

A lignina pode ser utilizada para substituir parcialmente o fenol em resinas fenólicas porque em sua complexa estrutura estão presentes anéis aromáticos do tipo fenólico (Figura 6). Assim, a lignina, uma macromolécula obtida de fontes vegetais, representa uma possibilidade de substituir parcial ou totalmente o fenol na preparação de resinas fenólicas (PAIVA; FROLLINI, 2001; PAIVA, FROLLINI, 2006; RAZERA, FROLLINI 
2004; RAMIRES, 2010). Dentre as várias tentativas de utilização de lignina, pode-se destacar a área de adesivos como uma das pioneiras. Na literatura podem-se encontrar registros da substituição parcial do fenol por lignina em resinas fenólicas, mas geralmente tem sido considerada somente a aplicação como adesivo (FALKEHAG, 1975; COOK; SELLERES, 1989; DANIELSON; SIMONSON, 1998; VASQUEZ et al., 2002).

O uso de lignina como substituto parcial do fenol em resinas fenólicas para aplicações em compósitos de matriz lignofenólica tem sido viável devido à semelhante estabilidade térmica da matriz lignofenólica quando comparada à matriz fenólica (PAIVA; FROLLINI, 2001; TITA, 2002; PAIVA; FROLLINI, 2006; RAMIRES, 2010).

Dentro deste contexto, espera-se também que o lignosulfonato de sódio seja um substituto em potencial do fenol em resinas fenólicas. No presente trabalho, lignosulfonato de sódio foi utilizado tanto para preparar a matriz como para modificar a superfície da fibra de sisal que reforçará esta matriz, visando intensificar as interações na interface fibra-matriz.

\subsection{Interface fibra-matriz}

O comportamento mecânico de compósitos é resultado das propriedades das fibras, da matriz e da interface fibra/matriz (CHAWLA, 1998). As propriedades mecânicas dos compósitos dependem também da boa dispersão da fibra na matriz, da minimização de vazios e adequada adesão interfacial fibra/matriz (ISLAM et al., 2010). No que se refere à região de interface fibra/matriz, esta deve ter uma boa adesão interfacial para garantir a transferência de carga da matriz para o reforço (SINGHA; THAKUR, 2008; HABIBI et al., 2008).

$\mathrm{Na}$ mistura de dois componentes de natureza química diversa, de qualquer dimensão ou forma, para que ocorra uma interação é essencial a existência de áreas de contato entre eles. Quanto maior for essa área, tanto maior será a possibilidade de ocorrer entre os dois componentes uma interação de natureza física, química ou físicoquímica (YOSOMIYA et al., 1990). Em todos os casos, as interações entre a fase dispersa e a matricial dependem da extensão da área de contato e da afinidade entre os componentes.

Neste contexto, é importante destacar a questão da molhabilidade, correspondente à capacidade de um líquido se espalhar sobre uma superfície sólida. A molhabilidade de um dado sólido por um líquido pode ser avaliada considerando o 
equilíbrio de forças em um sistema composto por uma gota de líquido em repouso em um plano de superfície sólida em atmosfera adequada (Figura 11). A gota de líquido se espalhará e molhará a superfície completamente apenas se isto resultar em uma redução de energia livre do sistema. 0 ângulo de contato $(\theta)$, de um líquido sobre a superfície da fibra sólida é um conveniente e importante parâmetro para caracterizar a molhabilidade. Comumente, o ângulo de contato é medido colocando uma gota séssil do líquido na superfície plana de um substrato sólido (CHAWLA, 1998).

Um ângulo de contato pequeno $\left(\theta<90^{\circ}\right)$ implica em boa molhabilidade, como mostrado na Figura 11b. A condição de $\theta=0^{\circ}$ (Figura 11a), corresponde a molhabilidade completa. Ângulos de contato superiores a $90^{\circ}$ estão relacionados a pouca ou nenhuma molhabilidade (Figura 11c).

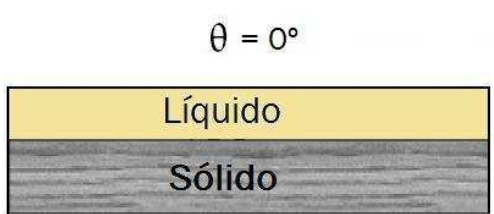

Molhabilidade completa

(a)

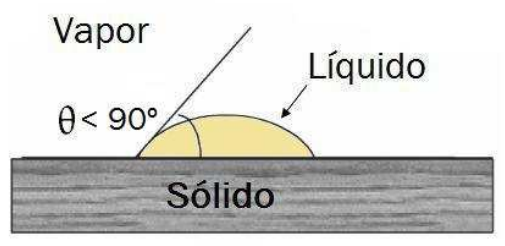

Molhabilidade parcial

(b)

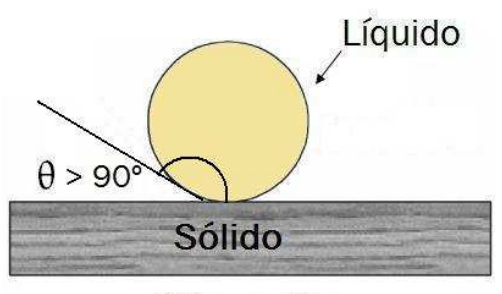

Não molha

(c)

Figura 11. Três diferentes condições de molhabilidade: (a) molhabilidade completa, (b) molhabilidade parcial e (c) condição que não molha (CHAWLA, 1998)

É importante ressaltar que molhabilidade e interações intensas não são termos sinônimos. A molhabilidade descreve o grau de contato íntimo entre um líquido e um sólido, mas isso não significa, necessariamente, uma forte interação com a interface. Pode-se ter excelente molhabilidade e uma interação de baixa energia, por exemplo envolvendo atração entre dipolos momentâneos gerados pela movimentação de elétrons, as quais são as únicas interações intermoleculares existentes entre materiais apolares. Um pequeno ângulo de contato, que significa boa molhabilidade, é uma condição necessária, mas não o suficiente, para fortes interações (CHAWLA, 1998).

Molhabilidade é um parâmetro muito importante em compósitos de matriz polimérica, visto que idealmente no processamento a resina deve penetrar no interior e revestir a superfície da fibra. Entre os materiais que são comumente usados como matrizes poliméricas, os que levam a termorrígidos, ou seja, os pré-polímeros, têm viscosidade menor que os termoplásticos fundidos. Comparativamente, os polímeros de 
matriz termoplástica mostram características de molhabilidade das fibras inferiores às dos termorrígidos (CHAWLA, 1998).

Em um compósito, as características da interface são determinadas pela descontinuidade de propriedades e são específicas para cada combinação reforço-matriz (MATTHEWS, 1999). Para efeito de estudos, assume-se que a interface é perfeitamente plana (caso ideal) (Figura 12a). Porém, comumente, a interface entre a fibra e a matriz é irregular (Figura 12b). Geralmente, a interface fibra-matriz irá assumir o mesmo perfil de rugosidade da fibra (CHAWLA, 1998).

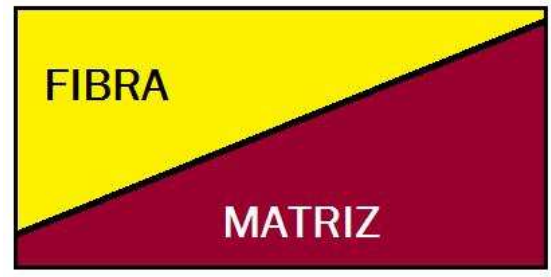

(a)

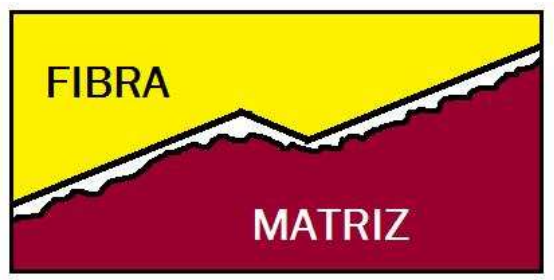

(b)

Figura 12. Interfaces entre o reforço e a matriz. (a) Interface ideal: planar; (b) Interface mais provável: rugosa (CHAWLA, 1998).

Uma vez que a matriz é colocada em contato íntimo com o reforço, ocorrerá interação interfacial. Diversos tipos de interação interfacial podem ocorrer e, dependendo do sistema em questão, mais de um tipo de interação pode ocorrer simultaneamente. Os diferentes mecanismos podem ser: ligação química, adesão mecânica, atração eletrostática e interdifusão(MATTHEWS, 1999). Na Figura 13 são representados apenas três tipos de mecanismos, dentre as diversas formas de interação.

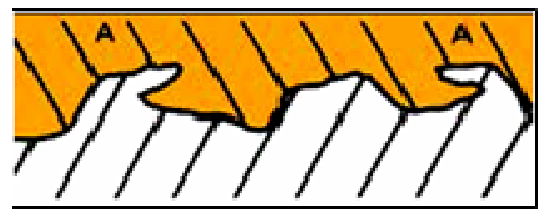

(a)

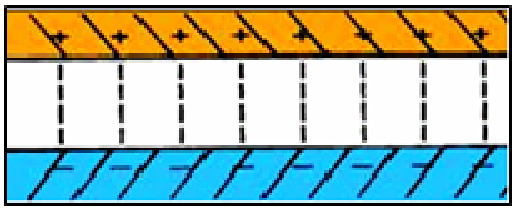

(b)

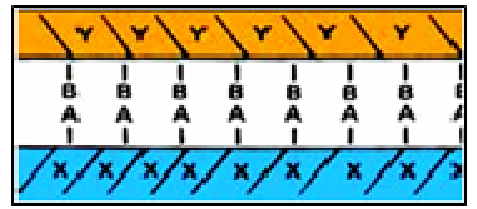

(c)

Figura 13. Mecanismos de interação interfacial; (a) adesão mecânica, (b) interação eletrostática e (c) ligação química (MATTHEWS, 1999).

A adesão mecânica (Figura 13a) ocorre quando o encaixe entre a matriz e reforço é resultante de interações de van der Waals (que corresponde a interações fracas, não 
incluindo ligações hidrogênio). Na maioria dos casos, esse mecanismo não é encontrado agindo isoladamente, geralmente ocorre em conjunto com outro tipo de mecanismo de interação (MATTHEWS, 1999). Uma superfície áspera, ou rugosa, pode contribuir para a força de interação na interface somente se a matriz líquida for capaz de molhar a superfície do reforço (CHAWLA, 1998).

A interação eletrostática ocorre entre a matriz e o reforço, quando uma superfície é carregada positivamente e a outra é carregada negativamente (Figura 13b). As interações eletrostáticas são de curto alcance e só são efetivas em distâncias da ordem da dimensão atômica. A presença de contaminantes sólidos ou gasosos pode afetar a eficiência da interação (MATTHEWS, 1999).

A ligação química é formada entre os grupos presentes na superfície do reforço e da matriz (representados por $Y$ e $X$ na Figura 13c) (MATTHEWS, 1999). Para que a interação seja mais efetiva, um agente de acoplamento ou de compatibilização pode ser usado, os quais são capazes de interagir com os dois componentes durante a preparação dos compósitos, introduzindo ligações químicas entre a fibra e matriz, ou interações intermoleculares favoráveis (MATTHEWS, 1999; FRANCO; VALADEZGONZÁLEZ, 2005; ISLAM et al., 2010). Por exemplo, o agente de acoplamento pode formar ligações hidrogênio entre a matriz $(Y)$ e o reforço $(X)$, como mostra a Figura 13c.

A ligação entre fibra e matriz, quando ocorre, é criada durante a fase de preparo do compósito. Por isso, o tipo de processamento do compósito tem influência fundamental sobre as propriedades mecânicas do material final. A estratégia mais usada para preparação de compósitos de fibras naturais consiste na mistura direta do polímero na fibra (GAY; HOA; TSAI, 2003; MU; WEl; FENG, 2009)

Matrizes poliméricas termorrígidas como os poliésteres, epóxi, e fenólicos, e termoplásticas como o polietileno, poliestireno, e polipropileno são utilizadas em compósitos. Os polímeros termoplásticos, no geral, têm pouca afinidade com as fibras lignocelulósicas devido às diferenças na estrutura química destas matrizes, quando comparadas as fibras. Estudos mostram que dentre os compósitos de poliéster, epóxi, e resina fenólica com fibras de sisal, a matriz do tipo fenólica teve melhores propriedades de tração e flexão que as resinas epóxi e poliéster, devido à intensa interação interfacial nos compósitos fenólicos, resultado de semelhança química estrutural entre a matriz e os componentes da fibra lignocelulósica (FRANCO; VALADEZ-GONZÁLEZ, 2005; PAIVA; FROLLINI, 2006; MEGIATTO, 2007a; MEGIATTO et al., 2009; RAMIRES et al., 2010). 
A transferência de carga na interface entre as duas fases diferentes é determinada pelo grau de adesão. Portanto, uma forte adesão na interface é necessária para uma transferência de carga efetiva através da interface. Esta situação leva ao desenvolvimento de estratégias de modificação da superfície da fibra, para um possível controle sobre a interface fibra-matriz (FRANCO; VALADEZ-GONZÁLEZ, 2005).

As características da interface dependem, portanto, das propriedades químicas e físicas dos constituintes, assim como da estrutura ao redor, o que faz com que a interface tenha uma forte influência na propriedade do material composto, por exemplo, na resistência ao impacto.

\subsection{Tratamentos em fibras lignocelulósicas}

A natureza polar e hidrofílica das fibras lignocelulósicas e a característica apolar e hidrofóbica de muitas matrizes poliméricas acarretam dificuldades para uma dispersão uniforme das fibras na matriz, o que prejudica as propriedades do compósito. A fim de intensificar as interações entre as duas fases, e consequentemente melhorar as propriedades mecânicas dos compósitos, podem ser aplicados tratamentos físicos ou químicos à superfície das fibras (BLEDZKI; REIHMANE; GASSAN, 1996; JOSEPH; THOMAS; PAVITHRAN, 1996; BLEDZKI; GASSAN, 1999; GHOSH; DAS, 2000; STAEL; TAVARES; D'ALMEIDA, 2000; LI; MAY; YE, 2000; MANSOUR et al., 2001; JOHN; SAIN, 2008; LI; HU; YU, 2008), e também podem ser realizadas modificações na matriz do compósito (CHAWLA, 1998).

Dependendo da aplicação final do compósito, fibras lignocelulósicas têm sido tratadas a fim de alcançar diferentes objetivos: busca de adesão entre fibra e matriz, homogeneização das propriedades das fibras, aumento de hidrofobicidade e busca de propriedades retardantes de chama (BISMARCK; MISHRA; LAMPKE, 2005). A natureza altamente polar e hidrofílica das fibras lignocelulósicas faz com que elas tenham forte afinidade para a absorção de umidade. Um tratamento adequado aumenta a resistência da fibra, reduz a tendência de absorção de umidade e facilita uma melhor interação fibra/matriz, o que consequentemente melhora as propriedades mecânicas dos compósitos (ISLAM et al., 2010).

A presença de grupos polares hidroxila na matriz fenólica (conforme destacado na Figura 14a) e nos principais componentes da fibra de sisal (celulose e lignina, Figura 14c 
e Figura 14d), favorece a adesão fibra/matriz, se comparado a compósitos de matrizes termoplásticas hidrofóbicas, como as poliolefinas.<smiles>CCc1cccc(Cc2cc(Cc3cc(Cc4ccc(COCc5cc(C)cc(C)c5O)c(O)c4C)cc(Cc4cccc(C)c4O)c3O)ccc2O)c1O</smiles>

(a)<smiles>COc1ccc(C(Oc2ccc(CC(CO)Oc3ccc(CC(CO)OC)cc3)cc2)C(CO)S(=O)(=O)[O-])cc1</smiles>

(b)

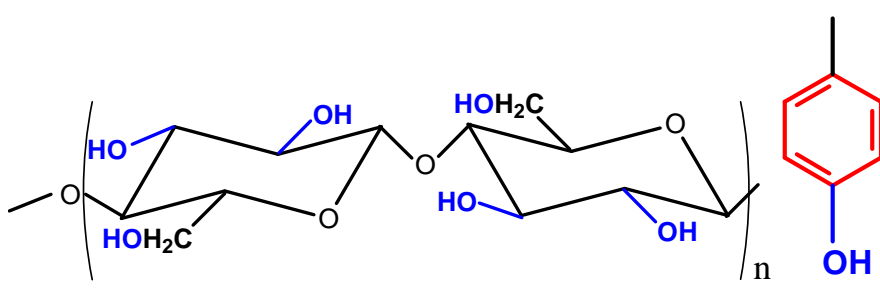

(c)<smiles>COc1cc(C)ccc1OC(C)(C)C</smiles>

(d)

Figura 14. Semelhança química-estrutural entre polímero fenólico, lignosulfonato de sódio e fibra lignocelulósica. (a) termorrígido fenólico, (b) parte da estrutura do lignosulfonato de sódio, (c) celobiose: principal unidade da celulose e (d) unidades presentes na lignina.

Visto que a lignina contém grupos polares (hidroxilas) e não-polares (hidrocarbônicos e anéis aromáticos), é esperado que ela possa melhorar a adesão entre os dois componentes do compósito, agindo como um compatibilizante entre o reforço de fibra natural e a matriz polimérica (ACHA; MARCOVICH; REBOREDO, 2009). Estas características da lignina, comum ao lignosulfonato e à matriz fenólica, usada no presente trabalho, conforme destacado na Figura 14, representam também uma possibilidade de intensificar ainda mais a interação entre a fibra e matriz polimérica fenólica, se o lignosulfonato estiver presente na superfície da fibra. 
O lignosulfonato, uma vez em contato com as fibras lignocelulósicas, pode estabelecer interações intermoleculares com componentes das fibras, como a própria lignina ou com a celulose. Se o tratamento ocorre, tem-se então uma fibra lignocelulósica com sua superfície "enriquecida" de frações típicas de lignosulfonato de sódio, o que pode inclusive facilitar a ocorrência de reações entre fibra-matriz durante a preparação do compósito, já que a resina tem estrutura química com grupos que podem reagir com o lignosulfonato (Figura 14), levando a uma maior adesão na região da interface. Além disso, é conveniente buscar tratamentos que envolvam materiais provenientes de fonte renovável, a fim de manter coerência com o objetivo de usar fibras naturais como substitutas de materiais provenientes de fontes não renováveis.

Paiva e Frollini (2006) avaliaram se modificações na superfície das fibras de sisal influíram sobre as propriedades dos compósitos, de matriz fenólica e lignofenólica, reforçados com as mesmas. Houve aumento na adesão na interface fibra/matriz quando as fibras foram submetidas a tratamentos via mercerização ( $\mathrm{NaOH} 10 \%)$ e esterificação com anidrido succínico. Quando as fibras foram tratadas com ar ionizado (1 h), não foi observado efeito pronunciado sobre a adesão. No entanto, seria interessante explorar tratamentos com ar ionizado em tempos maiores de duração, visto que este é um método aplicado por via seca, e que não envolve reagentes.

Botaro et al. (2009) aplicou tratamentos de mercerização (NaOH 2\%) e esterificação com dianidrido benzofenona-tetracarboxílico (BTDA) nas fibras de sisal, e obteve compósitos fenólicos com menor higroscopicidade se comparados aos compósitos preparados com fibras não-modificadas. Contudo, houve um decréscimo na resistência de impacto comparativamente aos de fibras não-modificadas.

Megiatto et al. (2008) modificaram as fibras de sisal via reação com ligninas hidroximetiladas. Este tratamento levou a uma intensificação na adesão interfacial, o que pôde ser observado através de melhoras nas propriedades de absorção de água do compósito preparado com esta fibra. No entanto, o tratamento químico foi agressivo para a fibra, o que diminuiu a resistência ao impacto destes materiais (MEGIATTO, 2008).

Devido aos motivos previamente mencionados, buscam-se tratamentos que não envolvam necessariamente reações químicas, como a adsorção de agentes de compatibilização, via efeito térmico ou irradiação com ultra-som. Neste trabalho, foi utilizado lignosulfonato, macromolécula oriunda de fonte renovável, como agente de modificação de superfície de fibras, via adsorção, usando tratamentos térmicos e irradiação com ultra-som. 


\subsubsection{Ultra-som}

O ultra-som é definido como ondas sonoras com frequência situada acima do limite audível para o ser humano, acima de $16 \mathrm{kHz}$. Tipicamente, o ultra-som está relacionado à faixa de frequencia que vai de 20 a 500 kHz (THOMPSOM; DORAISWAMY, 1999). 0 ultra-som se propaga, em geral, em líquidos, tecidos e sólidos. A velocidade de propagação em água é de aproximadamente 1500 m.s-1 (BISCEGLI, 2004).

Sons de alta intensidade e ultra-som são geralmente produzidos através de energia elétrica que causa movimento de expansão e compressão de uma superfície sólida, assim como acontece com bobinas de alto-falantes ou materiais piezoelétricos, por exemplo. Materiais que se expandem e contraem quando um campo elétrico é aplicado são chamados de piezoelétricos. Na produção do ultra-som, uma corrente elétrica alternada de alta freqüência é aplicada a um material piezoelétrico unido à parede de um recipiente metálico (FLANNIGAN; HOPKINS; SUSLICK, 2005).

Os efeitos químicos e mecânicos do ultra-som resultam do fenômeno chamado cavitação. A cavitação é a formação e o colapso de bolhas pela ação das ondas sonoras. O ultra-som é propagado via uma série de ondas de compressão e rarefação induzidas nas moléculas através do meio líquido. As bolhas são geradas durante o período de rarefação, ou pressão negativa, das ondas sonoras. Conforme o ultra-som se propaga os ciclos de expansão exercem pressão negativa nas moléculas do líquido, afastando-as entre si. Se o ultra-som é suficientemente intenso, os ciclos de expansão podem criar bolhas de ar (cavidades) no líquido. Isso ocorre quando a pressão negativa excede as forças intermoleculares que mantém a estrutura do líquido (FLANNIGAN; HOPKINS; SUSLICK, 2005).

Uma vez formadas, as bolhas irradiadas com ultra-som absorvem energia, as ondas de som crescem durante os ciclos de expansão, implodindo, posteriormente, durante os ciclos de compressão (Figura 15). Em determinadas condições, essas bolhas sofrem violentos colapsos, levando à geração de pontos de alta pressão e alta temperatura (FLANNIGAN; HOPKINS; SUSLICK, 2005). 


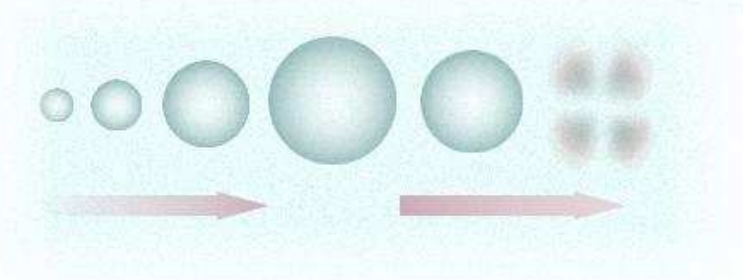

Figura 15. Demonstração da formação e colapso de bolha de cavitação.

Assim, os efeitos químicos (sono química) não se originam da interação direta de espécies moleculares, mas da cavitação acústica: formação, crescimento e colapso implosivo de bolhas no líquido. Espécies radicalares poderão ser geradas a partir do líquido (reagente ou solvente) que estavam aprisionados no interior destas bolhas que posteriormente implodem, podendo estas espécies reagir diretamente com o sólido (fibras) suspenso no meio (MASON et al., 2003).

Em líquidos puros, a bolha permanece esférica durante o colapso, pois o meio ao redor é homogêneo. Quando a cavitação ocorre perto de uma superfície sólida, o colapso é assimétrico e leva à formação de jatos líquidos com alta velocidade em direção à superfície do sólido, atingindo-a com força considerável. Esses jatos e ondas de choque associadas podem causar modificações superficiais substanciais. As colisões resultantes são capazes de provocar mudanças consideráveis na superfície, morfologia, composição, até aumentando a reatividade na superfície do sólido (HAGENSON; DORAISWAMY, 1998).

Os efeitos do ultra-som em fibras lignocelulósicas foram investigados por Gadhe, Gupta e Elder (2006). Estas fibras, após tratamento com ultra-som, foram analisadas por IGC (Cromatografia Gasosa Inversa), sendo observado um aumento da energia livre de superfície, sugerindo uma superfície mais ativa, o que levou a um aumento de molhabilidade das mesmas (GADHE; GUPTA; ELDER, 2006).

\subsection{Projetando compósitos}

Embora os compósitos poliméricos reforçados com fibras naturais despertem muito interesse, o desafio consiste em substituir plásticos convencionais reforçados com fibras como as de vidro, por biocompósitos que exibam estabilidade funcional e estrutural durante a estocagem e uso, e preferencialmente, que sejam suscetíveis à degradação ambiental quando eliminados. Uma abordagem consiste na produção de biocompósitos com propriedades superiores, através de modificações na fibra, 
modificação da matriz, e técnicas de processamento eficientes (Figura 16) (JOHN; SAIN, 2008).

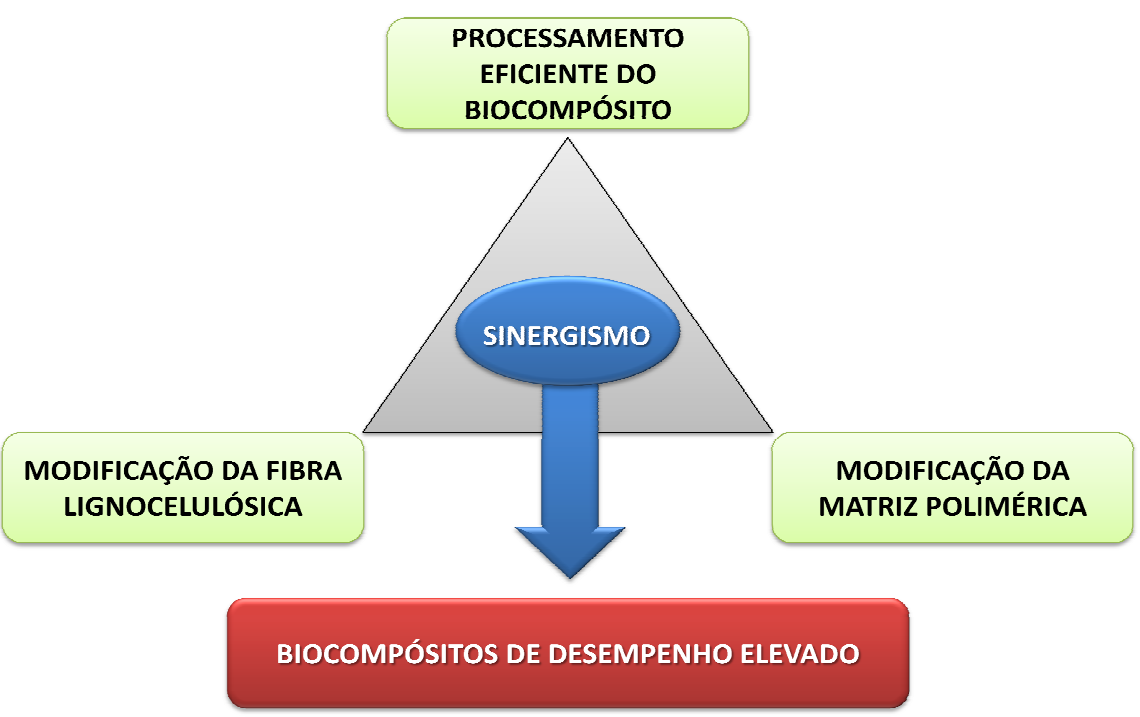

Figura 16. Combinação de elementos para concepção de biocompósitos de elevado desempenho (JOHN, 2008).

No presente trabalho, conforme mencionado, a superfície das fibras foi modificada, assim como a formulação da matriz polimérica, com lignosulfonato substituindo fenol.

\subsection{Caracterização de compósitos reforçados com fibras naturais}

\subsubsection{Propriedades mecânicas}

É através de ensaios mecânicos que se verifica se os materiais apresentam as propriedades que os tornarão adequados ao seu uso. O conhecimento das propriedades mecânicas de um compósito leva a um entendimento sobre a relação estrutura/propriedade da matriz, da fibra usada como reforço e da interface (PILATO; MICHNO, 1994).

Os ensaios mecânicos dos materiais são procedimentos padronizados que compreendem testes, cálculos, gráficos e consultas a tabelas, tudo isso em conformidade com normas técnicas. Realizar um ensaio consiste em submeter um objeto já fabricado ou um material que vai ser processado a situações que simulem os esforços que eles vão sofrer nas condições reais de uso, chegando a limites extremos de solicitação. 
Neste trabalho, os compósitos foram avaliados quanto à resistência à flexão e resistência ao impacto. A resistência ao impacto é uma das propriedades mais requisitadas para a especificação do comportamento mecânico de materiais poliméricos (HAGE JÚNIOR, 2004).

\subsubsection{Condutividade térmica e Difusividade térmica}

A utilização de compósitos reforçados com fibras lignocelulósicas na indústria automotiva, dentre outras, faz com que estudos relacionados à condutividade térmica destes materiais sejam importantes, por exemplo, no que diz respeito à influência na manutenção da climatização interna do veículo (KIM et al., 2006).

A condutividade térmica é uma propriedade do material que expressa o fluxo de calor que fluirá através do material se existir certo gradiente de temperatura ao longo do material (PAUL et al., 2008). Esta propriedade pode determinar os níveis de temperatura de trabalho de um material, sendo um importante parâmetro envolvendo problemas com transferência de calor no estado estacionário (SANTOS, 2004).

Em sólidos isolantes, a condução de calor ocorre por intermédio de acoplamentos de vibrações da rede estrutural, pois os elétrons não estão livres para se movimentar (CHOY, 1977). Os polímeros termoplásticos são tidos como isolantes térmicos pois, mesmo em estruturas cristalinas, são forças de interações físicas (forças secundárias) que atuam entre as cadeias, o que faz com que os acoplamentos sejam enfraquecidos (CARVALHO; FROLLINI, 2003).

A difusividade térmica é uma medida da rapidez com a qual o calor se propaga através de um material. Esta propriedade tem considerável interesse em aplicações onde materiais são expostos a altas temperaturas por um intervalo de tempo tão curto que o equilíbrio térmico sequer é atingido (choque térmico). A difusividade térmica é importante em problemas envolvendo estados não estacionários, o que ocorre durante o aquecimento e resfriamento de um polímero, ou ainda durante o processamento do material (SANTOS, 2004).

No presente trabalho, termorrígidos e compósitos foram caracterizados quanto à condutividade térmica, visando avaliar se a presença de fibras afeta a propriedade da matriz. 


\subsubsection{Absorção de água}

A alta capacidade das fibras naturais para absorção de água pode ter efeitos indesejáveis sobre as propriedades mecânicas e a estabilidade dimensional dos compósitos. Portanto, é importante estudar em detalhe o comportamento de absorção de água a fim de avaliar não só as conseqüências que a água absorvida pode ter, mas também de que forma pode-se minimizar essa absorção (KUSHWAHA; KUMAR, 2010).

A absorção de água em um material compósito é conduzida por três principais mecanismos, que incluem: (i) a difusão de moléculas de água para dentro dos vazios entre as cadeias de polímero, (ii) o transporte capilar de moléculas de água para as lacunas e falhas na interface entre as fibras e a matriz, devido à molhabilidade e impregnação incompleta, e (iii) o transporte de moléculas de água através de microfissuras na matriz, originadas durante o processamento. Embora todos os três mecanismos sejam ativos, o efeito global pode ser modelado considerando-se convenientemente o mecanismo de difusão (KUSHWAHA; KUMAR, 2010).

Os resultados do ensaio de absorção de água podem trazer informações sobre a interface reforço/matriz dos diversos compósitos preparados neste trabalho, principalmente sobre a intensidade de adesão que está ocorrendo na interface destes, tendo sido, principalmente por este motivo, realizada. 


\section{OBJETIVOS}

Considerando as inúmeras vantagens de aplicação de resinas fenólicas, busca-se a melhora de propriedades deste material pela introdução de reforços proveniente de fontes renováveis, originando compósitos.

Tendo como objetivo melhorar a molhabilidade das fibras de sisal, e consequentemente intensificar as interações na interface fibra/matriz, as fibras foram submetidas a tratamentos com lignosulfonato de sódio, em combinação com tratamentos térmico e de irradiação com ultra-som, visando valorizar o uso de matériasprimas renováveis como agentes de compatibilização em compósitos.

Com o intuito de aumentar ainda mais a compatibilidade fibra/matriz, o lignosulfonato também foi utilizado na formulação da matriz, em substituição ao fenol. Neste último caso, se tem também como meta aumentar a proporção de material oriundo de fonte renovável no compósito.

Desta forma, foram preparados materiais baseados principalmente em matéria prima proveniente de fontes naturais, ou seja, do tipo biocompósitos. 


\section{MATERIAIS E MÉTODOS}

\subsection{Origem dos materiais}

As fibras de sisal utilizadas neste trabalho foram adquiridas na forma de fios da empresa Sisal Sul Indústria e Comércio Ltda., São Paulo, SP. Não houve necessidade de lavar o material antes do pré-tratamento, pois o beneficiamento da fibra na indústria incluiu etapas de lavagem em água da mesma.

O lignosulfonato de sódio desaçucarado, sob o nome comercial VIXILEX SD, foi gentilmente cedido pela LignoTech Brasil (grupo Borregaard), Cambará do Sul, RS, onde o mesmo é obtido através do processo de polpação sulfito da madeira (Pinus taeda)4, como subproduto da obtenção da celulose.

\subsection{Pré-tratamento das fibras de sisal}

As fibras de sisal foram extraídas em um extrator sohxlet com capacidade de $5 \mathrm{~L}$, em uma mistura de cicloexano/etanol (1:1) por um período de $48 \mathrm{~h}$, sendo na sequência extraídas em água por um período de 24 h. Estes pré-tratamentos tiveram como objetivo eliminar extrativos orgânicos e também impurezas inorgânicas presente nas fibras. Estes extrativos correspondem a ceras, constituídas principalmente por moléculas geralmente apolares as quais prejudicariam as interações fibra-matriz no compósito. Após este período, as fibras foram lavadas com água, para a retirada do excesso de solventes orgânicos, sendo em seguida secas em estufa com circulação de ar a $105^{\circ} \mathrm{C}$, até massa constante.

\subsection{Tratamento das fibras de sisal}

As fibras de sisal, já extraídas segundo o item 3.2, foram submetidas a quatro tipos de tratamentos com o lignosulfonato de sódio. Antes dos tratamentos, as fibras de sisal foram cortadas em tamanho médio de 3,0 cm. Este comprimento de fibra foi utilizado para a preparação de compósitos durante todo trabalho.

Prepararam-se soluções aquosas de lignosulfonato de sódio em água (5\% em massa). Para cada $1000 \mathrm{~mL}$ de solução, foram imersas $12,5 \mathrm{~g}$ de fibras de sisal. $\mathrm{Na}$

\footnotetext{
${ }^{4}$ http://www.quimica.com.br/revista/qd404/empresa1.htm acessado em 11/02/2009 às 4h39min
} 
primeira modificação (M1), as fibras foram imersas na solução aquosa de lignosulfonato e submetidas à temperatura de $70{ }^{\circ} \mathrm{C}$ por $1 \mathrm{~h}$, com agitação mecânica constante. $\mathrm{Na}$ segunda modificação (M2), as fibras também foram imersas na mesma solução, mas submetidas à irradiação de ultra-som. O béquer, contendo as fibras suspensas na solução, foi colocado dentro do banho de ultra-som (modelo USC-1800, frequência de 40 kHz e potência 120 W) por $1 \mathrm{~h}$, com agitação periódica (a cada 15 min.). A terceira modificação (M3), foi similar a segunda, diferenciando no tempo de irradiação de ultrasom, que foi de 2 h. Na quarta modificação (M4), as fibras permaneceram imersas na solução de lignosulfonato durante $14 \mathrm{~h}$ e logo após este período foram submetidas à irradiação com ultra-som durante $1 \mathrm{~h}$.

Após cada tratamento, as fibras foram secas em estufa de circulação de ar (105 $\left.{ }^{\circ} \mathrm{C}\right)$ até massa constante. Através da diferença de massa entre as fibras antes do tratamento e após o tratamento, foram calculadas as porcentagens de aumento de massa nas fibras, consequência da quantidade de lignosulfonato adsorvida à superfície da fibra. A Tabela 1 resume as características dos tratamentos aplicados nas fibras de sisal.

Tabela 1. Resumo das modificações realizadas nas fibras de sisal, com solução aquosa de lignosulfonato de sódio (5\% em massa).

Tipo de tratamento

M1 - Modificação 1

M2 - Modificação 2

M3 - Modificação 3

M4 - Modificação 4
Térmico $\left(70^{\circ} \mathrm{C}\right)$

Irradiação com Ultra-som

Irradiação com Ultra-som

Imersão / Irradiação com Ultra-som
Tempo
$1 \mathrm{~h}$

$2 \mathrm{~h}$

\section{$1 \mathrm{~h}$}

\subsection{Caracterização das fibras de sisal}

Com a finalidade de avaliar a composição química das fibras de sisal, bem como a influência dos tratamentos nesta composição, as fibras tratadas e não tratadas, foram caracterizadas segundo teor de umidade, teor de cinzas e teor de componentes químicos majoritários: celulose, hemicelulose e lignina, seguindo normas padronizadas (HOAREAU et al., 2006; MEGIATTO et al., 2008). As fibras ainda foram submetidas à análise 
elementar, ensaio de tração, difração de raios $X$, espectroscopia na região do infravermelho, termogravimetria (TG), calorimetria exploratória diferencial (DSC) e microscopia eletrônica de varredura (MEV).

\subsubsection{Determinação do teor de umidade}

Esta determinação foi realizada de acordo com a Norma ABNT (NBR 9656), e foi realizada em triplicata. Em pesa-filtros previamente tarados, pesou-se $1 \mathrm{~g}$ de amostra $\left(m_{1}\right)$. As amostras foram secas em estufa com circulação de ar a $105^{\circ} \mathrm{C}$ por $4 \mathrm{~h}$. Após este período as amostras foram transferidas para um dessecador e em seguida foram pesadas até massa constante. 0 teor de umidade foi calculado pela Equação 1:

$$
\% \text { Umidade }=\frac{\mathrm{m}_{1}-\mathrm{m}_{2}}{\mathrm{~m}_{1}} \times 100
$$

Sendo:

$$
\begin{aligned}
& \mathrm{m}_{1}=\text { massa }(\mathrm{g}) \text { inicial da amostra } \\
& \mathrm{m}_{2}=\text { massa }(\mathrm{g}) \text { da amostra seca }
\end{aligned}
$$

\subsubsection{Determinação do teor de cinzas}

As cinzas foram determinadas segundo a norma TAPPI T211, em triplicata. Em cadinhos de porcelana refratária previamente tarados a $900{ }^{\circ} \mathrm{C}$, foram adicionados amostras de 1,0 g de fibra seca e moída. Os cadinhos foram então levados ao bico de Bunsen para combustão lenta da amostra até desaparecer a chama do seu interior. Em seguida, os cadinhos foram levados à mufla, a temperatura de $900^{\circ} \mathrm{C}$, por $4 \mathrm{~h}$. Após este período, as amostras calcinadas foram colocadas em dessecador para resfriamento, até massa constante. A porcentagem de cinzas foi calculada pela Equação 2.

$$
\% \text { Cinzas }=\frac{\mathrm{m}_{1}}{\mathrm{~m}_{2}} \times 100
$$

Sendo:

$$
\begin{aligned}
& \mathrm{m}_{1}=\text { massa }(\mathrm{g}) \text { de cinzas } \\
& \mathrm{m}_{2}=\text { massa }(\mathrm{g}) \text { da amostra seca }
\end{aligned}
$$




\subsubsection{Determinação do teor de holocelulose}

O teor de holocelulose, que corresponde aos teores de celulose e hemicelulose juntas, foi determinado de acordo com o método descrito na norma TAPPI T19-54, adaptada para as fibras lignocelulósicas (RAZERA, 2001), e em triplicata, conforme descrito a seguir.

Em um erlenmeyer de $1 \mathrm{~L}$ foi adicionado cerca de 3,0 g de amostra seca e moída, $250 \mathrm{~mL}$ de água destilada, 1,0 mL de ácido acético glacial e 2,5 g de clorito de sódio. Fechou-se o recipiente com outro erlenmeyer de $250 \mathrm{~mL}$ invertido sobre o primeiro, sendo o conjunto colocado em um banho termostatizado a $70 \pm 2^{\circ} \mathrm{C}$.

A mistura foi mantida sob agitação constante e, após $1 \mathrm{~h}$, foram adicionados mais 1,0 mL de ácido acético glacial e 2,5 g de clorito de sódio. Esta etapa foi repetida mais uma vez, e ao final de $3 \mathrm{~h}$, a mistura foi resfriada abaixo de $10{ }^{\circ} \mathrm{C} \mathrm{e}$, em seguida, filtrada em um funil de vidro sinterizado, previamente tarado. A holocelulose (sobrenadante) foi lavada com água destilada até pH idêntico ao da água utilizada, lavada com metanol e seca em estufa a $105^{\circ} \mathrm{C}$, até massa constante. A amostra foi resfriada em dessecador até massa constante. A porcentagem de holocelulose foi obtida pela Equação 3.

$$
\% \text { Holocelulose }=\frac{\mathrm{m}_{1}}{\mathrm{~m}_{2}} \times 100
$$

sendo:

$\%$ Holocelulose $=$ porcentagem do teor de holocelulose

$\mathrm{m}_{1}=$ massa $(\mathrm{g})$ de holocelulose seca

$\mathrm{m}_{2}=$ massa $(\mathrm{g})$ de amostra

Neste processo, a lignina é totalmente eliminada e a amostra final é composta de holocelulose, ou seja, celulose e hemicelulose (ou polioses).

\subsubsection{Determinação de $\alpha$-celulose}

A determinação do teor de celulose foi realizada com as amostras resultantes da determinação do teor de holocelulose e foi realizada em triplicata. Colocou-se 1,0 g de amostra de holocelulose em um almofariz e adicionou-se $10 \mathrm{~mL}$ de solução de $\mathrm{NaOH}$ $17,5 \%$. Deixou-se em repouso por 2 min e triturou-se por 8 min. Adicionou-se então mais $10,0 \mathrm{~mL}$ de solução de $\mathrm{NaOH}$ 17,5\% e deixou-se em repouso por mais 20 min. Adicionouse então $40 \mathrm{~mL}$ de água destilada e filtrou-se a vácuo em funil de vidro sinterizado 
(previamente tarado). Lavou-se o material retido (celulose) com água destilada até neutralizar. Lavou-se então com 200 mL de ácido acético diluído (20\%) e com mais 200 $\mathrm{mL}$ de água destilada. Secou-se em estufa de circulação de ar a $105^{\circ} \mathrm{C}$. Resfriou-se em dessecador e pesou-se. A determinação do teor de celulose presente na holocelulose foi feito de acordo com a Equação 4.

$$
\% \text { Celulose }=\frac{m_{1}}{m_{2}} \times 100
$$

Sendo:

$\%$ Celulose $=$ porcentagem do teor de celulose presente na amostra de holocelulose $\mathrm{m}_{1}=$ massa $(\mathrm{g})$ de celulose seca $\mathrm{m}_{2}=$ massa $(\mathrm{g})$ de holocelulose seca

0 percentual de hemicelulose (polioses) foi determinado pela diferença entre a porcentagem de holocelulose e $\alpha$-celulose da fibra,

\subsubsection{Determinação do teor de lignina}

Este método (FENGEL; WEGENER, 1989) fundamenta-se na hidrólise ácida dos polissacarídeos e conseqüente separação e determinação gravimétrica da lignina insolúvel em acido sulfúrico (72\%).

a) Teor de lignina Klason insolúvel

Essa análise foi realizada em triplicata. Pesou-se cerca de 1,0 g amostra, colocouse em um erlenmeyer de $250 \mathrm{~mL}$ com 15,0 ml de acido sulfúrico $72 \%$, e deixou-se em agitação mecânica constante por $2 \mathrm{~h}$ a temperatura ambiente. Em seguida, transferiu-se para um balão de 1,0 L adicionando-se $560 \mathrm{~mL}$ de água, seguindo de refluxo por $4 \mathrm{~h}$. Filtrou-se a lignina insolúvel obtida em funil de vidro sinterizado (previamente tarado) lavando-se varias vezes com água. A lignina insolúvel e então seca em estufa a $105^{\circ} \mathrm{C}$ até massa constante.

b) Teor de lignina Klason solúvel

O filtrado obtido da lignina Klason insolúvel foi analisado através de espectroscopia na região de ultravioleta (UV), sendo determinadas as absorbâncias nos comprimentos de onda de 280 e 215 nm como descritos no método TAPPI T13 m-54 (FENGEL; WEGENER, 1984). As concentrações de lignina em g.L-1 nas amostras diluídas foram calculadas pela Equação 5: 


$$
\mathrm{C}\left(\mathrm{g} . \mathrm{L}^{-1}\right)=\frac{4,53 \cdot\left(\mathrm{A}_{215}\right)-\mathrm{A}_{280}}{300}
$$

sendo:

$\mathrm{C}\left(\mathrm{g} . \mathrm{L}^{-1}\right)=$ concentração em g. $\mathrm{L}^{-1}$ de lignina Klason solúvel nas amostras diluídas $\mathrm{A}_{215}=$ valor da absorbância a $215 \mathrm{~nm}$

$\mathrm{A}_{280}=$ valor da absorbância a $280 \mathrm{~nm}$

Através da soma dos resultados obtidos em a) e b), se quantificou a concentração total de lignina das amostras.

\subsubsection{Análise elementar}

As análises elementares das fibras de sisal tratadas, não-tratada e do lignosulfonato de sódio foram realizadas no Centro de Análises Químicas do Instituto de Química de São Carlos (Universidade de São Paulo), usando um Analisador Elementar CES - Instruments EA/1110.

Esta técnica está baseada na combustão de uma amostra do material a ser analisada para determinação das quantidades de carbono, hidrogênio, nitrogênio e enxofre. 0 objetivo desta análise foi verificar a presença de enxofre (S) nas fibras de sisal modificadas com lignosulfonato de sódio, evidenciando a modificação.

\subsubsection{Microscopia Eletrônica de Varredura (MEV)}

A superfície e o interior das fibras de sisal foram analisados por Microscopia Eletrônica de Varredura (MEV), através do equipamento da marca ZEISS-LEICA modelo 440; aceleração de elétrons de 20 kV. Colocaram-se as amostras em um porta-amostra de alumínio e em seguida as amostras foram recobertas com uma fina camada de ouro.

\subsubsection{Difração de Raios X}

O Índice de Cristalinidade $\left(I_{c}\right)$ das fibras foi avaliado por Difração de Raios X. Pelo Difratograma de Raios $X$ da fibra é possível observar a presença de picos característicos da celulose, referentes aos planos cristalográficos, ângulos de Bragg (20). 0 índice de cristalinidade informa sobre a proporção de regiões cristalinas com relação às nãocristalinas presentes na amostra. 0 índice de cristalinidade é calculado utilizando-se a Equação 6, descrita por Buschlediller e Zeronian (BUSCHLEDILLER; ZERONIAN, 1992): 


$$
I_{c}=1-\frac{I_{1}}{I_{2}}
$$

$$
\begin{aligned}
\text { Sendo } I_{\mathrm{C}} & =\text { índice de cristalinidade } \\
& l_{1}=\text { intensidade do mínimo de difração }\left(2 \theta \text { em torno de } 18^{\circ}\right) \\
l_{2} & =\text { intensidade do máximo de difração }\left(2 \theta \text { em torno de } 22^{\circ}\right) .
\end{aligned}
$$

As análises de raios $X$ para as fibras de sisal tratadas e não tratadas, trituradas, foram feitas em um difratômetro RIGAKU com tubo de cobre selado, radiação $(k \alpha)$ e comprimento de onda $1542(\mathrm{k} \alpha) \AA ̊$. . As medidas foram realizadas à velocidade de $2^{\circ} \mathrm{min}^{-1}$, no intervalo angular de 5 a 50 (ângulo de Bragg 20), potência de $40 \mathrm{~mA}$ e $40 \mathrm{kV}$. As amostras foram previamente trituradas e secas em estufa de circulação de $\operatorname{ar}\left(105^{\circ} \mathrm{C}\right)$.

\subsubsection{Resistência à tração das fibras de sisal}

Os ensaios de tração das fibras de sisal foram realizados usando sistema de análise térmica dinâmico-mecânica. Um equipamento de DMA modelo 2980, da TA Instruments, foi empregado no modo tração. Dependendo do tratamento a que a fibra foi submetida, sua resistência a tração pode ser modificada, afetando as propriedades do compósito que foi reforçado por estas fibras. As fibras foram previamente secas em estufa com circulação de ar a $105^{\circ} \mathrm{C}$. As condições para análise foram:

Pré-carga: $1,2 \mathrm{~N}$

Rampa de força: $1 \mathrm{~N} \cdot \mathrm{min}^{-1}$ até $18 \mathrm{~N}$;

Módulo: Força controlada

Temperatura: $25^{\circ} \mathrm{C}$

Comprimento de análise das fibras (distância entre as garras): $15 \mathrm{~mm}$;

Tipo de garra: tensão para filme, adequada para ensaios de filmes e fibras.

\subsubsection{Espectroscopia na região do Infravermelho}

Os espectros de infravermelho para todas as amostras foram obtidos usando um espectrômetro BOMEM, modelo MB-102, na região de 400 a $4000 \mathrm{~cm}^{-1}$. As análises foram realizadas em pastilhas preparadas a partir de $1 \mathrm{mg}$ de fibra e $100 \mathrm{mg}$ de $\mathrm{KBr}$, prensados na forma de disco. As fibras foram previamente moídas e secadas à $105^{\circ} \mathrm{C}$. 


\subsubsection{Termogravimetria (TG)}

A análise termogravimétrica foi realizada com o equipamento da Shimadzu TG modelo $50 \mathrm{WSI}$. Utilizaram-se amostras com massa de aproximadamente 5,0 mg, colocadas em porta-amostra de platina. Realizaram-se corridas no intervalo $25-800{ }^{\circ} \mathrm{C}$, com razão de aquecimento de $10^{\circ} \mathrm{C} \cdot \mathrm{min}^{-1}$, em atmosfera de nitrogênio com fluxo de 20 $\mathrm{mL} \cdot \mathrm{min}^{-1}$.

\subsubsection{Calorimetria exploratório diferencial (DSC)}

A análise DSC foi realizada com o equipamento da Shimadzu DSC modelo 50. Foram utilizadas amostras com massa de aproximadamente 5,0 mg, colocadas em portas-amostra de alumínio selado, realizando-se corridas no intervalo de $25-400{ }^{\circ} \mathrm{C}$, com razão de aquecimento de $10^{\circ} \mathrm{C} / \mathrm{min}$, em atmosfera de nitrogênio, com fluxo de 20 $\mathrm{mL} / \mathrm{min}$.

\subsection{Síntese do pré-polímero fenólico}

Adicionou-se a um balão de três bocas, com agitação, o fenol, a solução de formaldeído (solução a 37\%) e o KOH, respectivamente nas proporções de 1,0:1,38:0,06 em massa. Aqueceu-se a $70{ }^{\circ} \mathrm{C}$. Após 5 min nesta temperatura, por ser a reação exotérmica, a temperatura subiu para $97^{\circ} \mathrm{C}$, retornando a $70^{\circ} \mathrm{C}$ após $40 \mathrm{~min}$. Mantevese então o sistema a $70{ }^{\circ} \mathrm{C}$ durante $1 \mathrm{~h}$. Resfriou-se até a temperatura ambiente e adicionou-se $\mathrm{HCl}$ (37\%) ao meio reacional até $\mathrm{pH}$ 7,8.

A água presente na solução de pré-polímero resol foi evaporada em um sistema sob pressão reduzida (rotaevaporador), em um intervalo de temperatura de 40 a $55^{\circ} \mathrm{C}$. Em seguida, a resina foi colocada em um recipiente vedado e armazenada a temperatura de aproximadamente $10^{\circ} \mathrm{C}$.

\subsection{Obtenção do termorrígido fenólico}

Pesou-se o pré-polímero fenólico em um béquer e montou-se um sistema com agitação mecânica e aquecimento. À temperatura de $50{ }^{\circ} \mathrm{C}$, adicionou-se gradativamente 10 \% em massa de resorcinol (Synth), como agente de aceleração de cura, e deixou-se agitar por 30 min para a dissolução do resorcinol. Na sequência, o pré-polímero foi vertido no molde metálico portátil, previamente revestido com cera de carnaúba (agente 
desmoldante), e levado à prensa onde se iniciou um ciclo de cura, estabelecido em trabalhos anteriores (RAZERA; FROLLINI, 2004). O molde metálico utilizado em todo trabalho, possui dimensões de $30 \mathrm{~cm}$ de comprimento e $14 \mathrm{~cm}$ de largura.

Ciclo de cura: Inicialmente não foi aplicada pressão no molde e manteve-se a temperatura de $65^{\circ} \mathrm{C}$ por $15 \mathrm{~min}, 75^{\circ} \mathrm{C}$ por $60 \mathrm{~min}, 85^{\circ} \mathrm{C}$ por $90 \mathrm{~min}, 95^{\circ} \mathrm{C}$ por $30 \mathrm{~min}$. Ao chegar à temperatura de $95{ }^{\circ} \mathrm{C}$ foi aplicada pressão no molde gradativamente ao longo de $15 \mathrm{~min}$, chegando à pressão final de 38,1 kgf.cm-2. Então, o ciclo seguiu com temperatura de $105^{\circ} \mathrm{C}$ por $30 \mathrm{~min}, 115^{\circ} \mathrm{C}$ por $60 \mathrm{~min}$ e finalmente $125^{\circ} \mathrm{C}$ por $90 \mathrm{~min}$. Em seguida, deixou-se resfriar até a temperatura ambiente e desmoldou-se a placa do polímero termorrígido obtido.

\subsection{Obtenção dos compósitos de matriz fenólica reforçados com fibras de sisal tratadas e não-tratada}

Para obtenção dos compósitos de matriz fenólica reforçados com fibras de sisal tratadas e não-tratadas, foi utilizado um misturador mecânico (Figura 17) (Misturador JVJ, Pardinho, SP) especialmente desenvolvido para esta linha de pesquisa, com a finalidade de facilitar a impregnação do pré-polímero na fibra.

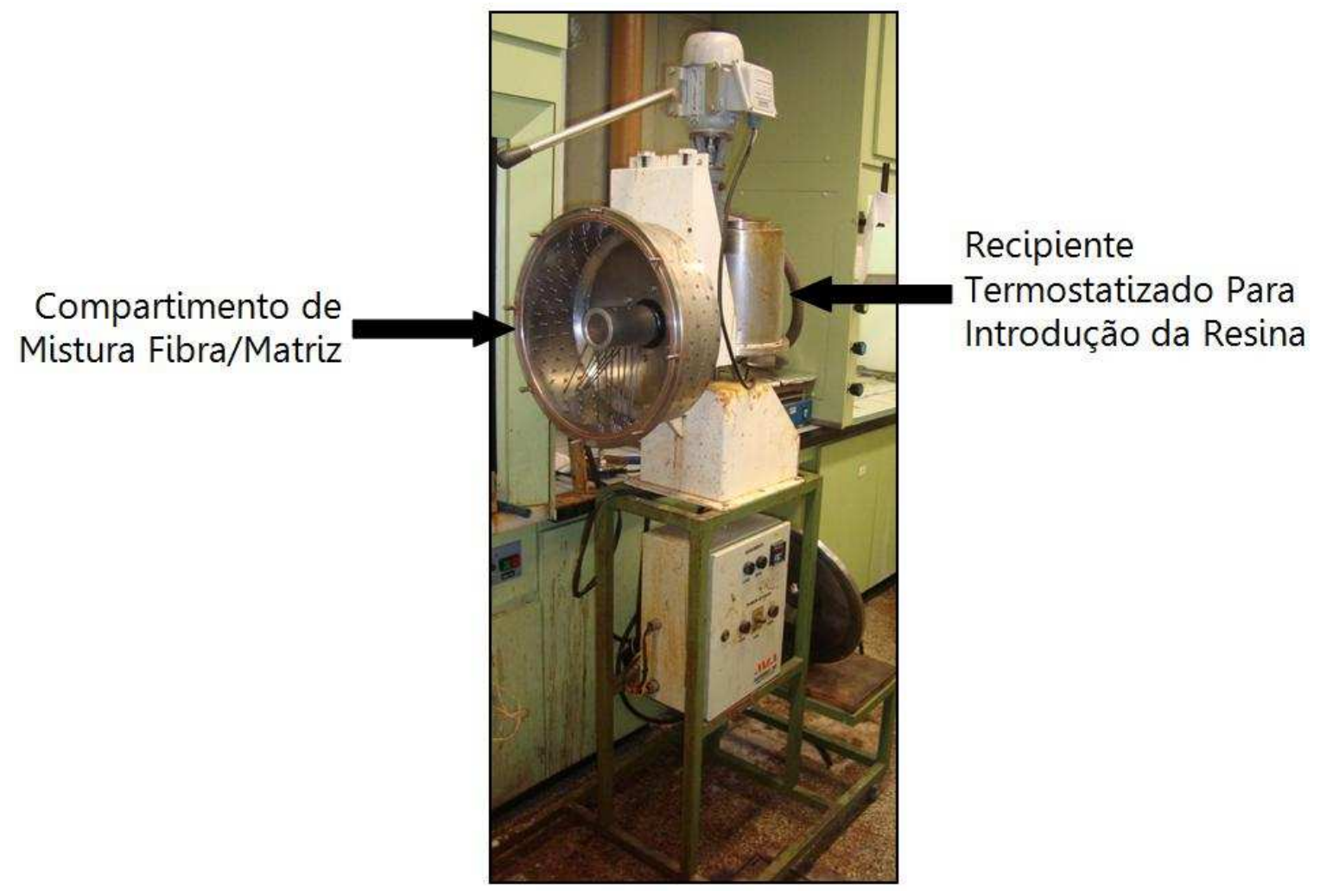

Figura 17. Sistema utilizado para misturar fibras na matriz. 
O pré-polímero fenólico foi aquecido a $50{ }^{\circ} \mathrm{C}$, e então adicionou-se o resorcinol (agente de cura). Após 30 min de solubilização sob agitação, o pré-polímero foi colocado no recipiente termostatizado do sistema mostrado na Figura 17, enquanto as fibras de sisal foram colocadas de forma dispersa no compartimento de mistura. A resina foi então ejetada por um jato de ar comprimido até o compartimento de mistura sobre as fibras. A impregnação fibra/resina foi feita durante $20 \mathrm{~min}$, com rotação de $20 \mathrm{rpm}$ do compartimento de mistura. Após este procedimento, a mistura foi vertida no molde metálico, previamente revestido com cera de carnaúba, e então submetido ao ciclo de cura estabelecido para resina fenólica, descrito no item 3.6.

A Figura 18 ilustra o processo de obtenção dos compósitos contendo matriz fenólica e fibras de sisal.

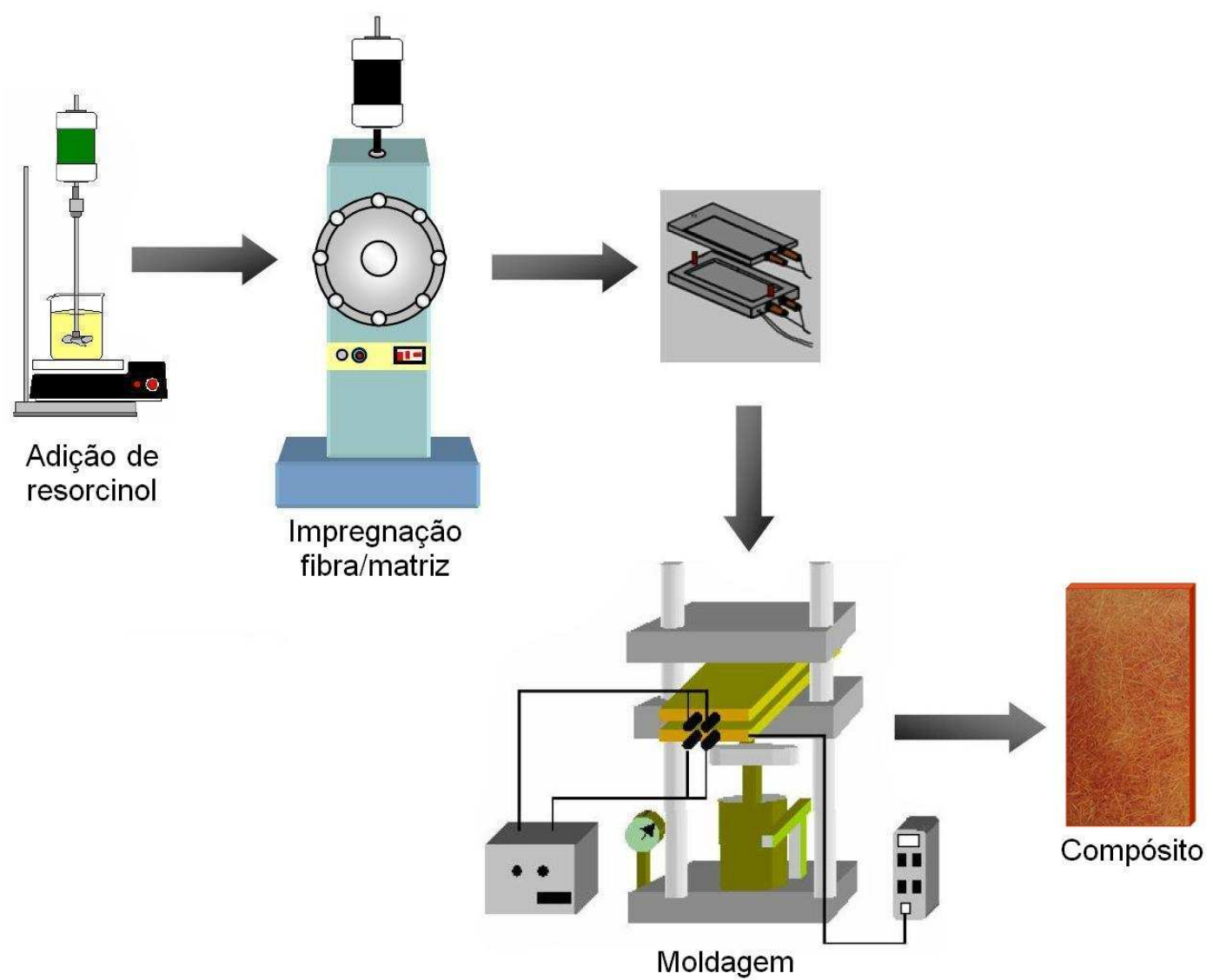

Figura 18. Representação do processo de obtenção dos compósitos de matriz fenólica e fibras de sisal (MEGIATTO JUNIOR, 2006).

Foram obtidos cinco diferentes compósitos, sendo o primeiro com fibra de sisal não modificada e outros quatro com fibras modificadas, correspondentes às quatro diferentes modificações realizadas no trabalho, descritas no item 3.3. Os compósitos 
foram obtidos em uma proporção de 30\% (em massa) de fibras (3 cm de comprimentos, distribuídas aleatoriamente) e 70\% de pré-polímero fenólico.

\subsection{Síntese do pré-polímero lignosulfonato-formaldeído}

Para a síntese do pré-polímero lignosulfonato-formaldeído, no qual o fenol foi totalmente substituído pelo lignosulfonato de sódio, utilizou-se a proporção de 1,0:1,4:0,07 para lignosulfonato, formaldeído (solução a 37\%) e KOH, respectivamente.

0 formaldeído foi colocado em um béquer ( 1 L) e adicionou-se aos poucos o lignosulfonato, com agitação constante. Manteve-se a agitação em velocidade alta por 15 min, em busca de uma solubilização completa. Transferiu-se a mistura para um balão de três bocas, em um sistema devidamente montado com agitação constante, manta de aquecimento e condensador de vapores. Adicionou-se aos poucos o $\mathrm{KOH}$ e deixou-se agitar vigorosamente por mais 40 min. Após essa etapa, o pH foi medido e encontrava-se por volta de 8 e 9. Em seguida, o sistema foi aquecido a $70{ }^{\circ} \mathrm{C}$ e mantido nesta temperatura por $1 \mathrm{~h}$. Posteriormente, aqueceu-se até $97^{\circ} \mathrm{C}$ pelo período de $2 \mathrm{~h}$. Então, desligou-se o aquecimento e verificou se o pH se encontrava em torno de 7,0.

A água presente na solução do pré-polímero foi evaporada em um sistema sob pressão reduzida (rotaevaporador), à temperatura em torno de $45{ }^{\circ} \mathrm{C}$. Em seguida, a resina foi colocada em um recipiente vedado e armazenada a temperatura de aproximadamente $10^{\circ} \mathrm{C}$.

\subsection{Obtenção do termorrígido lignosulfonato-formaldeído}

Para obtenção do termorrígido lignosulfonato-formaldeído, o pré-polímero lignosulfonato-formaldeído foi aquecido a uma temperatura máxima de $40{ }^{\circ} \mathrm{C}$, e então adicionou-se gradativamente 10 \% em massa de resorcinol (Synth), como agente de aceleração de cura, e deixou-se agitar por 20 min para a dissolução do resorcinol. $\mathrm{Na}$ sequência, o pré-polímero foi vertido ao molde, e a cura ocorreu sob um ciclo de cura previamente estabelecido, sendo o mesmo usado para obtenção de termorrígido a partir de resinas preparadas com lignina do tipo organossolve e formaldeído, descrito em trabalhos anteriores (RAZERA, 2006; RAMIRES, 2010).

Ciclo de cura para os termorrígidos lignosulfonato-formaldeído: Inicialmente não foi aplicada pressão no molde e manteve-se a temperatura de $50^{\circ} \mathrm{C}$ por $90 \mathrm{~min}$. Após 50 min na temperatura de $50{ }^{\circ} \mathrm{C}$ foi aplicada pressão no molde gradativamente ao longo de 
15 min, chegando à pressão final de 38,1 kgf.cm-2. Então, o ciclo seguiu com temperatura de $65^{\circ} \mathrm{C}$ por $60 \mathrm{~min}, 80^{\circ} \mathrm{C}$ por $60 \mathrm{~min}, 95^{\circ} \mathrm{C}$ por $30 \mathrm{~min}, 105^{\circ} \mathrm{C}$ por 30 min, $115^{\circ} \mathrm{C}$ por 60 min e finalmente $125^{\circ} \mathrm{C}$ por 120 min. Em seguida, deixou-se resfriar até a temperatura ambiente e desmoldou-se a placa do polímero termorrígido obtido.

\subsection{Obtenção dos compósitos de matriz lignosulfonato-formaldeído}

Para obtenção de compósitos de matriz lignosulfonato-formaldeído, o prépolímero lignosulfonato-formaldeído foi aquecido a uma temperatura máxima de $40{ }^{\circ} \mathrm{C}$, e então adicionou-se gradativamente $10 \%$ em massa de resorcinol (Synth), como agente de aceleração de cura, e deixou-se agitar por 20 min para a dissolução do resorcinol.

A impregnação do pré-polímero nas fibras foi realizada em duas etapas. Primeiramente, as fibras foram colocadas em frações dentro de um béquer (4 L), e o prépolímero foi vertido aos poucos sobre as fibras, e com o auxílio de pinças grandes o mesmo foi distribuído entre as fibras. No segundo momento, as fibras molhadas pelo pré-polímero foram colocadas diretamente no compartimento do misturador do sistema mostrado na Figura 17, e deu-se continuidade à impregnação, durante 20 min.

Após este procedimento, a mistura foi vertida no molde metálico, previamente revestido com cera de carnaúba, e então submetido ao ciclo de cura estabelecido para resina lignosulfonato-formaldeído, descrito no item 3.9.

Nesta etapa, foram obtidos inicialmente três diferentes compósitos. 0 primeiro foi preparado com fibra de sisal não modificada e os outros dois com fibras modificadas, correspondente às modificações M1 $\left(70^{\circ} \mathrm{C} / 1 \mathrm{~h}\right)$ e $\mathrm{M} 2$ (Ultra-som/1h), descritas detalhadamente no item 3.3. Os três compósitos foram obtidos em uma proporção de 30\% (em massa) de fibras e 70\% de pré-polímero fenólico.

A escolha de fibras modificadas pelo processo M1 e M2 para obter os compósitos nesta etapa do trabalho, foi feita de acordo com os resultados de resistência ao impacto dos compósitos fenólicos que foram preparados na etapa anterior. Os compósitos fenólicos reforçados com as fibras M1 e M2 resultaram em materiais com maiores valores de resistência ao impacto, conforme detalhado no capítulo Resultados e Discussão.

Ao retirar estes compósitos do molde, verificou-se que a quantidade de resina não foi suficiente. Visto que a falta de resina prejudicaria as propriedades mecânicas dos compósitos, decidiu-se então prepará-los novamente, agora com um excesso adicional 
de resina de aproximadamente $40 \%$ em relação à quantidade inicial de resina utilizada. Mesmo com excesso de resina, o terceiro compósito, preparado com a fibra de sisal M2, ao ser retirado do molde, foi observado insuficiência de resina. Devido este fato, este compósito foi preparado mais uma vez, com 63\% de excesso em relação à primeira vez. Esta necessidade de excesso de resina, comparativamente à fibra não tratada, foi um indicativo que a molhabilidade da resina aumentou, em decorrência do tratamento.

\subsection{Caracterização do lignosulfonato e dos pré-polímeros}

O lignosulfonato de sódio e os pré-polímeros foram caracterizados quanto à massa molar média e distribuição de massa molar utilizando cromatografia de exclusão por tamanho (SEC). A cromatografia de exclusão por tamanho (SEC) é uma técnica de fracionamento das cadeias poliméricas de um polímero, com relação ao volume hidrodinâmico que cada uma delas ocupa em solução (CANEVAROLO, 2004a). Durante a síntese dos pré-polímeros resóis, ocorrem várias reações competitivas, resultando num produto com dispersividade de massa molar. É necessário ainda considerar que através do estabelecimento de ligações hidrogênio entre grupos hidroxila do pré-polímero, pode ocorrer agregação, o que exerce grande influência na separação dos componentes da resina na análise cromatográfica (KNOP; 1985, TANAKA, 2001).

Foi utilizada também a técnica de espectroscopia na região de Infravermelho-IV, que fornece informações a respeito dos grupos funcionais introduzidos, assim como permite avaliar as reações ocorridas no processo de cura, quando estes espectros dos pré-polímeros são comparados com aqueles do polímero entrecruzado (PICCOLO; SANTOS; FROLLINI, 1997).

\subsubsection{Cromatografia de exclusão por tamanho (SEC)}

Utilizou-se um sistema cromatográfico líquido HP-SEC da marca Shimadzu equipado com: Bomba (modelo LC-10AD); Controlador de Sistema (modelo SCL-10 A);

Detector de Índice de Refração Diferencial (modelo RID 6 A); Detector Espectrofotométrico UV-Visível (modelo SPD-10AV); Forno para coluna (modelo CTO-10A); Processador de dados - Cromatopac (modelo C-R7AE) e Injetor de amostras / $20 \mu \mathrm{L}$ Rheodyne (modelo 7125), dados tratados com GPC Software para CLASS-LC10.

As condições de análise para o pré-polímero fenólico foram as seguintes: 
Colunas: pré-coluna PLgel +3 colunas em série Plgel $500 \mathrm{~A}+10^{3} \mathrm{~A}+10^{4} \mathrm{~A}$ (Polymer Laboratories) (7,5 mm DI x $300 \mathrm{~mm})$

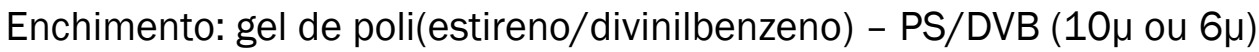

Limite de exclusão da coluna: 100 - 700.000 (PS)

Eluente: THF (Tedia / grau HPLC)

Fluxo: $1,0 \mathrm{~mL} \mathrm{~min}^{-1}$

Pressão: 7,06 MPa

Detector: UV/ $254 \mathrm{~nm}$

Temperatura: $35^{\circ} \mathrm{C}$

Loop: $20 \mu \mathrm{m}$

Curva de calibração: padrões de poliestireno com $M_{w} 770.000,330.000,195.000$, 66.000, 30.300, 22.000, 11.600, 7.000, 5.050, 2.950, 1.700, 1.060, 580, 106 g.mol-1. As condições de análise para o lignosulfonato de sódio e o pré-polímero lignosulfonato-formaldeído foram as seguintes:

Colunas em série: Pré-coluna Shodex OHpak KB-G + 2 colunas Shodex OHpak KB-806M (Waters)

Eluente: solução 0,1 N Nitrato de Sódio / Metanol (80:20 v/v)

Fluxo: 1,0 mL. $\mathrm{min}^{-1}$

Pressão: 4,02 MPa

Detector: IR Slope (IR): $60 \mu \mathrm{V}$

Temperatura: $35^{\circ} \mathrm{C}$

Bomba: A

Loop: $20 \mu \mathrm{L}$

Analise File: IRSHOD e UVSHOD

\subsubsection{Espectroscopia na região do infravermelho}

Os espectros de infravermelho com transformada de Fourier (modo transmitância) para os pré-polímeros foram obtidos usando um espectrômetro BOMEM, modelo MB102, na região de 400 a $4000 \mathrm{~cm}^{-1}$. Para os pré-polímeros as análises foram realizadas utilizando um suporte adequado para material viscoso, no qual foi depositada uma fina camada dos pré-polímeros. Para o lignosulfonato de sódio, as análises foram realizadas em pastilhas preparadas a partir de $1 \mathrm{mg}$ de lignosulfonato (previamente seco a $105{ }^{\circ} \mathrm{C}$ ) e $100 \mathrm{mg}$ de $\mathrm{KBr}$. 


\subsubsection{Análise termogravimétrica (TG)}

A análise de TG dos pré-polímeros foi realizada com o equipamento da Shimadzu TG modelo $50 \mathrm{WSI}$. Utilizaram-se amostras com massa de aproximadamente 5,0 mg, colocadas em panela de platina. Realizaram-se corridas no intervalo $25-800{ }^{\circ} \mathrm{C}$, com razão de aquecimento de $10{ }^{\circ} \mathrm{C} \cdot \mathrm{min}^{-1}$, em atmosfera de nitrogênio com fluxo de 20 $\mathrm{mL} \cdot \mathrm{min}^{-1}$.

\subsubsection{Calorimetria Exploratória Diferencial (DSC)}

A análise de DSC dos pré-polímeros foi realizada com o equipamento da Shimadzu DSC modelo 50. Foram utilizadas amostras com massa de aproximadamente $5,0 \mathrm{mg}$, colocadas em portas-amostra de alumínio selado, realizando-se corridas no intervalo de $25-240{ }^{\circ} \mathrm{C}$, com razão de aquecimento de $10{ }^{\circ} \mathrm{C} \cdot \mathrm{min}^{-1}$, em atmosfera de nitrogênio com fluxo de $20 \mathrm{~mL} \cdot \mathrm{min}^{-1}$.

\subsection{Caracterização dos termorrígidos e compósitos}

\subsubsection{Espectroscopia na região do infravermelho}

Os espectros de infravermelho com transformada de Fourier (modo transmitância), para os termorrígidos, foram obtidos usando um espectrômetro BOMEM, modelo MB-102, na região de 400 a $4000 \mathrm{~cm}^{-1}$. As análises foram realizadas em pastilhas preparadas a partir de $1 \mathrm{mg}$ de termorrígido e $100 \mathrm{mg}$ de $\mathrm{KBr}$, prensados na forma de disco. Os termorrígidos foram previamente moídos e secados à $105^{\circ} \mathrm{C}$.

\subsubsection{Resistência ao Impacto Izod}

O ensaio de impacto Izod foi realizado com corpos de prova não entalhados, conforme a norma ASTM D256, utilizando o equipamento CEAST Resil 25 (DEMa, Universidade Federal de São Carlos, São Carlos, SP). Os testes foram realizados à temperatura ambiente com velocidade de impacto de $4 \mathrm{~m} \cdot \mathrm{s}^{-1}$ e energia incidente de $5,5 \mathrm{~J}$.

O processo de usinagem dos compósitos, visando a obtenção de corpos de provas para os diferentes ensaios realizado neste trabalho, foi realizada na Oficina Mecânica do Instituto de Química de São Carlos (IQSC/USP). As placas de compósitos foram cortadas 
utilizando uma serra vertical, e as dimensões finais dos corpos de prova foram ajustadas com o uso de uma fresadora. Para o ensaio de impacto, foram obtidos os corpos de prova de impacto nas dimensões: $63,5 \mathrm{~mm}$ de comprimento, $12,7 \mathrm{~mm}$ de largura e 4,5 $\mathrm{mm}$ de espessura.

O termorrígido fenólico, e todos os compósitos de matriz fenólica e lignosulfonatoformaldeído foram submetidos ao ensaio de resistência ao impacto. O ensaio não foi realizado para o termorrígido lignosulfonato-formaldeído, pois não foi possível obter corpos de prova para este termorrígido, devido à fragilidade do mesmo.

\subsubsection{Resistência à flexão}

Os ensaios de resistência à flexão foram realizados segundo a norma $D$ 790, que descreve o método de carregamento em um sistema de três pontos (Figura 19). Utilizouse uma máquina universal de ensaios INSTRON, modelo 5569 (DEMa, Universidade Federal de São Carlos, São Carlos, SP).

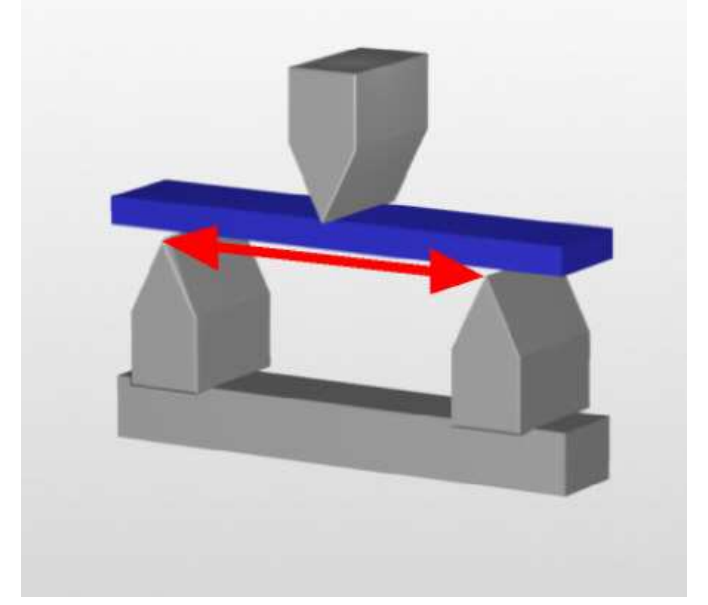

Figura 19. Esquema representativo do ensaio de flexão em três pontos.

Foram obtidos corpos de prova de dimensões $127 \mathrm{~mm}$ (comprimento), 12,7 mm (largura) e 3,2 mm (espessura). Conforme determinado pela norma, utilizou-se razão L/d = 16 (distância do vão de ensaios). Para um ensaio de flexão em três pontos, a deflexão na qual a máxima deformação permitida $(5,0 \%)$ irá ocorrer pode ser calculada através da Equação 7. A velocidade do ensaio foi calculada de acordo a Equação 8. Foi utilizado uma célula de carga com capacidade de 0,5 kN. Para cada amostra, foram realizados ensaios de flexão em seis corpos-de-prova, em média. 


$$
\begin{aligned}
& D=r L^{2} / 6 d \\
& R=Z L^{2} / 6 d
\end{aligned}
$$

sendo:

$\mathrm{D}=$ deflexão no ponto médio entre os apoios

$r=$ deformação

$L=$ distância entre os apoios

$\mathrm{d}=$ profundidade do corpo de provas

$\mathrm{R}=$ velocidade da travessa fixa

$Z$ = taxa de deformação na superfície oposta ao carregamento

A resistência à flexão ( $\left.\sigma_{\text {máx }}\right)$ é a máxima tensão sob flexão sustentada pelo corpo de prova durante o ensaio de flexão. Para um ensaio em três pontos, a resistência a flexão é dada pela Equação 9.

$$
\rho_{\text {máx }}=\frac{3 P_{\operatorname{máx}} L}{2 b d^{2}}
$$

sendo:

$\sigma_{\text {máx }}=$ resistência à flexão

$\mathrm{P}_{\text {máx }}=$ carga máxima de ruptura $(\mathrm{em} \mathrm{N})$

$L=$ distância entre os apoios

$\mathrm{b}=$ largura do corpo de prova

$\mathrm{d}=$ profundidade do corpo de prova

O módulo de flexão $\left(E_{f}\right)$, também chamado de módulo de elasticidade, é a razão dentro do limite de elasticidade entre a tensão de flexão e a deformação correspondente. É calculado traçando-se uma tangente na porção linear inicial da curva carga versus deflexão, utilizando a Equação 10.

$$
E_{f}=\frac{L^{3} m}{4 b d^{3}}
$$

O termorrígido fenólico, e todos os compósitos de matriz fenólica e matriz lignosulfonato-formaldeído foram submetidos ao ensaio de resistência a flexão. 0 ensaio 
não foi realizado para o termorrígido lignosulfonato-formaldeído, pois não foi possível obter corpos de prova para este termorrígido.

\subsubsection{Microscopia eletrônica de varredura (MEV)}

Após o ensaio de impacto Izod, as superfícies de fratura do termorrígido fenólico e de todos os compósitos foram analisadas utilizando-se um Microscópio Eletrônico de Varredura da marca Zeiss Leica, modelo 440, aceleração de elétrons de 20 kV. Colocaram-se as amostras em um porta-amostra de alumínio e em seguida a amostra foi recoberta com uma fina camada de ouro.

\subsubsection{Termogravimetria (TG)}

A análise de TG dos compósitos foi realizada conforme mencionado no item 3.11.3.

\subsubsection{Calorimetria Exploratória Diferencial (DSC)}

A análise de DSC dos compósitos foi realizada conforme mencionada no item 3.11.4.

\subsubsection{Análise térmica dinâmico-mecânica (DMTA)}

A análise térmica dinâmico-mecânica (DMTA, Dynamic Mechanical Thermal Analysis) tem sido amplamente usada para caracterização de polímeros através de detecção dos processos de relaxação, tanto macroscópicos quanto moleculares, por apresentar sensibilidade muito superior quando comparada a outras técnicas convencionais de análise térmica, como calorimetria exploratória diferencial (DSC). Essa técnica (DMTA) fornece informações a respeito da estabilidade mecânica em função da temperatura, do módulo de elasticidade e de perda, e ainda é um método direto para determinação da temperatura de transição vítrea (Tg) (CANEVAROLO, 2004b).

A resposta de um material viscoelástico quando uma tensão senoidal é aplicada pode ser separada em uma componente completamente em fase, E' (módulo de armazenamento), e outra componente fora de fase, E"' (módulo de perda). 0 módulo de armazenamento é a resposta elástica e corresponde à energia completamente recuperável e o módulo de perda é a resposta viscosa correspondendo à energia perdida 
através de movimentos internos. O ângulo de fase é calculado de acordo com a Equação 11:

$$
\tan \delta=\frac{E^{\prime \prime}}{E^{\prime}}
$$

A tangente do ângulo de perda, tan $\delta$, é adimensional e igual à razão entre a energia perdida (dissipada como calor) e a energia armazenada por ciclo.

Através desta técnica, será avaliado como o módulo de elasticidade muda em função da temperatura para os diversos materiais preparados e também a temperatura de transição vítrea será avaliada para os mesmos, pois o máximo de dissipação de calor por deformação unitária ocorre a uma temperatura em que o módulo de perda (E') é máximo e, a $1 \mathrm{~Hz}$ de freqüência essa temperatura é próxima da temperatura de transição vítrea determinada por outros métodos.

Esta técnica é também adequada para se avaliar a intensidade de interação na interface reforço/matriz, pois o módulo de armazenamento é diretamente proporcional a esta intensidade (POTHAN; THOMAS, 2003; WIELAGE et al.,2003; TRINDADE et al., 2005). Assim, comparando-se as curvas dos compósitos de matriz fenólica, lignosulfonato-formaldeído, reforçados com fibras de sisal tratadas em modos diferentes, como mencionados anteriormente, pode-se ter informações sobre as respectivas intensidades de interação na interface.

As análises de DMTA dos termorrígidos e compósitos, foi realizada utilizando um equipamento da DMA da marca TA Instruments, modelo 2980. Para estes ensaios, foram cortados corpos de prova com dimensões de $63,5 \mathrm{~mm}$ de comprimento, $12,7 \mathrm{~mm}$ de largura e 3,2 mm de espessura. 0 equipamento foi calibrado com um padrão metálico. 0 módulo de solicitação mecânica foi de flexão e a garra do tipo 3-point bending. As condições experimentais utilizadas foram: amplitude de oscilação de $20 \mathrm{~mm}, 1 \mathrm{~Hz}$ de frequencia, taxa de aquecimento de $2^{\circ} \mathrm{C} \cdot \mathrm{min}^{-1}$ e faixa de temperatura de 30 a $230{ }^{\circ} \mathrm{C}$.

\subsubsection{Absorção de água}

Os ensaios de absorção de água foram realizados de acordo com a norma ASTM D570, utilizando-se 3 corpos de prova $(72,6 \mathrm{~mm} ; 25,6 \mathrm{~mm}$ e 3,2 mm) para cada amostra. As amostras foram submetidas à imersão em água até saturação. Este ensaio, apesar da simplicidade experimental envolvida, pode trazer informações importantes, 
não só no que se refere ao que é obtido diretamente, ou seja, capacidade de absorção de água, mas também sobre homogeneidade do material, presença de vazios, interface fibra/matriz e, no caso de matriz termorrígida, grau de entrecruzamento.

A matriz polimérica e a fibra vegetal normalmente diferem no comportamento referente à absorção de água, quando analisados individualmente. Estudos realizados com compósitos reforçados com fibras vegetais mostraram que o modelo de difusão Fickiano é válido para o estudo de difusão de água nestes materiais (POTHAN; THOMAS, 2004).

A forma da curva de sorção definida pela Equação 12 pode ser usada para avaliar o comportamento do material segundo o modelo Fickiano:

$$
\frac{M_{t}}{M_{\infty}}=k t^{n}
$$

$M_{t}$ é conteúdo de umidade a um tempo $t ; M_{\infty}$ corresponde ao conteúdo de umidade no equilíbrio; $\mathrm{k}$ e $\mathrm{n}$ correspondem a constantes. A Equação 12 em escala logarítmica se torna:

$$
\log \left[\frac{M_{t}}{M_{\infty}}\right]=\log k+n \log t
$$

Substituindo-se os dados experimentais na Equação 13 pode-se fazer o estudo cinético do mecanismo de difusão, determinando-se $k$ e $n$ a partir do intercepto e da inclinação da parte linear da curva obtida. 0 valor de $k$ informa sobre a afinidade do material por água. Ainda, o coeficiente de difusão $(D)$ da água em compósitos pode ser calculado pela Equação 14, sendo $L$ a espessura do compósito.

$$
\frac{M_{t}}{M_{\infty}}=\frac{4}{L}\left(\frac{D}{\Pi}\right)^{0,5} t^{0,5}
$$

Essas informações são obtidas através de regressões lineares aplicadas nas curvas de absorção de água dos materiais. 0 coeficiente $D$ demonstra a habilidade das moléculas de água em penetrar dentro do compósito. 


\subsubsection{Condutividade térmica e difusividade térmica}

Inicialmente, foram obtidos valores de difusividade térmica de termorrígidos e compósitos, e posteriormente foram calculados os valores de condutividade térmica para cada material. A medida foi realizada pelo Laboratório de Propriedades Termofísicas e Prototipação (PROTOLAB, Araçoiaba da Serra, SP). A análise foi realizada segundo o método flash ou método de pulso de energia (norma ASTM E 1461), em um equipamento difusímetro Quadruflesh 1200 . Foram preparados corpos de prova de tamanho $40 \times 40$ $\mathrm{mm}$, e espessura variável entre 2 e $4 \mathrm{~mm}$. As medidas foram realizadas em três temperaturas: 10,25 e $50^{\circ} \mathrm{C}$. Foram realizadas entre quatro e cinco medidas para cada amostra, utilizando como resultado o valor médio. Para a temperatura de $10{ }^{\circ} \mathrm{C}$ foi utilizado atmosfera de argônio a baixa temperatura para evitar condensação de umidade no interior do equipamento. Para as demais temperaturas não há condensação. A impulsão de luz para todos os casos foi de $5000 \mathrm{~J}$.

Os valores de difusividade térmica $(\alpha)$ foram convertidos para condutividade térmica, através da Equação 15.

$$
\alpha=\frac{\lambda}{\rho c}
$$

Sendo

$\alpha=$ difusividade térmica $\left(m^{2} \cdot s^{-1}\right)$

$\lambda=$ condutividade térmica $\left(\mathrm{W} \cdot \mathrm{m}^{-1} \mathrm{~K}^{-1}\right)$

$\rho=$ densidade $\left(\mathrm{Kg}_{\mathrm{g}} \mathrm{m}^{-3}\right)$

$c=$ calor específico $\left(\mathrm{J} \cdot \mathrm{Kg}^{-1} \cdot \mathrm{K}^{-1}\right)$

Foram realizadas as medidas apenas nas seguintes amostras: termorrígido fenólico (TF), compósito de matriz fenólica reforçada com fibras de sisal não-modificadas (CF-FSNM), compósito de matriz fenólica reforçada com fibras de sisal modificadas em lignosulfonato/ultra-som/1 h (CF-FSM2), termorrígido lignosulfonato-formaldeído (TL) e compósitos de matriz lignosulfonato-formaldeído reforçada com fibras de sisal nãomodificadas (CL-FSNM). Estas amostras foram escolhidas a partir da avaliação das propriedades mecânicas para todos os compósitos preparados. 


\section{RESULTADOS E DISCUSSÃO}

\subsection{Caracterização das fibras}

\subsubsection{Composição}

A Tabela 2 exibe os valores médios dos teores de componentes encontrados para as fibras de sisal utilizadas no presente trabalho. Para cada tratamento aplicado às fibras de sisal, determinou-se a porcentagem de todos componentes, a fim de avaliar as possíveis variações que estes tratamentos pudessem causar na composição das fibras e, posteriormente, nas propriedades dos compósitos reforçados por estas fibras.

Tabela 2. Análise química das fibras de sisal não-modificadas e modificadas com lignosulfonato de sódio.

Fibras de sisal não-modificadas (FSNM), fibras de sisal submetidas à modificação 1: $70^{\circ} \mathrm{C} / 1 \mathrm{~h}$ (FSM1), fibras de sisal submetidas à modificação 2: ultra-som/1h (FSM2), fibras de sisal submetidas à modificação

3: ultra-som/2h (FSM3) e fibras de sisal submetidas à modificação 4: 14h imersão/1h de ultra-som (FSM4).

\begin{tabular}{|c|c|c|c|c|c|}
\hline Componente & FSNM & FSM1 & FSM2 & FSM3 & FSM4 \\
\hline Umidade (\%) & $6,8 \pm 0,1$ & $6,6 \pm 0,1$ & $6,8 \pm 0,8$ & $8,4 \pm 0,6$ & $9,7 \pm 0,2$ \\
\hline Cinzas (\%) & $0,6 \pm 0,1$ & $1,6 \pm 0,2$ & $1,3 \pm 0,6$ & $1,98 \pm 0,03$ & $1,4 \pm 0,1$ \\
\hline $\begin{array}{l}\text { Hemicelulose } \\
\text { (\%) }\end{array}$ & $35,2 \pm 2,4$ & $29,8 \pm 3,4$ & $29,7 \pm 0,9$ & $31,9 \pm 2,5$ & $29,3 \pm 1,3$ \\
\hline$\alpha$-Celulose (\%) & $51,8 \pm 2,3$ & $53,4 \pm 1,7$ & $52,8 \pm 2,6$ & $47,8 \pm 3,7$ & $54,5 \pm 0,8$ \\
\hline $\begin{array}{l}\text { Lignina Klason } \\
\text { insolúvel (\%) }\end{array}$ & $11,5 \pm 0,9$ & $13,7 \pm 0,7$ & $13,8 \pm 0,7$ & $12,4 \pm 1,4$ & $14,8 \pm 0,4$ \\
\hline $\begin{array}{l}\text { Lignina Klason } \\
\text { solúvel (\%) }\end{array}$ & $0,5 \pm 0,01$ & $1,2 \pm 0,5$ & $0,6 \pm 0,03$ & $0,7 \pm 0,1$ & $0,7 \pm 0,05$ \\
\hline $\begin{array}{l}\text { Lignina Klason } \\
\text { total (\%) }\end{array}$ & $12,0 \pm 0,9$ & $14,8 \pm 0,4$ & $14,4 \pm 0,6$ & $13,1 \pm 1,4$ & $15,5 \pm 0,5$ \\
\hline $\begin{array}{l}\text { Variação de } \\
\text { massa (\%) }\end{array}$ & -- & 4,3 & 4,8 & 7,1 & 7,5 \\
\hline
\end{tabular}

Os resultados obtidos para as fibras de sisal não-modificadas (FSNM) são comparáveis com resultados obtidos por Paiva e Frollini (2006), que obtiveram 1,4 \% de cinzas, $10,9 \%$ de umidade, $64,3 \%$ de $\alpha$-celulose, $27,4 \%$ de hemicelulose e $13,2 \%$ de lignina. Martin, Mattoso e Silva (2009) ao caracterizar as fibras de sisal obtidas de 
diferentes posições ao longo do comprimento da fibra, obteve valores de 0,8-1,5\% de cinzas, $77,4-88,4 \%$ de $\alpha$-celulose, $6,9-10,3 \%$ de hemicelulose, $7,4-11,4 \%$ de lignina. Percebe-se que os teores de celulose e hemicelulose diferem da fibra de sisal caracterizada no presente trabalho (FSNM, Tabela 2). As discrepâncias entre os valores relatados e o presente estudo são entendidas como devido ao fato da composição química das fibras lignocelulósicas dependerem de vários fatores, como a espécie, variedade, tipo de solo onde foram cultivadas, condições climáticas, parte da planta de onde são extraídas as fibras, idade da planta, entre outros (GUIMARÃES et al., 2009).

Após tratamentos das fibras de sisal, com solução saturada de lignosulfonato e secagem até massa constante, foi observado um aumento de massa das fibras modificadas. Os acréscimos de massa foram de 4,3\%, para a fibra FSM1 $\left(70{ }^{\circ} \mathrm{C}, 1 \mathrm{~h}\right)$, 4,8\% para a fibra FSM2 (ultra-som, 1h), 7,1\% para a fibra FSM3 (ultra-som, 2 h) e 7,5\% para a fibra FSM4 (14 h imersão/ 1h de ultra-som). Este aumento de massa é um fator indicativo de que houve deposição de lignosulfonato sobre a superfície da fibra. No entanto, observa-se que deixar a fibra imersa na solução de lignosulfonato durante $14 \mathrm{~h}$, para depois aplicar ultra-som, não aumenta a adsorção do lignosulfonato de forma significativa.

As fibras modificadas apresentaram um aumento do teor de lignina Klason total. A fibra de sisal não-modificada (FSNM) apresenta um teor de 12\%, enquanto as demais fibras modificadas apresentam teores maiores que este, chegando a um máximo de 15,5\% na fibra FSM4 (Tabela 2). Esta maior quantidade lignina Klason nas fibras modificadas também está relacionada à deposição de lignosulfonato à superfície da fibra. A fibra submetida a $14 \mathrm{~h}$ de imersão em solução de lignosulfonato seguido de $1 \mathrm{~h}$ de ultra-som (FSM4) foi a fibra que apresentou maior aumento de massa $(7,5 \%)$ e também o maior aumento no teor de lignina Klason. Desse modo, esta modificação (M4) foi a mais eficiente em termos de deposição de lignosulfonato à superfície da fibra, com as ressalvas feitas previamente.

O teor de hemicelulose nas fibras modificadas é menor em relação à fibra não modificada, como mostra a Tabela 2. 0 aquecimento a $70^{\circ} \mathrm{C}$ e os efeitos causados pela irradiação com ultra-som, através dos tratamento aplicados, podem ter eliminado frações de hemicelulose da fibra lignocelulósica. Ainda, o pH da solução de lignosulfonato antes do contato com as fibras é próximo de 8 , sendo que a extração de hemicelulose em fibras lignocelulósicas é favorecida em meio alcalino (OLIVEIRA, 2008). 
Observou-se um aumento no teor de cinzas, das fibras modificadas em relação à fibra não modificada (Tabela 2). Acredita-se que a presença do contra-íon sódio, presente no lignosulfonato, tenha causado o aumento no teor de cinzas, uma vez que houve deposição de lignosulfonato de sódio sobre a superfície das fibras.

Alguns teores de umidade são aproximados pelos erros, observando-se um acréscimo para as fibras FSM3 e FSM4, refletindo a higroscopicidade dos grupos sulfonatos presentes na superfície das fibras.

\subsubsection{Análise Elementar}

Os resultados de análise elementar de enxofre (S) para as fibras de sisal e para o lignosulfonato de sódio são apresentados na Tabela 3. A presença de S no lignosulfonato de sódio corresponde ao enxofre que foi inserido no mesmo, durante o processo de polpação sulfito. Shul'ga, Gomolko e Krut'ko (2007), através de análise elementar, determinaram cerca de $8 \%$ de enxofre em lignosulfonato purificado, enquanto que no presente trabalho determinou-se aproximadamente 6,5\%.

$\mathrm{Na}$ fibra de sisal não-modificada, não é observada a presença de enxofre, mas sim nas fibras modificadas, evidenciando a presença de lignosulfonato nas mesmas, confirmando a eficiência do tratamento.

Tabela 3. Análise elementar de S das fibras não-modificada e modificadas e do lignosulfonato de sódio.

\begin{tabular}{lc}
\multicolumn{1}{c}{ Amostra } & Teor de enxofre, S (\%) \\
\hline Fibra de sisal não-modificada & 0,00 \\
Fibra de sisal M1 $\left(1 \mathrm{~h} / 70^{\circ} \mathrm{C}\right)$ & 1,86 \\
Fibra de sisal M2 (1h/Ultra-som) & 1,83 \\
Fibra de sisal M3 (2h/Ultra-som) & 1,91 \\
Fibra de sisal M4 (14h imersão/1h Ultra-som) & 1,99 \\
Lignosulfonato de sódio & 6,47 \\
\hline
\end{tabular}

A fibra que passou pelo processo de modificação 4 (FSM4) apresenta o maior teor de enxofre, sendo coerente com o maior aumento de massa para esta fibra após a modificação. 


\subsubsection{Espectroscopia na região do Infravermelho}

A Figura 20 mostra os espectros na região de infravermelho da fibra de sisal nãomodificada e das fibras modificadas, e também do lignosulfonato de sódio. 0 espectro para a fibra de sisal não modificada (FSNM, Figura 20a) é característico de material lignocelulósico, conforme pode-se confirmar na Tabela 4.

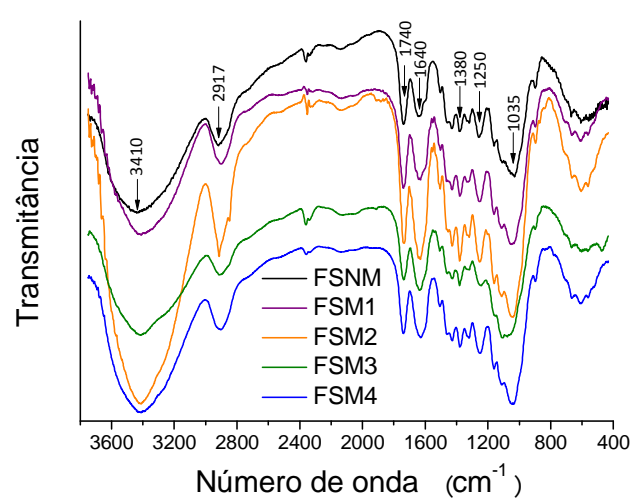

(a)

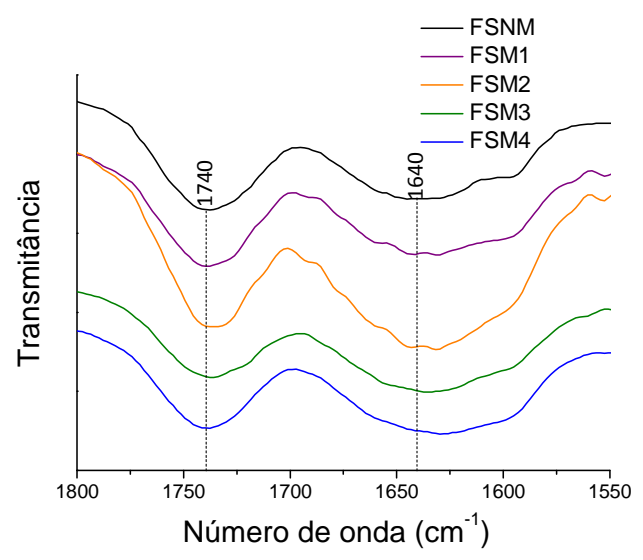

(c)

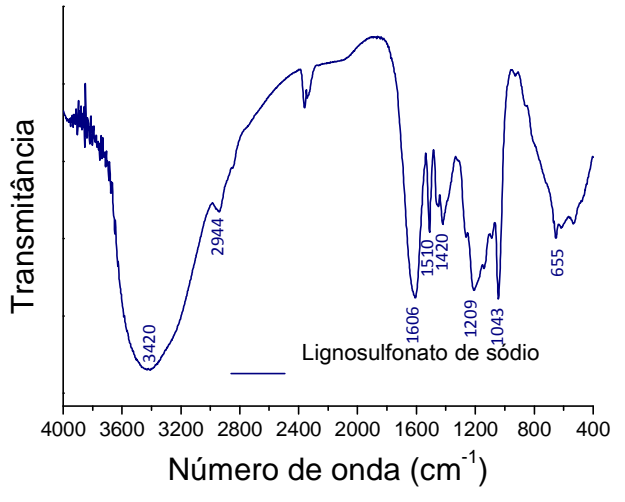

(b)

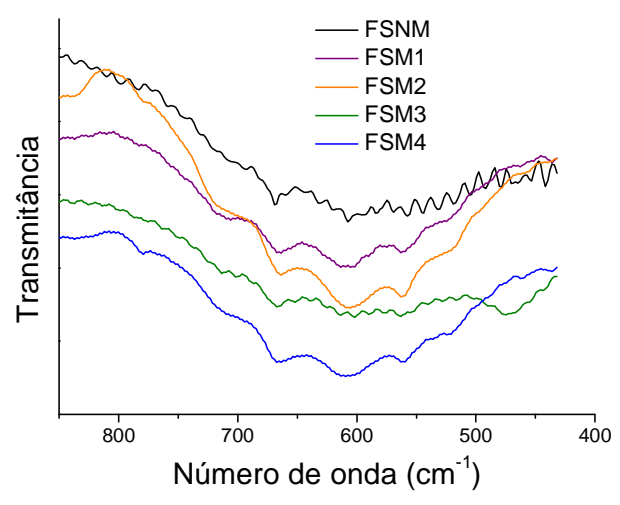

(d)

Figura 20. Espectros na região do infravermelho: (a) fibras de sisal não-modificadas (FSNM) e modificadas (FSM1, FSM2, FSM3 e FSM4); (b) lignosulfonato de sódio; (c) região ampliada (1800 a $1600 \mathrm{~cm}^{-1}$ ) do espectro das fibras de sisal não-modificadas e modificadas e (d) região ampliada (800 a $400 \mathrm{~cm}^{-1}$ ) do espectro das fibras de sisal não-modificadas e modificadas.

Após as modificações não foram observados grandes mudanças nos espectros das fibras modificadas, pois a quantidade de lignosulfonato depositada sobre a superfície da fibra é consideravelmente pequena frente à composição da fibra. Assim, os sinais da lignina original da fibra podem coincidir com os sinais do lignosulfonato depositado sobre a fibra. A banda característica de lignosulfonato em $655 \mathrm{~cm}^{-1}$ (Figura 
20b), correspondente à vibração dos grupos sulfônicos (SHUL'GA; GOMOLKO; KRUT'KO, 2007), pelos mesmos motivos citados a cima, não aparece com destaque nos espectros das fibras de sisal modificadas (Figura 20d).

Tabela 4. Principais absorções observadas no espectro na região do infravermelho da fibra de sisal e seus respectivos modos vibracionais (SILVERSTEIN; BASSLER; MORRIL, 1994)

\begin{tabular}{|c|c|}
\hline Número de onda $\left(\mathrm{cm}^{-1}\right)$ & Possivel atribuição \\
\hline $3420-3400$ & $\begin{array}{c}\text { Estiramento ou deformação axial da ligação O-H (ligações } \\
\text { hidrogênio intra e intermolecular) }\end{array}$ \\
\hline $2920-2860$ & Estiramento da ligação C-H de hidrocarbonetos saturados \\
\hline 1730 & Deformação axial da ligação $\mathrm{C}=0$ \\
\hline $1630-1625$ & Deformação axial das ligações C-C do anel aromático (lignina) \\
\hline 1380 & $\begin{array}{c}\text { Deformação angular simétrica e assimétrica da ligação C-H de } \\
\text { grupos metila }\end{array}$ \\
\hline 1250 & Deformação angular no plano da ligação $\mathrm{O}-\mathrm{H}$ \\
\hline 1163 & Deformação axial da ligação C-O-C de grupos metoxila \\
\hline $1051-1035$ & $\begin{array}{c}\text { Deformação axial simétrica da ligação C-O-C dos grupos } \\
\text { metoxilas (lignina) }\end{array}$ \\
\hline
\end{tabular}

As bandas próximas a 1740 e $1640 \mathrm{~cm}^{-1}$, atribuídas à deformação axial $\mathrm{C}=0$ e deformação axial das ligações $\mathrm{C}-\mathrm{C}$ do anel aromático, respectivamente, tiveram suas proporções relativas alteradas após as modificações (Figura 20c), o que provavelmente está relacionado à presença dos lignosulfonato que altera a banda a $1640 \mathrm{~cm}^{-1}$, cujas principais atribuições são mostradas na Tabela 5. 
Tabela 5. Principais absorções observadas em espectro de infravermelho de lignosulfonatos (FREDHEIM; BRAATEN; CHRISTENSEN, 2003; SHEN; ZHANG; ZHU, 2008; SHUL'GA et al., 2007; RODRIGUEZ, 2005;

KIM et al., 2008).

\begin{tabular}{cc}
\hline Número de onda $\left(\mathrm{cm}^{-1}\right)$ & Possivel atribuição \\
\hline 3420 & O-H deformação axial em lignina e lignosulfonatos \\
$3050-2840$ & C-H deformação axial (alifático + aromático) \\
$1600-1605$ & deformação do anel aromático \\
1510 & C-O estiramento em lignina e lignosulfonatos \\
1420 & S=0 estiramento grupo sulfônico \\
$1174-1222$ & C-O estiramento em lignosulfonatos \\
1192 & C-O estiramento em lignina e lignosulfonatos \\
1182 & C-O estiramento em lignosulfonatos \\
1050 & C-S vibração do grupo sulfônico \\
655 &
\end{tabular}

Tendo em vista que não foi realizada a análise da superfície das fibras modificadas, a detecção de sinais específicos do lignosulfonato é dificultada, uma vez que as fibras são pulverizadas para preparar a pastilha de $\mathrm{KBr}$.

\subsection{4 Índice de cristalinidade}

A Figura 21 mostra os difratogramas obtidos nas análises de raios $X$ das fibras de sisal não-modificadas (FSNM) e modificadas (FSM1, FSM2, FSM3 e FSM4), através dos quais foi possível calcular a cristalinidade das mesmas, como descrito no procedimento experimental (item 3.4.8). 


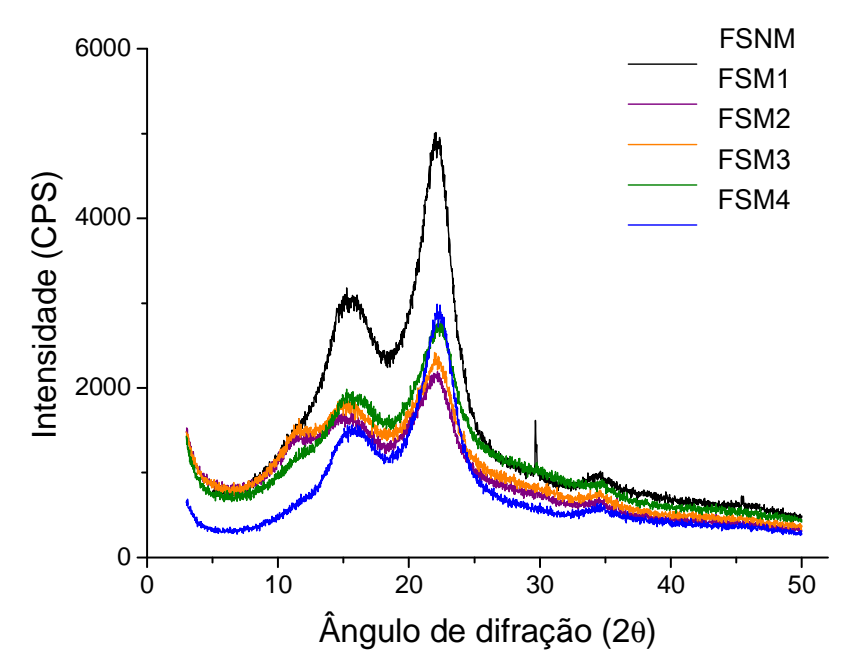

Figura 21. Difratogramas de raios $X$ das fibras de sisal submetidas às modificações (FSM1, FSM2, FSM3 e FSM4) e sem modificação (FSNM).

Os índices de cristalinidade $\left(I_{c}\right)$ para as fibras de sisal são mostradas na Figura 22, sendo possível observar um decréscimo deste valor para as fibras FSM1, FSM2 e FSM3, indicando aumento de domínios não-cristalinos. Como a celulose é a responsável pela cristalinidade da fibra, este resultado indica que aquecimento e irradiação com ultra-som na presença de lignosulfonato, pH em torno de 8,0, permite o afastamento de feixes de fibras e penetração das espécies presentes no meio $\left(\mathrm{Na}^{+} / \mathrm{H}_{2} \mathrm{O}\right)$ até os domínios cristalinos [semelhante à mercerização (MWAIKAMBO; ANSELL, 2001)], diminuindo a cristalinidade da fibra.

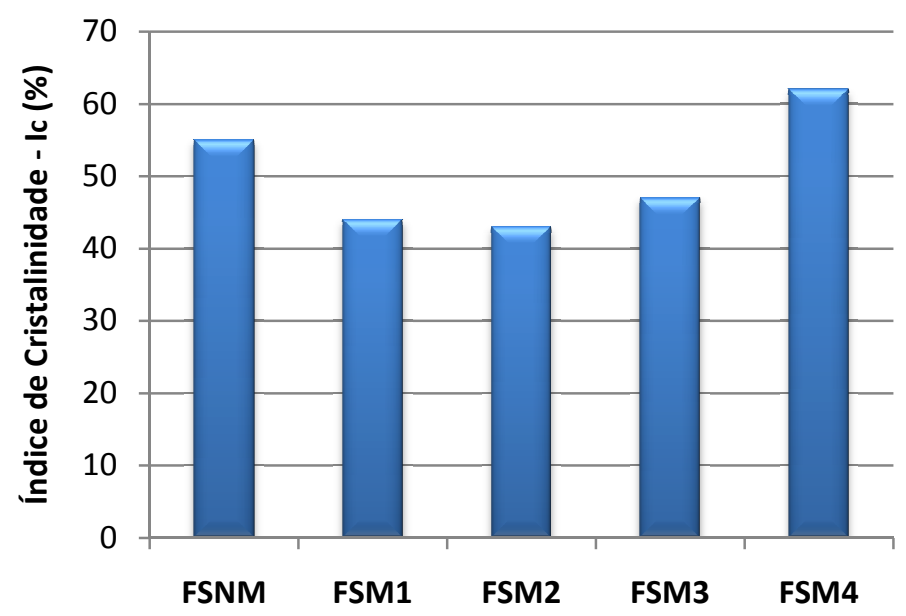

Figura 22. Índice de cristalinidade das fibras de sisal não-modifcadas e modificadas com lignosulfonato de sódio. FSNM - Fibra de sisal não-modificada; FSM1 - Fibra de sisal $\left(70^{\circ} \mathrm{C} / 1 \mathrm{~h}\right)$; FSM2 - Fibra de sisal (Ultra-som/1 h); FSM3 - Fibra de sisal (Ultra-som /2 h); FSM4 - Fibra de sisal (14 h imersão/1 h Ultrasom) 
A fibra FSM4 apresenta um comportamento diferenciado, se comparada às demais, pois ocorre um aumento no índice de cristalinidade após o tratamento. Este resultado pode indicar que o tratamento com ultra-som, após longo período de imersão das fibras em solução aquosa de lignosulfonato (14 h), permite um rearranjo de cadeias de celulose, aumentando a proporção de regiões com cadeias ordenadas e portanto, a cristalinidade.

\subsubsection{Resistência à tração das fibras}

Na Tabela 6 são encontrados os valores de resistência à tração e respectiva porcentagens de alongamento das fibras de sisal em estudo. É possível observar que após todos os tratamentos houve aumento considerável de resistência à tração das fibras. A remoção parcial de hemicelulose, após as modificações, observada na caracterização de componentes das fibras, pode ser responsável pelo aumento da resistência à tração das fibras, pois a densidade da região interfibrilar diminui, e consequentemente, a rigidez. Este fato favorece o rearranjo destas fibrilas ao longo da direção de deformação, acarretando em aumento na resistência à tração (BLEDZKI; GASSAN, 1999).

Tabela 6. Resistência à tração e alongamento das fibras de sisal não-modificadas e modificadas com lignosulfonato de sódio.

\begin{tabular}{lcc}
\hline Amostra & Resistência à tração (MPa) & Alongamento (\%) \\
\hline FSNM & $175 \pm 15$ & $1,7 \pm 0,2$ \\
FSM1 (70 $\mathrm{C} / 1 \mathrm{~h})$ & $616 \pm 60$ & $1,1 \pm 0,1$ \\
FSM2 (Ultra-som/1h) & $452 \pm 46$ & $1,2 \pm 0,1$ \\
FSM3 (Ultra-som/ 2h) & $397 \pm 20$ & $0,9 \pm 0,1$ \\
FSM4 (14h imersão/1 $\mathrm{h}$ Ultra-som) & $465 \pm 63$ & $0,8 \pm 0,1$ \\
\hline
\end{tabular}

Este aumento da resistência à tração das fibras de sisal modificadas também se refletiu na atuação destas como agente de reforço, pois compósitos fenólicos reforçados com estas fibras tratadas apresentaram, no geral, maiores valores de resistência ao impacto se comparados ao compósito contendo fibras de sisal não modificadas, 
conforme será discutido posteriormente. Os desvios aproximam os valores de alongamento das fibras tratadas, sendo todos menores que a da fibra não tratada, indicando que os tratamentos tornaram as fibras menos resistentes ao alongamento.

\subsubsection{Microscopia eletrônica de varredura (MEV)}

As imagens de MEV permitem a avaliação da morfologia da superfície da fibra. Assim, foi possível obter informações sobre os efeitos de tratamentos realizados nas fibras lignocelulósicas e na interface fibra/matriz.

A Figura 23 mostra as imagens de MEV da superfície da fibra de sisal não modificada. Observa-se a presença de alguns fragmentos na superfície do sisal, provavelmente provenientes de resíduos de células parênquimas, nas quais a fibra estava ligada (MEGIATTO JÚNIOR, 2006).

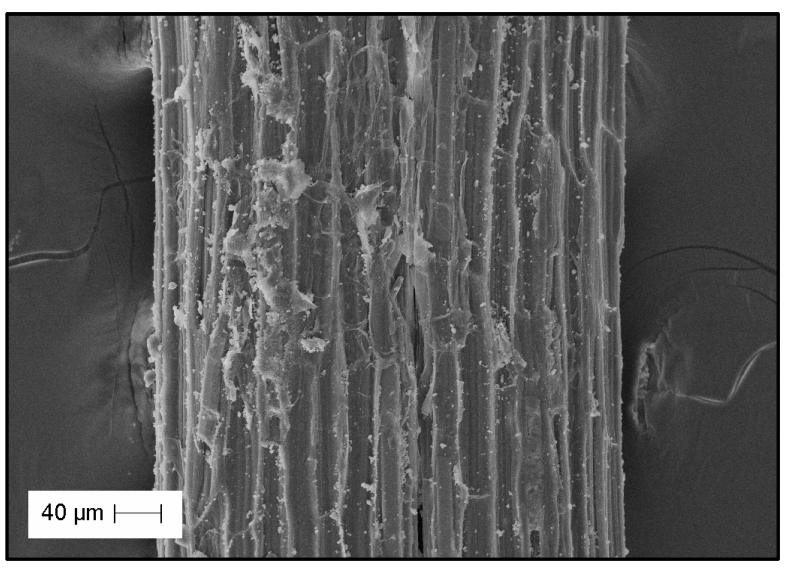

(a)

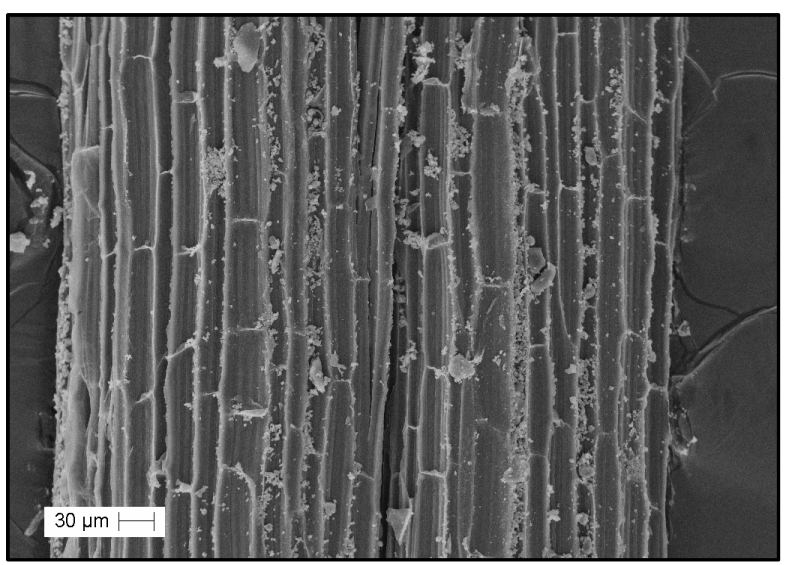

(b)

Figura 23. Imagens de MEV da superfície da fibra de sisal não-modificada (FSNM).

Como se pode observar na Figura 24a e Figura 24b a modificação com lignosulfonato $/ 70^{\circ} \mathrm{C} / 1 \mathrm{~h}$ (FSM1) levou a uma superfície de fibra mais homogênea, sugerindo a deposição de uma fina camada, conseqüência de macromoléculas de lignosulfonato de sódio adsorvidas na superfície da fibra. Para as fibras modificadas sob irradiação com ultra-som (FSM2, FSM3 e FSM4), além de se observar essa camada, microfissuras são observadas na superfície das fibras, que estão indicadas por setas na Figura 24 e Figura 25. Essas microfissuras podem ser decorrentes do efeito do ultra-som (ou efeito de cavitação) sobre a superfície das fibras.

$\mathrm{Na}$ fibra modificada com lignosulfonato/1 h de ultra-som (FSM2), as microfissuras se distribuíram de forma não-homogênea sobre a superfície. Em algumas regiões não foram encontradas microfissuras. Na Figura 24d está mostrada um zoom da região 
delimitada pela linha amarela da Figura 24c. Observa-se que as microfissuras (pequenas fendas) são resultados de uma ação mecânica sobre a superfície da fibra.

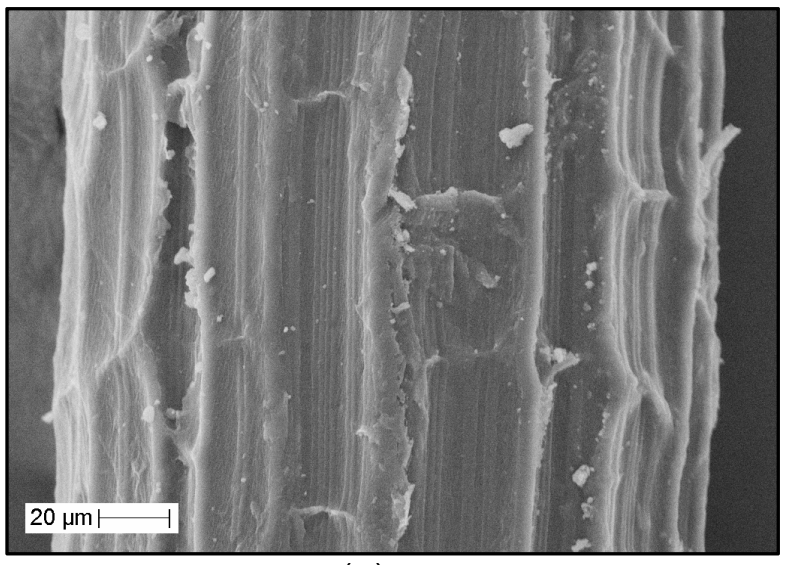

(a)

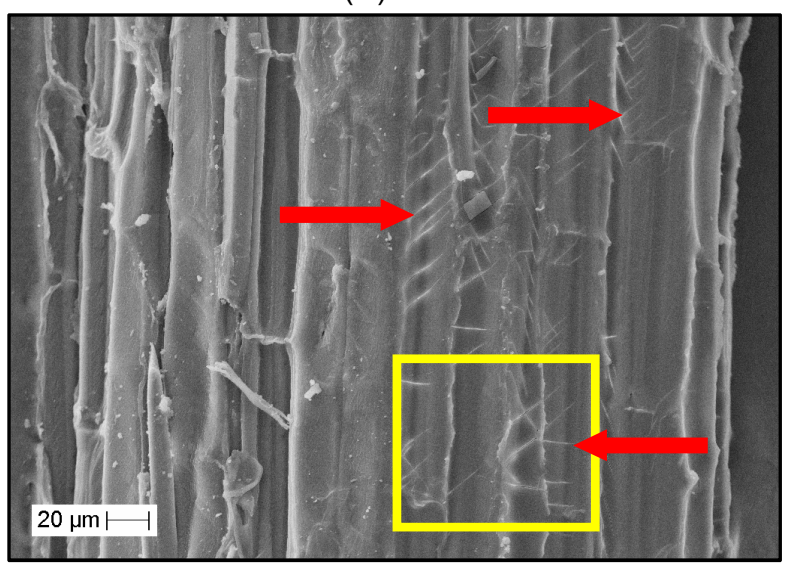

(c)

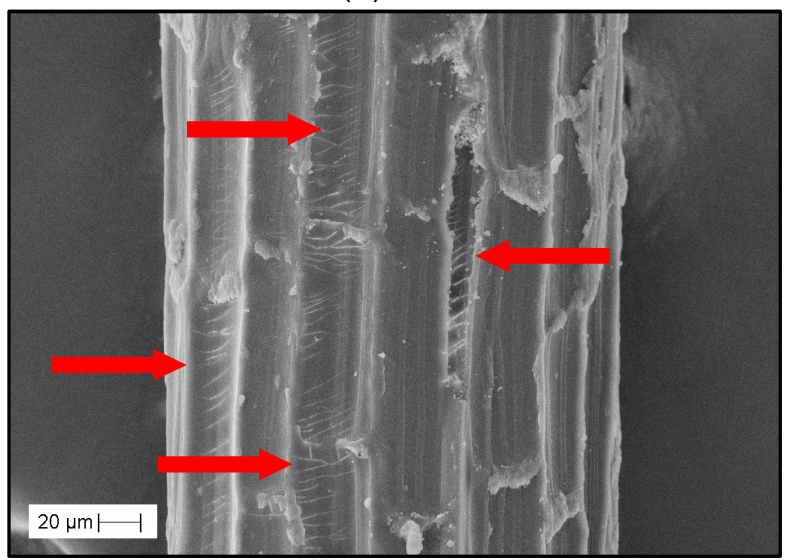

(e)

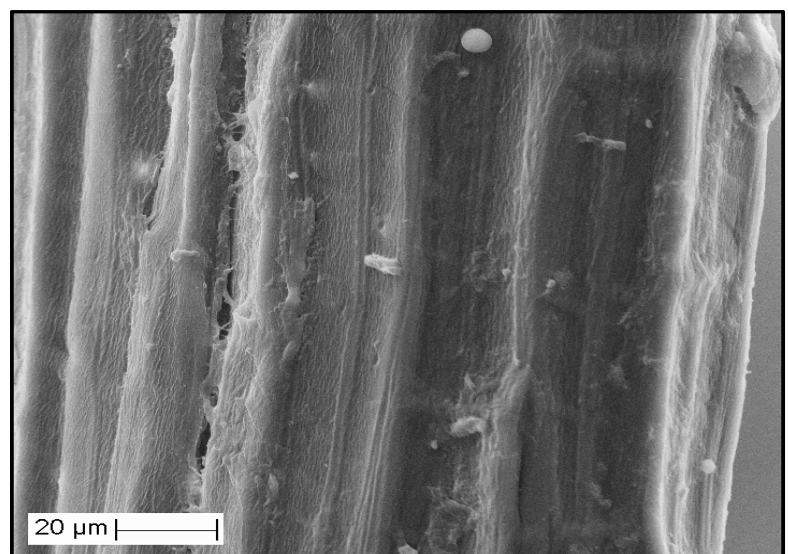

(b)

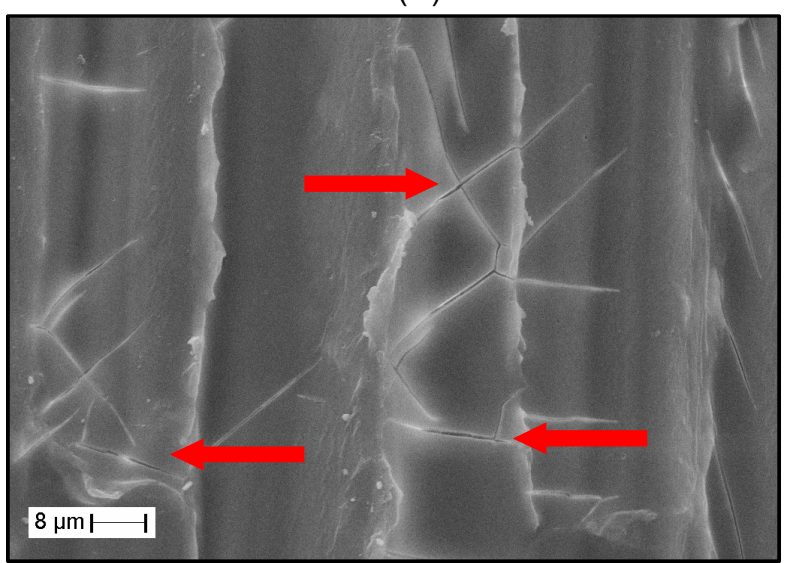

(d)

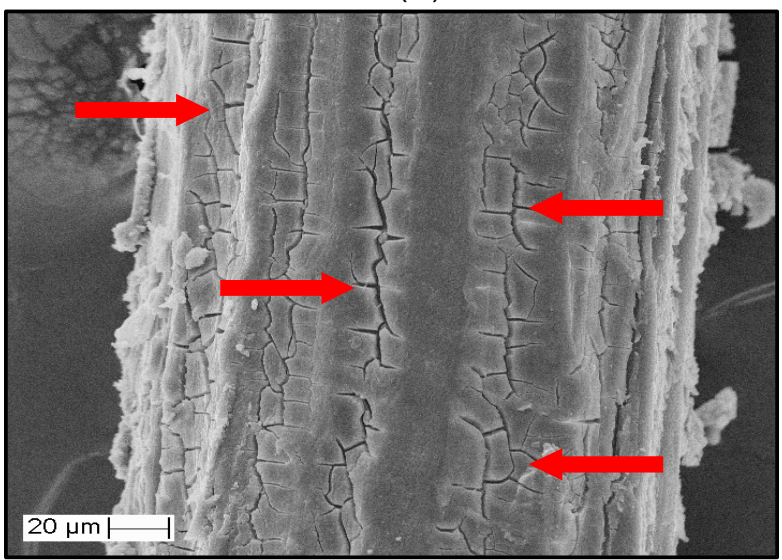

(f)

Figura 24. Imagens de MEV da superfície das fibras de sisal modificadas. (a) e (b) FSM1: fibra de sisal modificação 1 (70 ㄷ/1 h); (c), (d), (e) e (f) FSM2: fibra de sisal modificação 2 (Ultra-som/1 h)

Nas fibras modificadas com lignosulfonato/ultra-som/2 h (FSM3) 0 comportamento foi semelhante à FSM2 (Figura 24e e Figura 24f). Entretanto, nesta fibra, 
encontrou-se microfissuras em quantidade superior e com abertura das fendas relativamente maiores em relação à FSM2.

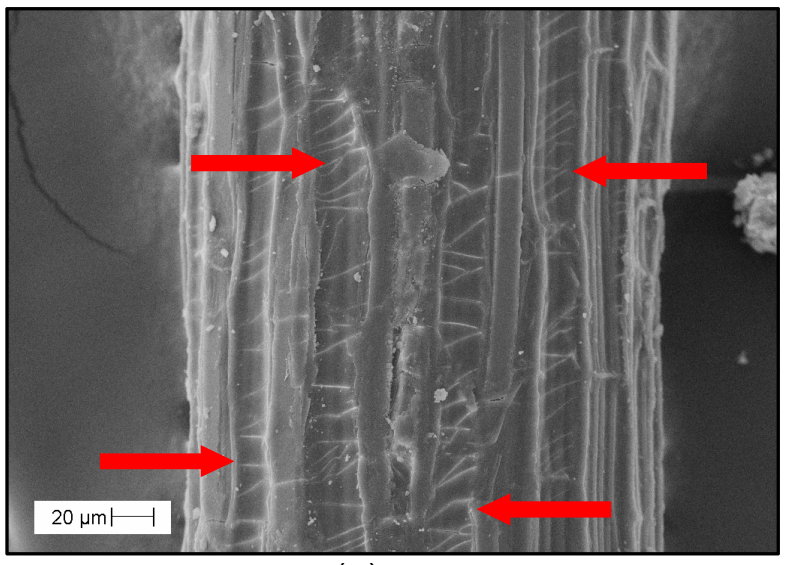

(a)

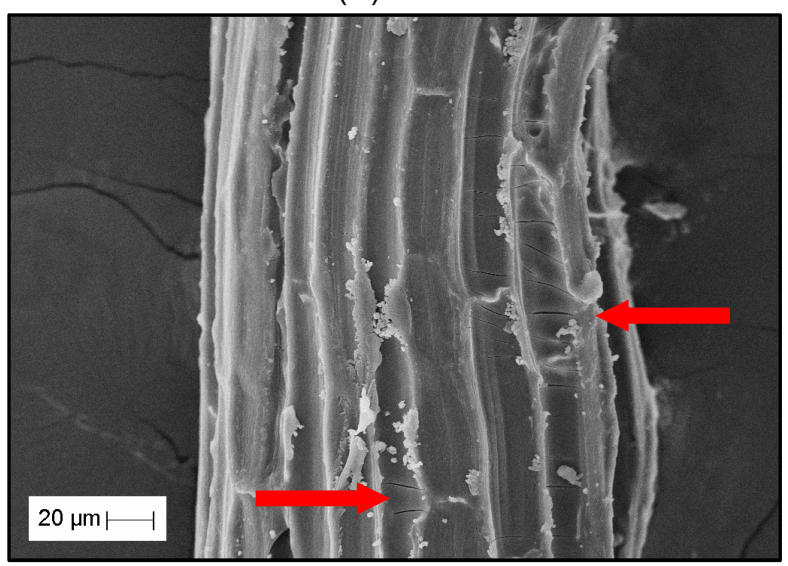

(c)

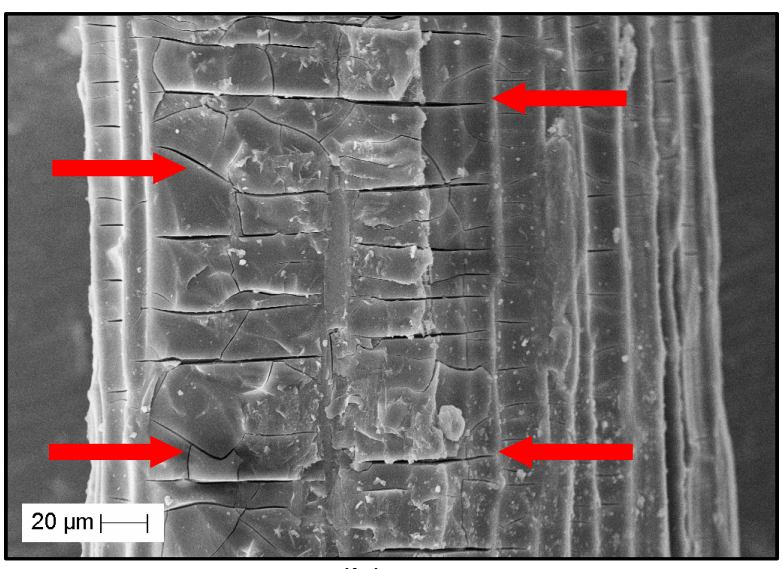

(b)

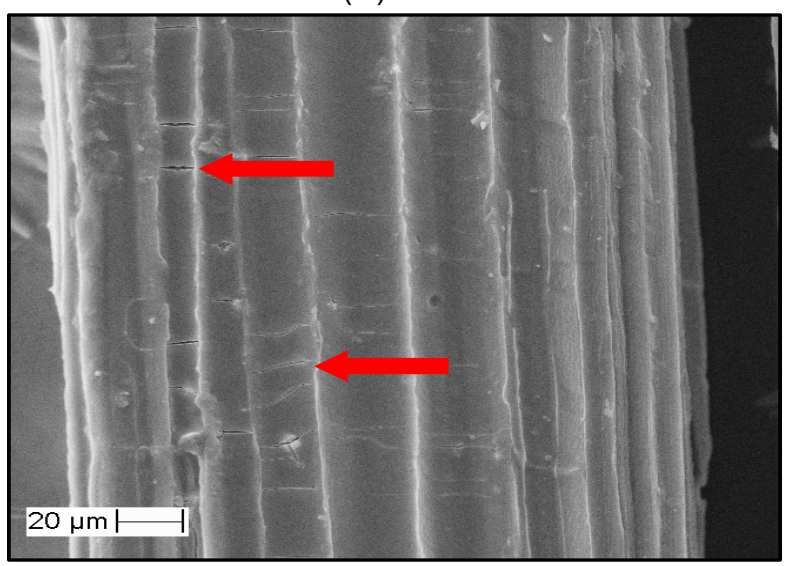

(d)

Figura 25. Imagens de MEV da superfície das fibra de sisal modificadas. (a) e (b) FSM3: fibra de sisal modificação 3 (Ultra-som/2 h); (c) e (d) FSM4: fibra de sisal modificação 4 (14 h imersão/ 1h Ultra-som)

As fibras que foram submetidas à modificação 4 (FSM4, imersas em solução aquosa de lignosulfonato por 14 horas, seguido de irradiação de ultra-som por $1 \mathrm{~h}$ ), apresentaram morfologia semelhante às FSM2 (Figura 25c e Figura 25d).

\subsubsection{Análise Térmica}

As curvas de análise térmica (TG, dTG e DSC) para as fibras de sisal em estudo são apresentadas na Figura 26. Considerando a curva TG (Figura 26a), da temperatura ambiente até aproximadamente $230{ }^{\circ} \mathrm{C}$ todas as fibras tem um comportamento semelhante e apresentam perda de 5\% de massa, em média, que corresponde a perda de água presente nas fibras. A decomposição da fibra de sisal inicia a partir de aproximadamente $250{ }^{\circ} \mathrm{C}$, quando inicia a decomposição da hemicelulose seguida de 
celulose. Em torno de $400{ }^{\circ} \mathrm{C}$, para a fibra não-modificada (curva de cor preta), ocorre uma mudança de inclinação na curva devido o início do processo de decomposição da lignina. A presença do lignosulfonato na superfície da fibra muda o comportamento das curvas e pode ter retardado a degradação dos outros componentes, fazendo com que a perda de massa fosse mais lenta a partir de $400{ }^{\circ} \mathrm{C}$. Em torno de $500{ }^{\circ} \mathrm{C}$ inicia outro processo de decomposição, responsável pela quebra de ligações da lignina, que vai até praticamente massa constante em torno de $650^{\circ} \mathrm{C}$.

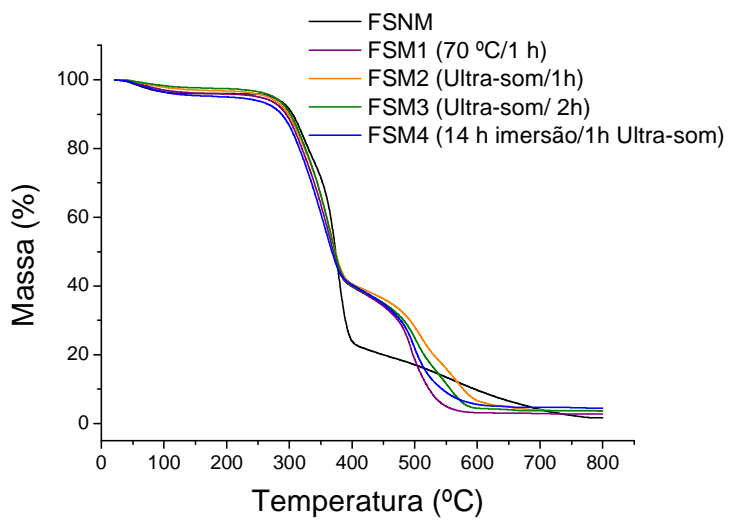

(a)

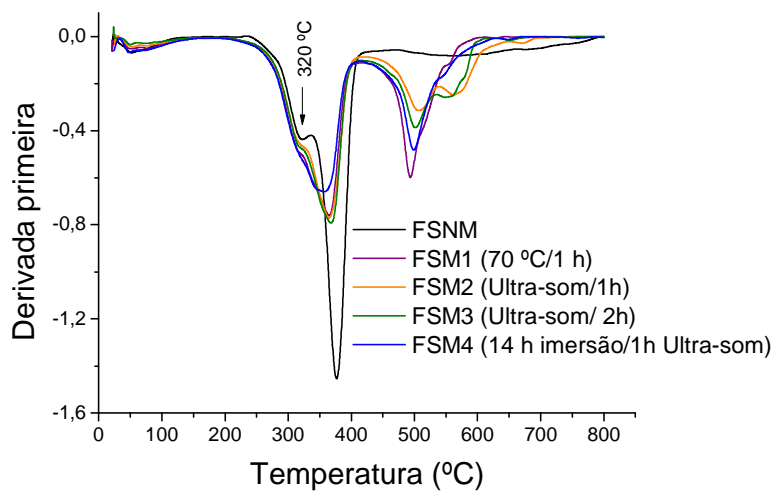

(b)

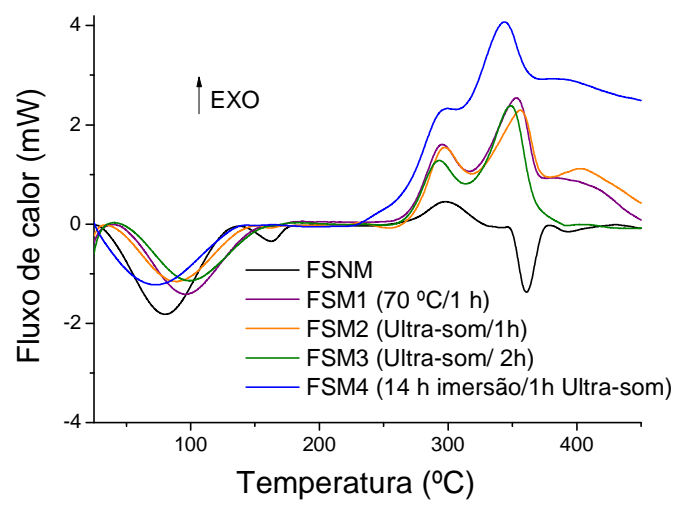

(c)

Figura 26. Curvas (a) TG, (b) dTG e (c) DSC das fibras de sisal nao modificada e modificadas com lignosulfonato de sódio (FSM1, FSM2, FSM3 e FSM4), atmosfera de $\mathrm{N}_{2}$, fluxo de $20 \mathrm{~mL}^{-\mathrm{min}^{-1}}$ e razao de aquecimento de $10^{\circ} \mathrm{C} \cdot \mathrm{min}^{-1}$.

A Figura 26b mostra a derivada primeira das curvas TG das fibras de sisal em estudo. Para a fibra de sisal não-modificada (FSNM), o pico que se encontra em $32{ }^{\circ} \mathrm{C}$ corresponde à decomposição de hemicelulose, menos evidente para outras amostras, devido à diminuição no teor de hemicelulose (Tabela 2). 0 pico em $376{ }^{\circ} \mathrm{C}$ está associado à decomposição da celulose. Observa-se que para as fibras modificadas, este 
pico está deslocado para temperaturas entre 356 e $367^{\circ} \mathrm{C}$, indicando que a eliminação da hemicelulose tornou a celulose mais sensível à decomposição térmica. A fração de lignosulfonato introduzida na superfície da fibra tem propriedades que não necessariamente são similares a protolignina, já que as primeiras não fazem parte de uma rede de entrecruzamento, como as últimas (MEGIATTO JÚNIOR, 2006). Desse modo, os picos em torno de $500{ }^{\circ} \mathrm{C}$, para as fibras modificadas, podem corresponder à decomposição da fração de lignosulfonato presente na superfície da fibra.

As curvas DSC para as fibras de sisal (Figura 26c) mostram comportamento típico de fibras lignocelulósicas. Os picos endotérmicos, observados em todas as fibras, na faixa de $75^{\circ}$ a $100^{\circ} \mathrm{C}$ são atribuídos à evaporação de umidade presente nas amostras. 0 pico exotérmico, também em todas as fibras, observado em $297{ }^{\circ} \mathrm{C}$ é devido à decomposição de hemicelulose. Os picos endotérmicos, para a fibra não-modificada, e exotérmico para as fibras modificadas, em torno de $360^{\circ} \mathrm{C}$ são devido à decomposição da celulose. Os processos de decomposição são exotérmicos, mas quando são acompanhados pela liberação de subprodutos voláteis, o pico endotérmico gerado por estes pode "mascarar" o exotérmico referente à decomposição (MEGIATTO JÚNIOR, 2006). A Figura 26c mostra que para a fibra não-tratada, a liberação de voláteis foi mais intensa, sendo observado um pico endotérmico. A presença de lignosulfonato na superfície das fibras deve ter dificultado esta liberação de voláteis, sendo observados picos exotérmicos.

\subsection{Caracterização do lignosulfonato, dos pré-polímeros e termorrígidos fenólico e lignosulfonato-formaldeído}

Os lignosulfonatos foram usados também na preparação de pré-polímeros, em substituição ao fenol. Por isso, algumas caracterizações, mais pertinentes ao seu uso como "macromonômero", serão relatadas neste item.

\subsubsection{Espectroscopia na região do infravermelho}

O espectro do lignosulfonato de sódio já foi apresentado na Figura 20, e os devidos comentários já foram realizados no item 4.1.3. A Figura 27 e a Figura 28 apresenta o espectro na região do infravermelho para o pré-polímero/termorrígido fenólico e para o pré-polímero/termorrígido lignosulfonato-formaldeído, respectivamente. 


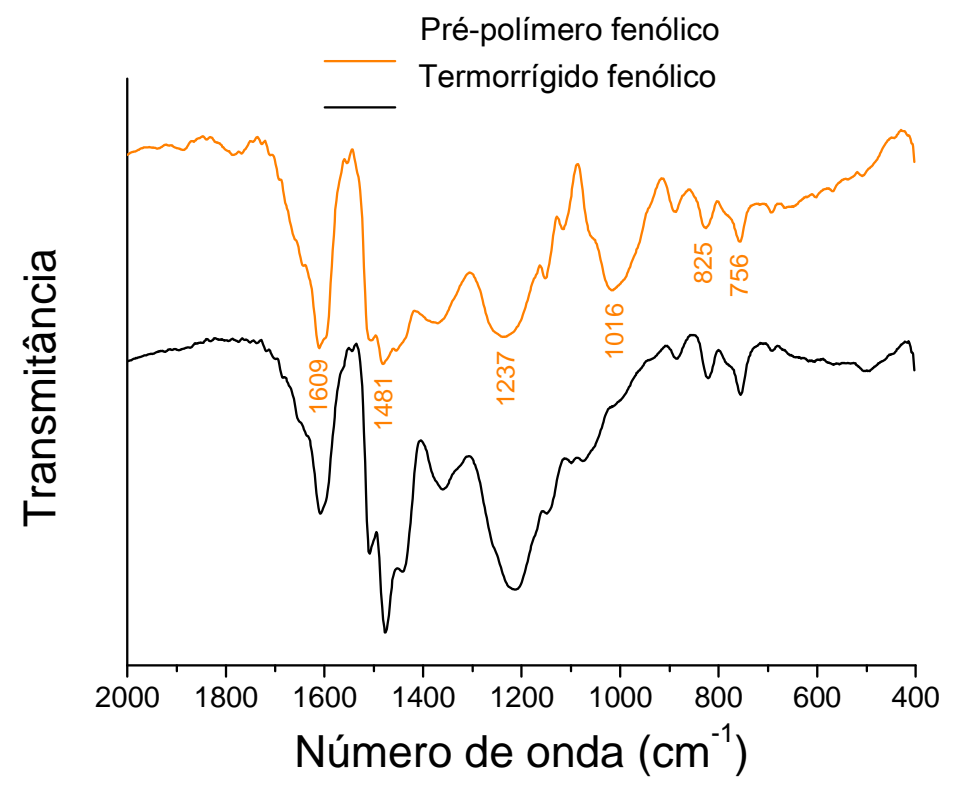

Figura 27. Espectros na região do infravermelho para o termorrígido e pré-polímero fenólico.

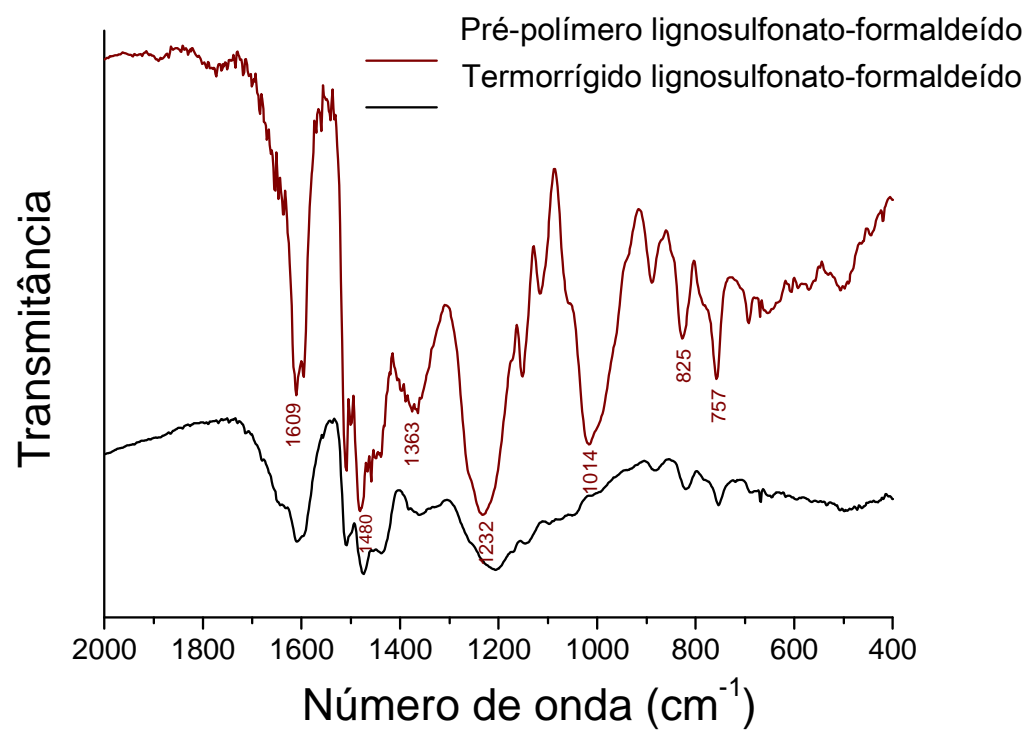

Figura 28. Espectros na região do infravermelho para o termorrígido e pré-polímero lignosulfonatoformaldeído.

Os sinais observados para o pré-polímero/termorrígido fenólico são similares aos apresentados pela pré-polímero/termorrígido lignosulfonato-formaldeído, e por isso considera-se as atribuição dadas na Tabela 7. 
Tabela 7. Principais absorções observadas no espectro de infravermelho da resina fenólica, resina lignosulfonato-formaldeído e seus respectivos termorrígidos (SILVERSTEIN; BASSLER; MORRIL, 1994;

RAMIRES, 2010)

\begin{tabular}{|c|c|}
\hline Número de onda $\left(\mathrm{cm}^{-1}\right)$ & Possivel atribuição \\
\hline 3330 & $\begin{array}{l}\text { Deformação axial simétrica das hidroxilas }(-\mathrm{OH}) \text { dos grupos } \\
\text { alcoólicos e fenólicos }\end{array}$ \\
\hline $2940-2890$ & Deformação axial da ligação C-C em grupos metileno \\
\hline 1609 & Deformação axial da ligação $\mathrm{C}=\mathrm{C}$ do anel aromático \\
\hline $1595-1460$ & Deformação axial da ligação $\mathrm{C}=\mathrm{C}$ do anel aromático \\
\hline 1363 & Deformação angular da ligação $\mathrm{C}-\mathrm{H}$ em grupos metila \\
\hline 1232 & Deformação angular simétrica no plano da ligação C-O \\
\hline 1014 & Deformação axial da ligação C-O-C de grupos metoxila \\
\hline 825 & $\begin{array}{c}\text { Deformação angular da ligação } \mathrm{C}-\mathrm{H} \text { fora do plano em anéis } \\
\text { unidos por ligações orto-para }\end{array}$ \\
\hline 757 & $\begin{array}{c}\text { Deformação angular da ligação } \mathrm{C}-\mathrm{H} \text { fora do plano em anéis } \\
\text { unidos por ligações orto-orto }\end{array}$ \\
\hline
\end{tabular}

Como as figuras representam apenas uma região do espectro de infravermelho, não são mostradas as bandas próximas a $3330 \mathrm{~cm}^{-1}$ que corresponde a uma banda alargada e de grande intensidade, devido à presença de grupos hidroxilas presentes nos anéis. Os picos observados próximos de 825 e $757 \mathrm{~cm}^{-1}$ correspondem a deformação da ligacao $\mathrm{C}-\mathrm{H}$ fora do plano em aneis unidos por ligacoes orto-para e orto-orto, respectivamente. A maior intensidade relativa do pico em $755 \mathrm{~cm}^{-1}$ se deve a predominância das ligações orto-orto no processo de crescimento da cadeia dos prépolimeros (RAMIRES, 2010).

\subsubsection{Cromatografia de exclusão por tamanho (Size Exclusion Chromatography, SEC)}

A Figura 29 mostra os cromatogramas obtidos na determinação da massa molar média do lignosulfonato e pré-polímeros lignosulfonato-formaldeído e fenólico, através de cromatografia de exclusão por tamanho. 


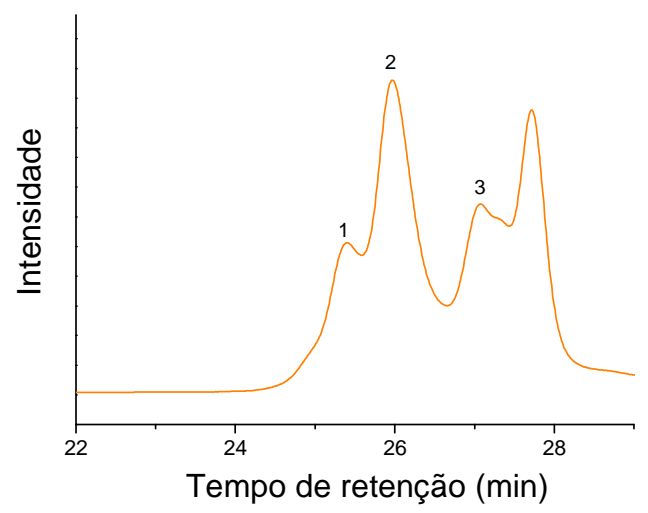

(a)

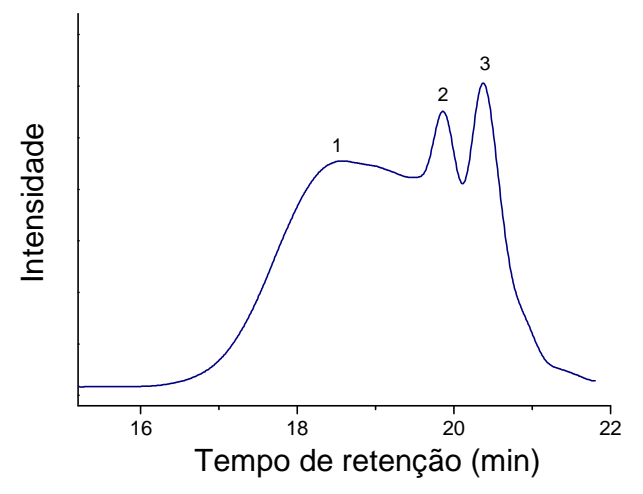

(b)

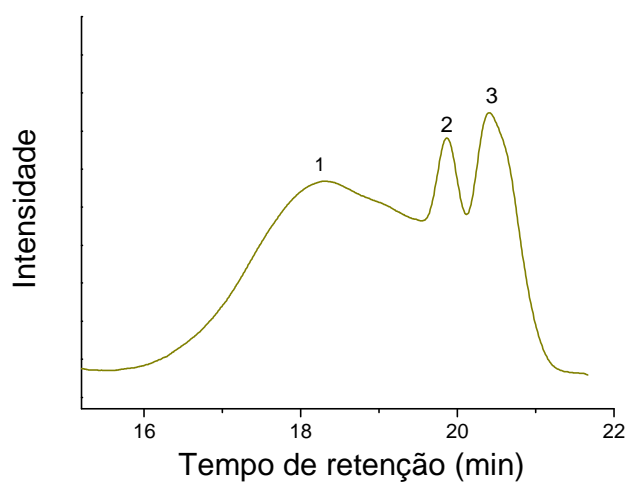

(c)

Figura 29. Cromatogramas de distribuição de massa molar: (a) pré-polímero fenólico, (b) lignosulfonato e (c) pré-polímero lignosulfonato-formaldeído.

Destaca-se que a massa molar média determinada é relativa aos padrões e solvente utilizados, não podendo ser considerada em termos absolutos. O pré-polímero fenólico não foi totalmente solúvel em tetraidrofurano (THF), e a massa molar encontrada corresponde à massa molar da fração solúvel das amostras. Provavelmente, a fração não solúvel corresponde à fração de maior massa molar média das amostras. De qualquer forma, considera-se procedente relatar estes dados, pois a partir dos mesmos, de forma indireta se tem informações sobre a fração não solubilizada. A Tabela 8 mostra as massas molares médias referentes aos picos indicados na Figura 29a, assim como a polidispersividade $\left(\mathrm{M}_{\mathrm{w}} / \mathrm{M}_{\mathrm{n}}\right)$. Estes valores sugerem que houve formação de oligômeros, especialmente pentâmeros, tetrâmeros e trímeros (SILVA, 2006), os quais foram solúveis no solvente usado, correspondendo às frações não solubilizadas a maior massa molar média. 
Tabela 8. Massa molar ponderal média $\left(M_{w}\right)$, massa molar numérica média $\left(M_{n}\right)$ e polidispersividade $\left(\mathrm{M}_{\mathrm{w}} / \mathrm{Mn}_{\mathrm{n}}\right)$ da resina fenólica.

\begin{tabular}{cccc}
\hline Pico & $M_{n}\left(\mathrm{~g} \cdot \mathrm{mol}^{-1}\right)$ & $M_{\mathrm{w}}\left(\mathrm{g} \cdot \mathrm{mol}^{-1}\right)$ & $M_{\mathrm{w}} / M_{n}$ \\
\hline 1 & 528 & 521 & 1,0 \\
2 & 356 & 350 & 1,0 \\
3 & 205 & 203 & 1,0 \\
\hline
\end{tabular}

O lignosulfonato de sódio e o pré-polímero lignosulfonato-formaldeído foram totalmente solúveis no solvente utilizado, solução 0,1 $\mathrm{N} \mathrm{NaNO}_{3} /$ Metanol (80:20 v/v). Assim a massa molar encontrada corresponde ao total das frações presentes. A Tabela 9 apresenta as massas molares médias referentes aos picos indicados na Figura 29b e Figura 29c, assim como a polidispersividade $\left(M_{w} / M_{n}\right)$.

Tabela 9. Massa molar ponderal média $\left(\mathrm{M}_{\mathrm{w}}\right)$, massa molar numérica média $\left(\mathrm{M}_{\mathrm{n}}\right)$ e polidspersividade $\left(\mathrm{M}_{\mathrm{w}} / \mathrm{M}_{\mathrm{n}}\right)$ do lignosulfonato e da resina lignosulfonato-formaldeído.

\begin{tabular}{cccc}
\hline Pico & $M_{n}\left(\mathrm{~g} \cdot \mathrm{mol}^{-1}\right)$ & $M_{\mathrm{w}}\left(\mathrm{g} \cdot \mathrm{mol}^{-1}\right)$ & $M_{\mathrm{w}} / M_{n}$ \\
\hline Lignosulfonato & & & \\
1 & 4668 & 9716 & 2,1 \\
2 & 1071 & 1123 & 1,0 \\
3 & 423 & 484 & 1,1 \\
\hline Resina lignosulfonato-formaldeído & & & 2,9 \\
1 & 5450 & 15592 & 1,0 \\
2 & 1043 & 1085 & 1,1 \\
\hline
\end{tabular}

Os cromatogramas relacionados ao lignosulfonato e respectivo pré-polímero apresentam o mesmo padrão.

Na fração correspondente ao pico 1, é observado acréscimo na massa molar média do pré-polímero, comparativamente ao lignosulfonato (Tabela 9), o que sugere que, além da introdução do grupo $-\mathrm{CH}_{2} \mathrm{OH}$ nos anéis do "macromonômero", consequência da reação com formaldeído, também ocorreu reação de macromonômeros entre si, o que leva a certo aumento na massa molar média e aumenta a polidispersividade. 


\subsubsection{Análise Térmica}

A decomposição de ligninas e lignosulfonatos ocorre em uma ampla faixa de temperaturas resultando em cerca de 30 a 50\% de produto carbonizado e voláteis de baixa massa molar (JAKAB et al., 1993). Segundo estudos de Jakab et al. (1993) os cátions presentes nos lignosulfonatos (como $0 \mathrm{Na}^{+}$do lignosulfonato utilizado neste trabalho) podem catalisar a decomposição térmica dos mesmos. Eles concluíram que o ín sódio facilita a clivagem de grupos funcionais e a formação de produto carbonizado e, ainda, o íon sódio pode promover reações entre grupos funcionais, que foi indicada pela distribuição diversificada de produtos de baixa massa molar.

A curva TG para o lignosulfonato de sódio (Figura 30a) mostra que até $200{ }^{\circ} \mathrm{C}$ há uma perda de massa de aproximadamente 3\%, que pode estar relacionado à perda de umidade. Ao alcançar $800{ }^{\circ} \mathrm{C}$, o lignosulfonato perde apenas $40 \%$ de sua massa, coerente com resultados encontrados na literatura (SANTOS; CURVELO, 1999). Os lignosulfonatos começam a se decompor com a cisão de grupos sulfonatos, em temperaturas relativamente baixas (JAKAB et al., 1993). A curva dTG do lignosulfonato indica picos em $238{ }^{\circ} \mathrm{C}$ e $330^{\circ} \mathrm{C}$, que podem estar relacionados à esta etapa de decomposição.

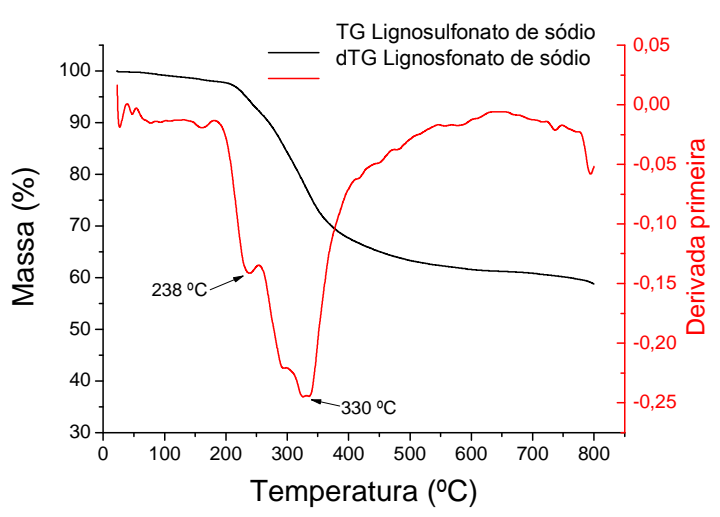

(a)

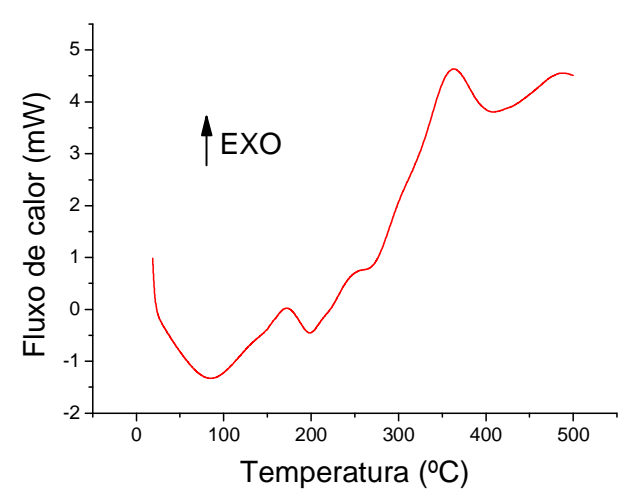

(b)

Figura 30. Curvas TG/dTG e DSC para o lignosulfonato de sódio, atmosfera de $\mathrm{N}_{2}$, fluxo de $20 \mathrm{~mL}^{\mathrm{min}} \mathrm{m}^{-1} \mathrm{e}$ razão de aquecimento de $10^{\circ} \mathrm{C} \cdot \mathrm{min}^{-1}$.

$\mathrm{Na}$ Figura 30b observa-se a curva DSC para o lignosulfonato de sódio. 0 pico endotérmico próximo à $85{ }^{\circ} \mathrm{C}$ pode ser atribuído à vaporização de água. Como mencionado anteriormente, a decomposição do lignosulfonato inicia pela cisão do grupo 
sulfonato, que pode estar relacionada à endoterma em torno de $200{ }^{\circ} \mathrm{C}$, com evidente formação de voláteis. $\mathrm{O}$ pico exotérmico em $360{ }^{\circ} \mathrm{C}$ possivelmente está relacionado à decomposição de grupos alifáticos, na sequência ocorrendo decomposição dos anéis aromáticos.

A curva dTG do pré-polímero fenólico, mostrada na Figura 31a, apresenta um pico em torno de $155^{\circ} \mathrm{C}$, sendo relacionado às etapas de condensação deste pré-polímero, que ocorreram durante a varredura e que foram acompanhadas por liberação de água (RAMIRES, 2010). Ressalta-se que estas varreduras foram feitas com uma razão de aquecimento de $10{ }^{\circ} \mathrm{C} \cdot \mathrm{min}^{-1}$ e que a temperatura deste pico, atribuído a reações de entrecruzamento durante a varredura, foi mais alta que aquela normalmente utilizada no ciclo de cura (seção 3.6), em que o intervalo de permanência em cada temperatura foi muito superior ao desta análise dinâmica. A curva dTG para o termorrígido fenólico, nesta mesma região, não apresenta picos significativos, pois se trata de amostra já entrecruzada.

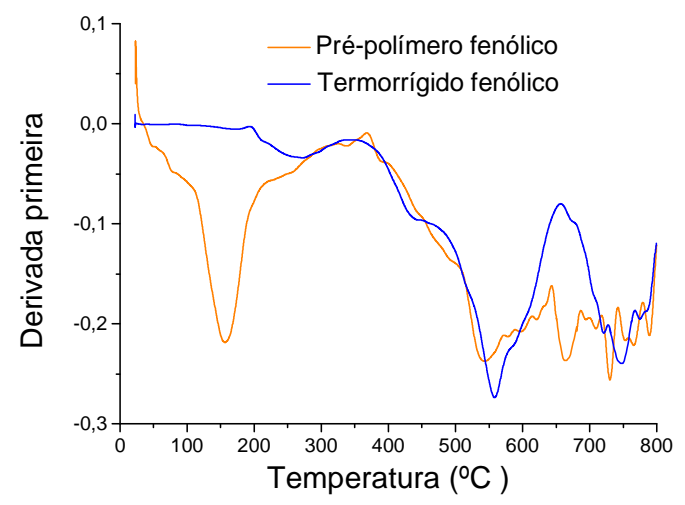

(a)

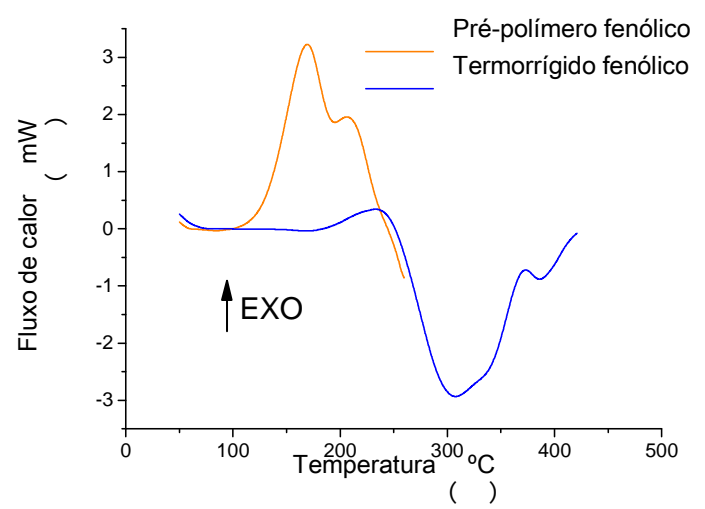

(b)

Figura 31. Curvas (a) dTG e (b) DSC para o pré-polímero e termorrígido fenólico, atmosfera de $\mathrm{N}_{2}$, fluxo de $20 \mathrm{~mL} \cdot \mathrm{min}^{-1} \mathrm{e}$ razão de aquecimento de $10^{\circ} \mathrm{C} \cdot \mathrm{min}^{-1}$.

Nas curvas dTG para o pré-polímero e termorrígido fenólico, mostradas na Figura 31a, é possível observar picos próximos a $550^{\circ} \mathrm{C}$, que são decorrentes da decomposição de anéis aromáticos em ambos materiais.

As curvas DSC para o pré-polímero e termorrígido fenólico são apresentadas na Figura 31b. Observa-se que para o pré-polímero há um pico exotérmico em torno de 170 ${ }^{\circ} \mathrm{C}$, que corresponde ao processo de cura térmica da resina que ocorre durante a varredura da amostra. As cadeias dos pré-polímeros fenólicos possuem grande 
proporção de grupos hidroximetilas ligados aos anéis aromáticos. Assim, para entrecruzar o pré-polímero e necessário somente aquecê-lo para que as reações de condensação continuem (RAMIRES, 2010). A curva para o pré-polímero fenólico vai até $260{ }^{\circ} \mathrm{C}$, que é a temperatura recomendada pelo fabricante do porta-amostra, para materiais no estado líquido. A curva DSC para o termorrígido apresenta um pico exotérmico próximo de $230^{\circ} \mathrm{C}$ que pode corresponder à cura residual, e outro pico em torno de $310^{\circ} \mathrm{C}$, referente à eventos térmicos relacionados à vaporização de voláteis e produtos de reações termooxidativas dos polímeros (TITA, 2002).

A Figura 32 apresenta as curvas dTG e DSC para o pré-polímero e termorrígido lignosulfonato-formaldeído. A curva dTG para o pré-polímero revela, através do pico em torno de $135^{\circ} \mathrm{C}$ Figura 32a, perda de água devido a cura que ocorre durante a varredura. A curva dTG para o termorrígido não apresenta mudanças significativas neste intervalo de temperatura.

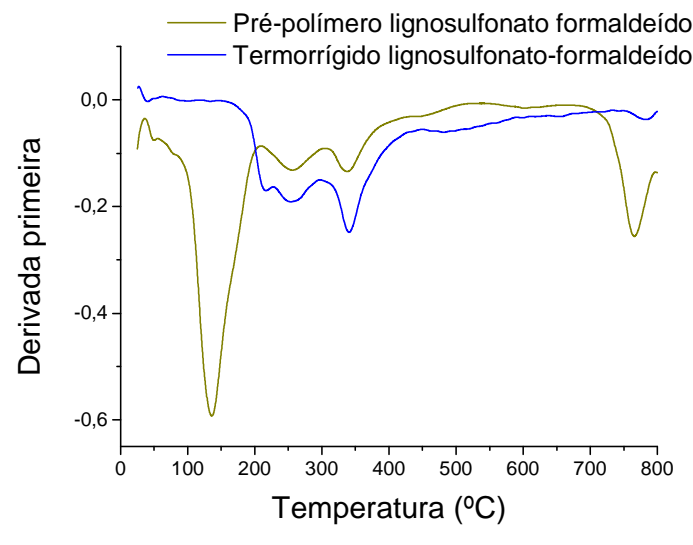

(a)

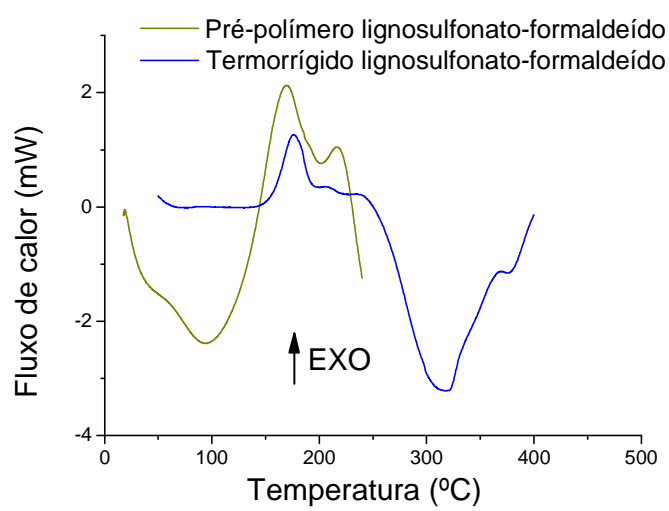

(b)

Figura 32. Curvas (a) dTG e (b) DSC para o pré-polímero e termorrígido lignosfulfonato-formaldeído; atmosfera de $\mathrm{N}_{2}$, fluxo de $20 \mathrm{~mL} \cdot \mathrm{min}^{-1}$ e razão de aquecimento de $10^{\circ} \mathrm{C} . \mathrm{min}^{-1}$.

Os picos exotérmicos próximos de $175{ }^{\circ} \mathrm{C}$ mostrados nas curvas DSC do prépolímero e termorrígido lignosulfonato-formaldeído (Figura 32b), indicam cura térmica e cura residual, respectivamente. O termorrígido fenólico apresenta um pico endotérmico em torno de $320{ }^{\circ} \mathrm{C}$ correspondente à liberação de voláteis no processo de decomposição do lignosulfonato presente nas cadeias poliméricas. 


\subsection{Caracterização dos compósitos de matriz fenólica}

\subsubsection{Resistência ao Impacto}

A tenacidade é a propriedade que representa uma medida da habilidade de um material para absorver energia até a sua fratura (CALLISTER, 2007). Uma maneira de medir a tenacidade é através de ensaios em velocidades elevadas como sob impacto padronizado. A tenacidade de um material solicitado sob impacto é conhecida como resistência ao impacto (HAGE JÚNIOR, 2004).

$\mathrm{Na}$ Figura 33 encontram-se os valores de resistência ao impacto para o termorrígido fenólico (TF) e dos compósitos de matriz fenólica (CF) reforçados com fibras de sisal não-modificada (FSNM) e modificadas (FSM1, FSM2, FSM3 e FSM4). A resistência ao impacto encontrada para o termorrígido fenólico, 19 J.m-1, encontra-se dentro da faixa de valores encontrados em trabalhos anteriores, como 12,8 J.m-1 (PAIVA; FROLLINI, 2001), 13 J.m-1 (JOSEPH et al., 2002; MEGIATTO JÚNIOR, 2006) e 25 J.m-1 (SILVA, 2006).

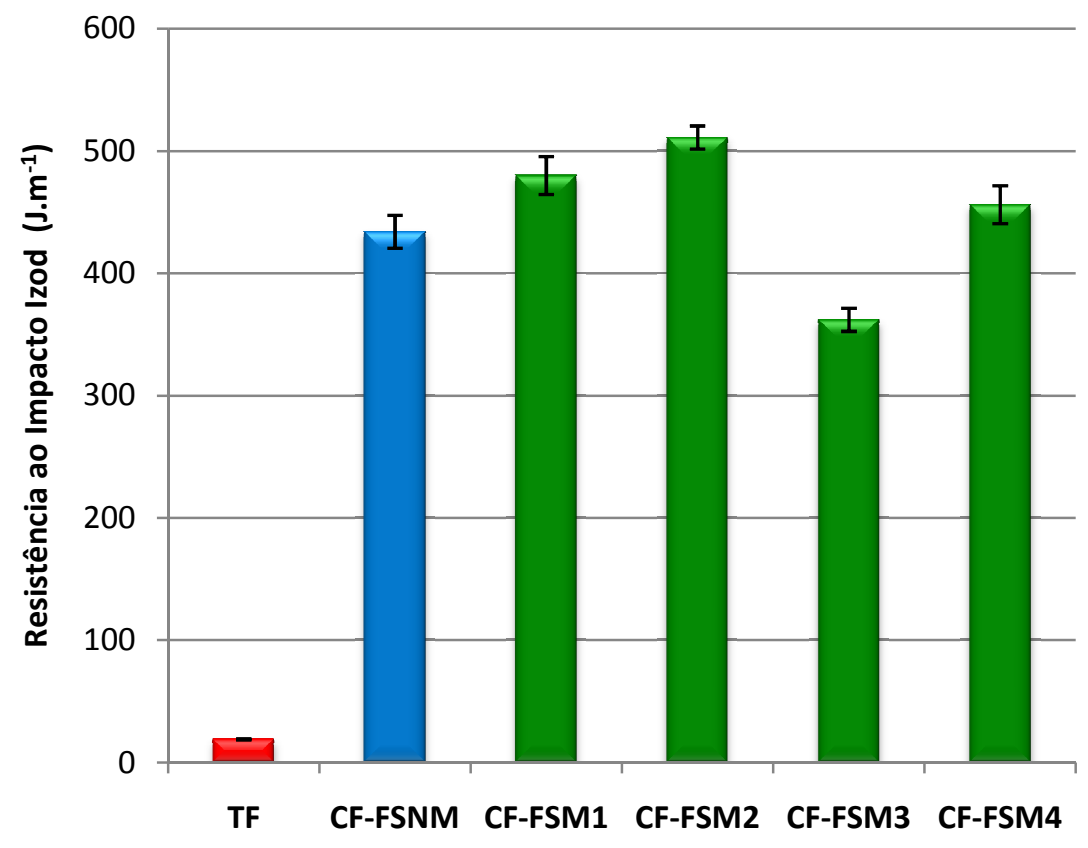

Figura 33. Resistência ao Impacto Izod (corpos de prova não entalhados) de termorrígido fenólico (TF) e compósitos de matriz fenólica (CF) reforçados com fibras de sisal não-modificadas (FSNM) e fibras modificadas (FSM1, FSM2, FSM3 e FSM4), 30\% em massa e com $3 \mathrm{~cm}$ de comprimento (distribuição aleatória). 
É conhecido que a inserção de fibras lignocelulósicas, modificadas ou não, em matriz fenólica aumenta consideravelmente a resistência ao impacto deste material (PAIVA; FROLLINI, 2001). O valor obtido para o compósito com fibra de sisal não-

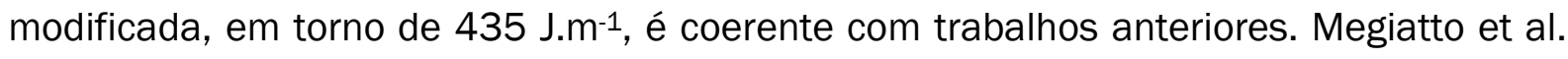
(2007a) obtiveram um valor de $443{\mathrm{~J} . \mathrm{m}^{-1}}^{-1}$ para o esse mesmo tipo de compósito, e valores menores que este quando reforçou a matriz fenólica com fibras de sisal modificadas via oxidação com $\mathrm{ClO}_{2}$ e posterior reação com ácido furfurílico e poli(álcool furfurílico).

Durante o processo de impregnação das fibras, pode-se observar visualmente uma melhora na molhabilidade das fibras modificadas em relação às fibras nãomodificadas, provavelmente devido ao afastamento provocado nos feixes de fibras pelos tratamentos, assim como pelas fortes interações intermoleculares entre a fibra e o prépolímero, intensificados principalmente pela presença de grupos polares no lignosulfonato e no pré-polímero, assim como pela presença de anéis aromáticos em ambos, aumentando a afinidade.

Após o ensaio de impacto, os compósitos reforçados com fibras de sisal não modificadas (FSNM), com fibras modificadas em lignosulfonato/70 ${ }^{\circ} \mathrm{C} / 1 \mathrm{~h}$ (FSM1), em lignosulfonato/ultra-som/1 h (FSM2) e em imersão na solução de lignosulfonato por $14 \mathrm{~h}$ seguido de irradiação de ultra-som por $1 \mathrm{~h}$ (FSM4), apresentaram na maioria das amostras o fenômeno conhecido como "fiber bridging", em que a fibra não rompe durante o ensaio de impacto, e forma uma ponte entre as partes fraturadas da matriz (Figura 34a). 0 compósito reforçado com fibras modificadas em lignosulfonato/ultrasom/2h (FSM3) praticamente não apresentou o fenômeno "fiber bridging", ou seja, a fibra e a matriz romperam no mesmo momento (Figura 34b), compatível com o menor valor de resistência ao impacto. 


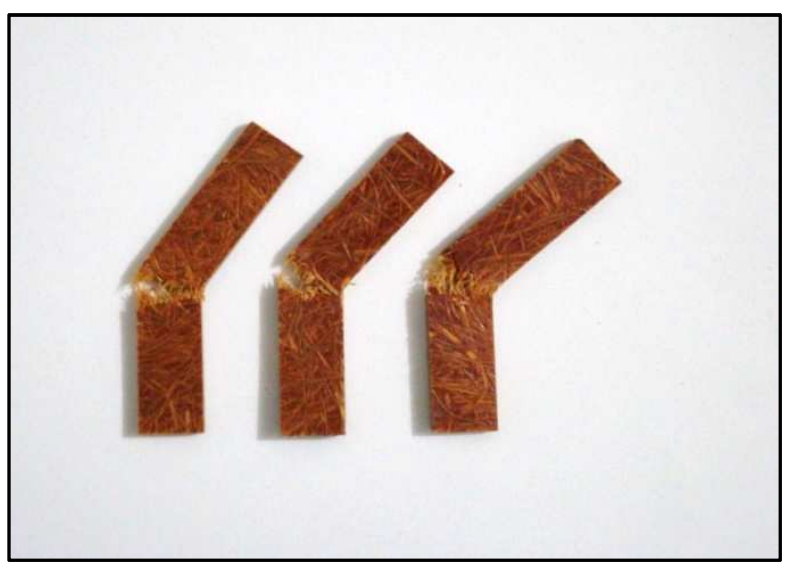

(a)

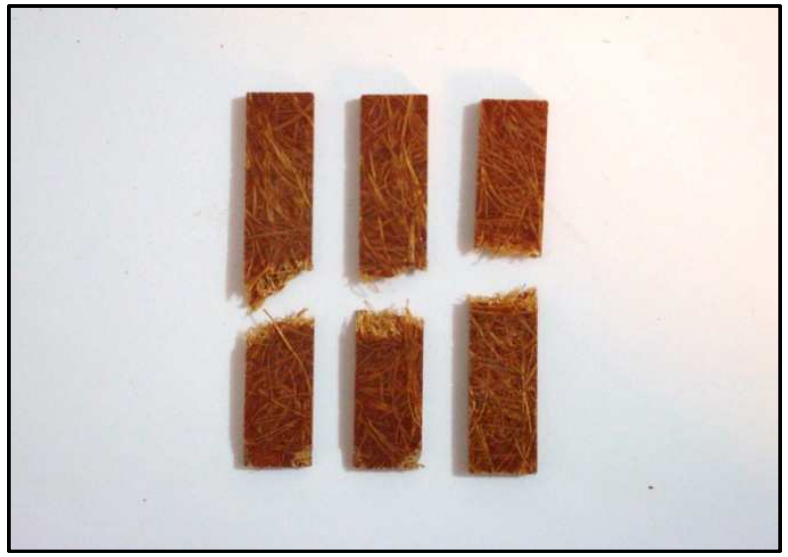

(b)

Figura 34. Corpos-de-prova de compósitos fenólicos reforçados com fibras de sisal, após ensaio de impacto. (a) fenômeno "fiber bridging" observado nos compósitos CF-FSM1, CF-FSM2, CF-FSM4 (b) ruptura completa observada no compósito CF-FSM3.

Houve aumento no valor de resistência ao impacto dos compósitos preparados com as fibras FSM1 e FSM2, embora os desvios aproximem alguns resultados. A adsorção do lignosulfonato sobre a superfície da fibra deve ter aumentado a compatibilidade desta com a matriz fenólica, devido à interação de anéis aromáticos que estão presentes na estrutura molecular do lignosulfonato, da matriz, e dos componentes das fibras de sisal. Ainda, grupos polares presentes no lignosulfonato, na matriz, e nos componentes das fibras, podem favorecer as interações intermoleculares das fibras com a matriz fenólica. A modificação sob irradiação de ultra-som/1h levou a um resultado ainda melhor (511 J.m-1) se comparado a modificação por aquecimento à $70{ }^{\circ} \mathrm{C}(480 \mathrm{~J}$. $\mathrm{m}^{-1}$ ). Isto pode ser explicado pelos efeitos causados pelo ultra-som sobre a superfície da fibra. Os efeitos do ultra-som são decorrentes do colapso de microbolhas que são formadas pela ação das ondas sonoras, efeito denominado cavitação, o que pode ter separado melhor os feixes de fibras, melhorando a impregnação pré-polímero/fibra e, portanto a interface fibra/matriz.

As fibras de sisal modificadas com lignosulfonato sob irradiação de ultra-som/2 $\mathrm{h}$ (FSM3) levaram a menor resistência ao impacto dos compósitos reforçados com estas fibras. Este tratamento ocasionou uma deposição mais eficiente de lignosulfonato sobre a fibra (7,1\% de aumento de massa após modificação). A diminuição no valor de resistência ao impacto (382 J.m-1, abaixo do valor para compósitos reforçados com fibras não-modificadas), indica que o tratamento levou a uma fibra que suporta um pouco menos a transferência de carga matriz/fibra no impacto. A fibras correspondentes à 
modificação 4 (FSM4) levou a um compósito de resistência ao impacto semelhante àquele preparado com fibra não-modificada. Em princípio, o longo tempo de imersão das fibras na solução aquosa de lignosulfonato pode ter contrabalanceado os efeitos possivelmente causados pela $1 \mathrm{~h}$ de irradiação de ultra-som, no sentido de parcialmente fragilizar a fibra.

\subsubsection{Resistência à flexão}

A resistência à flexão (ASTM D790) representa a tensão máxima desenvolvida na superfície de uma barra quando sujeita a dobramento, e aplica-se aos materiais rígidos, ou seja, aqueles que não vergam excessivamente sob ação de uma carga. A força de tensão induzida pela carga de flexão é uma combinação de forças de compressão e tensão, indicadas pelas setas da Figura 35.

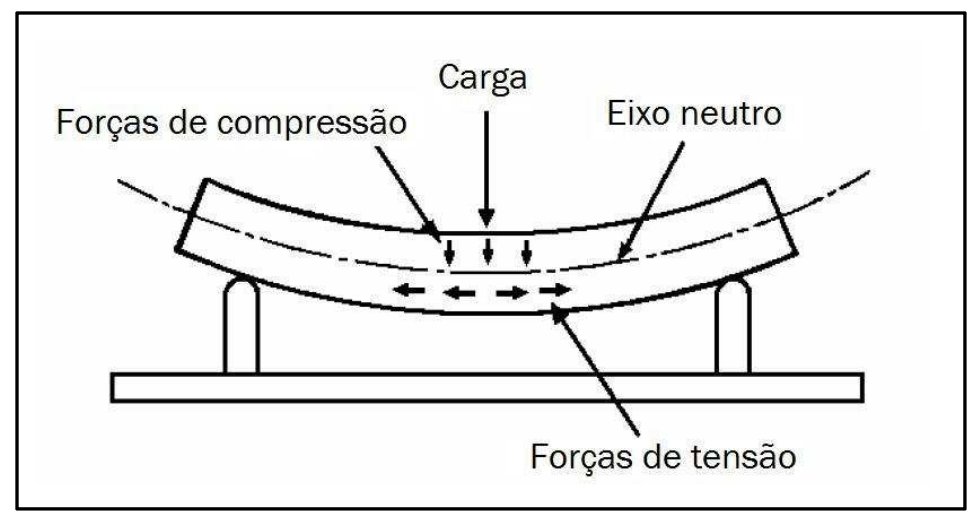

Figura 35. Representação esquemática das forças que agem num ensaio de flexão (CHAWLA, 1987).

A estrutura molecular do polímero é responsável pelo seu comportamento mecânico. De acordo com este comportamento, os materiais poliméricos podem ser classificados em termos de rigidez, fragilidade ou tenacidade. Em meio a diferentes comportamentos típicos de polímeros, é válido destacar o comportamento da classe em que se inserem as resinas fenólicas. Estes polímeros possuem elevado módulo de elasticidade e baixo alongamento na ruptura, podendo ou não escoar antes de sua ruptura (CANTO; PESSAN, 2004).

Na Figura 36 é possível observar os valores de resistência à flexão do termorrígido fenólico e de todos os compósitos preparados com matriz fenólica. Joseph et al. (2002) obtiveram uma resistência à flexão de $10 \mathrm{MPa}$ para o termorrígido fenólico. Considerando os desvios das medidas, o valor de $16 \mathrm{MPa}$ encontrado neste trabalho é 
compatível com o resultado encontrado na literatura. Percebe-se que inserção de fibras de sisal, modificadas ou não, na matriz fenólica aumentou consideravelmente a resistência à flexão deste termorrígido.

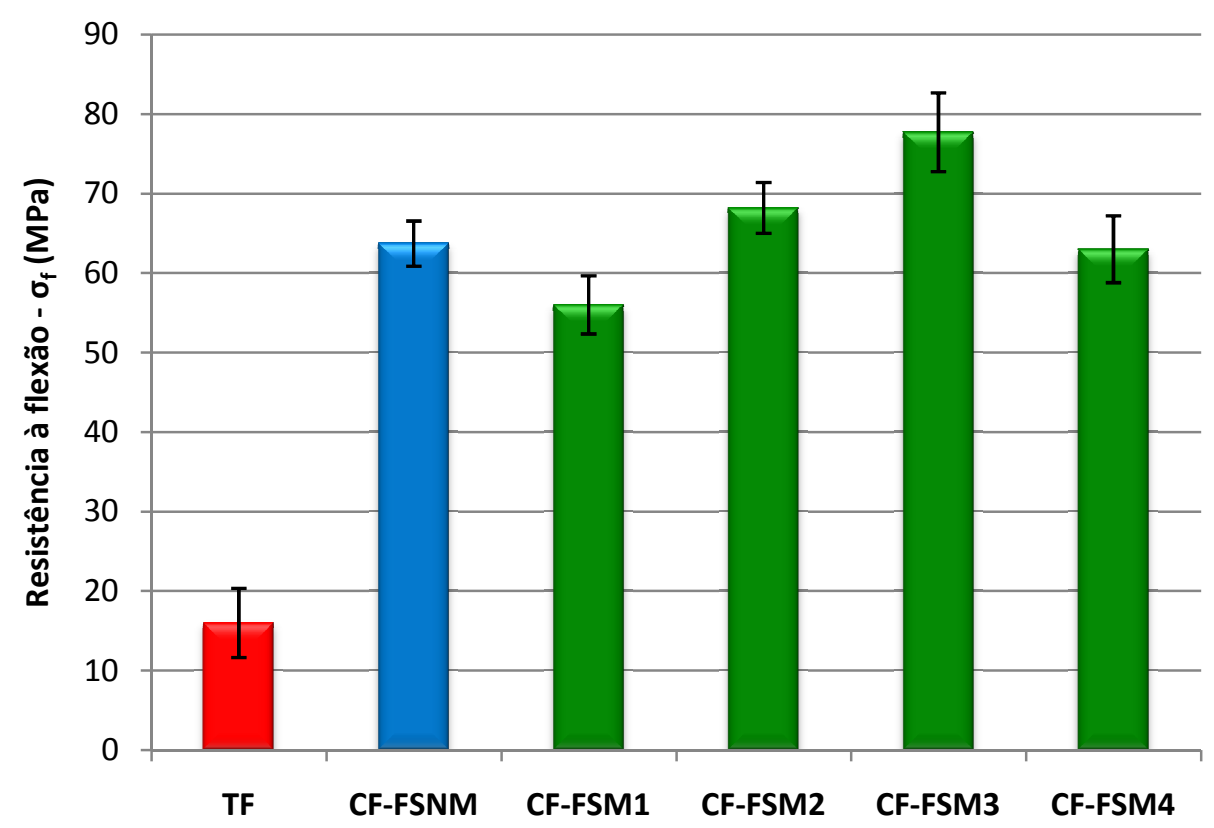

Figura 36. Resistência à flexão de termorrígido fenólico (TF) e compósitos de matriz fenólica (CF) reforçados com fibras de sisal não-modificada (FSNM) e modificadas (FSM1, FSM2, FSM3 e FSM4), 30\% em massa e $3 \mathrm{~cm}$ de comprimento (distribuição aleatória).

Neste ensaio, o compósito fenólico preparado com fibra modificada em ultrasom/2 h (CF-FSM3) alcançou o maior valor de resistência à flexão dentre todos os compósitos (77,7 MPa), embora o desvio aproxime para o valor de CF-FSM2. Isto sugere que a modificação de fibra aplicada proporcionou melhor adesão interfacial entre fibra e matriz. Considerando os respectivos desvios, os compósitos preparados com fibras modificadas (CF-FSM1 e CF-FSM4) e com fibras não-modificadas (CF-FSNM) apresentaram valores semelhantes de resistência à flexão, o que implica que estes tratamentos não influenciaram nas propriedades de flexão destes compósitos.

Pode-se observar uma tendência no aumento da resistência à flexão dos compósitos no sentido da modificação M1 até a M3, entre si, que sugere aumento da adesão interfacial fibra-matriz conforme foram realizados tratamentos nas fibras. A tendência de aumento de propriedade mecânica que é observada nos compósitos CFFSM1 e CF-FSM2, para resistência à flexão, também é observada no ensaio de impacto Izod (Figura 33). 
Através do ensaio de flexão, é possível também obter o módulo de elasticidade tangente $\left(E_{f}\right)$, ou simplesmente módulo de elasticidade, que é usado para medir a rigidez de um material. Este parâmetro pode ser obtido através do coeficiente angular da porção linear inicial da curva tensão-deformação (KU et al., 2009). Os valores de $E_{f}$ para o termorrígido e os compósitos fenólicos podem ser observados na Figura 37.

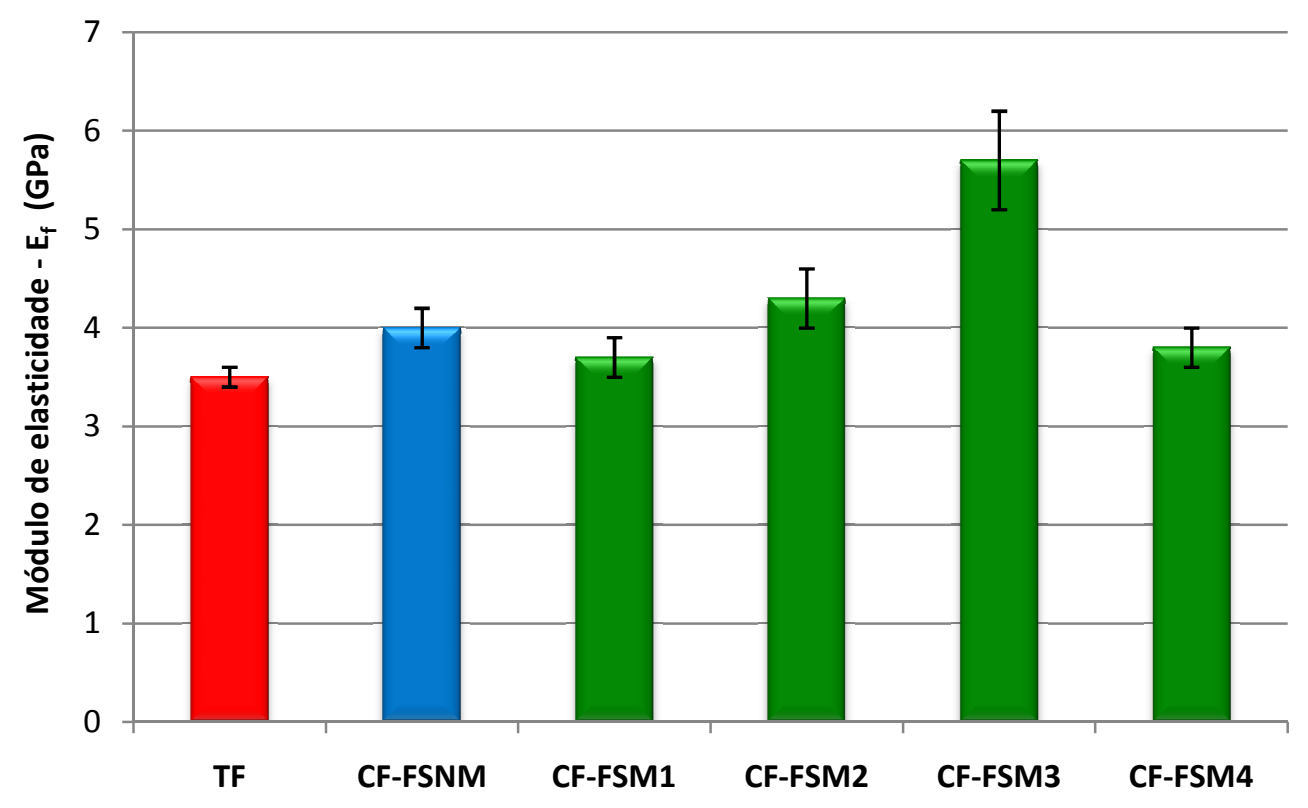

Figura 37. Módulo de flexão (ou elasticidade) de termorrígido fenólico (TF) e compósitos de matriz fenólica (CF) reforçados com fibras de sisal não-modificada (FSNM) e modificadas (FSM1, FSM2, FSM3), 30\% em massa e $3 \mathrm{~cm}$ de comprimento (distribuição aleatória).

O módulo de elasticidade encontrado para o termorrígido fenólico é cerca de 3,5 GPa. Os compósitos CF-FSNM, CF-FSM1, CF-FSM2 e CF-FSM4 apresentam $E_{f}$ um pouco maior que o termorrígido não reforçado, embora os desvios aproximem alguns valores. Entretanto, para o compósito CF-FSM3, cuja modificação das fibras ocorreu via irradiação de ultra-som/2 h, o módulo de elasticidade aumenta cerca de 60\% comparativamente ao termorrígido fenólico, devido a forte adesão fibra/matriz neste compósito, conforme já comentado. 


\subsubsection{Microscopia Eletrônica de Varredura (MEV)}

A Figura 38 mostra a superfície de fratura típica do termorrígido fenólico, após o ensaio de Impacto. A aparência da fratura é do tipo frágil, com ocorrência de regiões espelhadas, indicadas pelas setas amarelas.

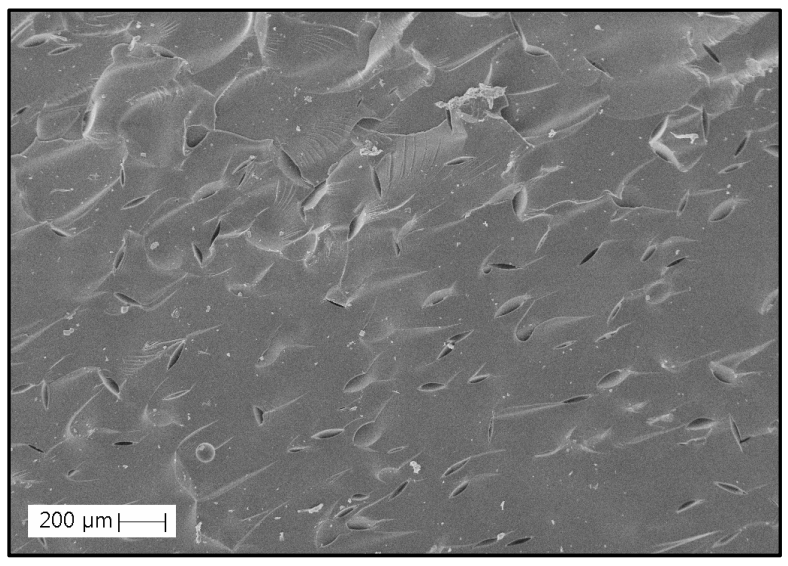

(a)

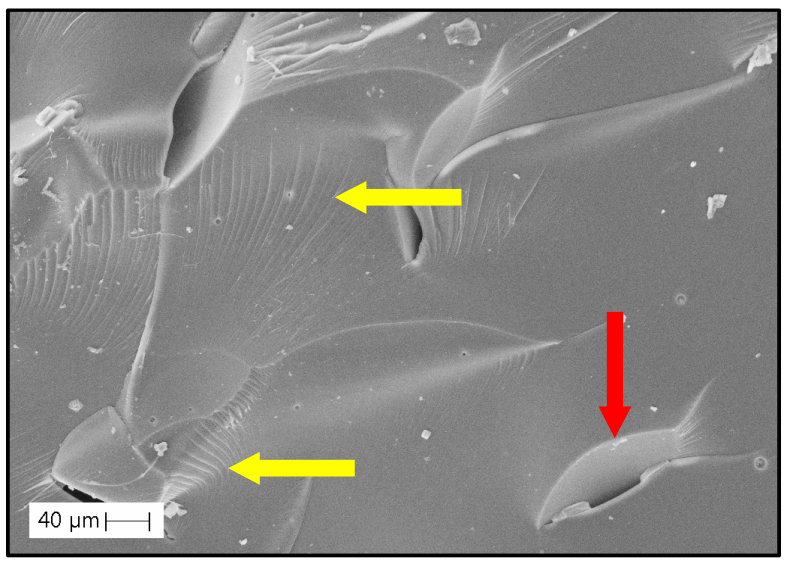

(b)

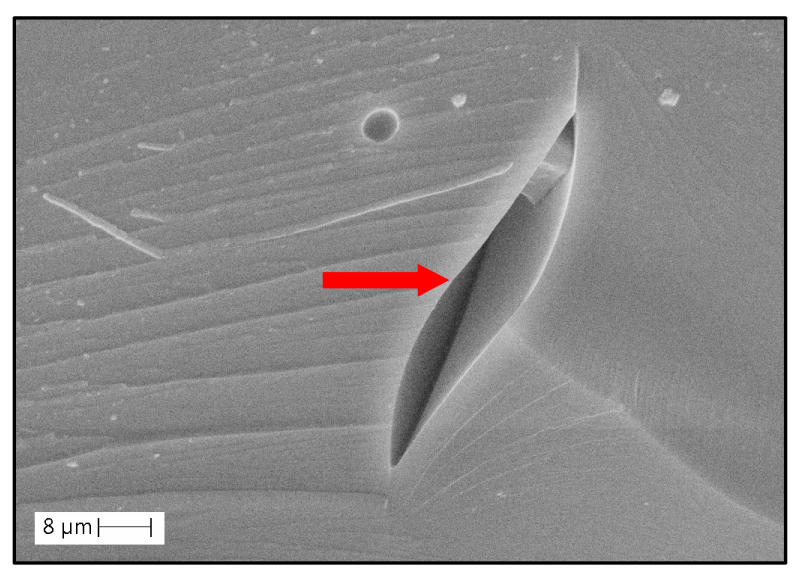

(c)

Figura 38. Imagens de MEV da superfície de fratura do termorrígido fenólico com ampliação de (a) 100, (b) 500 e (c) 3000 vezes.

A presença de vazios, indicados pelas setas vermelhas (Figura 38), é decorrente da volatilização de água residual, assim como daquela gerada na reação de condensação do pré-polímero fenólico. Geralmente, quando maior a quantidade de vazios, piores são as propriedades mecânicas do material. Os vazios podem atuar como concentradores de tensão, reduzindo a capacidade de transporte de carga e a capacidade de absorção de energia do material (PAIVA; FROLLINI, 2001). 
Após o ensaio de impacto, foram obtidas imagens de MEV da superfície de fratura dos compósitos fenólicos reforçados com fibras modificadas e não-modificadas. $\mathrm{Na}$ Figura 39 podem ser observadas imagens para o compósito preparado com fibra nãomodificada (CF-FSNM). Apesar da presença de regiões com boa adesão, representada por setas amarelas (Figura 39b), este compósito apresentou o mecanismo conhecido como "pull out", que ocorre quando a fibra é liberada da matriz, indicando uma menor adesão interfacial, mostrada pela seta vermelha na Figura 39a. Observou-se também a propagação de trincas ao redor da fibra, mostrada pela seta vermelha na Figura 39b. Estas trincas são indicativos de transferência de carga, aplicada durante o ensaio, da matriz para a fibra (MEGIATTO JÚNIOR, 2006).

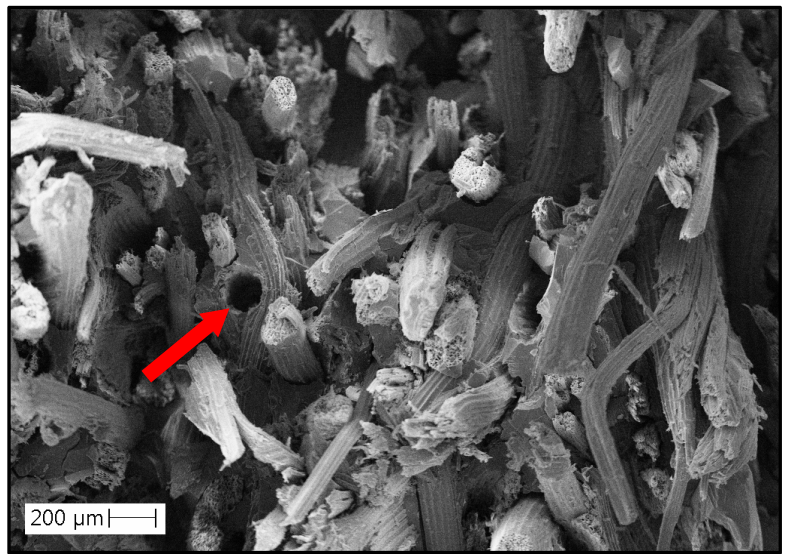

(a)

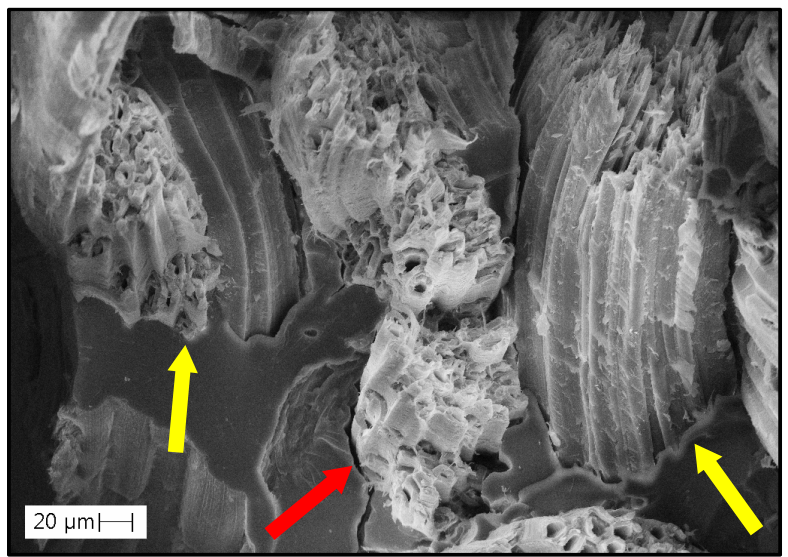

(b)

Figura 39. Imagens de MEV da superfície de fratura de compósitos fenólicos reforçados com fibras de sisal não-modificada.

No geral, foi possível observar uma adesão interfacial fibra/matriz menos eficiente no compósito preparado com fibra não-modificada (CF-FSNM) em relação ao compósito preparado com fibra modificada em lignosulfonato/70 ${ }^{\circ} \mathrm{C} / 1 \mathrm{~h}$ (CF-FSM1), mostrado na Figura 40. O CF-FSM1 apresenta um valor de resistência de impacto um pouco maior que o reforçado com fibras não-modificadas, compatível com uma adesão mais intensa se comparado ao CF-FSNM. 


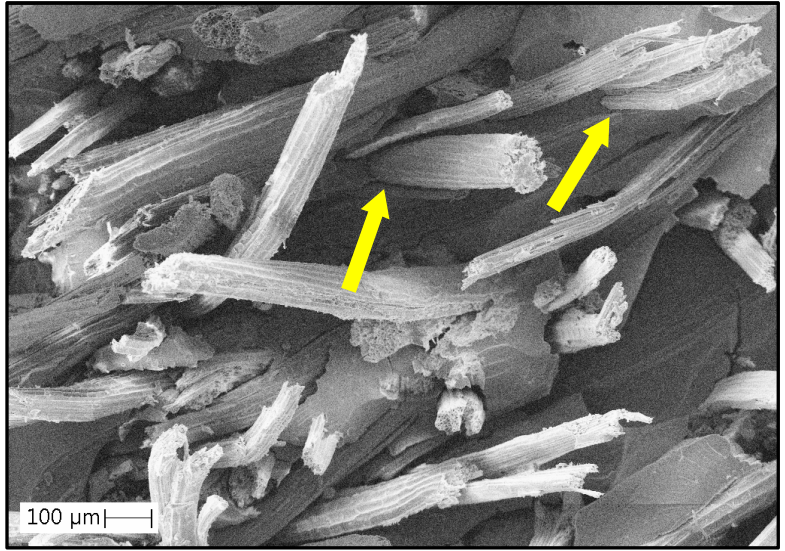

(a)

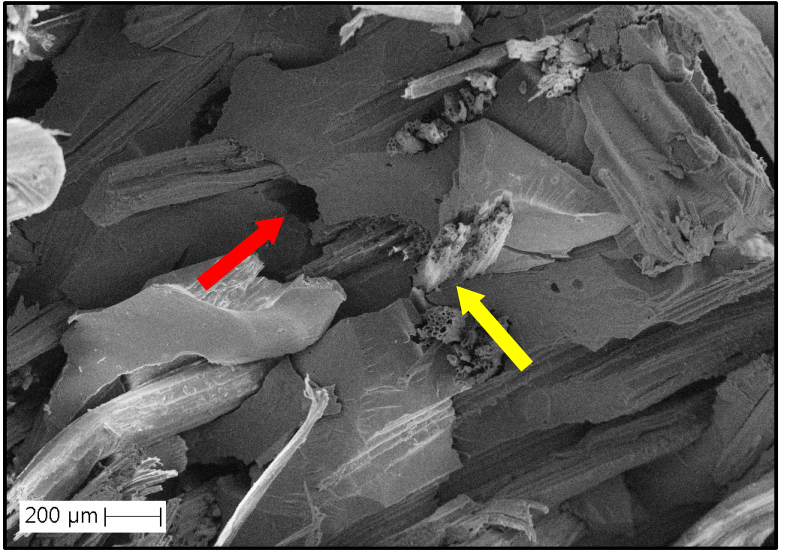

(b)

Figura 40. Imagens de MEV da superfície de fratura de compósitos fenólicos reforçados com fibras de sisal modificadas por aquecimento à $70^{\circ} \mathrm{C} / 1 \mathrm{~h}$ (CF-FSM1).

Para o compósito modificado em lignosulfonato/ultra-som/1h (CF-FSM2) foi possível observar também regiões de boa adesão (representado na Figura 41a), e que podem estar relacionadas também aos efeitos do ultra-som na superfície da fibra. Já para o compósito com fibras modificado em lignosulfonato/ultra-som/2 h (CF-FSM3) observou-se uma quantidade considerável, maior que os outros compósitos, de fibras que romperam junto com a matriz após o ensaio de impacto (Figura 42).

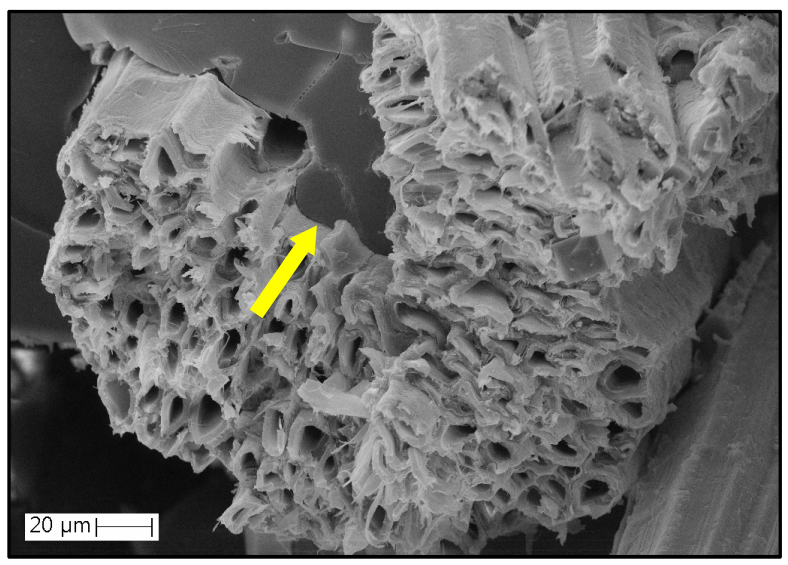

(a)

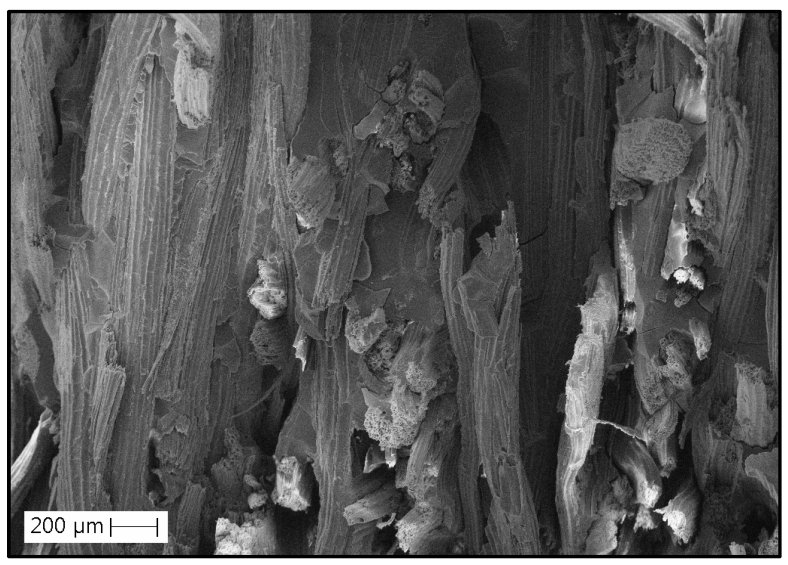

(b)

Figura 41. Imagens de MEV da superfície de fratura de compósitos fenólicos reforçados com fibras de sisal modificadas em ultra-som/1 h (CF-FSM2). 


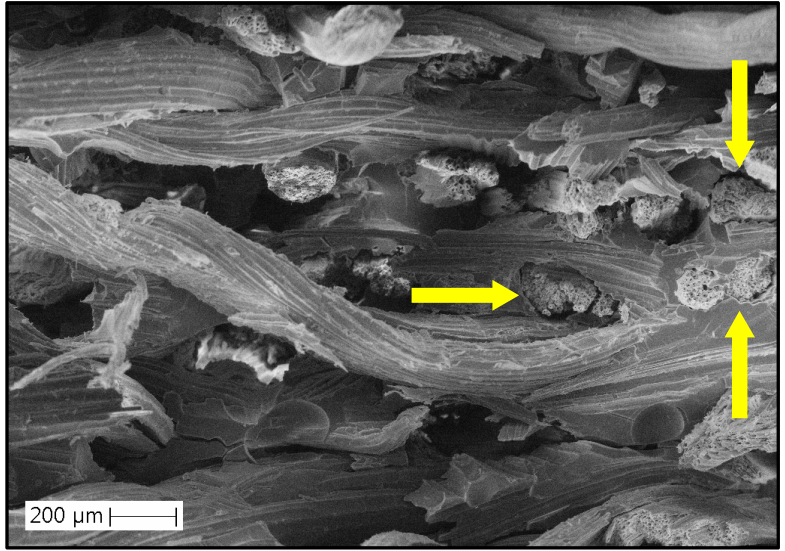

(a)

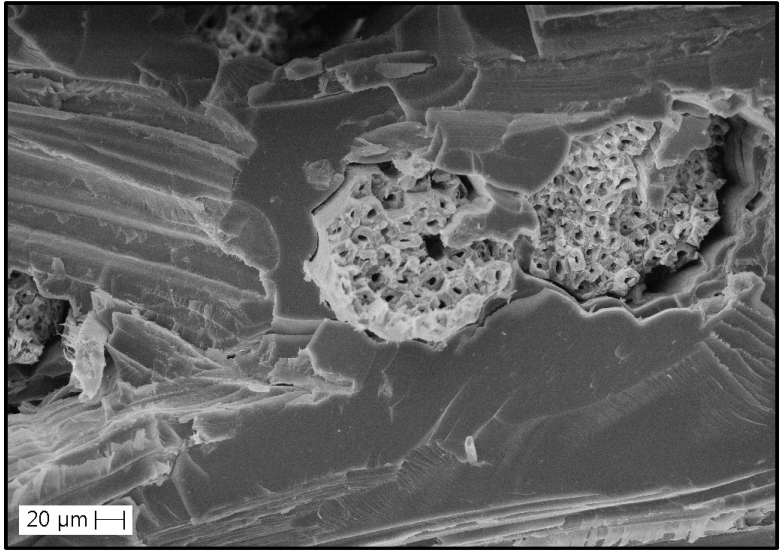

(b)

Figura 42. Imagens de MEV da superfície de fratura de compósitos fenólicos reforçados com fibras de sisal modificadas em ultra-som/2 h (CF-FSM3).

O compósito CF-FSM4, cuja modificação das fibras ocorreram por meio de imersão $14 \mathrm{~h}$ em solução de lignosulfonato seguido de irradiação de ultra-som por $1 \mathrm{~h}$, apresentou características de superfície de fratura semelhante ao compósito preparado com fibra não-modificada, onde pode ser observado elevada ocorrência do mecanismo "pull out" (Figura 43a), embora tenha-se encontrado algumas regiões com boa adesão (Figura 43b).
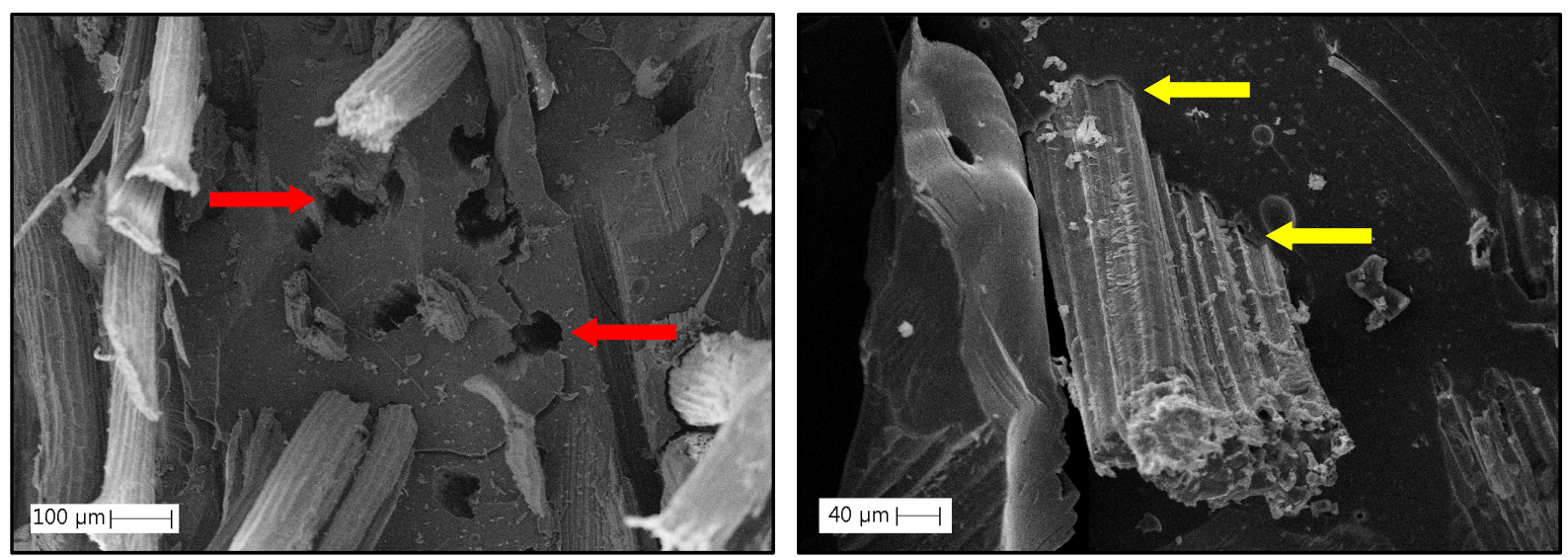

Figura 43. Imagens de MEV da superfície de fratura de compósitos fenólicos reforçados com fibras de sisal modificadas em $14 \mathrm{~h}$ imersão em lignosulfonato(aq) /2 h ultra-som (CF-FSM4). 


\subsubsection{Análise Térmica}

O objetivo da análise térmica é estudar o efeito do aquecimento sobre os materiais a fim de que a estabilidade destes possa ser avaliada para aplicações em diversos campos (SINGHA; THAKUR, 2008).

$\mathrm{Na}$ Figura 44a estão mostradas as curvas termogravimétricas para o termorrígido fenólico e para os compósitos fenólicos com fibras não-modificadas e modificadas em diverentes condições conforme descrito anteriormente (Tabela 1). Observa-se que os compósitos fenólicos apresentam estabilidade térmica menor, se comparados ao termorrígido fenólico, em consequência da presença das fibras de sisal que se decompõem em temperatura inferior à dos termorrígidos.

Pode se observar que até $250^{\circ} \mathrm{C}$ todos os compósitos apresentam estabilidade térmica semelhante. No entanto, em aproximadamente $160{ }^{\circ} \mathrm{C}$ o compósito de sisal preparado com fibra não-modificada (CF-FSNM), apresenta uma perda de massa de aproximadamente $4,5 \%$ nesta faixa de temperatura, relacionada à voltalização de moléculas de água, enquanto que nos compósitos preparados com fibras modificadas com lignosulfonato de sódio (CF-FSM1, CF-FSM2, CF-FSM3 e CF-FSM4) essa perda de massa corresponde à apenas 2,5\%, sugerindo que a adesão neste último foi maior, com menos espaço disponível para acomodar moléculas de água. 


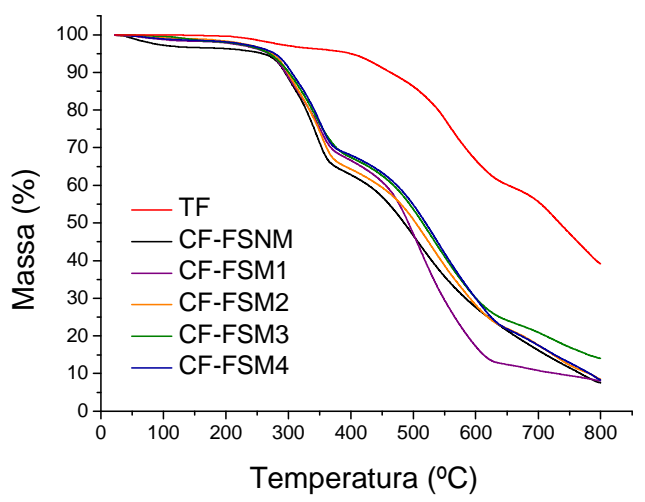

(a)

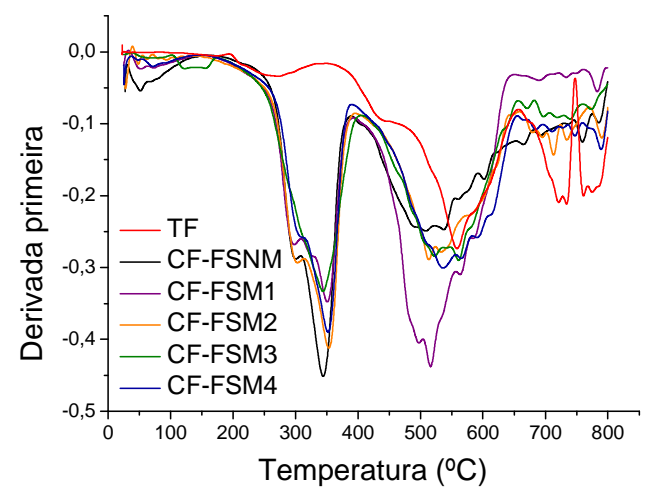

(b)

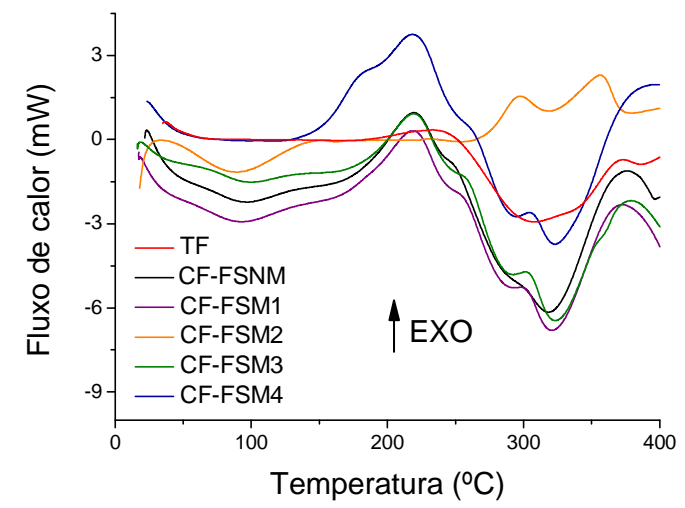

(c)

Figura 44. Curvas (a) TG, (b) dTG e (c) DSC para o termorrígido fenólico (TF) e compósitos fenólicos preparados com fibras de sisal não-modificadas (CF-FSNM) e modificadas (CF-FSM1, CF-FSM2, CF-FSM3 e CF-FSM4), atmosfera de $\mathrm{N}_{2}$, fluxo de $20 \mathrm{~mL} \mathrm{~min}^{-1}$ e razão de aquecimento de $10^{\circ} \mathrm{C} . \mathrm{min}^{-1}$.

A decomposição dos compósitos iniciou em aproximadamente $250{ }^{\circ} \mathrm{C}$, temperatura em que inicia também à decomposição da fibra de sisal. Nas curvas dTG para os compósitos fenólicos (Figura 44b) está evidente para todas as amostras um pico em aproximadamente $350{ }^{\circ} \mathrm{C}$, que é referente à decomposição da celulose. A decomposição do termorrígido inicia a partir de $400{ }^{\circ} \mathrm{C}$. $\mathrm{Na}$ curva dTG, os picos encontrados a partir de $500{ }^{\circ} \mathrm{C}$ podem estar relacionados à decomposição dos anéis aromáticos da resina fenólica.

As curvas refletiram o comportamento das fibras e do termorrígido, já discutidos previamente.

As curvas DSC para os compósitos fenólicos apresentam basicamente os mesmos eventos térmicos, que são mostrados na Figura 44c. Verificam-se picos exotérmicos em torno de $220^{\circ} \mathrm{C}$, que provavelmente estão relacionados à cura residual da matriz. Este 
pico não é observado para o compósito CF-FSM2, cujas fibras foram modificadas em ultra-som/1 h.

A vaporização de voláteis gerados por reações termooxidativas da matriz e a degradação da celulose das fibras podem ser fatores responsáveis pelo pico na região de $320{ }^{\circ} \mathrm{C}$ (PAIVA, 2006), que são encontrados na forma de endotermas para todos os compósitos fenólicos, exceto o CF-FSM2 que exibem-os exotermicamente.

De maneira geral, os compósitos fenólicos reforçados com fibras de sisal modificadas ou não-modificadas, apresentam comportamento térmico semelhante.

\subsubsection{Análise Térmica Dinâmico-Mecânica}

As propriedades dinâmico-mecânicas de compósitos reforçados com fibras dependem da natureza da matriz, da distribuição e orientação das fibras como reforço, da natureza da interface fibra-matriz e da região de interfase. Até mesmo uma pequena mudança na natureza química e física da fibra para uma dada matriz podem resultar em notáveis mudanças na dinâmica global propriedades dinâmico-mecânicas globais dos compósitos (IDICULA et al., 2009). A camada da matriz que recobre as fibras, imediatamente posterior a interface, pode ter propriedades diferentes do restante do material, pois as interações com as fibras podem alterar a mobilidade das cadeias polimericas da matriz (TRINDADE et al., 2005; PAIVA, FROLLINI, 2002).

A Figura 45 apresenta o módulo de armazenamento (E'), módulo de perda (E') e tan $\delta$, em função da temperatura, para o termorrígido fenólico e para os compósitos fenólicos reforçados com fibras de sisal modificadas ou não.

É possível perceber que a inserção de fibras em matriz fenólica aumenta consideravelmente o módulo de armazenamento do material reforçado (Figura 45a). 0 compósito CF-FSM2, cujas fibras foram modificadas em ultra-som/ 1h, foi o único que apresentou módulo de armazenamento superior ao compósito reforçado com fibras nãomodificadas. Este comportamento é coerente com resultados já apresentados em itens anteriores, como o maior valor de resistência ao Impacto Izod, e também módulo de flexão superior ao do compósito reforçado com fibras não-modificadas. Estes resultados, indicam que o tratamento aplicado à fibra de sisal (lignosulfonato/ultra-som/1 h) proporcionou aumento da adesão interfacial fibra/matriz. As demais modificações em fibras de sisal, geraram compósitos com módulo de armazenamento um pouco menor que o compósito reforçado com fibras não-modificadas, como mostrado na Figura 45a. 
Destaca-se que o módulo do termorrígido aumenta após $150{ }^{\circ} \mathrm{C}$, indicando entrecruzamento durante a varredura, o que não ocorreu para os compósitos.

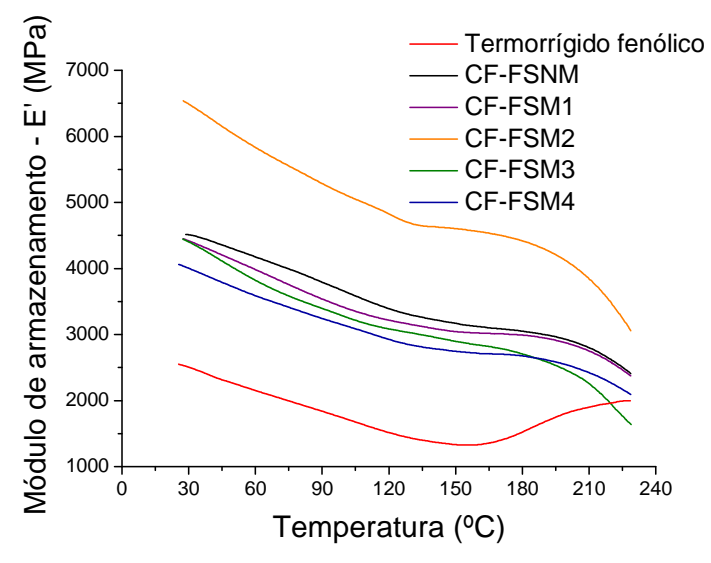

(a)

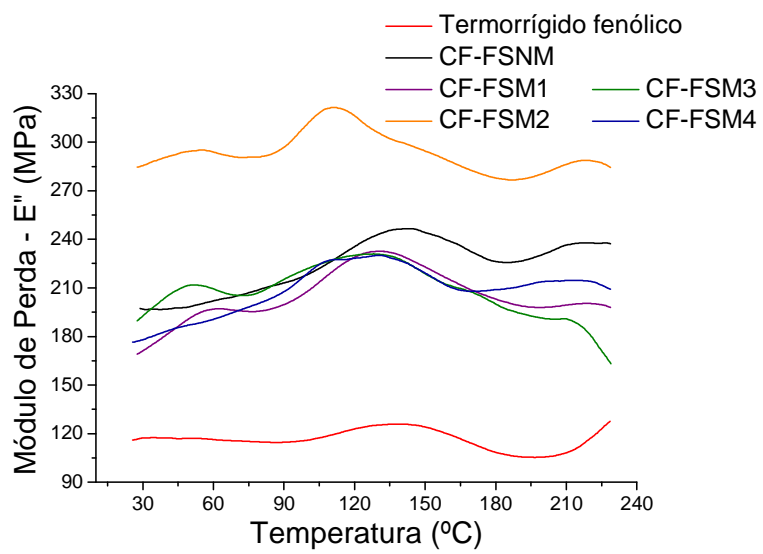

(b)

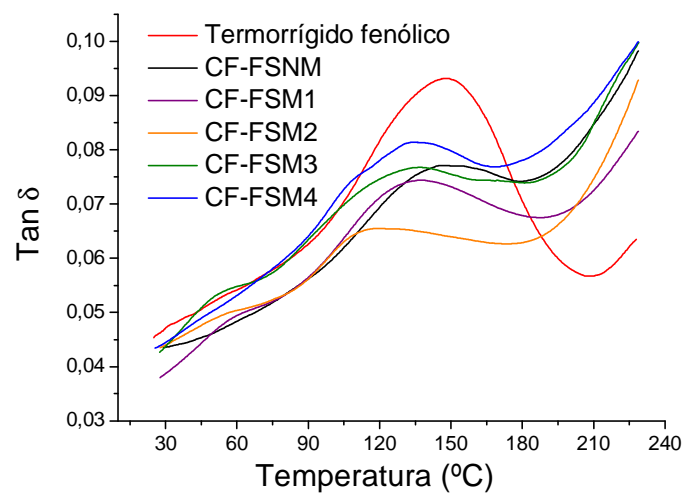

(c)

Figura 45. (a) Módulo de armazenamento ( $E$ ') em função da temperatura, (b) Módulo de perda ( $E$ ") em função da temperatura e (c) Tan $\delta$ em função da temperatura para o termorrígido fenólico (TF) e compósitos fenólicos reforçados com fibras sisal não-modificadas (CF-FSNM) e modificadas (CF-FSM1, CFFSM2, CF-FSM3, CF-FSM4).

O módulo de perda do termorrígido fenólico e dos compósitos estão mostrados na Figura 45b. O máximo da curva E" pode ser considerado como uma indicação do intervalo em que ocorre a transição vítrea do termorrígido fenólico, que se encontra em torno de 120 e $140{ }^{\circ} \mathrm{C}$. A transição vítrea é associada ao movimento de segmentos localizados entre pontos de entrecruzamento. Nos compósitos estes picos aparecem mais alargados, pois segmentos presente em camadas mais próximas à fibra se movimentam com maior dificuldade, devido às interações fibra/matriz. 


\subsubsection{Absorção de água}

Na Figura 46 pode-se observar as curvas de absorção de água para o termorrígido fenólico e compósitos fenólicos preparados com fibras modificadas e não-modificada. Destaca-se que este ensaio foi feito considerando amostras sem proteção lateral e imersas em água, a fim de simular as condições mais agressivas que o material poderia ser submetido quando em aplicação.

É possível observar que, após as fibras lignocelulósicas serem inseridas na matriz fenólica, ocorre um significativo aumento na absorção de água. A presença de grupos polares nos componentes da fibra lignocelulósica faz com que a fibra tenha uma maior interação com moléculas de água. Ainda, os volumes livres no interior das fibras e os possíveis vazios na região de interface fibra/matriz são fatores que podem contribuir para o aumento da absorção de água.

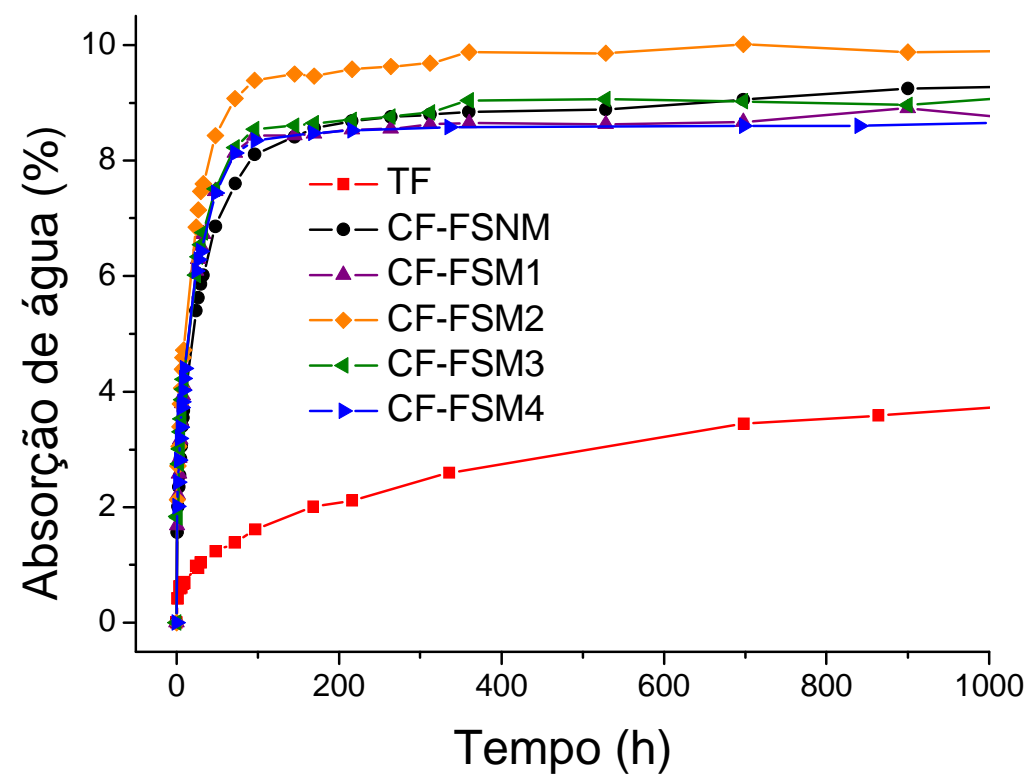

Figura 46. Resultados de absorção de água para o termorrígido fenólico (TF) e compósitos fenólicos (CF) reforçados com fibras de sisal não-modificadas (FSNM) e modificadas (FSM1, FSM2, FSM3 e FSM4)

Os compósitos fenólicos com fibras de sisal modificadas e não-modificadas apresentaram absorção de água semelhante (Figura 46), chegando a um máximo de aproximadamente 10\%. 0 compósito CF-FSM2, cujas fibras foram modificadas em ultrasom/1 h, apresentou absorção de água um pouco maior que os demais, sendo a diferença não significativa. Assim, os tratamentos aplicados para deposição de 
lignosulfonato nas fibras de sisal não influenciaram no comportamento dos compósitos reforçados por estas fibras em termos de absorção de água.

Para avaliar o tipo de mecanismo envolvido no processo de difusão de água nos compósitos contendo fibras modificadas de diversas maneiras aplicou-se a lei de Fick para a difusão. Os respectivos parâmetros foram calculados através de regressão linear das curvas de absorção de água, utilizando equações apresentadas no item 3.12.8 (gráficos se encontram no anexo 1).

O parâmetro $\mathrm{k}$ traz informações sobre a afinidade do material com água, tendo sido obtido um valor de 0,1 para o termorrígido fenólico e 0,2 para todos os compósitos fenólicos, como consequência da introdução de fibras hidrofílicas. Assim, se considera que os compósitos fenólicos preparados com fibras não-modificadas e modificadas apresentaram o mesmo mecanismo de difusão de moléculas de água para o interior do material, e também apresentam basicamente a mesma afinidade por água.

A afinidade do material compósito por água e governada, principalmente, pela natureza química dos componentes do compósito, sendo esta dependência mais pronunciada para a natureza química das fibras. Como neste estudo, foi adsorvida uma macromolécula (lignosulfonato) com características semelhantes à componentes presentes no material lignocelulósico, a natureza química das fibras de sisal não foi muito modificada, logo o parâmetro k não se alterou.

O coeficiente de difusão (D) para o termorrígido fenólico e para os compósitos em estudo são mostrados na Figura 47. O aumento do coeficiente $D$, que ocorre quando se passa do termorrígido para os compósitos, é explicado devido às interações fibra-matriz no compósito, que ocasiona uma menor quantidade de grupos polares livres para interagir com a água, via ligação hidrogênio, comparativamente ao termorrígido. Caso houvesse uma quantidade maior de grupos polares disponíveis, as ligações hidrogênio entre a água e o material desacelerariam a difusão destas moléculas no interior do material, aumentando D.

Para os compósitos de fibra não modificada (CF-FSNM) e fibra modificada em $2 \mathrm{~h}$ de ultra-som (CF-FSM3) não houve variação no valor deste coeficiente ( $D=24.10^{-3}$ $\left.\mathrm{mm}^{2} \cdot \mathrm{h}^{-1}\right)$, mostrando que a água se difundiu para o interior do material com a mesma habilidade. 


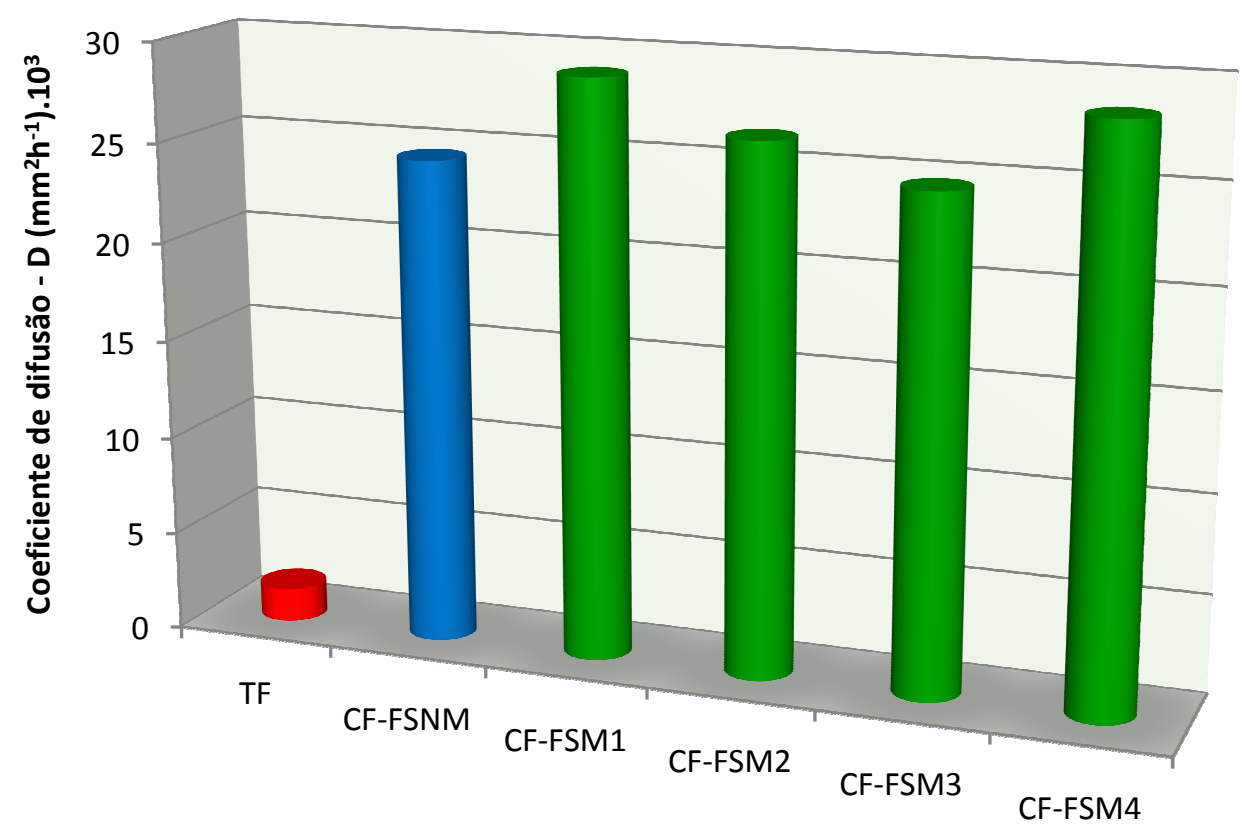

Figura 47. Coeficiente de difusão (D) para o termorrígido fenólico (TF) e compósitos fenólicos (CF) reforçados com fibras de sisal não-modificadas (FSNM) e modificadas (FSM1, FSM2, FSM3 e FSM4)

Para os compósitos de fibras modificadas via tratamento térmico (CF-FSM1), ultrasom/1 h (CF-FSM2), e via 14 h de imersão seguido de ultra-som/1 h (CF-FSM4) obtevese coeficientes de valores 29,26 e 28,5.10-3 $\mathrm{mm}^{2} . \mathrm{h}^{-1}$, respectivamente, indicando que houve difusão de água com maior rapidez nesses compósitos, se comparada ao compósito de fibra não modificada. Este aumento nos valores de D representa uma adesão fibra/matriz mais eficiente nestes compósitos, o que corrobora com resultados de resistência ao impacto. As fibras de sisal se tornaram menos expostas nestes materiais, fazendo com que a interação com as moléculas de água fosse menos intensa, aumentando a velocidade de difusão destas. 


\subsection{Caracterização dos compósitos de matriz lignosulfonato-formaldeído}

A placa do termorrígido lignosulfonato-formaldeído sem fibras, obtida após cura, se mostrou extremamente frágil, como pode ser observado na Figura 48a. Assim, não foi possível confeccionar corpos de prova com as dimensões requisitadas nos ensaios de resistência ao impacto, flexão, absorção de água e análise térmica dinâmico-mecânica para este tipo de termorrígido, para efeito de comparação com os compósitos. Portanto, pode-se afirmar que a introdução de fibras diminui consideravelmente a fragilidade do termorrígido, já que foi possível obter tais medidas para os compósitos (Figura 48b).

Como mencionado no procedimento experimental, nesta etapa do trabalho foram preparados apenas três tipos de compósitos de matriz lignosulfonato-formaldeído (CL). Além de preparar este tipo de compósito com fibras de sisal não-modificadas (FSNM), as fibras FSM1 e FSM2 foram escolhidas para preparar estes compósitos, devido aos maiores valores de resistência ao impacto obtidos, quando estas fibras reforçaram a matriz fenólica.

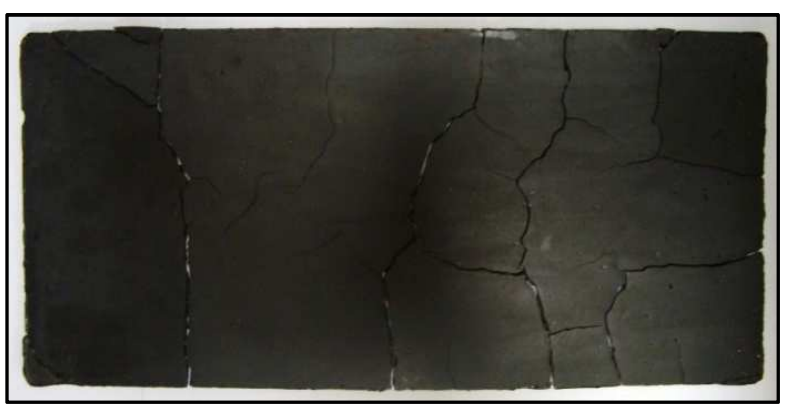

(a)

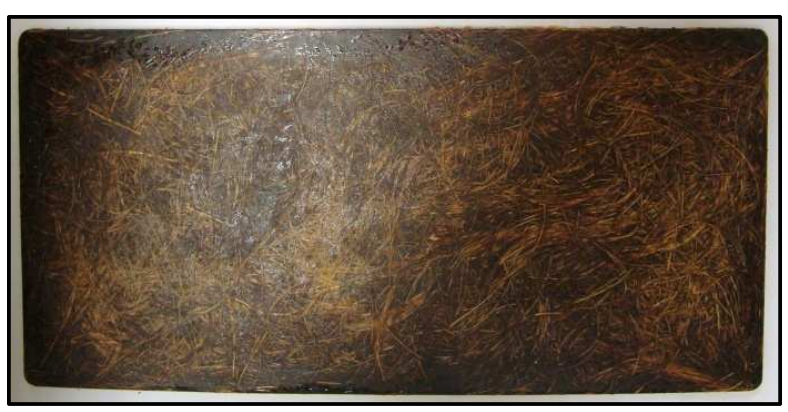

(b)

Figura 48. Fotografia de placa de termorrígido lignosulfonato-formaldeído sem fibras (a) e compósito de matriz lignosulfonato-formaldeído reforçado com fibra de sisal

Os compósitos de matriz lignosulfonato-formaldeído foram preparados primeiramente com 30\% de fibras de sisal e 70\% de resina lignosulfonato-formaldeído, assim como os compósitos fenólicos. No entanto, o aumento da molhabilidade das fibras fez com que essa proporção de resina fosse insuficiente para preencher toda placa do compósito, após a cura, devido à alta penetração da resina no interior da fibra. A Figura 49a mostra regiões de compósitos em que se observa a insuficiência de resina para moldagem. Esta observação fez com que excessos de resina fossem acrescentados na preparação destes compósitos. Para os compósitos preparados com fibras de sisal não- 
modificadas (CL-FSNM) e fibras modificadas em $70{ }^{\circ} \mathrm{C} / 1 \mathrm{~h}$ (CL-FSM1), foi necessário $40 \%$ de excesso de resina para que a placa fosse totalmente preenchida, como pode ser observado na Figura 49.

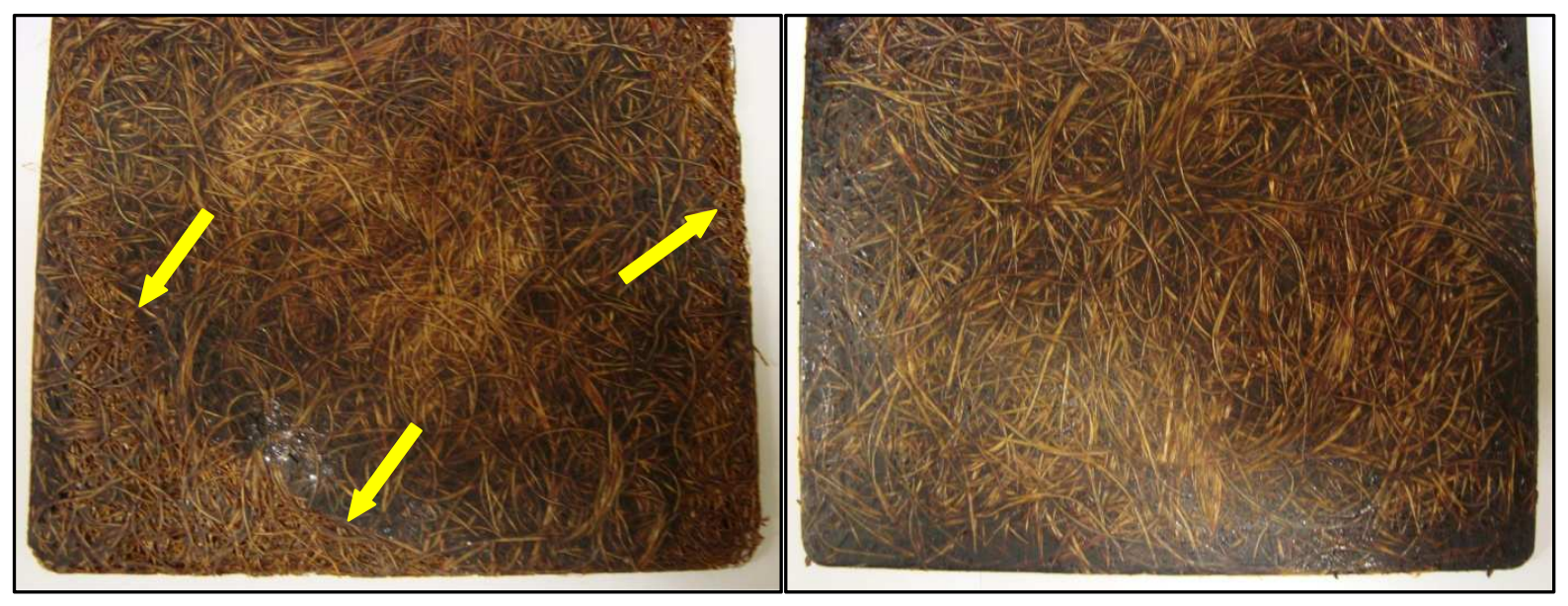

(a)

(b)

Figura 49. Fotografia de compósitos de matriz lignosulfonato-formaldeído reforçados com fibras de sisal.

(a) sem excesso de resina e (b) com excesso de resina.

Para o compósito preparado com fibras de sisal modificadas com ultra-som/1 $\mathrm{h}$ (CL-FSM2), os $40 \%$ de excesso de resina ainda não foram suficientes, assim sendo, preparou-se este compósito com excesso de 63\%. Ressalta-se que, nos compósitos em que foram adicionados excesso de resina, consequentemente a porcentagem final de fibra na matriz foi menor que 30\% (usada nos compósitos fenólicos), como mostrada na Tabela 10. 
Tabela 10. Porcentagem de fibras nos compósitos de matriz lignosulfonato-formaldeído conforme quantidade de resina utilizada no processamento.

\begin{tabular}{lc}
\multicolumn{1}{c}{ Compósito } & \% Fibras no compósito \\
\hline CL-FSNM sem excesso de resina & 30,0 \\
CL-FSM1 sem excesso de resina & 30,0 \\
CL-FSM2 sem excesso de resina & 30,0 \\
CL-FSNM com 40\% de excesso de resina & 25,8 \\
CL-FSM1 com 40\% de excesso de resina & 24,2 \\
CL-FSM2 com 40\% de excesso de resina & 23,5 \\
CL-FSM2 com 63\% de excesso de resina & 20,8 \\
\hline
\end{tabular}

Para os compósitos preparados com excesso de $40 \%$ de resina, as porcentagens finais de fibras não são idêntica entre si devido o vazamento de quantidades (cuidadosamente medidas) de resina do molde durante o processo de cura, o que por sua vez, revela de maneira indireta as quantidades reais de resina que eram necessária para molhar tais fibras e preencher todo molde.

\subsubsection{Resistência ao Impacto}

Os resultados de resistência ao impacto para os compósitos de matriz lignosulfonato-formaldeído reforçados com fibras de sisal, com excessos e sem excesso de resina, são mostrados na Figura 50. É evidente que nos compósitos em que a resina foi insuficiente, foram obtidos valores relativamente baixos de resistência ao impacto, se comparados ao que foram preparados com excesso de resina, provavelmente devido a alta quantidade de vazios que foi extremamente alta. 


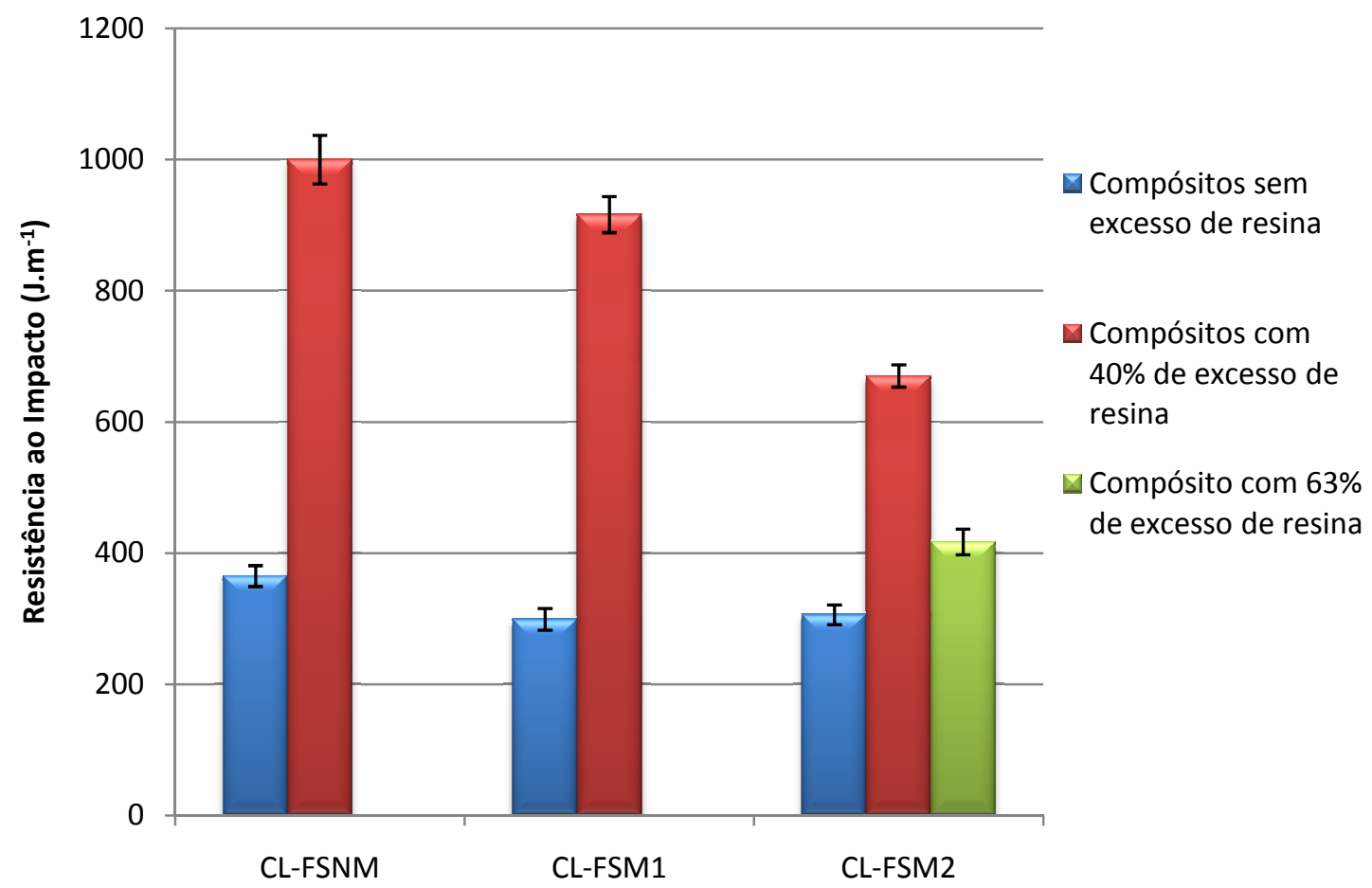

Figura 50. Resistência ao Impacto Izod (corpos de prova não entalhados) de compósitos de matriz lignosulfonato-formaldeído reforçados com fibras de sisal não-modificada (CL-FSNM) e modificadas (CLFSM1 e CL-FSM2).

0 termorrígido lignosulfonato-formaldeído sem fibras se apresentou extremamente frágil e menos resistente, se comparado ao termorrígido fenólico. Com a inserção de fibras, e acréscimo de resina (40\%), foram obtidos altos valores de resistência ao impacto, se comparados aos compósitos análogos preparados com matriz fenólica. Ressalta-se que todas amostras de compósitos de matriz lignosulfonatoformaldeído, que foram submetidos ao ensaio de impacto, apresentaram o fenômeno “fiber bridging”, como mostrado na Figura 51. Este fato é uma indicação de boa adesão na interface fibra/matriz. 


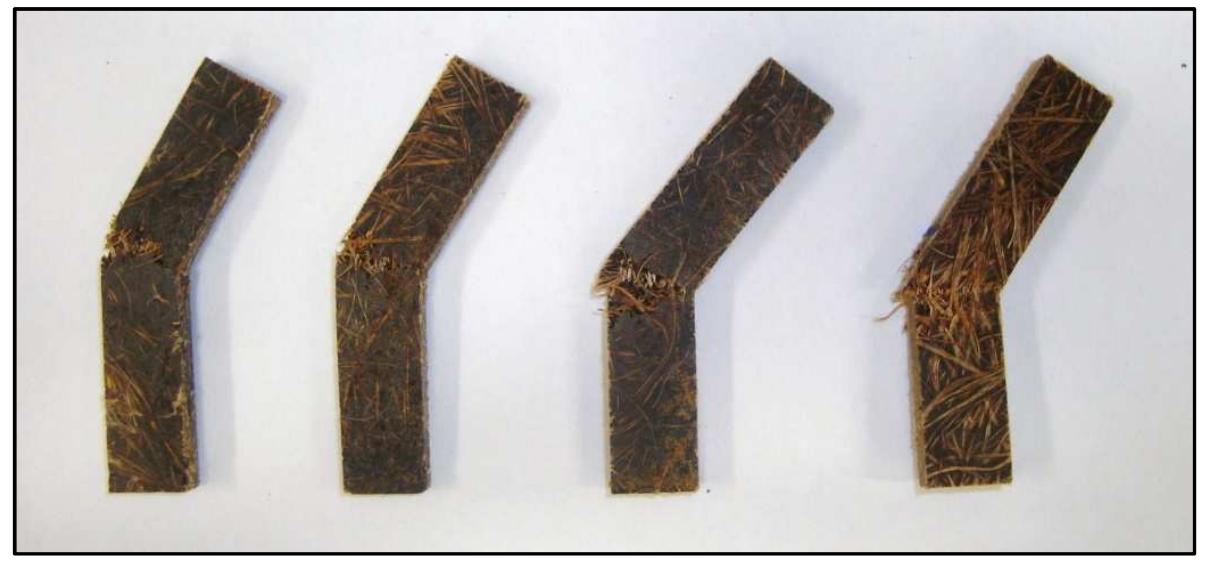

Figura 51. Fotografia de corpos de prova de compósitos de matriz lignosulfonato-formaldeído reforçados com fibras de sisal não-modificadas e modificadas (CL-FSNM, CF-FSM1 e CF-FSM2)

O compósito de matriz lignosulfonato-formaldeído preparado com fibras de sisal não modificadas (CL-FSNM) alcançou resistência ao impacto surpreendente de 1000 J.m 1, o que corresponde a um aumento de aproximadamente $130 \%$ do valor encontrado para o compósito fenólico reforçado com fibras de sisal não-modificadas (CF-FSNM), cuja resistência ao impacto foi em torno de $435 \mathrm{J.m}^{-1}$ (Figura 33). Quando as fibras modificadas (FSM1 e FSM2) foram inseridas na matriz lignosulfonato-formaldeído, com excesso de 40\%, observou-se também excelente aumento na resistência ao impacto destes compósitos (916 J.m-1 para CL-FSM1 e 670 J.m-1 para CL-FSM2) quando comparado aos compósitos fenólicos correspondentes (480 J.m-1 para CF-FSM1 e 511 J.m-1 para CF-FSM2). Estes resultados são relevantes, se comparado a outros compósitos de matrizes baseadas em ligninas e reforçados com fibras de sisal que já foram realizados no grupo de pesquisa no qual este trabalho se insere (PAIVA; FROLLINI, 2001; RAMIRES, 2010).

Os grupos polares presentes no lignosulfonato usado na preparação da matriz, aliado à presença de estruturas aromáticas típicas de lignina, devem em muito ter favorecido as interações com grupos polares e a lignina (presente na fibra), respectivamente, intensificando a adesão na interface, levando a uma eficiente transferência de carga da matriz para a fibra, durante o impacto.

Embora as modificações aplicadas às fibras de sisal, tanto via tratamento térmico (FSM1) quanto por ultra-som/1h (FSM2), tenham proporcionado aumento na resistência ao impacto de compósitos fenólicos, quando estas foram inseridas na matriz lignosulfonato-formaldeído, a resistência ao impacto diminui em relação ao compósito de mesma matriz preparado com fibras de sisal não-modificadas, mostrando que, neste 
grupo, a modificação introduzida na formulação da matriz foi mais importante que a das fibras.

Para o compósito CL-FSM3, mesmo aumentando o excesso de resina para $63 \%$, em busca do preenchimento de toda placa após cura em molde, a resistência ao impacto obtida foi menor do que para o compósito preparado com $40 \%$ de excesso de resina. Esse decréscimo pode ser associado ao aumento da quantidade de matriz neste compósito, sendo a matriz lignosulfonato-formaldeído mais frágil que a matriz fenólica.

As estruturas químicas semelhantes do lignosulfonato e da resina lignosulfonatoformaldeído, e a presença do primeiro na superfície da fibra não causaram o efeito de adesão fibra/matriz mais intenso que era esperado. Isso implica que para compósitos de matriz lignosulfonato-formaldeído, apenas as fibras de sisal não-modificadas, são necessárias para prover compósitos de elevado desempenho em termos de resistência ao impacto, não sendo prioridade as modificações em fibras do tipo que são citadas neste trabalho.

\subsubsection{Resistência à Flexão}

A Figura 52 mostra os resultados de resistência à flexão para os compósitos de matriz lignosulfonato-formaldeído preparados com fibras de sisal não-modificadas (CLFSNM) e modificadas (CL-FSM1 e CL-FSM2). Como citado anteriormente, não foi possível obter corpo-de-prova para o termorrígido sem fibras, visto a característica frágil do mesmo. De um modo geral, estes compósitos apresentam valores de resistência à flexão menores em relação aos compósitos fenólicos, preparados na etapa anterior deste trabalho. Esse decréscimo em relação aos compósitos fenólicos pode ser relacionado à maior fragilidade da matriz lignosulfonato-formaldeído comparativamente à matriz fenólica. 


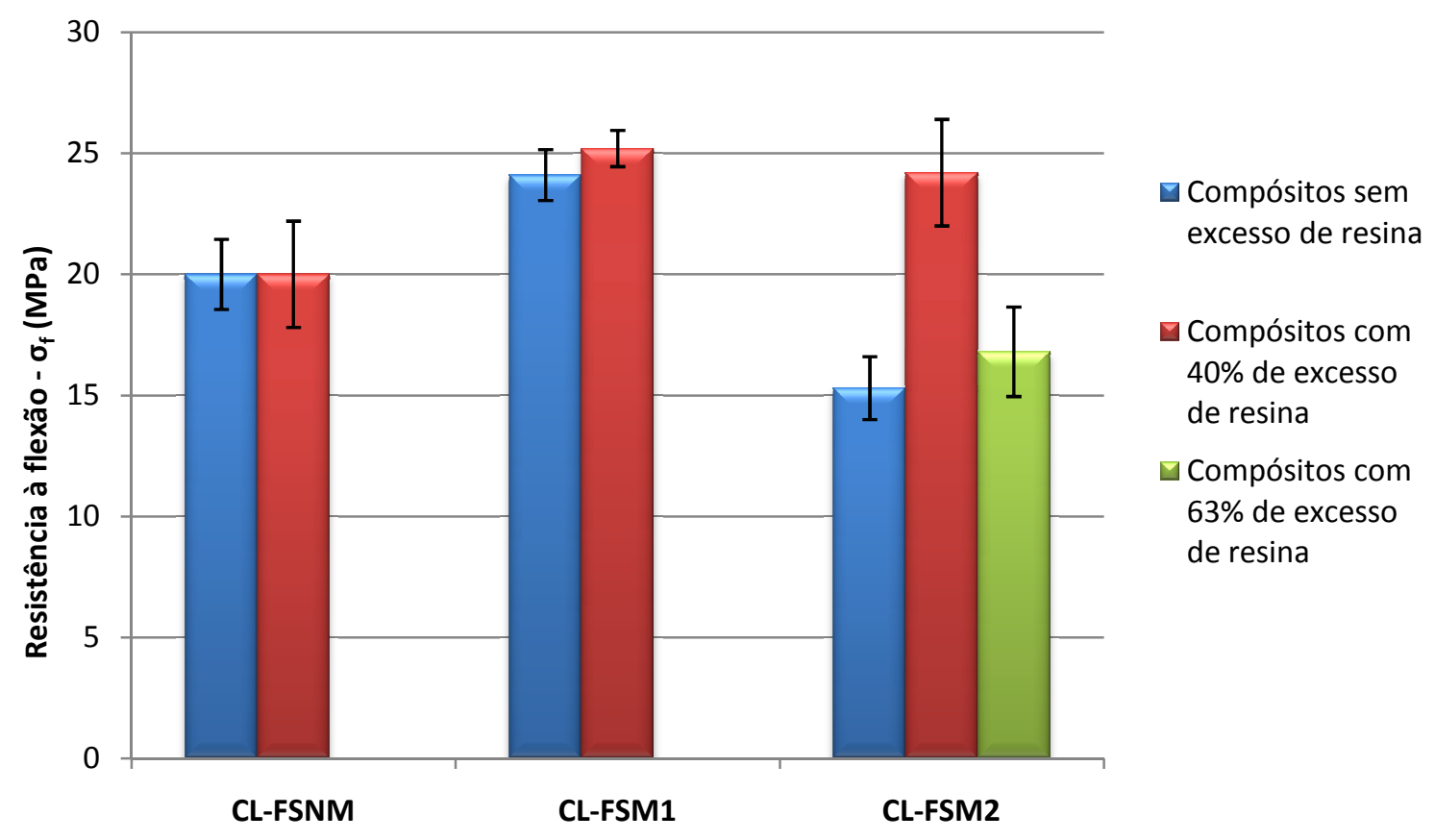

Figura 52. Resistência à flexão de compósitos de matriz lignosulfonato-formaldeído reforçado com fibras de sisal não-modificadas (CL-FSNM) e modificadas (CL-FSM1 e CL-FSM2)

Os compósitos de matriz lignosulfonato-formaldeído reforçados com fibra de sisal não modificadas (CL-FSNM), apresentaram resistência à flexão similar (20 MPa), para as amostras preparadas sem excesso e com $40 \%$ de excesso de resina. Considerando-se 0 desvio-padrão, pode-se dizer que os compósitos CL-FSM1, sem excesso e com 40\% de excesso, também apresentaram resultados próximos (em torno de $25 \mathrm{MPa}$ ). 0 compósito CL-FSM2, preparado com 40\% de excesso de resina, apresentou resistência à flexão maior que aqueles preparados sem excesso de resina e com $63 \%$ de excesso de resina.

Em se tratando dos compósitos preparados com 40\% de excesso de resina, as modificações aplicadas às fibras de sisal, contribuíram para o aumento da resistência à flexão dos respectivos compósitos.

O módulo de elasticidade para os compósitos em estudo são mostrados na Figura 53. Os compósitos de matriz lignosulfonato-formaldeído, de maneira geral, apresentaram módulos de elasticidade menores, com valores máximos em torno de 2 GPa, comparativamente aos compósitos fenólicos, que apresentaram valores entre 3 e 6 GPa. 


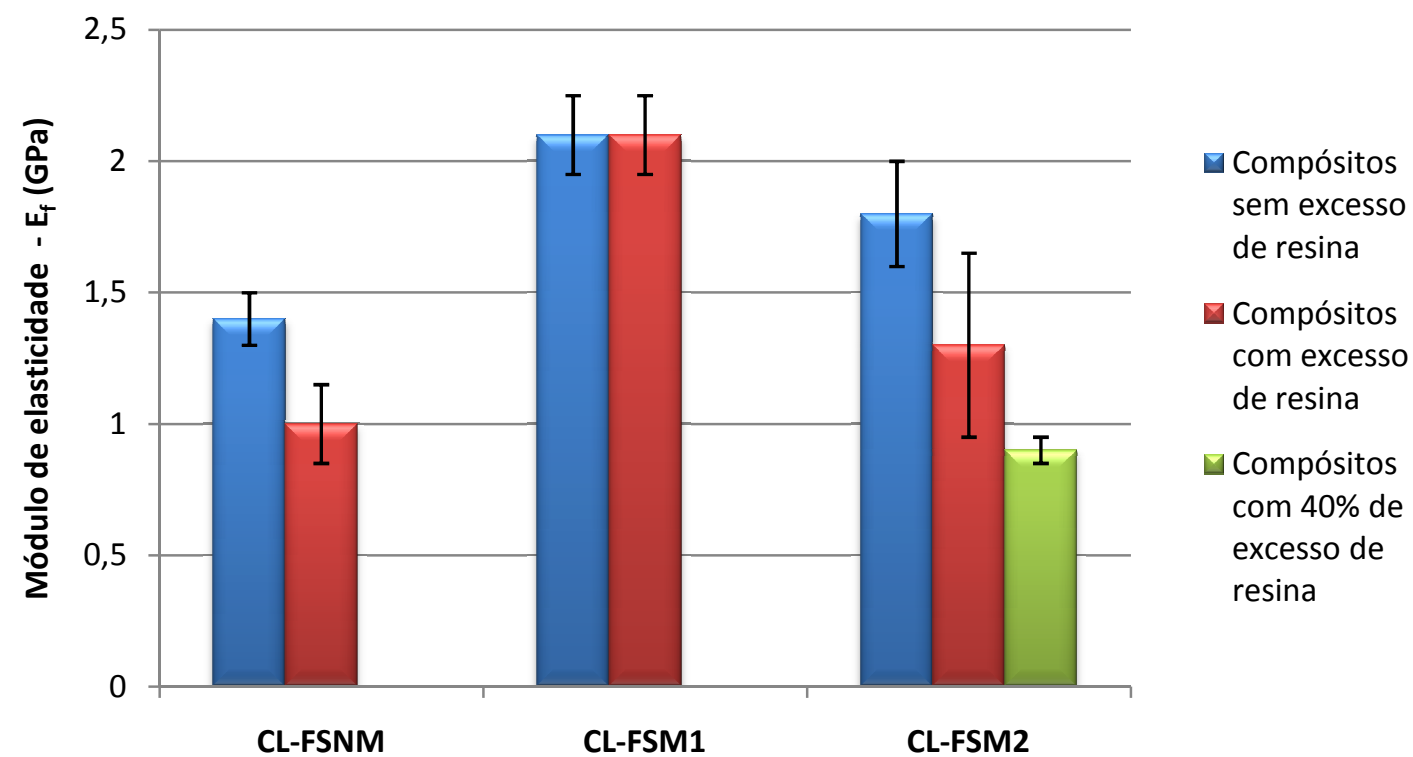

Figura 53. Módulo de flexão de compósitos de matriz lignosulfonato-formaldeído (CL) reforçados com fibras de sisal não-modificada (FSNM) e modificadas (FSM1 e FSM2).

A matriz lignosulfonato-formaldeído é propensa a ser mais higroscópica que a matriz fenólica, devido ao maior número de grupos presentes em sua estrutura que podem interagir com a água, quando comparado à resina fenólica. As moléculas de água presentes na amostra podem agir como plastificantes e tornar estes compósitos menos rígidos do que os compósitos fenólicos.

Para o compósito CL-FSM2, ocorreu um decréscimo no módulo de elasticidade conforme se aumentou a quantidade de resina. Este comportamento pode ser explicado pela fragilidade e também pela higroscopicidade da matriz lignosulfonato-formaldeído.

\subsubsection{Microscopia eletrônica de varredura (MEV)}

A Figura 54 apresenta as imagens de MEV para a superfície de fratura em $\mathrm{N}_{2}$ líquido do termorrígido lignosulfonato-formaldeído, uma vez que não foi possível realizar ensaio de impacto deste material. Os microvazios observados, indicados pelas setas vermelhas, são relativamente bem menores que os encontrados no termorrígido fenólico. Ainda assim, as imagens revelam uma estrutura frágil. 


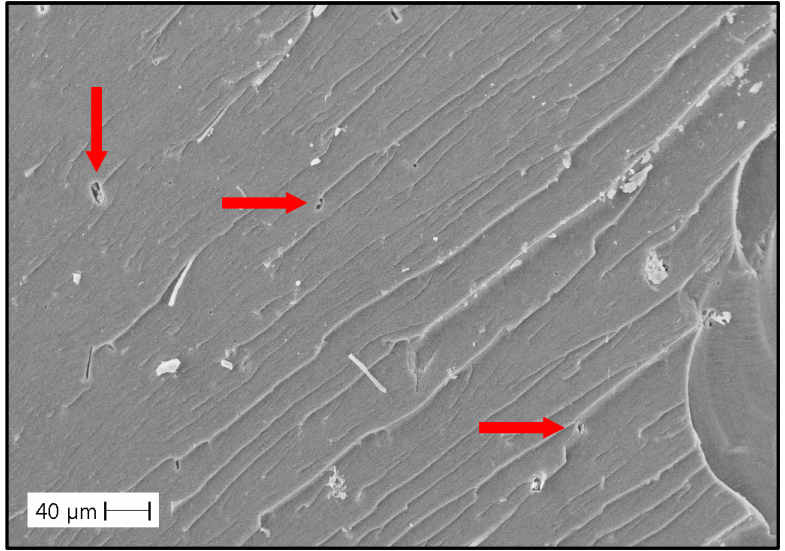

(a)

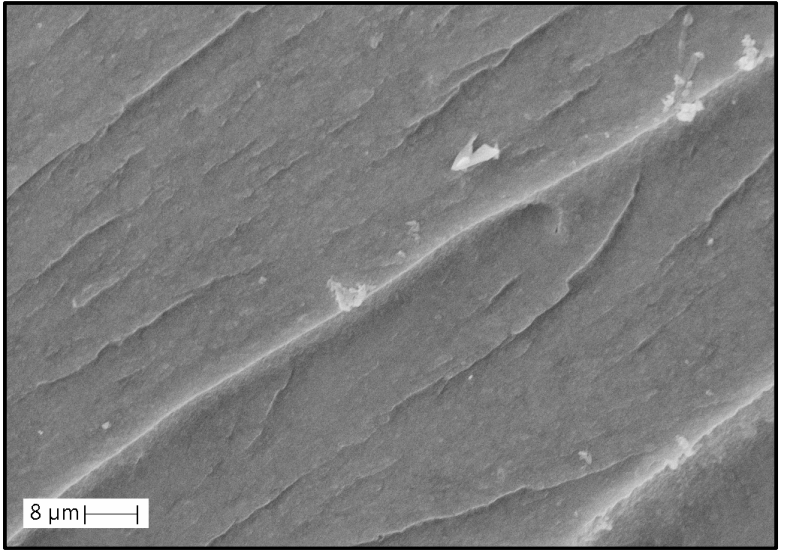

(b)

Figura 54. Imagens de MEV da superfície fraturada em $\mathrm{N}_{2}(\mathrm{l})$ do termorrígido lignosulfonato-formaldeído.

Após o ensaio de impacto dos compósitos de matriz lignosulfonato-formaldeído reforçados com fibras de sisal não-modificada e modificadas, tentou-se obter imagens de MEV da superfície de fratura.

A Figura 55 mostra a superfície de fratura dos compósitos preparados com fibras de sisal modificadas e não-modificadas, sem excesso de resina. Podem-se observar as fibras expostas devido o estilhaçar da matriz durante o ensaio de impacto (CL-FSNM, Figura 55a). É evidente a presença de trincas na matriz, indicadas por setas vermelhas, em todos os compósitos sem excesso de resina. Observa-se também estilhaços de matriz próximos as fibras, indicados por setas verdes. Estas observações condizem com os resultados de impacto, que foram mais baixos para os compósitos em que a quantidade inicial de resina foi insuficiente. Ainda assim, foram observadas algumas regiões em que a matriz estava bem aderida às fibras, sugerindo um recobrimento eficiente (seta amarelas), provavelmente devido à sua estrutura química semelhante a da lignina presente na superfície da fibra. 


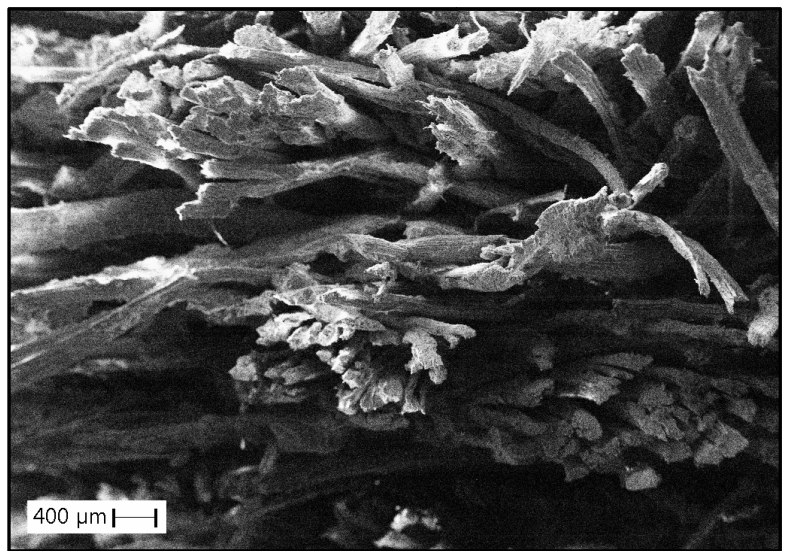

(a)

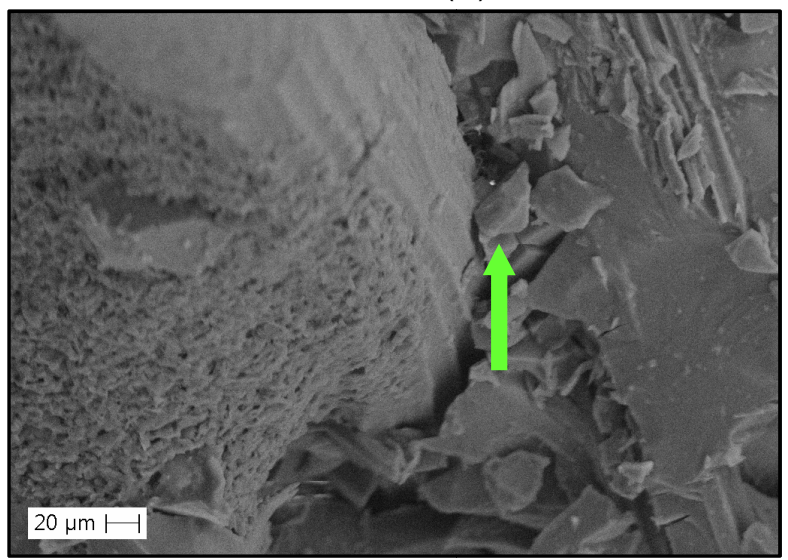

(c)

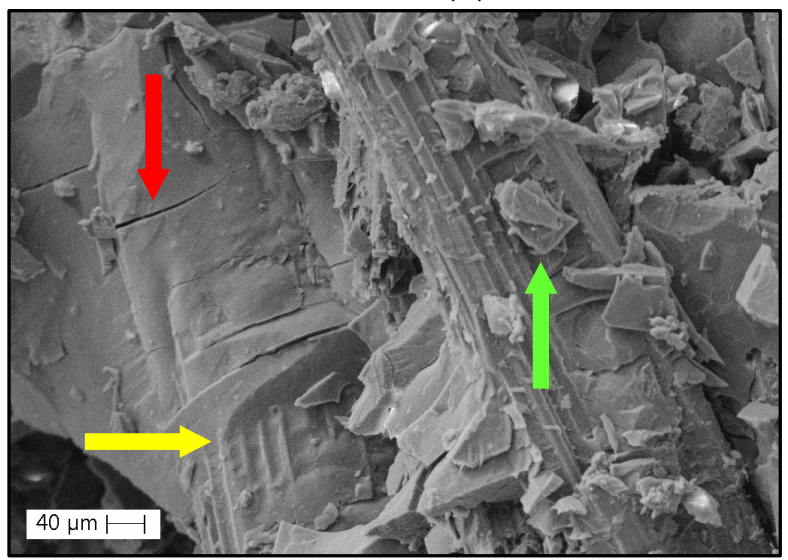

(e)

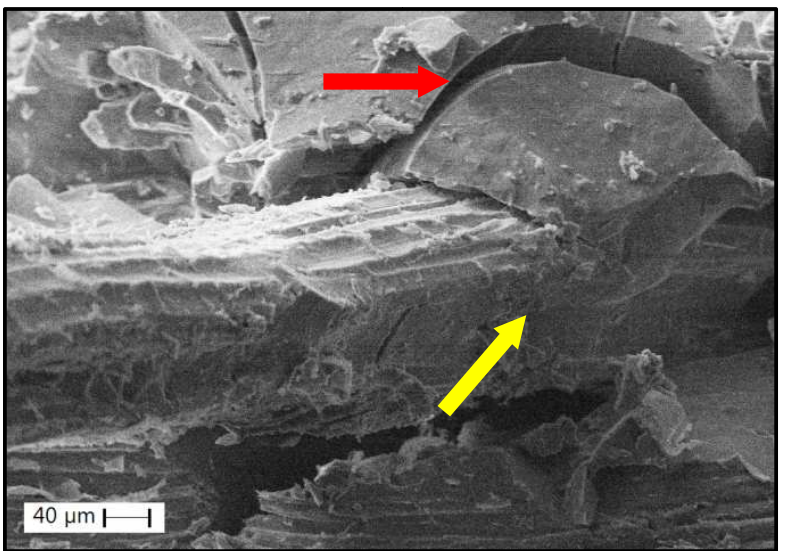

(b)

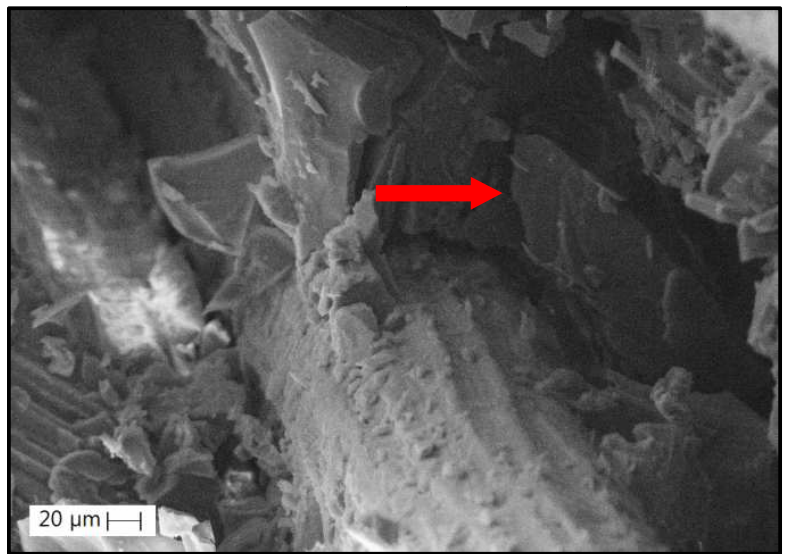

(d)

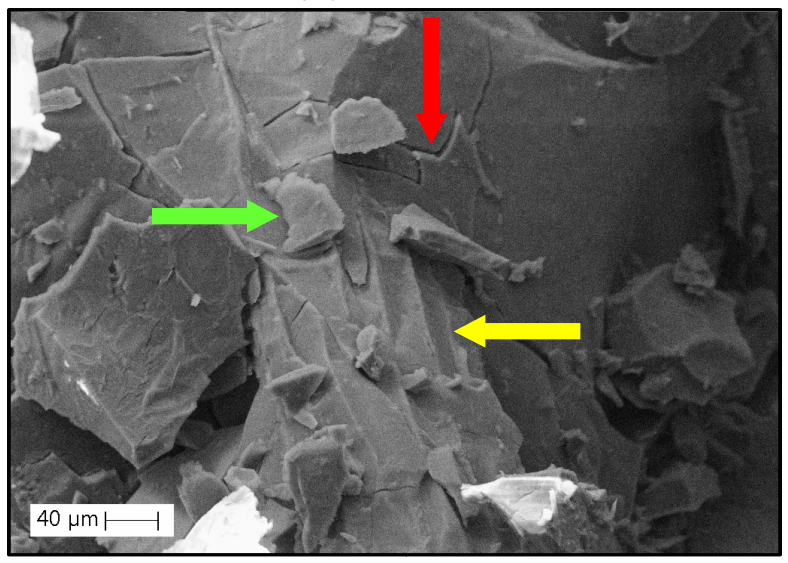

(f)

Figura 55. Imagens de MEV da superfície de fratura de compósitos de matriz lignosulfonato-formaldeído preparados sem excesso de resina. (a) e (b) CL-FSNM: compósito com fibras de sisal não-modificadas; (c) e (d) CL-FSM1: compósito com fibras de sisal modificadas a $70^{\circ} \mathrm{C} / 1 \mathrm{~h}$; (e) e (f) CL-FSM2: compósito com fibras de sisal modificadas em ultra-som/ $1 \mathrm{~h}$

As superfícies de fratura dos compósitos de matriz lignosulfonato-formaldeído preparados com 40 e 63\% de excesso de resina são mostradas na Figura 56. Para os compósitos com fibras modificadas com 40\% de excesso (CL-FSM1 e CL-FSM2) e com $63 \%$ de excesso (CL-FSM2), foi possível obter imagens em que mostra claramente a 
matriz aderida eficientemente sobre a fibra, Figura 56b e Figura 56c. Não foi possível obter mais imagens do compósito CL-FSNM, além da Figura 56a, no entanto, é válido lembrar que o compósito CL-FSNM alcançou uma resistência de impacto superior aos demais, logo se supõe que a adesão/fibra matriz tenha sido intensa, como as observadas para os compósitos de fibras modificadas (CL-FSM1 e CL-FSM2).

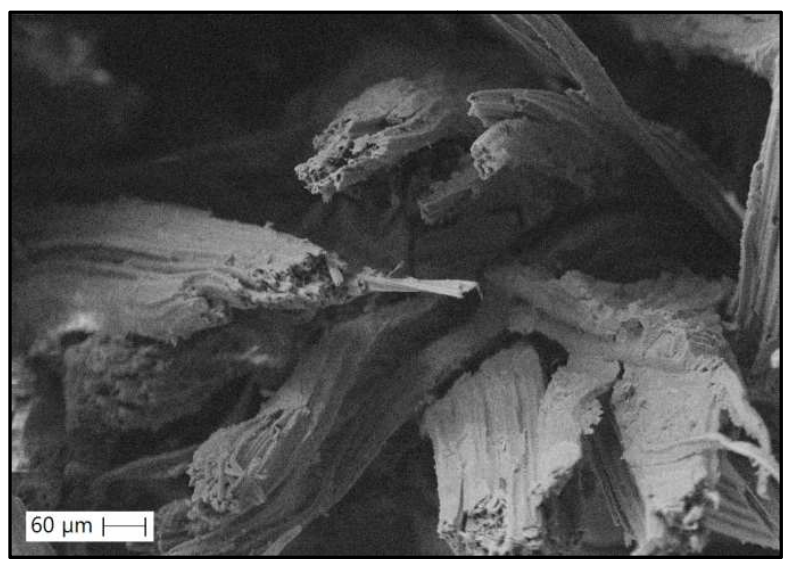

(a)

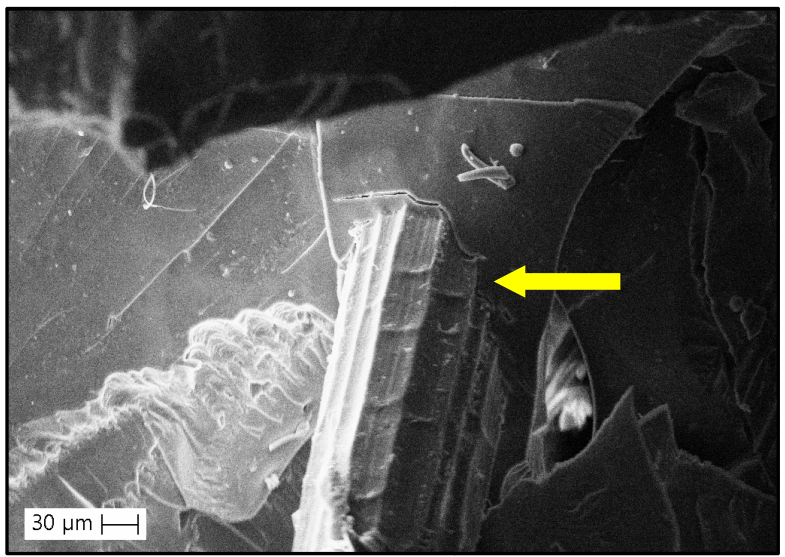

(c)

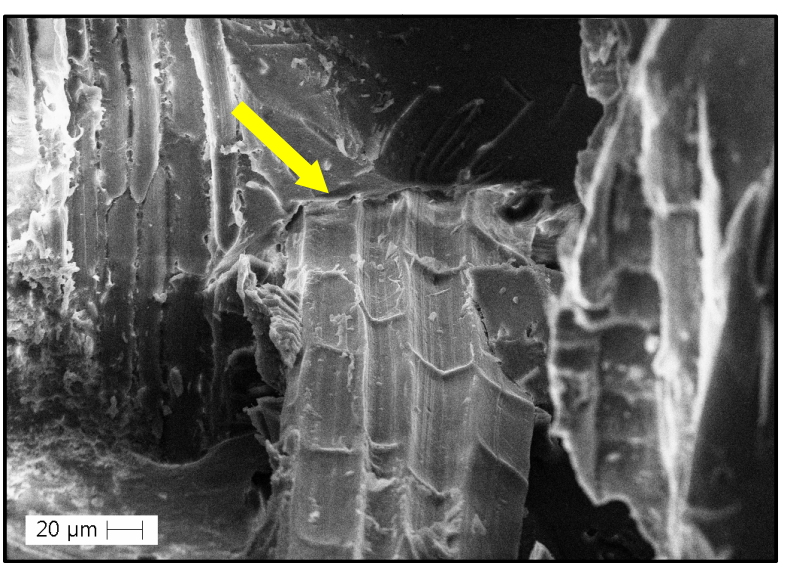

(b)

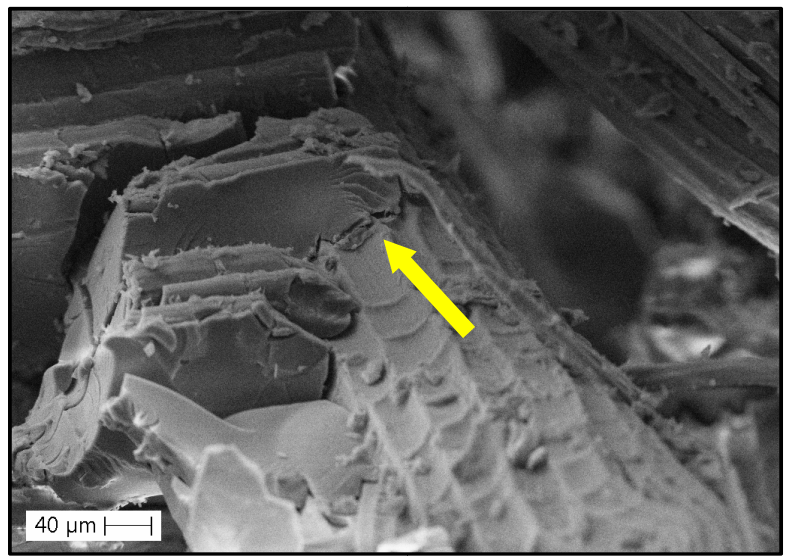

(d)

Figura 56. Imagens de MEV da superfície de fratura de compósitos de matriz lignosulfonato-formaldeído preparados com excesso de resina. (a) CL-FSNM: compósito com fibras de sisal não-modificadas - com $40 \%$ de excesso; (b) CL-FSM1: compósito com fibras de sisal modificadas em $70^{\circ} \mathrm{C} / 1 \mathrm{~h}-$ com $40 \%$ de excesso; (c) CL-FSM2: compósito com fibras de sisal modificadas em ultra-som/1 h - com $40 \%$ de excesso e (d) CL-FSM2: compósito com fibras de sisal modificadas em ultra-som/1 $\mathrm{h}$ - com $63 \%$ de excesso.

Para todos os compósitos apresentados nesta seção, não foi observado ocorrência do mecanismo "pull-out", que indica uma forte interação fibra/matriz. 


\subsubsection{Análise Térmica}

Na Figura 57 estão mostradas as curvas TG, dTG e DSC, respectivamente, para o termorrígido lignosulfonato-formaldeído (TL) e compósitos de matriz lignosulfonatoformaldeído $(\mathrm{CL})$ reforçados com fibras modificadas e não-modificadas. As análises foram realizadas considerando os compósitos preparados com $40 \%$ de excesso de resina, visto que os materiais componentes de cada compósito são os mesmos, e a quantidade de amostra é muito pequena, não sendo necessário realizar as medidas para outras porcentagens de excesso de resina.

A curva dTG apresenta um pico em aproximadamente $330{ }^{\circ} \mathrm{C}$ para todos compósitos, que pode ser atribuído à decomposição térmica da celulose presente nas fibras de sisal. Essa decomposição também é confirmada por picos endotérmicos na curva DSC (Figura 57c), encontrados na mesma região de temperatura. Para o termorrígido, esse pico pode representar o início da decomposição de grupos relacionados ao lignosulfonato, constituinte da matriz.

Os compósitos de matriz lignosulfonato-formaldeído apresentaram próximo a $800{ }^{\circ} \mathrm{C}$ (Figura 57a), uma maior quantidade de massa do que para os compósitos fenólicos. Isto pode estar relacionado à presença de íons $\mathrm{Na}^{+}$na resina lignosulfonatoformaldeído, como mencionado anteriormente. Ainda, os compósitos CL apresentam menor quantidade de massa que o TL em $800{ }^{\circ} \mathrm{C}$, devido à presença das fibras nos compósitos. 


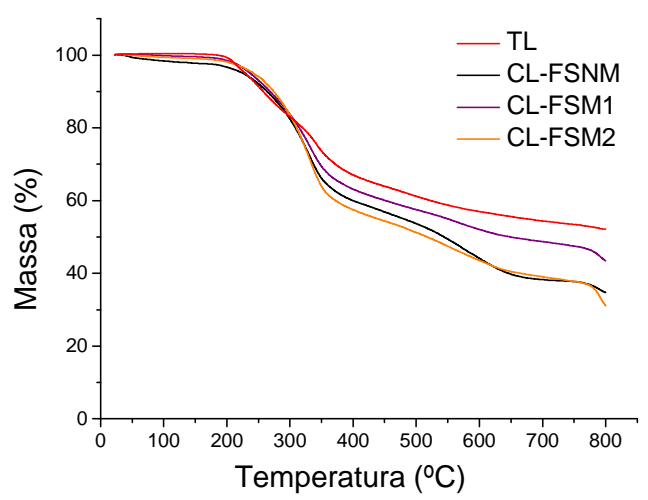

(a)

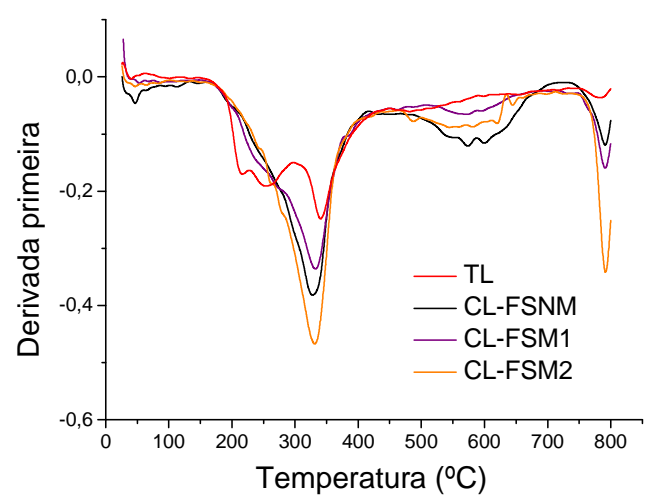

(b)

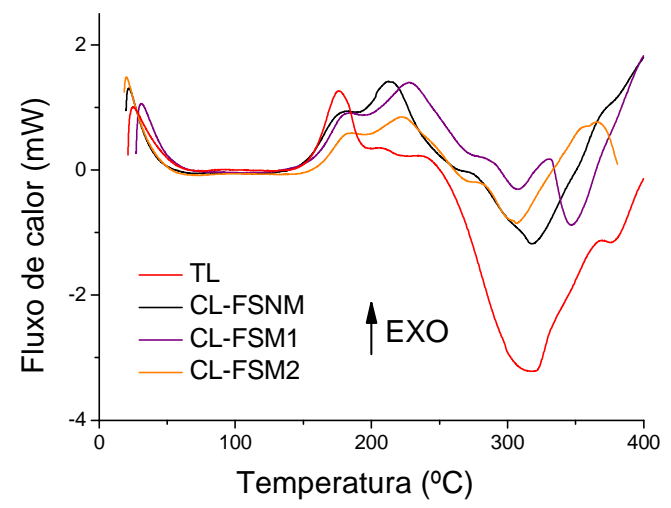

(c)

Figura 57. Curvas (a) TG, (b) dTG e (c) DSC para o termorrígido lignosulfonato-formaldeído (TL) e compósitos de matriz lignosulfonato-formaldeído reforçados com fibras de sisal não-modificadas (CLFSNM) e modificadas (CL-FSM1 e CL-FSM2), atmosfera de $\mathrm{N}_{2}$, fluxo de $20 \mathrm{~mL}$.min-1 e razão de aquecimento de $10^{\circ} \mathrm{C} \cdot \mathrm{min}^{-1}$.

De maneira geral, as curvas de análise térmica refletem o comportamento do termorrígido lignosulfonato-formaldeído e das fibras, já mostrados anteriormente. Assim sendo, a presença do lignosulfonato de sódio na superfície das fibras de sisal após as modificações, não alterou o comportamento térmico dos compósitos preparados com estas fibras.

\subsubsection{Análise térmica dinâmico-mecânica}

A análise termica dinâmico-mecânica foi realizada apenas para os compósitos de matriz lignosulfonato-formaldeído preparados com 40\% e 25\% de excesso de resina, uma vez que não foi possível obter corpos de prova para aqueles que foram preparados sem excesso de resina. 
Os compósitos de matriz lignosulfonato-formaldeído (CL) apresentaram valores de módulo de armazenamento menores (Figura 58a) comparativamente aos compósitos fenólicos (CF) (Figura 45a). A substituição total do fenol por lignosulfonato deve ter diminuído o entrecruzamento da matriz, pois o lignosulfonato é uma macromolécula e seu grande volume pode ter causado um impedimento estérico, dificultando a formação de ligações cruzadas entre os segmentos das cadeias (RAMIRES, 2010). Um menor grau de entrecruzamento seria responsável pela menor rigidez do compósito, justificando os menores valores de E' obtidos para os compósitos de matriz lignosulfonato-formaldeído comparativamente aos compósitos fenólicos.

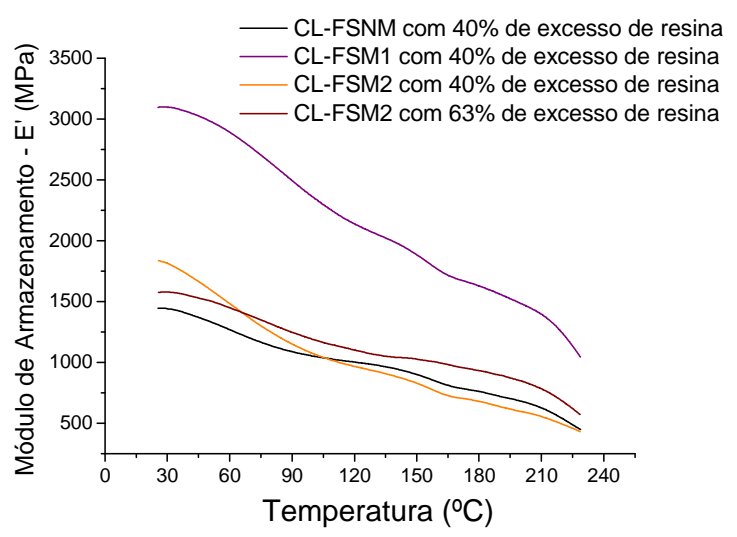

(a)

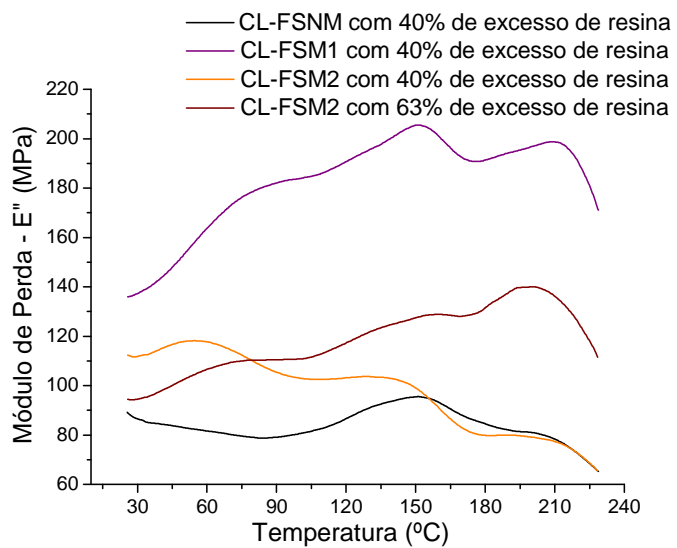

(b)

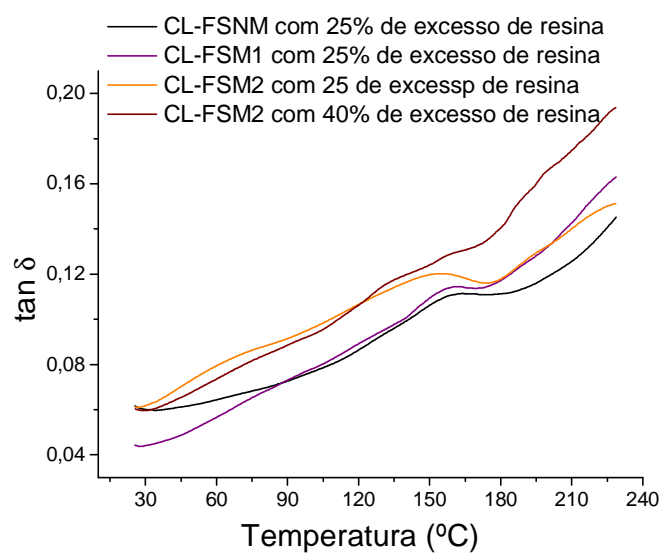

(c)

Figura 58. (a) Módulo de armazenamento ( $E$ ') em função da temperatura, (b) Módulo de perda ( $E$ ") em função da temperatura e (c) Tan $\delta$ em função da temperatura para os compósitos de matriz lignosulfonatoformaldeído reforçados com fibras sisal modificadas e não-modificadas.

Os valores de E' para o compósito CL-FSM1 foram maiores se comparados aos compósitos de matriz lignosulfonato-formaldeído preparados com fibras nãomodificadas. Esse acréscimo nos valores de E' pode indicar interação fibra-matriz mais 
intensa neste compósito. Para os compósitos CL-FSNM e CL-FSM2 (com 40 e 25\% de excesso), a diferença nos módulos de armazenamento não foram significativas.

A transição vítrea dos compósitos de matriz lignosulfonato-formaldeído encontrase em torno de $150{ }^{\circ} \mathrm{C}$, como mostra o comportamento do módulo de perda (E") (Figura 58b) para estes compósitos. Este valor de temperatura é próximo ao encontrado para os compósitos fenólicos.

\subsubsection{Absorção de água}

As curvas de absorção de água para todos compósitos de matriz lignosulfonatoformaldeído, com ou sem excesso de resina, são mostradas na Figura 59. Conforme já citado, não foi possível obter amostras do termorrígido lignosulfonato-formaldeído sem fibras. Era esperado que, para os compósitos sem excesso de resina, ou seja, em que a quantidade de resina foi insuficiente para preenchimento de toda placa do compósito, a absorção de água fosse superior àqueles em que os compósitos foram devidamente preenchidos pela resina. A grande quantidade de vazios e a maior exposição das fibras foram os fatores decisivos para esta maior absorção de água.

Os compósitos de matriz lignosulfonato-formaldeído com $40 \%$ de excesso de resina apresentaram porcentagens de absorção de água razoavelmente diferentes entre si. O compósito CL-FSNM chegou a aproximadamente 9\%, enquanto que o compósito CLFSM1 alcançou os 13\%. O compósito CL-FSM2 mostrou uma absorção de água ao redor de 3\%, o que é relevante, se comparado aos outros compósitos de mesma matriz. Para efeito de comparação, é válido ressaltar que os compósitos fenólicos, preparados na etapa anterior deste trabalho, mostraram absorção de água semelhantes entre si, e alcançaram um máximo de aproximadamente $9 \%$. 


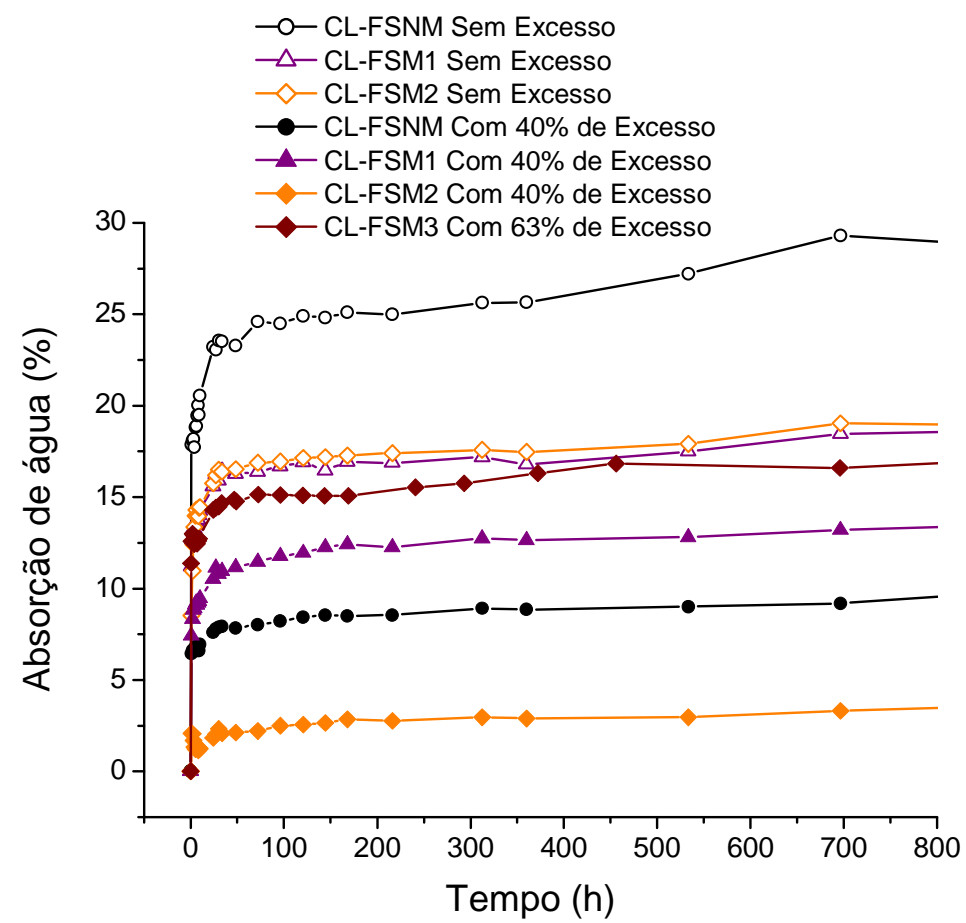

Figura 59. Curvas de absorção de água para compósitos de matriz lignosulfonato-formaldeído reforçado com fibras de sisal não-modificadas (CL-FSNM) e modificadas (CL-FSM1 e CL-FSM2), e preparados com diferentes proporções de resina.

Para avaliar o mecanismo envolvido no processo de difusão de água nos compósitos lignosulfonato-formaldeído utilizou-se a lei de Fick para a difusão, descrita no item 3.12.8. Os gráficos utilizados para o cálculo dos parâmetros k e D encontram-se no anexo 1. Os compósitos preparados sem excesso de resina, ou com excesso de 40\%, apresentaram valores de $\mathrm{k}$ de 0,5 ou 0,6 . Somente com excesso de $63 \%$ o valor de $\mathrm{k}$ passou para 0,7 , possivelmente devido a maior disponibilidade de grupos polares para interação com água.

O coeficiente de difusão (D) para os compósitos de matriz lignosulfonatoformaldeído são apresentados na Figura 60. Os valores de D para CL-FSNM e CL-FSM1, quando estes compósitos foram preparados sem excesso de resina, são um pouco maiores que quando preparados com $40 \%$ de excesso de resina. Quanto maior o valor de D, mais rápida é a difusão das moléculas de água no interior do material. Provavelmente, os grupos sulfonatos introduzidos em maior quantidade quando excesso de resina foi utilizado, são os responsáveis por isto, já que têm afinidade por água, e as interações envolvidas desaceleram as moléculas de água, diminuindo D. 


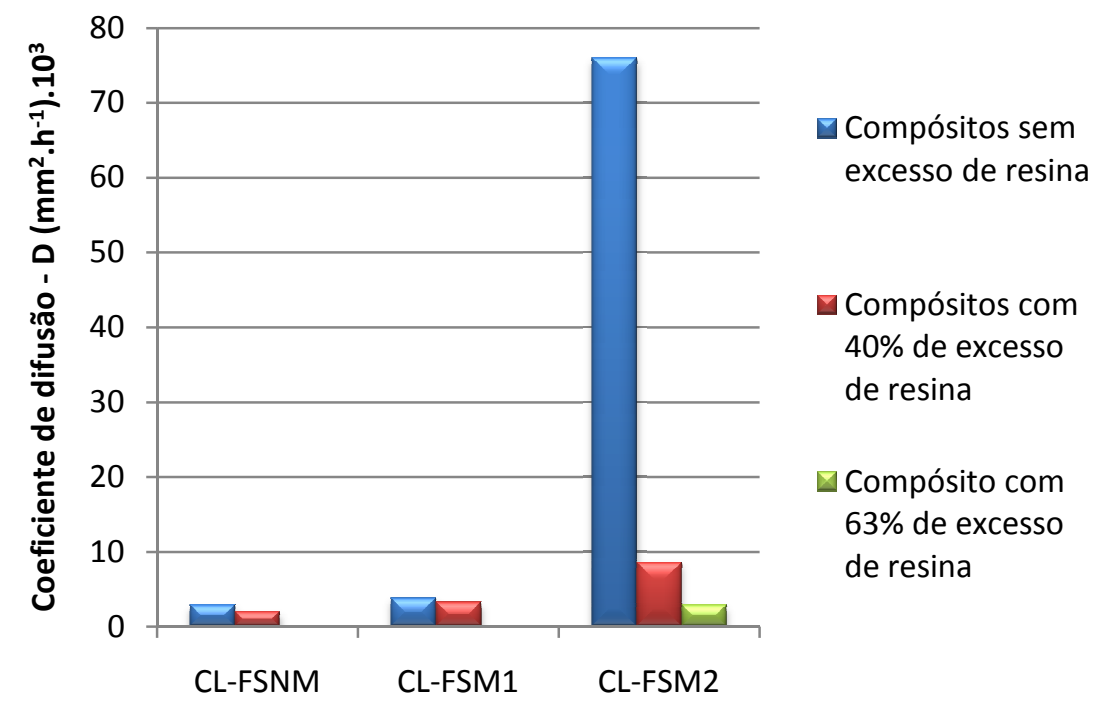

Figura 60. Coeficiente de difusão (D) para compósitos de matriz lignosulfonato-formaldeído reforçados com fibras não-modificadas (CL-FSNM) e fibras modificadas (CL-FSM1 e CL-FSM2), em diferentes proporções de resina.

Para o compósito CL-FSM2 o valor de D para o material preparado sem excesso é muito superior aos preparados com 40\% e 63\% de excesso de resina. Neste caso, provavelmente a elevada quantidade de vazios observada no compósito preparado sem exceso de resina, facilitou uma rápida difusão de água para o interior do material, o que correspondeu ao fator mais importante do processo, e não a influência das interações intermoleculares.

No presente trabalho, as matrizes correspondem a termorrígidos (e não a termoplásticos, constituídos por cadeias individuais), portanto com espaços disponíveis entre os entrecruzamentos, com grupos polares, sendo estas matrizes reforçadas por fibras lignocelulósicas hidrofílicas, o que leva o material com certa complexidade no que diz respeito aos mecanismos envolvidos na absorção de água. Deve-se ressaltar que a utilização do modelo de Fick para os materiais preparados corresponde a uma tentativa de usar os resultados obtidos de forma comparativa, no sentido de correlacionar os mesmos com outras propriedades avaliadas, e não de rigorosamente considerar os valores individuais obtidos para os respectivos parâmetros. 


\subsection{Condutividade térmica e difusividade térmica de termorrígidos e compósitos}

A condutividade térmica de um material é definida como a taxa em que calor é trocado através de uma área unitária, quando o material está sujeito a um gradiente de temperatura unitário.

A condutividade térmica dos polímeros é bem baixa, quando comparada com a condutividade de materiais metálicos, e de alguns materiais cerâmicos (SANTOS, 2003). $\mathrm{Na}$ Tabela 11, são apresentados as propriedades dos materiais avaliados no presente estudo. Foi empregado um método indireto para determinação da condutividade térmica, o método de pulso de energia, em que primeiramente é obtida a difusividade térmica, e a partir desta propriedade, obteve-se condutividade térmica.

Tabela 11. Difusividade térmica, capacidade térmica, densidade e condutividade térmica para termorrígido fenólico (TL), compósitos fenólicos reforçados com fibras de sisal não modificada (CF-FSNM) e modificada

(CF-FSM2: ultra-som/1 h), termorrígido lignosulfonato-formaldeído (TL) e compósito de matriz lignosulfonato-formaldeído reforçado com fibras de sisal não-modificadas (CL-FSNM).

\begin{tabular}{|c|c|c|c|c|c|}
\hline Amostra & $\mathrm{T}\left({ }^{\circ} \mathrm{C}\right)$ & $\begin{array}{c}\alpha \text { Difusidade } \\
\text { térmica(1) } \\
\left(* 10^{-7} \mathrm{~m}^{2} \cdot \mathrm{s}^{-1}\right)\end{array}$ & $\begin{array}{c}C_{p}(2) \\
\left(J \cdot \mathrm{kg}^{-1} \cdot K^{-1}\right)\end{array}$ & $\begin{array}{c}\rho \text { Densidade }^{(3)} \\
\left(\mathrm{kg} \cdot \mathrm{m}^{-3}\right)\end{array}$ & $\begin{array}{c}\lambda \text { Condutividade } \\
\text { térmica(4) } \\
\left(\mathrm{W} \cdot \mathrm{m}^{-1} \cdot \mathrm{K}^{-1}\right)\end{array}$ \\
\hline \multirow{3}{*}{ TF } & 10 & $1,59 \pm 0,01$ & 1105 & $1250 \pm 10$ & $0,22 \pm 0,01$ \\
\hline & 25 & $1,43 \pm 0,01$ & 1187 & $1248 \pm 10$ & $0,21 \pm 0,01$ \\
\hline & 50 & $1,29 \pm 0,04$ & 1321 & $1244 \pm 10$ & $0,21 \pm 0,01$ \\
\hline \multirow{3}{*}{ CF-FSNM } & 10 & $1,93 \pm 0,03$ & 1105 & $1265 \pm 10$ & $0,27 \pm 0,01$ \\
\hline & 25 & $2,26 \pm 0,12$ & 1187 & $1263 \pm 10$ & $0,34 \pm 0,02$ \\
\hline & 50 & $2,01 \pm 0,04$ & 1321 & $1259 \pm 10$ & $0,33 \pm 0,01$ \\
\hline \multirow{3}{*}{ CF-FSM2 } & 10 & $1,85 \pm 0,04$ & 1105 & $1248 \pm 10$ & $0,26 \pm 0,01$ \\
\hline & 25 & $1,75 \pm 0,03$ & 1187 & $1246 \pm 10$ & $0,26 \pm 0,01$ \\
\hline & 50 & $1,98 \pm 0,01$ & 1321 & $1242 \pm 10$ & $0,32 \pm 0,01$ \\
\hline \multirow{3}{*}{ TL } & 10 & $1,59 \pm 0,01$ & 1105 & $1346 \pm 10$ & $0,24 \pm 0,01$ \\
\hline & 25 & $1,68 \pm 0,11$ & 1187 & $1344 \pm 10$ & $0,27 \pm 0,02$ \\
\hline & 50 & $1,59 \pm 0,05$ & 1321 & $1340 \pm 10$ & $0,28 \pm 0,01$ \\
\hline \multirow{3}{*}{ CL-FSNM } & 10 & $1,60 \pm 0,06$ & 1105 & $1330 \pm 10$ & $0,24 \pm 0,01$ \\
\hline & 25 & $1,55 \pm 0,04$ & 1187 & $1328 \pm 10$ & $0,24 \pm 0,01$ \\
\hline & 50 & $1,60 \pm 0,06$ & 1321 & $1324 \pm 10$ & $0,28 \pm 0,01$ \\
\hline
\end{tabular}

(1) Determinação via método flash - método analítico de determinação de Difusividade Térmica via estimativa de parâmetros por mínimos quadrados não-lineares baseada na solução analítica da equação 
de calor pelo método dos quadrupolos térmicos; valores iniciais obtidos pelo método de Momentos temporais (Degiovanni). Softwares Diffu.m v.3.0 .

(2) Dados obtidos pela equação:

$\mathrm{C}_{p}=0,1264 \mathrm{E} 4+0,9556 * \mathrm{~T}+0,01457 * \mathrm{~T}^{2}-\left(0,6881 \mathrm{E} 5 / \mathrm{T}^{2}\right)$; de 20 a $50^{\circ} \mathrm{C}$; valor a $10^{\circ} \mathrm{C}$ extrapolado linearmente.

Fonte; Composite Science and Technology 29 (1987) 189-210.

(3) $\quad \rho=$ densidade geométrica medida a $25^{\circ} \mathrm{C}$; coeficiente de expansão térmica considerado $\alpha=4 \mathrm{E}^{-5}$ $\mathrm{K}^{-1}$; densidade corrigida pela equação:

$[1-3 \alpha(T-25)] \rho$

Fonte: Handbook of Condensed Matter and Material Data. W. Martienssen, H. Warlinmont, Springer 2005, $1119 \mathrm{p}$.

(4) Condutividade térmica calculada pelo produto: $\lambda=\alpha \cdot C_{p} . \rho$

Carvalho, Frollini e Santos (2003) relataram a condutividade térmica do termorrígido fenólico $\left(0,265 \pm 3 \% W \cdot m^{-1} \cdot K^{-1}\right)$ e do termorrígido lignofenólico $(0,286 \pm 4 \%$ W. $\mathrm{m}^{-1} \cdot \mathrm{K}^{-1}$ ), em que a lignina substitui $30 \%$ do fenol na formulação, tendo sido estas condutividades avaliadas pelo método do fio quente. Os resultados obtidos para o termorrígido fenólico e termorrígido lignosulfonato-formaldeído, mostrados na Tabela 11, são próximos aos resultados encontrados na literatura, embora os métodos usados tenham sido diferentes. Embora nos compósitos parte do termorrígido seja substituído por fibras, isto praticamente não levou a alteração na condutividade térmica, pois os compósitos fenólicos e lignosulfonato-formaldeído reforçados com fibras de sisal apresentaram condutividade próxima de seus respectivos termorrígidos. Ainda, a condutividade térmica dos materiais não apresentou variação significativa no intervalo de 10 a $50{ }^{\circ} \mathrm{C}$, o que indica que na aplicação, variações de temperatura neste intervalo não afetam esta propriedade.

Takagi et al. (2007) prepararam compósitos de poli(ácido lático) reforçados com fibras de bambu e caracterizaram estes materiais segundo a condutividade térmica. Ao comparar os resultados com compósitos reforçados com fibras de vidro e carbono, eles notaram que os compósitos reforçados com fibras lignocelulósicas apresentaram condutividade térmica de cerca de 50\% menor que os compósitos reforçados com fibras sintéticas (vidro e carbono). Segundo os autores, a razão desse decréscimo seria que a celulose, principal componente das fibras lignocelulósicas, apresenta condutividade térmica muito inferior às fibras de vidro e carbono (TAKAGI et al., 2007). 


\section{CONCLUSÕES}

De acordo com os resultados obtidos, pode-se concluir que foi acertada a escolha do lignosulfonato de sódio como agente de compatibilização em compósitos de matriz termorrígida fenólica. Os tratamentos aplicados nas fibras de sisal com lignosulfonato de sódio, associados à irradiação ultra-som, consistem em tratamentos promissores, pois modificam a morfologia da superfície das fibras sem levar a alterações drásticas, sendo que a separação dos feixes de fibra que ocorre permite melhor interação fibra/matriz na interface.

Estes tratamentos foram mais eficientes que aqueles via reações químicas, já realizados nas fibras de sisal (PAIVA; FROLLINI, 2006; MEGIATTO et al., 2007a; MEGIATTO et al., 2008), as quais levaram a intensa adesão fibra matriz, mas, o meio reacional em que as fibras foram modificadas foi agressivo para estas, levando a uma ação como reforço menos eficiente.

Os resultados de resistência ao impacto mostraram que as fibras modificadas via adsorção do lignosulfonato por aquecimento e irradiação com ultra-som, ambos tratamentos com $1 \mathrm{~h}$ de duração, levaram a compósitos fenólicos com melhores propriedades mecânicas (480 J.m-1 e 511 J.m-1).

A escolha do lignosulfonato como macromonômero na preparação da resinas fenólicas também foi acertada, pois foi possível obter compósitos com elevados valores resistência ao impacto (1000 J.m-1), se comparados aos compósitos de matriz fenólica. Ainda, em trabalhos anteriores, lignina do tipo organossolve foi utilizada como substituta do fenol em resinas fenólicas, levando a compósitos com resistência em torno de 512 J.m-1.

As modificações nas fibras de sisal, para os compósitos de matriz lignosulfonatoformaldeído, não provocaram os efeitos esperados nas propriedades mecânicas destes materiais. No entanto, observou-se pelas imagens de MEV uma boa adesão na interface fibra/matriz, resultado da semelhança químico-estrutural entre a matriz e a fibra de sisal, mostrando que, neste caso, a modificação na formulação da matriz foi o fator que mais influenciou as propriedades dos materiais.

Os termorrígidos, assim como os compósitos, apresentaram condutividade térmica próxima, ou seja, a presença de fibras de sisal não alterou a condutividade do 
material, o que indica que estes materiais reforçados podem ser usados em aplicações em que esta propriedade seja importante.

As propriedades dos materiais aqui investigados fazem com que estes se tornem atraentes para aplicações nas indústrias automobilística e aeronáutica (aplicações não estruturais), com a vantagem que na sua produção são utilizados materiais oriundos de fontes renováveis, como as fibras lignocelulósicas e o lignosulfonato, assim como tratamentos que visam modificação da superfície das fibras que ocorrem via aquecimento e a irradiação com ultra-som, o que vem de encontro às atuais políticas de sustentabilidade e preservação do meio-ambiente. 


\section{REFERÊNCIAS}

ACHA, B. A.; MARCOVICH, N. E.; REBOREDO, M. M. Lignin in Jute Fabric-Polypropylene Composites. Journal of Applied Polymer Science , v. 113, n. 3, p. 2480-1487, 2009.

ADLER, E. Lignin chemistry - past, present and future. Wood Science and Technology, v. 11, n. 3, p. 169-218, 1977.

ALEMDAR, A.; SAIN, M. Biocomposites from wheat straw nanofibers: Morphology, thermal and mechanical properties. Composites Science and Technology, v. 68, p. 557-565, 2008

ALONSO, M. V.; RODRÍGUEZ, J.; OLIET, M.; RODRÍGUEZ, F.; GILARRANZ, M. A.; GARCÍA, J. Caracterización de lignosulfonatos como etapa previa a su hidroximetilación. In: CONGRESSO IBEROAMERICANO DE INVESTIGACIÓN EM CELULOSA Y PAPEL, 2000, Iguazú, Argentina. Anais... . Iguazú: 2000. 1p.

BERLIN, A. A.; VOLFSON, S. A.; ENIKOLOPIAN, N. S.; NEGMATOV, S. S. Principles of polymer composites. Berlin: Springer-Verlag, 1986. 124p.

BISCEGLI, C. I. Conceitos da física do ultra-som. São Carlos: Embrapa Instrumentação Agropecuária, USP, 2004. 18 p. (Série Documentos)

BISMARCK, A.; MISHRA, S.; LAMPKE, T. Plant Fibers as Reinforcement for Green Composites. In: MOHANTY, A. K.; MISRA M.; DRZAL, L. T. (Ed.). Natural fibers, biopolymers, and biocomposites. Boca Raton: Taylor \& Francis, 2005. p. 37-108.

BLEDZKI, A.K.; GASSAN, J. Composites Reinforced with Cellulose Based Fibres. Progress in Polymer Science, v. 24, p. 221-274, 1999.

BLEDZKI, A.K.; REIHMANE, S.; GASSAN, J. Properties and Modification Methods for Vegetable Fibers for Natural Fiber Composites. Journal of Applied Polymer Science, v. 59, p. 1329-1336, 1996.

BOTARO, V. R.; SIQUEIRA, G.; MEGIATTO JR., J. D.; FROLLINI, E. Sisal fibers treated with $\mathrm{NaOH}$ and benzophenonetetracarboxylic dianhydride as reinforcement of phenolic matrix. Journal of Applied Polymer Science, v. 115, p. 269-276, 2010.

BRODOS, E.; PILLIN, I.; MONTRELAY, N.; BALEY, C. Could biopolymers reinforced by randomly scattered flax fibre be used in structural applications? Composites Science and Technology, v. 67, n. 3-4, p. 462-470, 2007.

BUSCHLEDILLER, G.; ZERONIAN, S. H. Enhancing the reactivity and strength of cotton fibers. Journal of Applied Polymer Science, v. 45, n. 6, p. 967-979, 1992.

CALLISTER, W. D. Materials science and engineering: an Introduction. New York: John Wiley \& Sons, 2007. 975 p. 
CANEVAROLO JUNIOR, S. V. Análise térmica dinâmico-mecânica. In: CANEVAROLO JUNIOR, S. V. (Ed.). Técnicas de caracterização de polímeros. São Paulo: Artliber, 2004b. p. 263-283.

CANEVAROLO JUNIOR, S. V. Cromatografia de exclusão por tamanho. In: CANEVAROLO JR., S. V. (Ed). Técnicas de caracterização de polímeros. São Paulo: Artliber, 2004a. p. 117-145.

CANTO, L. B.; PESSAN, L. A. Resistência à tração, flexão e compressão. In: CANEVAROLO JUNIOR, S. V. (Ed.). Técnicas de caracterização de polímeros. São Paulo: Artliber, 2004b. p. 342-360.

CARVALHO, G.; PIMENTA, J. A.; SANTOS, W. N.; FROLLINI, E. Phenolic and lignophenolic closed cells foams: thermal conductivity and other properties. Polymer: Plastics Technology and Engineering, v. 42, n. 4, p. 605-626, 2003.

CHAWLA, K. K. Composites materials. New York: Springer, 1998. p. 1-129.

CHOY, C. L. Thermal conductivity of polymers. Polymer, v. 18, p. 984-1003, 1977.

COOK, P. M.; T. SELLERS. Organosolv lignin-modified phenolic resins. Acs Symposium Series, v. 397, p. 324-333, 1989.

DANIELSON, B.; SIMONSON, R. Kraft lignin in phenol formaldehyde resin. Part 1. Partial replacement of phenol by kraft lignin in phenol formaldehyde adhesives for plywood. Journal of Adhesion Science and Technology, v. 12, n. 9, p. 923-939, 1998.

DE PAOLI, M-A.; FURLAN, L. T. Sugar cane bagasse-lignin as photo-stabilizer for butadiene rubber. Polymer Degradation and Stability, v. 11, p. 327-337, 1985.

FALKEHAG, S. I. Lignin in Materials. Applied Polymer Symposium, v. 28, p. 247-257, 1975.

FENGEL, D; WEGENER, G. Wood: chemistry, ultrastructure, reactions. New York: Walter de Gruyter, 1989. 613 p.

FINK, J. K. Reactive polymers fundamentals and applications: a concise guide to industrial polymers. New York: William Andrew Publishing, 2005. 770 p.

FLANNIGAN, D. J.; HOPKINS, S. D.; SUSLICK, K. S. Sonochemistry and sonoluminescence in ionic liquids, molten salts, and concentrated electrolyte solutions. Journal of Organometallic Chemistry, v. 690, n. 15, p. 3513-3517, 2005.

FOWLER, P. A.; HUGHES, J. M.; ELIAS, R. M. Biocomposites: technology, environmental credentials and market forces. Journal of the Science of Food and Agriculture, v.86 n. 12, p. 1781-1789, 2006.

FRANCO, P. J. H.; VALADEZ-GONZÁLEZ, A. Fiber-Matrix Adhesion in natural fiber composites. In: MOHANTY, A. K.; MISRA M.; DRZAL, L. T. (Ed.). Natural fibers, biopolymers, and biocomposites. Boca Raton: Taylor \& Francis, 2005. p. 177-230. 
FREDHEIM, G. E.; BRAATEN, S. M.; CHRISTENSEN, B. E. Comparison of molecular weight and molecular weight distributions of softwood and hardwood lignosulfonates. Journal of Wood Chemistry and Technology, v. 23, n. 2, p. 197-215, 2003.

FREDHEIM, G. E.; BRAATEN, S. M.; CHRISTENSEN, B. E. Molecular weight determination of lignosulfonates by size-exclusion chromatography and multi-angle laser light scattering. Journal of Chromatography A, v. 942 n. 1-2, p. 191-199, 2002.

FROLLINI, E. Lignina como substituta parcial do fenol em espumas e compósitos reforçados com fibras lignocelulósicas. 2002. 215f. Tese (Livre Docente) - Instituto de Química de São Carlos, Universidade de São Paulo, São Carlos, 2002.

FROLLINI, E.; PAIVA, J. M. F.; TRINDADE, W. G.; RAZERA, I. A. T.; TITA, S. P. Plastics and composites from lignophenols. In: WALLENBERGER, F. T.; WESTON, N. (Ed.). Natural Fibers, Plastics and Composites. Local: Kluwer Academic, 2004. p. 193-225.

GADHE, J. B.; GUPTA, R. B.; ELDER, T., Surface modification of lignocellulosic fibers using high-frequency ultrasound. Cellulose, v. 13, n. 1, p. 9-22, 2006.

GAY, D.; HOA, S. V.; TSAI, S. W. Composite materials: design and applications. Boca Raton: CRC, 2002. 531 p.

GEORGOPOULOS, S.T.; TARANTILI, P.A.; AVGERINOS, E.; ANDREOPOULOS, A.G.; KOUKIOS, E.G. Thermoplastic polymers reinforced with fibrous agricultural residues. Polymer Degradation and Stability, v. 90, p. 303-312, 2005.

GOSH, P.; DAS, D., Modification of jute by some low molecular weight glycols and a polyol under thermal treatment. European Polymer Journal, v. 36, n. 10, p. 2147-2157, 2000.

GUIMARÃES, J. L.; FROLLINI, E.; DA SILVA, C. G.; WYPYCH, F.; SATYANARAYANA, K. G. Characterization of banana, sugarcane bagasse and sponge gourd fibers of Brazil. Industrial Crops and Products , v. 30, n. 3, p. 407-415, 2009.

GUTIÉRREZ, A.; RODRIGUEZ, I. M.; DEL RIO, J. C. Chemical composition of lipophilic extractives from sisal (Agave sisalana) fibers. Industrial Crops and Products, v. 28, n. 1, p.81-87, 2008.

HABIBI, Y.; EI-ZAWAWY, W. K.; IBRAHIM, M. M.; DUFRESNE, A. Processing and characterization of reinforced polyethylene composites made with lignocellulosic fibers from Egyptian agro-industrial residues. Composites Science and Technology, v. 68, n. 7-8, p. 1877-1885. 2008.

HAGE JÚNIOR, E. Resistência ao impacto. In: CANEVAROLO JÚNIOR, S. V. (Ed.). Técnicas de caracterização de polímeros. São Paulo: Artliber, 2004. p. 361-384.

HAGENSON, L. C.; DORAISWAMY, L. Comparison of the effects of ultrasound and mechanical agitation on a reacting solid-liquid system. Chemical Engineering Science, v. 53, n. 1, p. 131-148, 1998.

HERAKOVICH, C. T. Mechanics of fibrous composites. New York: John Wiley, 1998. 480p 
HOAREAU, W.; OLIVEIRA, F. B.; GRELIER, S.; SIEGMUND, B.; FROLLINI, E.; CASTELLAN, A. Fiberboards based on sugarcane bagasse lignin and fibers. Macromolecular Materials and Engineering, v. 291, n. 7, p. 829-839, 2006.

IDICULA, M.; SREEKUMAR, P. A.; JOSEPH, K.; THOMAS, S. Natural fiber hybrid composites - a comparison between compression molding and resin transfer molding. Polymer Composites, v. 30, n14. 10, p. 17-1425, 2009.

ISLAM, M. N.; RAHMAN, M. R.; HAQUE, M. M.; HUQUE, M. M. Physico-mechanical properties of chemically treated coir reinforced polypropylene composites. Composites Part A-Applied Science and Manufacturing, v. 41, n. 2, p. 192-198, 2010.

JAKAB, E.; FAIX, O.; TILL, F.; SZEKELY, T., The effect of cations on the thermaldecomposition of lignins. Journal of Analytical and Applied Pyrolysis , v. 25, p. 185-194, 1993.

JOHN, M. J.; THOMAS, S. Biofibres and biocomposites. Carbohydrate Polymers, v. 71, n. 3, p. 343-364, 2008.

JOSEPH, K.; THOMAS, S.; PAVITHRAN, C. Effect of chemical treatment on the tensile properties of short sisal fibre-reinforced polyethylene composites. Polymer, v. 37, n. 23, p. 5139-5149, 1996.

JOSEPH, S.; SREEKALA, M. S.; OOMMEN, Z; KOSHY, P; THOMAS, S. A comparison of the mechanical properties of phenol formaldehyde composites reinforced with banana fibres and glass fibres. Composites Science and Technology, v. 62, n. 14, p. 1857-1868, 2002.

JOSHI, S. V.; DRZAL, L. T.; MOHANTY, A. K.; ARORA, S. Are natural fiber composites environmentally superior to glass fiber reinforced composites? Composites Part A-Applied Science and Manufacturing, v. 35, n. 3, p. 371-376, 2004.

KEENER, T. J.; STUART, R. K.; BROWN, T. K. Maleated coupling agents for natural fibre composites. Composites Part a-Applied Science and Manufacturing, v. 35, n. 3, p. 357 362, 2004.

KIM, S. W.; LEE, S. H.; KANG, J. S.; KANG, K. H. Thermal conductivity of thermoplastic reinforced with natural fibers. International Journal of Thermophysics, v. 27, p. 18731881, 2006.

KNOP, A; PILATO, L. A. Phenolic resins. Berlin: Springer-Verlag, 1985. 313 p.

KU, H.; TRADE, M.; NIXON, R.; WONG, P. Flexural properties of phenolic resin reinforced with glass powder: Preliminary results. Journal of Applied Polymer Science, v. 116, n. 1, p. 347-354, 2010.

KUSHWAHA, P. K.; KUMAR, R. Studies on water absorption of bamboo-epoxy composites: Effect of silane treatment of mercerized bamboo. Journal of Applied Polymer Science, v. 115, n. 3, p. 1846-1852, 2010.

LI, Y.; HU, C. J.; YU, Y. Interfacial studies of sisal fiber reinforced high density polyethylene (HDPE) composites. Composites Part a-Applied Science and Manufacturing, v. 39, n. 4, p. 570-578, 2008. 
LI, Y.; MAI, Y. W.; YE, L. Mai, et al. Sisal fibre and its composites: a review of recent developments. Composites Science and Technology, v. 60, n. 11, p. 2037-2055, 2000.

MAFFEZZOLI, A.; CALO, E.; ZURLO, S.; MELE, G.; TARZIA, A.; STIFANI, C. Cardanol based matrix biocomposites reinforced with natural fibres. Composites Science and Technology, v. 64 , n. 6 , p. 839-845, 2004.

MANSOUR, O.; EL-HADY, B. A.; IBRAHIM, S. K.; GODA, M. Lignocellulose-polymer composites. V. Polymer-Plastics Technology and Engineering, v. 40, n. 3, p. 311-320, 2001.

MARTIN, A. R.; MATTOSO, L. H. C.; SILVA, O. R. R. F. Caracterização química e estrutural de fibra de sisal da variedade Agave sisalana. Polímeros: Ciência e Tecnologia, v. 19, n. 1, p. 40-46, 2009.

MASON, T. J.; JOYCE, E.; PHULL, S. S.; LORIMER, J. P. Potential uses of ultrasound in the biological decontamination of water. Ultrasonics Sonochemistry, v. 10, n. 6, p. 319-323, 2003.

MATTHEWS, F. L.; RAWLINGS, R.D. Composites materials: engineering and Science. Cambridge: Woodhead Publishing, 1999. p. 59-64.

MAZUMDAR, S. K. Composites manufacturing: materials, product and processing engineering. Boca Raton: CRC, 2002. 420 p.

MEGIATTO JUNIOR, J. D. Fibras de sisal: estudo de propriedades e modificações químicas visando aplicação em compósitos de matriz fenólica. 2006. 262f. Tese (Doutorado em Físico-Química) - Instituto de Química de São Carlos, Universidade de São Paulo, São Carlos, 2006.

MEGIATTO, J. D.; HOAREAU, W.; GARDRAT, C.; FROLLINI, E.; CASTELLAN, A. Sisal fibers: Surface chemical modification using reagent obtained from a renewable source; Characterization of hemicellulose and lignin as model study. Journal of Agricultural and Food Chemistry, v. 55, n. 21, p. 8576-8584, 2007b.

MEGIATTO, J. D.; OLIVEIRA, F. B.; ROSA, D. S.; GARDRAT, C.; CASTELLAN, A.; FROLLINI, E. Renewable resources as reinforcement of polymeric matrices: Composites based on phenolic thermosets and chemically modified sisal fibers. Macromolecular Bioscience, $\mathrm{v}$. 7, n. 9-10, p. 1121-1131, 2007a.

MEGIATTO, J. D.; SILVA, C. G.; RAMIRES, E. C.; FROLLINI, E. Thermoset matrix reinforced with sisal fibers: Effect of the cure cycle on the properties of the biobased composite. Polymer Testing , v. 28, n. 8, p. 793-800, 2009.

MEGIATTO, J. D.; SILVA, C. G.; ROSA, D. S.; FROLLINI, E. Sisal chemically modified with lignins: Correlation between fibers and phenolic composites properties. Polymer Degradation and Stability, v. 93, n. 6, p. 1109-1121, 2008.

MISHRA, S.; MOHANTY, A. K.; DRZAL, L. T.; MISRA, M.; HINRICHSEN, G. A review on pineapple leaf fibers, sisal fibers and their biocomposites. Macromolecular Materials and Engineering, v. 289 n. 11, p. 955-974, 2004. 
MOHANTY, A. K.; MISRA, M.; DRZAL L. T.; SELKE, S. E.; HARTE, B. R.; HINRICHSEN, G. Natural fibers, biopolymers, and biocomposites: An Introduction. In: MOHANTY, A. K.; MISRA M.; DRZAL, L. T. (Ed.). Natural fibers, biopolymers, and biocomposites. Boca Raton: Taylor \& Francis, 2005. p. 1-36.

MOHANTY, A. K.; WIBOWO, A.; MISRA, A.; DRZAL, L. T. Effect of process engineering on the performance of natural fiber reinforced cellulose acetate biocomposites. Composites Part A-Applied Science and Manufacturing, v. 35, n. 3, p. 363-370. 2004.

MONTEIRO, S. N.; LOPES, F. P. D.; FERREIRA, A. S.; NASCIMENTO, D. C. O. Natural-fiber polymer-matrix composites: cheaper, tougher, and environmentally friendly. Journal of the Minerals, Metals and Materials Society, v. 61, n. 1, p. 17-22, 2009.

MU, Q. H.; WEI, C.; FENG, S. Y. Studies on mechanical properties of sisal fiber/phenol formaldehyde resin in-situ composites. Polymer Composites, v. 30, n. 2, p. 131-137, 2009.

MWAIKAMBO, L. Y.; ANSELL, M. P. Chemical modification of hemp, sisal, jute, and kapok fibers by alkalization. Journal of Applied Polymer Science, v. 84, n. 12, p. 2222-2234, 2002.

MYRVOLD, B. O. A new model for the structure of lignosulphonates Part 1. Behaviour in dilute solutions. Industrial Crops and Products, v. 27 n. 2, p. 214-219, 2008.

OLIVEIRA, F. B. Utilização de matéria-prima obtida de fonte renovável na preparação de compósitos de matriz do tipo fenólica. 2008. 175f. Tese (Doutorado em Físico-Química) Instituto de Química de São Carlos, Universidade de São Paulo, São Carlos, 2008.

PAIVA, J. M. F.; FROLLINI, E. Sugarcane bagasse reinforced phenolic and lignophenolic composites. Journal of Applied Polymer Science, v. 83, n. 4, p. 880-888, 2001.

PAIVA, J. M. F.; FROLLINI, E. Unmodified and modified surface sisal fibers as reinforcement of phenolic and lignophenolic matrices composites: thermal analyses of fibers and composites. Macromolecular Materials and Engineering, v. 291, n. 4, p. 405417, 2006.

PAIVA, J. M. F; FROLLINI, E. Sugarcane bagasse reinforced phenolic and lignophenolic composites. Journal of Applied Polymer Science, v. 83, n. 4, p. 880-888, 2001

PATURAU, J.M. By products of the cane sugar industry. 3. ed. Amsterdam: Elsevier, 1989. v. 11, p. 36-41.

PAUL, S. A.; BOUDENNE, A.; IBOS, L.; CANDAU, Y.; JOSEPH, K.; THOMAS, S. Effect of fiber loading and chemical treatments on thermophysical properties of banana fiber/polypropylene commingled composite materials. Composites: Part A, v. 39, p. 15821588, 2008.

PERVAIZ, M.; SAIN, M. M. Carbon storage potential in natural fiber composites. Resources Conservation and Recycling, v. 39, n. 4, p. 325-340, 2003. 
PICCOLO, R. S. J.; SANTOS, F.; FROLLINI, E. Sugar cane bagasse lignin in resol-type resin: Alternative application for lignin-phenol-formaldehyde resins. Journal of Macromolecular Science-Pure and Applied Chemistry, v. A34, n. 1, p. 153-164, 1997.

PILATO, A. L; MICHNO, M. J. Advanced composite materials. New York: Springer-Verlag, 1994. 208 p.

PLANK, J. Applications of biopolymers and other biotechnological products in building materials. Applied Microbiology and Biotechnology, v. 66, n. 1, p. 1-9, 2004.

POTHAN, L. A.; THOMAS, S. Effect of hybridization and chemical modification on the water-absorption behavior of banana fiber-reinforced polyester composites. Journal of Applied Polymer Science, v. 91, n. 6, p.3856-3865, 2004.

POTHAN, L. A.; THOMAS, S. Polarity parameters and dynamic mechanical behaviour of chemically modified banana fiber reinforced polyester composites. Composites Science and Technology, v. 63, n. 9, p. 1231-1240, 2003.

POU, J.; BOUTINGUIZA, M.; QUINTERO, F.; LUSQUINOS, F.; SOTO, R.; PEREZ-AMOR, M. Comparative study of the cutting of car interior trim panels reinforced by natural fibers. Journal of Laser Applications, v. 13, n. 3, p. 90-95, 2001.

RAMIRES, E. C. Biocompósitos a partir de matrizes poliméricas baseadas em lignina, tanino e glioxal reforçadas com fibras naturais. 2010. 277f. Tese (Doutorado em FísicoQuímica) - Instituto de Química de São Carlos, Universidade de São Paulo, São Carlos, 2010.

RAY, D.; SENGUPTA, S.; SENGUPTA, S. P.; MOHANTY, A. K.; MISRA, M. A study of the mechanical and fracture Behavior of jute-fabric-reinforced clay-modified thermoplastic starch-matrix composites. Macromolecular Materials and Engineering, v. 292, n. 10-11, p. 1075-1084, 2007.

RAZERA, I. A. T. Fibras lignocelulósicas como agente de reforço de compósitos de matriz fenólica e lignofenólica. São Carlos, 2006. 167f. Tese (Doutorado em Físico-Química) Instituto de Química de São Carlos, Universidade de São Paulo, São Carlos, 2006.

RAZERA, I. A. T.; FROLLINI, E. Composites based on jute fibers and phenolic matrices: Properties of fibers and composites. Journal of Applied Polymer Science, v. 91, n. 2, p. 1077-1085, 2004.

RODRÍGUEZ, J. M. P. Estudio del curado de resinas ligno-novolacas. Propriedades termomecánicas de los produtos curados. 2005. 327f. Tese (Doctorado em Ciencias Químicas) - Facultad de Ciencias Químicas - Departamento de Ingeniería Química, Universidad Complutense de Madrid, Madrid, 2005.

SANTOS, F.; CURVELO, A. A. S. Utilização de ligninas em resinas fenólicas. 1. Preparação de novolacas a partir de lignosulfonatos. Polímeros: Ciência e Tecnologia, v. 9, n. 1, p. 49-58, 1999.

SANTOS, W. N. Condutividade térmica, difusividade térmica e calor específico. In: CANEVAROLO JUNIOR, S. V. (Ed.). Técnicas de caracterização de polímeros. São Paulo: Artliber, 2004. p. 263-283. 
SAUNDERS, K. J. Organic polymer chemistry. 2.ed. New York: Chapman and Hall, 1988. p. 316-337.

SHEN, Q.; ZHANG, T.; ZHU, M. F. A comparison of the surface properties of lignin and sulfonated lignins by FTIR spectroscopy and wicking technique. Colloids and Surfaces APhysicochemical and Engineering Aspects, v. 320, n. 1-3, p. 57-60, 2008.

SHEN, Q.; ZHANG, T.; ZHU, M. F. A comparison of the surface properties of lignin and sulfonated lignins by FTIR spectroscopy and wicking technique. Colloids and Surfaces aPhysicochemical and Engineering Aspects, v. 320, n. 1-3, p. 57-60, 2008.

SHUL'GA, N. V; GOMOLKO, L. A.; KRUT'KO, N. P. Dependence of composition and characteristics of lignosulfonates on the procedures of their recovery and purification. Russian Journal of Applied Chemistry, v. 81, n. 7, p.1164-1170, 2008

SHUL'GA, N. V.; GOMOLKO, L. A.; KRUT'KO, N. P. Dependence of composition and characteristics of lignosulfonates on the procedures of their recovery and purification. Russian Journal of Applied Chemistry, v. 81, n. 7, p. 1245-1251, 2008.

SILVA, C. G. Fibras celulósicas têxteis em compósitos de matriz fenólica. 2006. $161 \mathrm{f}$. Dissertação (Mestrado em Ciência e Engenharia de Materiais) - Escola de Engenharia de São Carlos, Instituto de Física de São Carlos, Instituto de Química de São Carlos, Universidade de São Paulo, São Carlos, 2006.

SILVERSTEIN, R. M.; BASSLER, G. C.; MORRIL T. C. Identificação espectrométrica de compostos orgânicos. Rio de Janeiro: Guanabara Koogan, 1994. p. 93-152.

SINGHA, A. S.; THAKUR, V. K. Fabrication of Hibiscus sabdariffa fibre reinforced polymer composites. Iranian Polymer Journal, v. 17, n. 7, p. 541-553, 2008.

STAEL, G. C.; TAVARES, M. I. B.; D'ALMEIDA, J. R. M. Tensile and flexural behaviour of sugar cane bagasse waste reinforced EVA matrix composites. Polymers \& Polymer Composites, v. 8, n. 7, p. 489-495, 2000.

TANAKA, I. A. Estudo de propriedades de compósitos de matriz termorrígida fenólica reforçados com fibra de juta. 2001. 153f. Dissertação (Mestrado em Físico-Química) Instituto de Química de São Carlos, Universidade de São Paulo, São Carlos, 2001.

TEJADO, A.; PENA, C.; LABIDI, J.; ECHEVERRIA, J. M.; MONDRAGON, I. Physico-chemical characterization of lignins from different sources for use in phenol-formaldehyde resin synthesis. Bioresource Technology, v. 98, n. 8, p. 1655-1663, 2007.

THIELEMANS, W.; WOOL, R. P. Butyrated kraft lignin as compatibilizing agent for natural fiber reinforced thermoset composites. Composites Part A-Applied Science and Manufacturing, v. 35, n. 3, p. 327-338, 2004.

THOMPSON, L. H.; DORAISWAMY, L. K., Sonochemistry: science and engineering. Industrial \& Engineering Chemistry Research, v. 38, n. 4, p. 1215-1249, 1999.

TITA, S. P. S. Efeito dos tratamentos de superfície das fibras de bagaço de cana-deaçúcar e sisal nas propriedades de compósitos de matriz fenólica e lignofenólica. 2002. 
202f. Dissertação (Mestrado em Físico-Química) - Instituto de Química de São Carlos, Universidade de São Paulo, São Carlos, 2002.

TRINDADE, W. G.; HOAREAU, W.; MEGIATTO, J. D.; RAZERA, I. A. T.; CASTELLAN, A.; FROLLINI, E. Thermoset phenolic matrices reinforced with unmodified and surface-grafted furfuryl alcohol sugar cane bagasse and curaua fibers: Properties of fibers and composites. Biomacromolecules, v. 6, n. 5, p. 2485-2496, 2005.

TRINDADE, W. G.; HOAREAU, W.; RAZERA, I. A. T.; RUGGIERO, R.; FROLLINI, E.; CASTELLAN, A. Phenolic thermoset matrix reinforced with sugar cane bagasse fibers: Attempt to develop a new fiber surface chemical modification involving formation of quinones followed by reaction with furfuryl alcohol. Macromolecular Materials and Engineering, v. 289, n. 8, p. 728-736. 2004.

VÁSQUEZ, G.; GONZÁLES-ALVAREZ, J.; LÓPEZ-SUEVOS, F.; FREIRE, S.; ANTORRENA, G. Curing kinetics of tannin-phenol-formaldehyde adhesives as determined by DSC. Journal of thermal analysis and calorimetry, v. 70, p. 19-28, 2002.

WAMBUA, P.; IVENS, J.; VERPOEST, I. Natural fibres: can they replace glass in fibre reinforced plastics? Composites Science and Technology, v. 63, n. 9, p.1259-1264, 2003.

YOSOMIYA, R.; MORIMOTO, K.; NAKAJIMA, A.; IKADA, Y.; SUZUKI, T. Adhesion and bonding in composites. New York: Marcel Dekker, 1990. 357p.

ZÁRATE, C. N.; ARANGUREN, M. I.; REBOREDO, M. M. Thermal degradation of a phenolic resin, vegetable fibers, and derived composites. Journal of Applied Polymer Science, $v$. 107 , p. 2977-2985, 2008. 
ENSAIO DE ABSORÇÃO DE ÁGUA

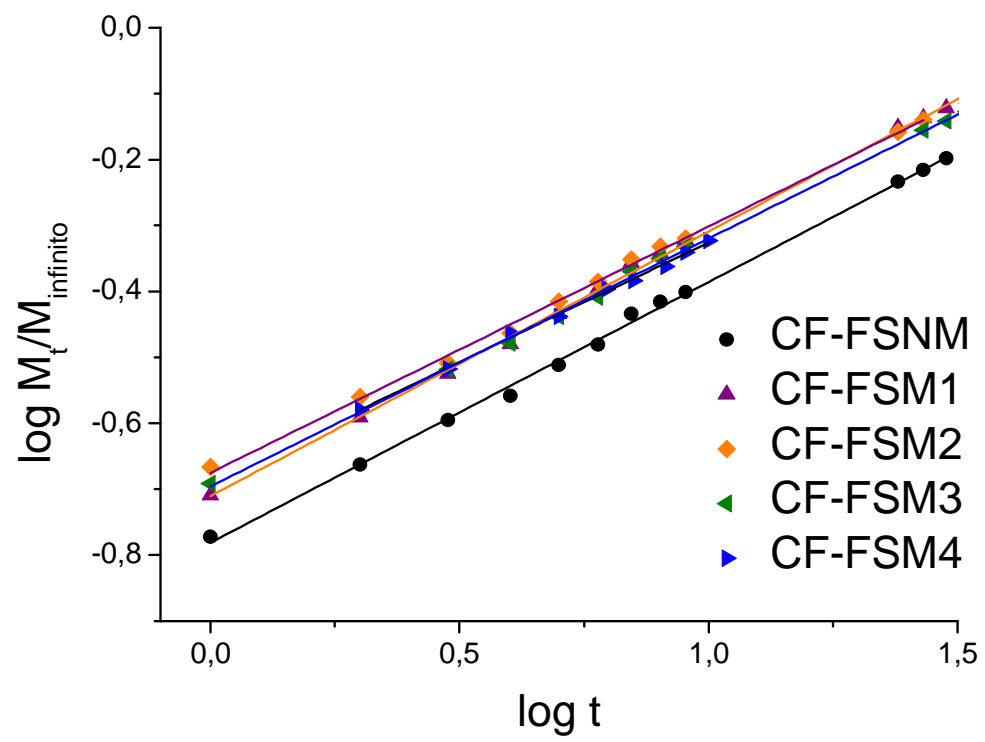

Gráfico de log $\left(\mathrm{M}_{\mathrm{t}} / \mathrm{M}_{\infty}\right)$ versus log t, para a determinação do parâmetro k dos compósitos de matriz fenólica reforçados com fibras de sisal não-modificadas (CF-FSNM) e modificadas (CF-FSM1, CF-FSM2, CF-FSM3 e CF-FSM4).

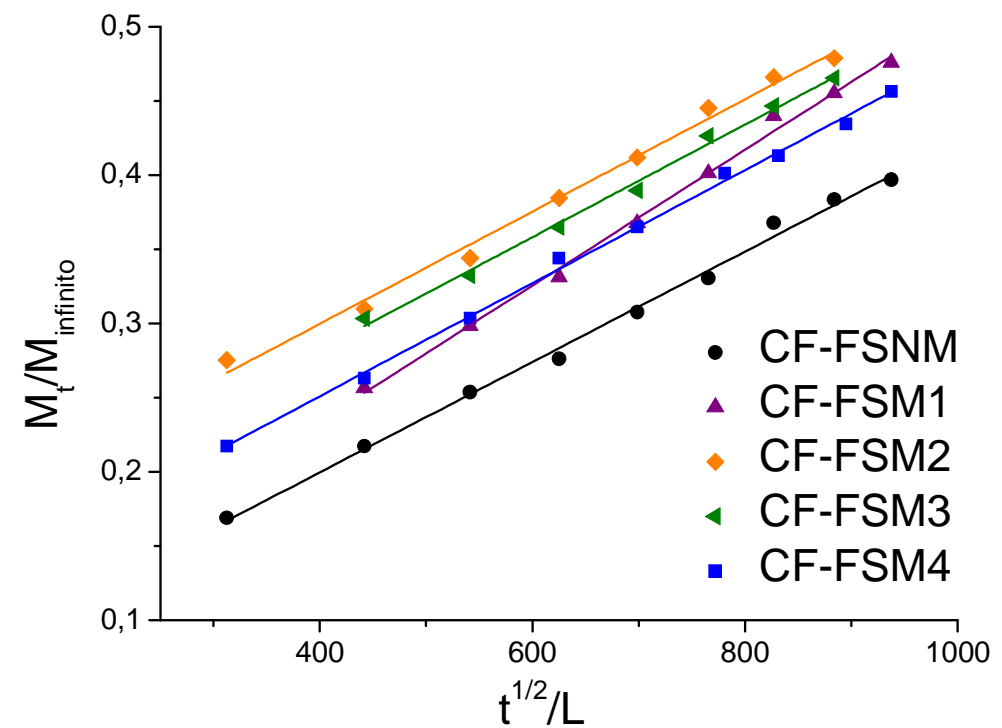

Gráfico de $M t / M^{\infty}$ versus $t^{1 / 2} / L$, para a determinação do coeficiente de difusão, $D$, compósitos de matriz fenólica reforçados com fibras de sisal não-modificadas (CF-FSNM) e modificadas (CF-FSM1, CF-FSM2, CF-FSM3 e CF-FSM4). 


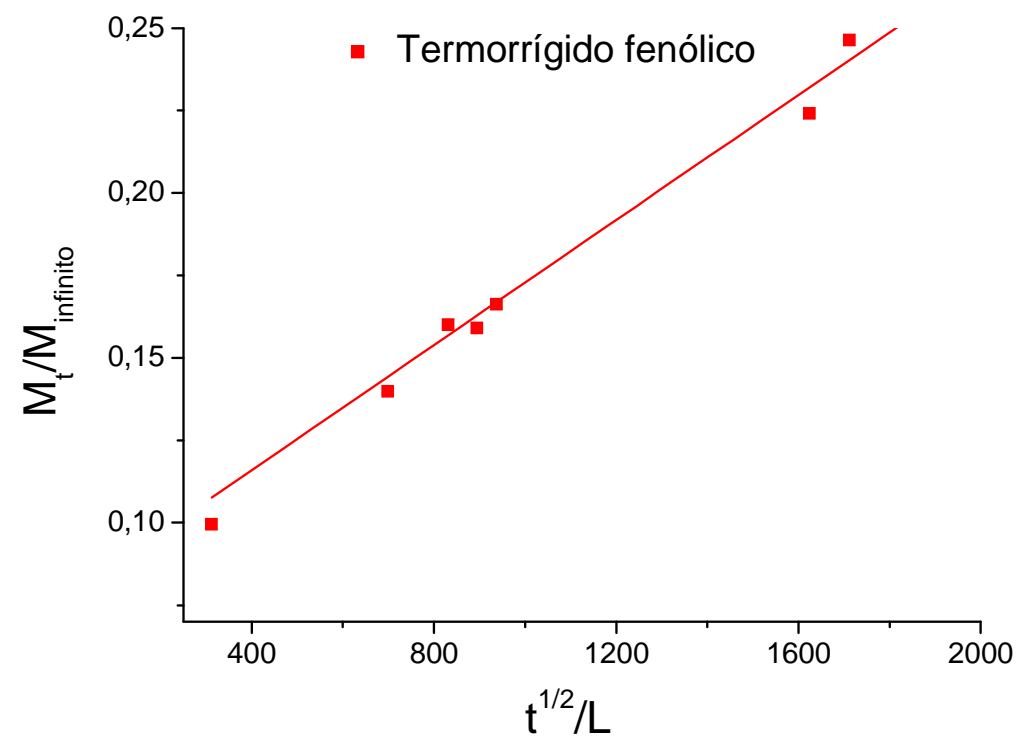

Gráfico de $M^{t} / M^{\infty}$ versus $t^{1 / 2} / L$, para a determinação do coeficiente de difusão, $D$, do termorrígido fenólico.

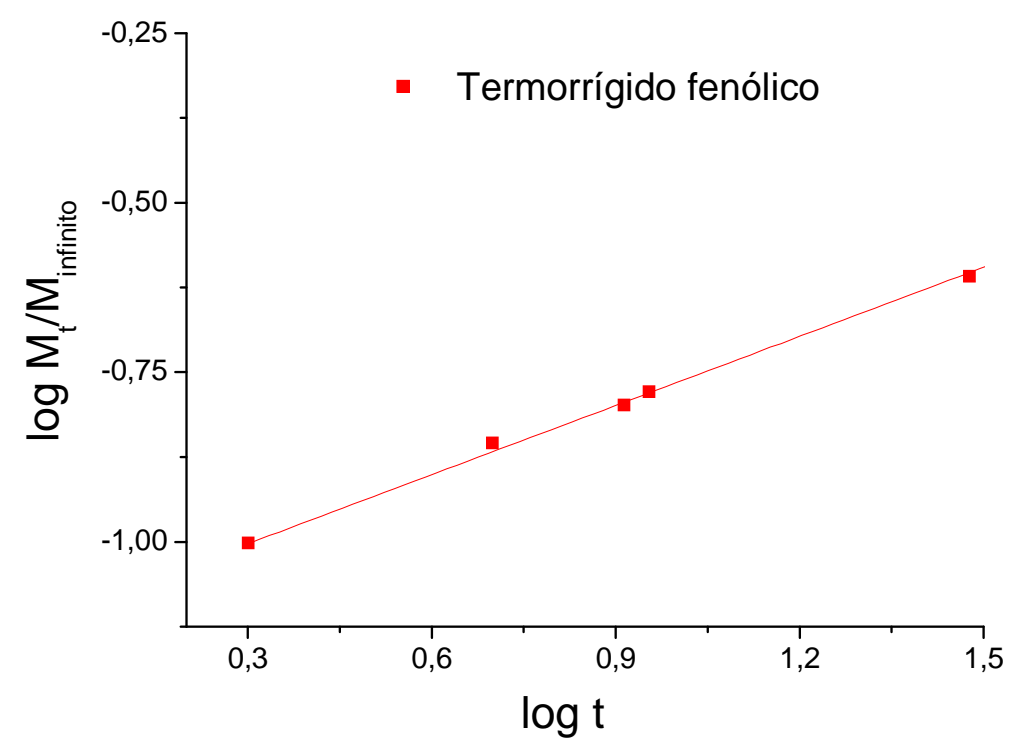

Gráfico de $\log \left(\mathrm{M}_{\mathrm{t}} / \mathrm{M}_{\infty}\right)$ versus log t, para a determinação do parâmetro $\mathrm{k}$ do termorrígido fenólico 


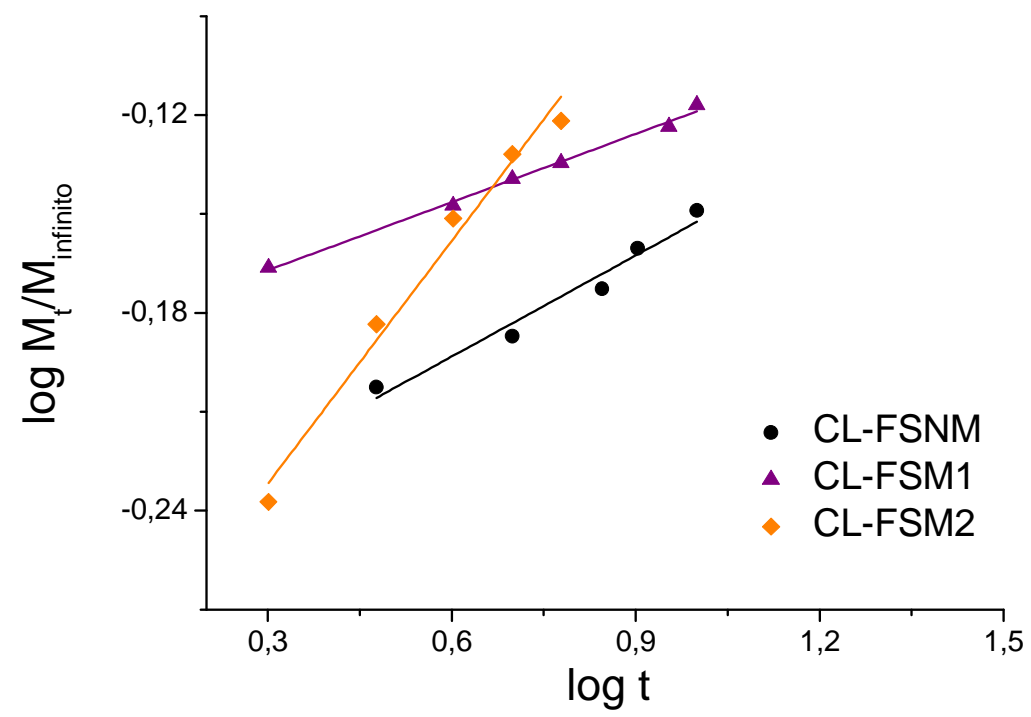

Gráfico de log $\left(\mathrm{M}_{\mathrm{t}} / \mathrm{M}_{\infty}\right)$ versus log $\mathrm{t}$, para a determinação do parâmetro k para compósitos de matriz lignosulfonato-formaldeído (sem excesso) reforçados com fibras de sisal nãomodificadas (CL-FSNM) e modificadas (CL-FSM1 e CL-FSM2).

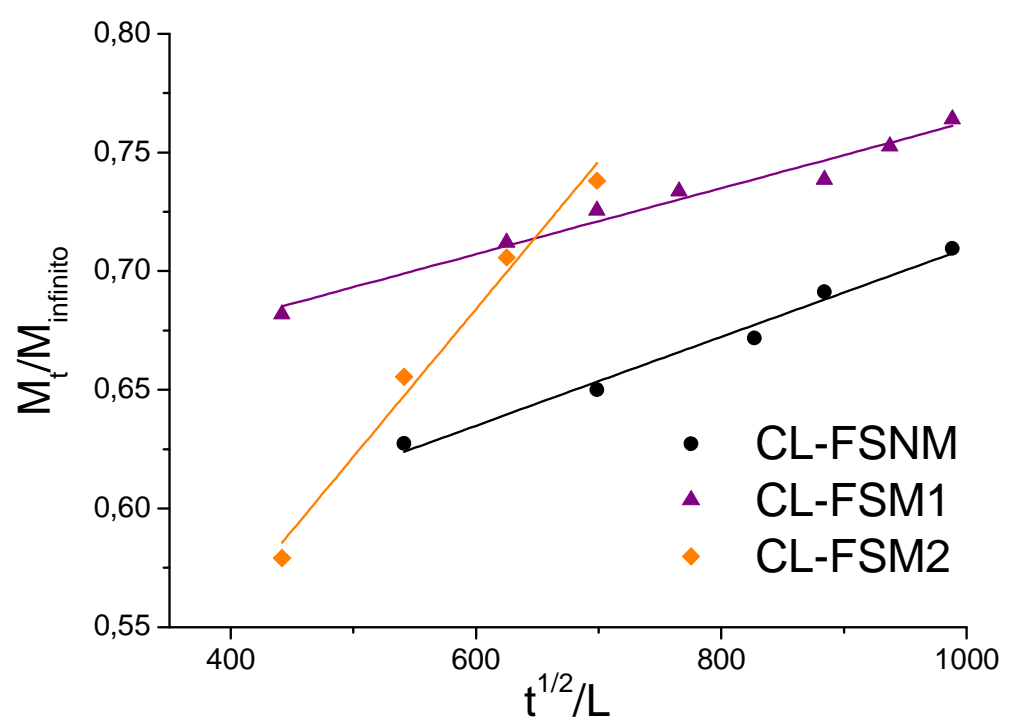

Gráfico de $\left(M_{t} / M_{\infty}\right)$ versus $t^{1 / 2} / L$, para a determinação do coeficiente de difusão, $D$, dos compósitos de matriz lignosulfonato-formaldeído (sem excesso) reforçados com fibras de sisal não-modificadas (CF-FSNM) e modificadas (CF-FSM1 e CF-FSM2) 


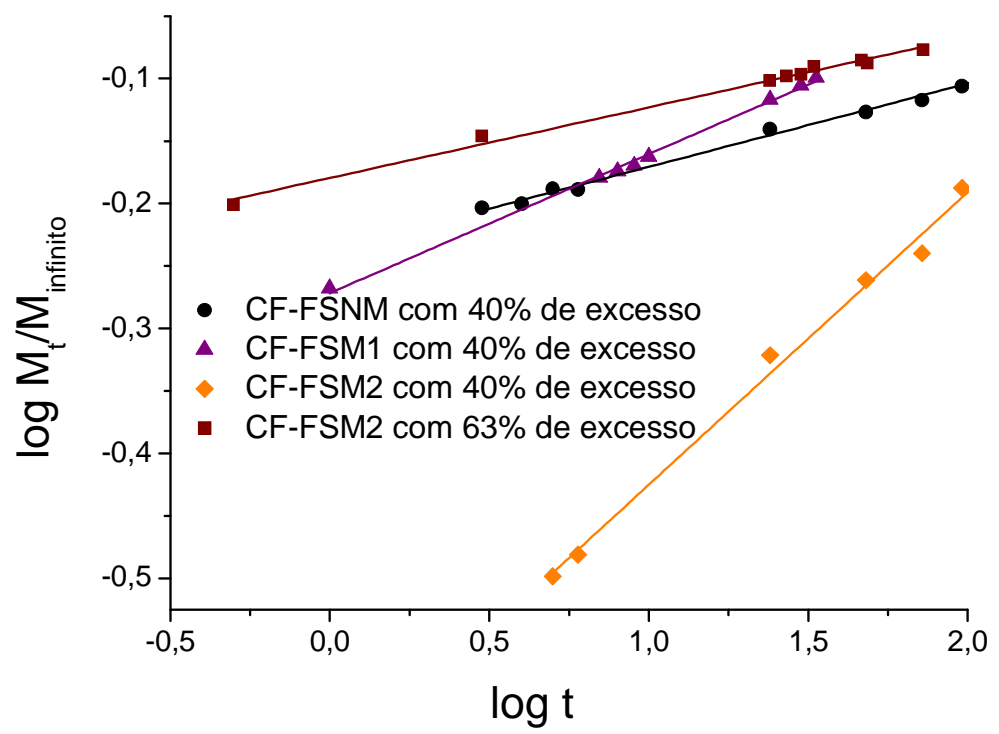

Gráfico de log $\mathrm{M}_{\mathrm{t}} / \mathrm{M}_{\infty}$ versus log t, para a determinação do parâmetro k para compósitos de matriz lignosulfonato-formaldeído (com excesso) reforçados com fibras de sisal nãomodificadas (CL-FSNM) e modificadas (CL-FSM1 e CL-FSM2).

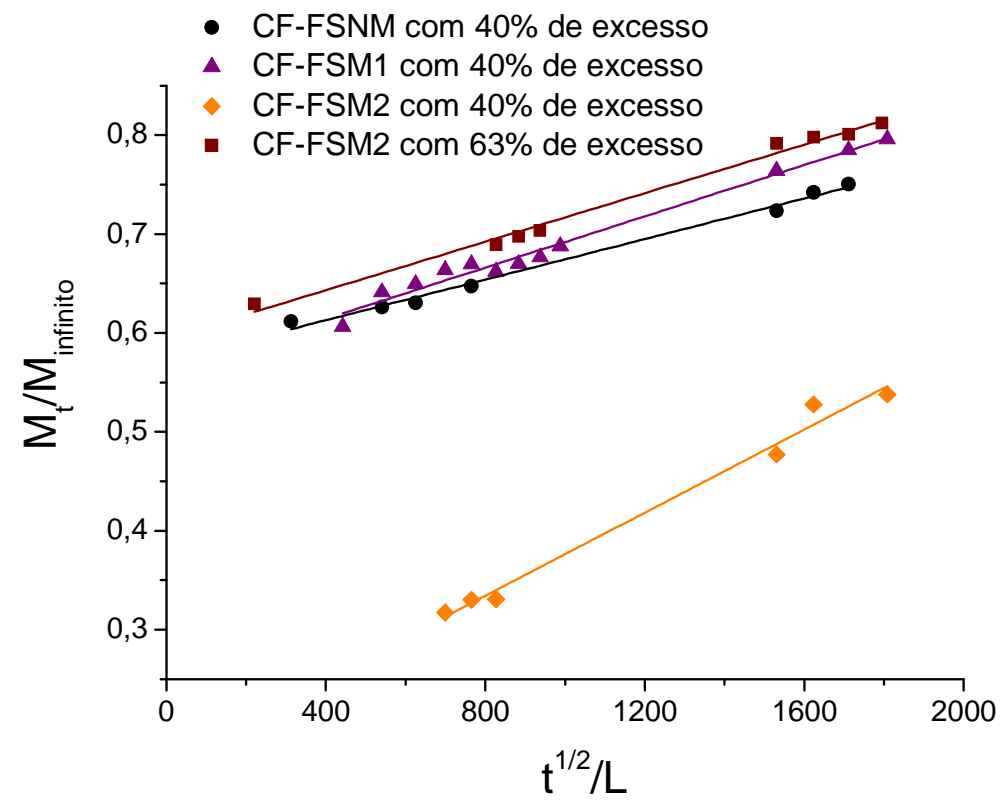

Gráfico de $\mathrm{M}_{\mathrm{t}} / \mathrm{M}_{\infty}$ versus $\mathrm{t}^{1 / 2} / \mathrm{L}$, para a determinação do coeficiente de difusão, $\mathrm{D}$, dos compósitos de matriz lignosulfonato-formaldeído (com excesso) reforçados com fibras de sisal não-modificadas (CF-FSNM) e modificadas (CF-FSM1 e CF-FSM2) 